\title{
Targeting Families' Assistance: Evaluating Family and Employment Tax Credits in New Zealand's Tax-Benefit System
}

by

Patrick John Nolan

\begin{abstract}
A thesis submitted to
the Victoria University of Wellington in fulfilment of the requirements for the degree of Doctor of Philosophy in Public Policy
\end{abstract}

School of Government

Victoria University of Wellington

2005 


\section{Table of Contents}

Index of Figures iv

Index of Tables vi

Disclaimer viii

Abstract

Acknowledgements $\quad$ xi

INTRODUCTION 1

1 General Introduction 1

1.1 Introduction 1

1.2 The Policy Problem and Context 2

1.3 The Research Topic and Structure of the Study 7

1.4 Conclusion 12

I FRAMEWORKS, CRITERIA, AND METHODOLOGY 14

2 Frameworks for Evaluating Tax-Benefit Programmes $\quad 15$

$\begin{array}{ll}2.1 & 15\end{array}$

2.2 Horizontal Equity and Vertical Equity 16

2.3 Optimal Tax Theory 22

2.4 Non-Welfarist Models and the Valuation of Labour 29

2.5 Integrating Taxation and Expenditure Decisions 33

$\begin{array}{lll}2.6 & \text { Conclusion } & 39\end{array}$

3 Criteria for Evaluating Tax-Benefit Programmes 42

3.1 Introduction 42

3.2 Income Adequacy 42

3.3 Labour Supply and Excess Burden 51

3.4 Administration and Compliance 64

$\begin{array}{lll}3.5 & \text { Conclusion } & 71\end{array}$ 
4 Methodology for Evaluating Tax-Benefit Programmes 74

4.1 Introduction 74

$\begin{array}{lll}4.2 & \text { Evidence Based Policy } & 75\end{array}$

4.3 Average and Effective Marginal Tax Rates 78

4.4 Model-Family Approach 82

4.5 TaxMod-A and the Household Economic Survey 84

4.6 Comparative Policy Analysis 90

4.7 Conclusion 93

II EVOLUTION AND OPERATION OF NEW ZEALAND'S TAX-BENEFIT SYSTEM $\quad 95$

5 New Zealand's Tax-Benefit System 96

5.1 Introduction 96

5.2 The Wage Earners' Welfare State 96

5.3 Neo-Liberal Policy Settings 103

5.4 Neo-Liberal Reform and Social Assistance Expenditure 111

5.5 Social Development and Making Work Pay 116

$\begin{array}{ll}5.6 \text { Conclusion } & 120\end{array}$

6 New Zealand's Family Assistance Tax Credits 122

6.1 Introduction 122

6.2 Evolution of the Family Assistance Programmes 123

6.3 Estimating Entitlement and Take-Up 138

$\begin{array}{ll}6.4 \text { Conclusion } & 146\end{array}$

7 Anglo-American Family and Employment Tax Credits 149

$\begin{array}{lll}7.1 & \text { Introduction } & 149\end{array}$

$\begin{array}{lll}7.2 & \text { Comparison of Tax-Benefit Systems } & 149\end{array}$

7.3 Comparison of Family and Employment Tax Credits 154

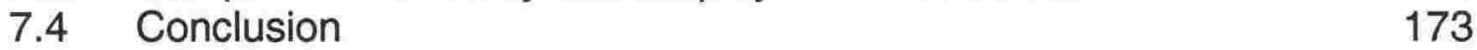

III EVALUATING NEW ZEALAND'S TAX-BENEFIT SYSTEM 176

$8 \quad$ Income Adequacy 177

8.1 Introduction 177

8.2 Population Heterogeneity and Income Inequality 178

$\begin{array}{ll}8.3 \text { Poverty } & 185\end{array}$

8.4 Living Standards 191

8.5 Duration of Benefit Receipt 194

$\begin{array}{ll}8.6 \text { Conclusion } & 196\end{array}$

9 Financial Incentives for Labour Supply 199

9.1 Introduction 199

9.2 Main Benefits and Family Assistance 200

9.3 Accommodation and Childcare Assistance 210

9.4 Comparison with Other Anglo-American Countries 213

$\begin{array}{ll}9.5 \text { Conclusion } & 215\end{array}$ 
IV EVALUATING THE WORKING FOR FAMILIES REFORMS

10 Evaluating the Working for Families Reforms 218

10.1 Introduction 218

10.2 Headcount Poverty Rates 219

10.3 EMTR Profiles 223

10.4 Generosity of Family and Employment Tax Credits 233

10.5 Administration and Compliance 237

10.6 Possible Further Reforms 239

10.7 Conclusion 246

11 Conclusion 248

11.1 Introduction 248

11.2 The Role of Family and Employment Tax Credits 250

11.3 Designing Family and Employment Tax Credits 254

11.4 Evaluating the Working for Families Reforms 257

$\begin{array}{ll}11.5 \text { Conclusion } & 260\end{array}$

APPENDIX AND REFERENCES 262

Appendix Anglo-American Family and Employment Tax Credits 263

$\begin{array}{ll}\text { References } & 268\end{array}$ 


\section{Index of Figures}

Figure 3.1: Hypothetical Pre-Transfer and Post-Transfer Income Distributions

Figure 3.2: Income and Substitution Effects with Stylised Indifference Curves and Budget Constraints

Figure 5.1: Social Assistance Net Expenditure by Type 1980-81 to 1999-2000 (\% of GDP)

Figure 5.2: Social Assistance Net Expenditure by Type (Excluding Pensions) $1980-81$ to $1999-2000$ (\% of GDP)

Figure 5.3: Social Assistance Net Expenditure by Type (Excluding Pensions) 1980-81 to 1999-2000 (\% of Social Assistance Expenditure)

Figure 5.4: Tax Expenditures 1980-81 to $1999-2000$ (\% of GDP)

Figure 5.5: Proportion of Social Assistance Expenditure through the Tax System $1980-81$ to $1999-2000$

Figure 7.1: Family and Employment Tax Credits for a Sole-Parent with Two Children (Aged 3 and 5) and Earning \$10.00 Per-Hour (2004-05)

Figure 7.2: Family and Employment Tax Credits for a Primary Earner with Two Children (Aged 3 and 5) and Earning NZ\$15.00 Per-Hour (2004-05)

Figure 7.3: Family and Employment Tax Credits for a Secondary Earner with Two Children (Aged 3 and 5) and Earning NZ\$15.00 Per-Hour (2004-05)

Figure 9.1: EMTR Schedule and Budget Constraint of a Sole-Parent with Two Children (Aged 3 and 5) and Earning \$10 Per-Hour (2004-05)

Figure 9.2: EMTR Schedule and Budget Constraint of a Sole-Parent with Two Children (Aged 3 and 5) and Earning \$15 Per-Hour (2004-05)

Figure 9.3: EMTR Schedule and Budget Constraint of a Primary Earner with Two Children (Aged 3 and 5) and Earning \$15 Per-Hour (2004-05)

Figure 9.4: EMTR Schedule and Budget Constraint of a Secondary Earner and Two Children (Aged 3 and 5) and Earning \$15 Per-Hour (2004-05)

Figure 10.1: Post-Working for Families Budget Constraint and EMTR Profile of a Sole-Parent with Two Children (Aged 3 and 5) and Earning $\$ 10.00$ Per-Hour

Figure 10.2: Impact of Working for Families on the EMTR Profile of a SoleParent with Two Children (Aged 3 and 5) and Earning $\$ 10.00$ Per-Hour

Figure 10.3: Post-Working for Families Budget Constraint and EMTR Profile of a Primary Earner with Two Children (Aged 3 and 5) and Earning $\$ 15.00$ Per-Hour

Figure 10.4: Impact of Working for Families on the EMTR Profile of a Primary Earner with Two Children (Aged 3 and 5) and Earning \$15.00 Per-Hour

Figure 10.5: Impact of Working for Families on the EMTR Profile of a Secondary Earner with Two Children (Aged 3 and 5) and Earning $\$ 15.00$ Per-Hour

Figure 10.6: Impact of Working for Families on the EMTR Profile of a Secondary Earner with Two Children (Aged 3 and 5) and Earning $\$ 15.00$ Per-Hour 
Figure 10.7: Family and Employment Tax Credits for a Sole-Parent with Two

Children (Aged 3 and 5) and Earning \$10.00 Per-Hour

Figure 10.8: Family and Employment Tax Credits for a Primary Earner with

Two Children (Aged 3 and 5) and Earning NZ\$15.00 Per-Hour

Figure 10.9: Family and Employment Tax Credits for a Secondary Earner with

Two Children (Aged 3 and 5) and Earning NZ\$15.00 Per-Hour

Figure 10.10: EMTR Profiles of a Sole-Parent ( $\$ 10$ Gross Per-Hour) Prior to Working for Families, Post Working for Families, and Post Alternative Reform

Figure 10.11: EMTR Profiles of a Primary Earner ( $\$ 15$ Gross Per-Hour) Prior to Working for Families, Post Working for Families, and Post Alternative Reform

Figure 10.12: EMTR Profiles of a Secondary Earner ( $\$ 15$ Gross Per-Hour)

Post Working for Families and Post Alternative Reform 


\section{Index of Tables}

Table 1.1: Research Questions by Chapter

Table 4.1: OECD Purchasing Power Parity Rates (2004)

Table 5.1: Net Main Benefit Rates Before and After 1991 Reforms

Table 5.2: Flattening of New Zealand's Personal Income Tax Scale (1981 to 2001)

Table 5.3: Social Assistance Expenditures by Benefit Type (2004-05)

Table 6.1: Antecedents to the Family Assistance Programmes

Table 6.2: Family Support Unabated Entitlement and Abatement Regime

Table 6.3: Family Tax Credit Unabated Entitlement and Abatement Regime

Table 6.4: Child Tax Credit/In-Work Payment Unabated Entitlement and Abatement Regime

Table 6.5: Parental Tax Credit Unabated Entitlement and Abatement Regime

Table 6.6: Family Benefit and Family Assistance Fiscal Cost (\$ Million)

Table 6.7: Timing and Accuracy of Family Assistance Payments (Year to 31 March 2001)

Table 6.8: Family Assistance Programmes (1 April 2005)

Table 7.1: Expenditure on Family Cash Benefits and Total Public Social Expenditure (2001)

Table 7.2: Expenditure on Family Cash Benefits and Active Labour Market Programmes (2001)

Table 7.3: Structure of Child Benefit Package for Sole-Parent With One Child Earning Average Female Earnings (UK£ Per-Month) (2001)

Table 7.4: Structure of Child Benefit Package for Couple With Two Children and One Earner on Average Male Earnings (UK£ Per-Month) (2001)

Table 8.1: Anglo-American Demographic and Labour Market Indicators (2001)

Table 8.2: Estimates of Gini Coefficients in New Zealand (1983-84 to 1995-96)

Table 8.3: Families in Quintile One by Number of Children (1988-1998)

Table 8.4: Incidence and Severity of Poverty (1997 and 2000)

Table 8.5: International Estimates of Child Poverty at 60\% Family Median Income (2000-01)

Table 8.6: Constraints in Consumption Experienced By Children (2000)

Table 9.1: Distribution of Individuals by EMTRs and Benefit Receipt (2003-04)

Table 9.2: Comparison of Anglo-American Financial Incentives for Labour Supply (2002)

Table 10.1: Estimated Impact of Working for Families on Headcount Poverty Rates

Table 10.2: Distribution of Static Financial Gains from WFF

Table 10.3: Working for Families and Couples' Financial Incentives to Work

Table 10.4: Financial Incentives to Work for Low-Wage and High-Wage Couples (Fully Implemented Working for Families) 
Table A.4: United Kingdom Family and Employment Tax Credits (1 July 2004 $(\mathrm{NZ} \$)$ )

Table A.5: United States Family and Employment Tax Credits (1 July 2004 $(\mathrm{NZ} \$))$ 


\section{Disclaimer}

This thesis was submitted for examination in the month prior to the 2005 general election. As a result of the election the parameters of the Working for Families package have changed with the New Zealand Labour Party proposal for extending assistance being implemented. This proposal was modelled in this study as one of a number of possible adjustments to Working for Families. However, unless otherwise stated the package modelled and evaluated in this thesis is government policy prior to the election. No changes have been made to the arguments or conclusions in this thesis since submission. 


\section{Abstract}

In 2004 the Labour-led government announced a series of tax-benefit reforms (the Working for Families reforms) that will account for an estimated $\$ 1.17$ billion per-annum of new spending when fully implemented by 1 April 2007. These reforms aim to both reduce rates of child poverty and improve financial incentives for paid work at low wages, particularly for caregivers. Changes to family and employment tax credits (the Family Assistance programmes) are central to these reforms.

This study reviews methods for measuring the effectiveness of family and employment tax credits, evaluates the Working for Families reforms, and considers possible improvements to Working for Families. Questions that this study considers are:

- What roles should family and employment tax credits play in tax-benefit systems?

- How should family and employment tax credits be designed? Should eligibility for assistance reflect work effort as opposed to family structure?

- What lessons do historical and comparative perspectives on Working for Families provide?

- Will New Zealand's Working for Families reforms achieve the optimal design and role of family and employment tax credits?

- What improvements, if any, could be made to the Working for Families reforms?

This study concludes that the Working for Families reforms represent significant income redistribution towards families with children but little change will be made to the overall design of the Family Assistance programmes, some of which have remained largely unchanged since 1986. Working for Families does not fully address the need to reform the Family 
Assistance programmes in the light of important social and economic changes that have taken place over the last two decades, such as the breakdown of the breadwinner model of social arrangements and the liberalisation of the labour market. This study thus considers a number of improvements to Working for Families, ranging from simplifying the structure of the Family Assistance Tax Credits to a more radical redesign of these programmes. This study concludes that more clearly established policy priorities and a greater understanding of the relative effectiveness of different tax-benefit instruments are required if New Zealand is to develop a taxbenefit system that achieves a desired level of redistribution to families with children at least economic cost. 


\section{Acknowledgements}

Generous financial support for this project was provided through a Ryoichi Sasakawa Young Leader's Scholarship. For this assistance I am grateful to the fellowship committee and to Fiona Coote, the administrator of the fund. The Social Policy Evaluation and Research Secretariat (SPEaR) based in the Ministry of Social Development provided further financial support for this study. I am grateful to Paul Honeybone, the SPEaR project manager, for his management of this award and for his ongoing support for this study. The opportunity to develop parts of this study on a contract basis with the New Zealand Treasury was helpful. The Victoria University of Wellington School of Government provided additional financial support for this study through funding a Senior Tutor position. Without this financial support from these institutions this study would not have been possible.

The Victoria University of Wellington School of Government provided a collegial environment for PhD study. I would like to thank Associate Professor Robert (Bob) Stephens, my primary supervisor, and Dr Paul Callister, my secondary supervisor, for their guidance and feedback. I would also like to thank Ann Walker and Associate Professor Robert (Bob) Gregory for the insights they provided me on social capital and the current state of the All Black rugby team at our occasional seminars at the Backbencher (with Colin Meads looking over our shoulders).

I was fortunate to have the support of a number of different government departments while working on this study. The New Zealand Treasury was particularly supportive of this research. Ivan Tuckwell made a significant contribution to this study and to the development of tax and transfer policy over many years through his work with TaxMod. Another Treasury modeller, Matthew Bell, was a valuable source of expertise and enthusiastic support. Vicky Robertson and the tax team at the Treasury, particularly Rienk Asscher 
and Emma Fairbrother, willingly engaged in debate on the issues contained in this study and funded parts of this thesis on a contract basis. I learned a great deal from Professor John Creedy, of the University of Melbourne, on issues related to labour supply modelling while he was based at the Treasury. Roger Hurnard of the Social Policy Branch of the Treasury was also a useful source of expertise. I also benefited from frequent e-mail discussions with Tom Hall, my former manager in the Treasury tax section, while he was based at the World Bank in Washington.

Martin Neylan and Sandra Watson from the Inland Revenue Department provided useful input to this study. I have been consistently impressed by the professionalism of the department's Policy Advice Division and their open attitude towards research. Dee Collins of the Ministry of Social Development provided a key point of contact with that agency. I benefited from discussion on this research at various stages from other officials from this agency, particularly Michael Fletcher, who is now at the Families Commission. Nick Johnson, an lan Axford Fellow who was based at both the Treasury and the Ministry of Social Development provided a useful sounding board for the arguments in this study and information on the tax and transfer system in the United States of America.

I have benefited from discussions with many other officials, members of the press, parliamentary researchers, and Members of Parliament sharing a range of perspectives. I am grateful for the interest they have shown in this study and their willingness to listen to and critique my findings. I have treated all discussions with Members of Parliament as being confidential. I would like to thank Mark Vink and Simon Hay, both from the New Zealand Treasury, who provided useful sounding boards while serving as advisors to Members of Parliament.

Time spent on a PhD thesis often comes at an opportunity cost of time with friends and family. There are many people who I have unfairly neglected over the last few years. Sarah Wynn-Williams patiently accepted the burden of being in a relationship with both myself and my thesis and helped make the last few years so enjoyable. Chris Hubscher has also been a valued friend and source of political debate over many years. 
Finally, and most importantly, I would like to acknowledge my debt to my mother (Veronica), father (the late Tom), brother (Matthew), and sister (Sarah) and her family for supporting me during my university study and fostering my interest in public policy. I look forward to spending more time with my friends and family with the completion of this study.

All errors and omissions in this study remain the responsibility of the author. 
INTRODUCTION 


\section{General Introduction}

\subsection{Introduction}

In 2004 the Labour-led government announced a series of tax-benefit reforms (the Working for Families reforms) that will account for an estimated $\$ 1.17$ billion per-annum of new spending when fully implemented by 1 April 2007. These reforms aim to both reduce rates of child poverty and improve financial incentives for paid work at low wages, particularly for caregivers. Changes to family and employment tax credits (the Family Assistance programmes) are central to these reforms.

This study reviews methods for measuring the effectiveness of family and employment tax credits, evaluates the Working for Families reforms, and considers possible improvements to Working for Families. Questions that this study considers are:

- What roles should family and employment tax credits play in tax-benefit systems?

- How should family and employment tax credits be designed? Should eligibility for assistance reflect work effort as opposed to family structure?

- What lessons do historical and comparative perspectives on Working for Families provide?

- Will New Zealand's Working for Families reforms achieve the optimal design and role of family and employment tax credits?

- What improvements, if any, could be made to the Working for Families reforms?

This chapter introduces the policy problem that the Working for Families reforms aim to address, defines the research topic and scope, and explains 
the study's structure. In section two this chapter discusses the policy settings and assumptions regarding family structures that underpinned the early development of New Zealand's tax-benefit system. Changes to these settings and patterns of family structures over the last two decades are then discussed. In section three this chapter defines the research topic and scope. Following this the structure of the study and the key research questions by chapter are explained.

\subsection{The Policy Problem and Context}

A number of policy settings and assumptions regarding family structures underpinned the development of New Zealand's tax-benefit system. The development of New Zealand's tax-benefit system following World War Two was in an economic and social environment of low and generally short-term unemployment and where couples with children and a single male breadwinner were the most common family type. The social assistance system developed alongside policies that aimed to attain full employment and to ensure adequate market incomes for male breadwinners in families. Social assistance programmes were funded with progressive taxation and were generally provided on an income tested basis. Key exceptions to this income testing were the provision of the universal Family Benefit and universal pensions.

\section{Beveridge's Dilemma}

In New Zealand the provision of the universal Family Benefit reflected previous experience with income testing of family allowances, which was seen to limit the expansion of production during World War Two through discouraging increased work effort, and the movement towards universal provision of family allowances in Britain following the Beveridge report [McClure, 1998, pp. 97-98]. Yet in the preparation of his report Beveridge was confronted with the dilemma of reconciling a tax-benefit system ensuring income adequacy with a competitive labour market. Competitive labour markets did not generally adjust wages (paid to individuals) according to the number of children in a worker's family. However, in order to ensure families 
have adequate incomes, tax-benefit systems targeted assistance according to family size. Consequently when wages were low and family sizes were large the income from work could fail to provide an adequate family income and be less than the income from government transfers when not working [Mendelson, 2001, p. 1]. As a consequence of this dilemma the design of taxbenefit systems needed to balance the goals of encouraging the supply of labour and ensuring adequate incomes. This balance had to be found within a constraint of limited government funds.

In 1946 in the United Kingdom Beveridge's eventual solution was to pay family allowances to mothers with two or more children as he believed husbands' market wages were adequate for raising one child [Mendelson, 2005, p. 1; Millar, 2001, p. 192]. At this time in New Zealand the more generous universal Family Benefit was paid to mothers for every child in the family. These early efforts to reconcile Beveridge's dilemma reflected an economic and social environment of low and generally short-term unemployment and where couples with children and a single male breadwinner were the most common family type. It was assumed that men had dependents and women did not and that married women rarely worked in paid employment [Beaglehole, 1993, p. 2]. The costs of childrearing were seen as an important consideration in assessing families' need for financial assistance and a relatively high value was placed upon caregivers' time outside the labour market. Family allowances were thus provided to address families' financial needs, promote increased birth rates, and reinforce women's maternal roles in society [Beaglehole, 1993, p. 2].

\section{Increasing Population Heterogeneity and Tax-Benefit Reform}

These initial efforts to resolve Beveridge's dilemma seemed increasingly out of place in the light of important changes taking place in patterns of family structures, labour market outcomes, and policy settings, particularly in the two decades since 1984. Following the 1984 election of the fourth Labour government there was an ideological shift favouring retrenchment of the welfare state in New Zealand [Boston, 1999a, p. 9]. A feature of this retrenchment was a shift in social assistance expenditure towards targeted and residual assistance for working-aged people on low-incomes, particularly 
the unemployed and sole-parents, and which reflected attempts to respond to new and emerging economic conditions, such as the decline of full employment (for male breadwinners in families) and the greater role of market-based setting of wage rates.

Over the last two decades there has also been a shift towards a broad based and low rate tax system and a tax-mix shift away from income taxes towards consumption taxes [Stephens, 1993, p. 45; McLeod, Chatterjee, et al, 2001b, p. 11]. The shift towards flatter personal income tax scales, in conjunction with greater targeting of social assistance expenditure, changed the roles of taxation and social assistance programmes with targeted spending becoming the primary vehicle for redistribution [Stephens, 1997, p. 473]. Further, although policies have emphasised a broad based and low rate approach to income taxation, the combination of income taxes and abatement of targeted social assistance has led to poverty traps at lower income levels [St John and Rankin, 2002, p. 2; Nolan, 2004c, p. 4]. Poverty traps occur when people receive little or no increase in income in the hand when they increase their hours of work and have implications for a wide range of policy issues, including the labour supply of primary and secondary earners, the demand for childcare assistance, and the formation and stability of family structures [Nolan, 2003, p. 4].

As with many other OECD countries New Zealand has experienced significant changes in family structures over the last two decades. These changes have included the breakdown of the breadwinner model of social arrangements, increasing numbers of sole-parent families, and increasing numbers of dual-income families. For instance, between 1976 and 2001 the percentage of two-parent families in New Zealand decreased from 62 to 42 percent of families (excluding single-person families). There were corresponding increases in the proportions of couples without children from 29 to 39 percent and sole-parent families from 9 to 19 percent [Statistics New Zealand, 2002b, pp. 9-10].

Important changes in the labour market have also taken place over the last 20 years. Liberalisation of the labour market has been associated with increasing part-time and casual work, variations in weekly hours of work, and variations in wage rates. There has been a decline in employment among 
prime working-aged men, particularly low-skilled workers, and an increase in women's employment rates and representation in managerial and professional occupations [Singley and Callister, 2003, p. 3]. Changes in family structures and labour markets have influenced the polarisation of work, with a growth in both work-rich families, including dual-earner couples, and work-poor families, including couples where neither partner is in paid work [Singley and Callister, 2003, p. 1]. Along with changes in participation in work the distributions of weekly hours of work have also changed, with a 2004 study estimating that New Zealand has relatively high proportions of its population working 50 or more hours per-week [Messenger, 2004].

Changes in family structures (especially the growth in sole-parent families and older families without children), changes in employment outcomes, changes in the distribution of wages and salaries (which comprise approximately 80 percent of market income), and a growing proportion of workers in their prime earning years and with higher educational qualifications were reflected in an increase in income inequality in New Zealand from 1983 to 1998 [O'Dea, 2000, pp. 25-32]. Concerns were also increasingly expressed regarding the need to alleviate child poverty. Research by the New Zealand Poverty Measurement Project concluded that the incidence of poverty (the proportion of the family type below the poverty line) increased with the number of children in the family. Further, although the incidence of poverty was low among working families a significant proportion (almost 30 percent in 1998) of the families below a poverty threshold of 60 percent of equivalised disposable family income were working families [Stephens and Waldegrave, 2001].

These changes, particularly the increasing heterogeneity in family structures and increasing incidence of part-time and part-year work, have increased the complexity of designing tax-benefit programmes. Increasing variations in hours of weekly work have, for instance, made it increasingly difficult to design hours-based thresholds to encourage people to move from part-time to full-time employment. Increased numbers of social assistance recipients have also increased fiscal costs associated with increasing levels of main welfare benefits to respond to changes in the level and incidence of poverty. Consequently additional demands have been placed upon 
supplementary assistance and private charity to address areas of emerging needs [Stephens, 1999, p. 251]. These additional demands upon supplementary assistance have themselves led to increased complexity in the tax-benefit system, due to the administration and compliance issues associated with these programmes.

The social assistance and income tax systems were largely devised as separate systems. However, changes in family structures, employment outcomes, and the designs of tax-benefit programmes, such as the taxation of main welfare benefits and the provision of supplementary assistance to non-beneficiaries, have meant that large proportions of the population are now affected by both systems simultaneously [Stephens, 1997, p. 471]. Further, over the last 20 years the income tax system has taken an increasingly prominent role in the provision of social assistance payments. Thus while total expenditure through the tax system fell from 1980-81 to 1999-2000, social assistance expenditure through the tax system accounted for a relatively stable proportion of GDP and the proportion of total social assistance expenditure provided through the tax system increased. This social policy role of the income tax system will expand further following the Working for Families reforms (of which reform to the Family Assistance Tax Credits is central) in New Zealand. The Working for Families reforms are forecast to account for an estimated $\$ 1.17$ billion per-annum of new spending when fully implemented by 1 April 2007. Of this total the Family Assistance reforms are forecast to account for $\$ 1.19$ billion per-annum of new spending and part of their cost - along with the costs of changes to accommodation and childcare assistance - will be offset by reductions in the levels of main welfare benefits.

New Zealand is not unusual in turning to reform of family and employment tax credits in efforts to reduce child poverty, improve financial incentives for caregivers' labour supply, and modernise tax-benefit systems. Reform to these programmes has been central to tax-benefit reforms throughout the Anglo-American world [Mendelson, 2005; Bradbury, 2004; Nolan, 2004a, forthcoming]. In the United States, for instance, by 2004 federal expenditure on the Earned Income Tax Credit and Child Tax Credit was almost equal to the combined expenditure on Food Stamps and 
Temporary Assistance to Needy Families [United States Treasury, 2005]. Family and employment tax credits are able to provide tax relief on a more targeted basis than changes to personal income tax scales and, as they are generally provided through personal income tax systems, are seen to more strongly reinforce work effort than traditional welfare programmes [Alstott, 1995; Nolan and Fairbrother, 2005]. This use of family and employment tax credits is often part of a reform strategy emphasising active labour market policies [Adler, 2004, p. 88].

\subsection{The Research Topic and Structure of the}

\section{Study}

\section{Research Topic and Scope}

This study reviews methods for measuring the effectiveness of family and employment tax credits, evaluates the Working for Families reforms, and considers possible improvements to Working for Families. Changes to family and employment tax credits (the Family Assistance programmes) are central to these reforms. Family tax credits are refundable tax rebates generally paid to families with dependent children irrespective of workforce status. Employment tax credits are refundable tax rebates paid to families who satisfy work-based criteria. Employment tax credits may also be based on family structure. Family and employment tax credits are generally income tested on the basis of gross joint caregiver income. Refundable tax rebates are added to caregivers' incomes net of personal income taxes and social assistance abatement. The level of assistance provided to a family by a refundable tax rebate is not limited to the family's tax liability.

New Zealand has a unitary Westminster political system with social security largely funded, purchased, and provided at the central government level. Local governments have a limited role in the social security system, with the major exception being the direct provision of some subsidised housing at local-government level. While there has been some devolution of purchasing and provision of various social services to quasi-governmental organisations and private charitable groups since the mid-1980s, the funding, 
purchasing, and provision of social security largely remains the role of central government. There are few contributory social security programmes, with the major exception being the system of levy-funded accident insurance (the Accident Compensation Corporation scheme) [St John, 1999, p. 174]. Noncontributory social assistance has three tiers:

- First tier assistance (main benefits) providing basic income support.

- Second-tier assistance (non-discretionary supplementary assistance) providing additional assistance to cover circumstances in which needs are considered to be higher than those covered by main benefits alone.

- Third-tier assistance (discretionary supplementary assistance) providing further and discretionary assistance for a limited set of circumstances [Stephens, 1999, p. 240].

The Ministry of Social Development and the Inland Revenue Department administer the major social assistance programmes. (A summary of the major programmes in New Zealand's tax-benefit system can be found in Nolan [2003, pp. 45-52].)

This study focuses on the provision of family and employment tax credits to families with children. There are a wide range of important policy instruments other than family and employment tax credits, such as the provision of childcare assistance and access to paid parental leave. As well as their design, the full impact of family and employment tax credits reflects their interaction with these other policy instruments. However, in this study family and employments tax credits are given emphasis due to the prominence of these programmes in recent and ongoing tax-benefit reforms and the lack of their previous research. Further, there are a number of reasons for the focus of this study on families with children.

- Firstly, families with children make up a large proportion of the New Zealand population. The 2001 Census, for example, identified that of the 967,614 families (excluding the 307,635 one-person families) in New Zealand the most common was a couple with children (accounting for 42 percent $(407,793)$ of families). A further 19 percent $(182,919)$ of families were sole-parent families [Statistics New Zealand, 2002b, p. 1].

- Secondly, although families without dependent children were the largest single family-type in poverty in 1998, the incidence of poverty (the 
proportion of the family type below the poverty line) and the problems associated with poverty tended to increase with the presence of children in the family [Stephens and Waldegrave, 2001, pp. 90-93].

- Thirdly, financial incentives for labour supply facing families with children are of particular interest for policymakers due to differences in the cost structures of families with and without children and the interaction of family-based income transfer programmes, joint caregiverbased income transfer programmes, individual-based personal income tax programmes, and individual-based market incomes. Increasing emphasis is also being placed upon increasing the labour supply of sole-parents and secondary earners in families with children in order to:

- ensure families have access to adequate financial resources and address child poverty;

- address any fall in labour supply due to the long-term shrinking of working age populations;

o help caregivers maintain employment-related skills;

- provide caregivers with sources of financial independence;

- support progress towards gender equity; and

o increase the income tax base and GDP [OECD, 2001a, pp. 129130; Bryant, Jacobsen, Bell, and Garrett, 2004, p. 8].

\section{Structure of the Study}

The structure of and key questions addressed in this study are shown in table 1.1. There are four core parts to this study. Following the general introduction to issues facing the tax-benefit system in the current chapter, in part one the study considers frameworks for evaluating tax-benefit programmes and then, based on this discussion, develops the criteria and methodology for evaluating these programmes. In part two the study describes the evolution and operation of New Zealand's tax-benefit system and Family Assistance programmes. Part two also contains a comparison of the tax-benefit systems in New Zealand and other Anglo-American countries, which illustrates similarities and differences in the designs and roles of family and employment tax credits in these countries. The criteria and methodology developed in part one and the policy context identified in part two are used to 
evaluate the tax-benefit system in part three of this study. Following this the Working for Families and a number of alternative reforms are evaluated in part four of the study. Part four concludes with discussion of future directions for reform and evaluation and a summary of the study's findings.

\section{Table 1.1: Research Questions by Chapter}

\begin{tabular}{|c|c|}
\hline Part One & Chapter Two: Frameworks for Evaluating Tax-Benefit Programmes \\
\hline & $\begin{array}{l}\text { - What principles underpinned universal provision of social assistance } \\
\text { and progressive tax scales? }\end{array}$ \\
\hline & $\begin{array}{l}\text { What principles underpinned the move towards targeted provision and } \\
\text { broad based and low rate taxes? }\end{array}$ \\
\hline & $\begin{array}{l}\text { - What are the implications of attributing different values to domestic } \\
\text { production for these principles? }\end{array}$ \\
\hline & $\begin{array}{l}\text { - What are the implications of relaxing the analytical separation between } \\
\text { taxation and expenditure decisions for these principles? }\end{array}$ \\
\hline & Chapter Three: Criteria for Evaluating Tax-Benefit Programmes \\
\hline & $\begin{array}{l}\text { - How should poverty thresholds be set? What is the appropriate income } \\
\text { sharing unit? How should variations in families' cost structures be } \\
\text { taken into account? What poverty measures should be used? }\end{array}$ \\
\hline & $\begin{array}{l}\text { How can financial incentives to supply labour be evaluated? What role } \\
\text { do uncertainty and administrative incentives play in labour supply? } \\
\text { What empirical evidence is there on tax-benefit programmes' effects } \\
\text { on labour supply? How are labour supply and poverty outcomes } \\
\text { related? What is the relationship between labour supply and excess } \\
\text { burden? }\end{array}$ \\
\hline & $\begin{array}{l}\text { What criteria can be used to evaluate administration of and compliance } \\
\text { with tax-benefit programmes? What are the relative strengths and } \\
\text { weaknesses of tax-based and welfare-based assistance? }\end{array}$ \\
\hline & Chapter Four: Methodology for Evaluating Tax Benefit Programmes \\
\hline & $\begin{array}{l}\text { - What are the implications of evidence based policy and New Zealand's } \\
\text { public management framework for research on the tax-benefit system? }\end{array}$ \\
\hline & $\begin{array}{l}\text { How can the effects of reforms on individual families be estimated? } \\
\text { What assumptions should be made regarding the characteristics of } \\
\text { hypothetical families (e.g., wage rates, numbers of children, and } \\
\text { degree of sharing of resources)? }\end{array}$ \\
\hline & $\begin{array}{l}\text { How can the effects of reforms on the population as a whole be } \\
\text { estimated? What roles can arithmetic and behavioural microsimulation } \\
\text { modelling play? What are the respective strengths and weaknesses of } \\
\text { administrative and survey data? }\end{array}$ \\
\hline & $\begin{array}{l}\text { How should family and employment tax credits be modelled? How } \\
\text { should differences in purchasing power be taken into account? }\end{array}$ \\
\hline
\end{tabular}


Table 1.1: Research Questions by Chapter

\begin{tabular}{|c|c|}
\hline \multirow[t]{12}{*}{ Part Two } & Chapter Five: New Zealand's Tax-Benefit System \\
\hline & $\begin{array}{l}\text { What were the early policy settings of the tax-benefit system? What } \\
\text { underpinned these settings? }\end{array}$ \\
\hline & $\begin{array}{l}\text { What were the neo-liberal policy settings? How were neo-liberal policy } \\
\text { settings reflected in social assistance expenditure? }\end{array}$ \\
\hline & $\begin{array}{l}\text { What changes in policy settings have taken place since the election of } \\
\text { Labour-led governments after } 1999 \text { ? }\end{array}$ \\
\hline & Chapter Six: New Zealand's Family Assistance Tax Credits \\
\hline & $\begin{array}{l}\text { What were the antecedents to the Family Assistance Tax Credits? } \\
\text { What policy objectives did these programmes pursue? }\end{array}$ \\
\hline & $\begin{array}{l}\text { How have the designs and objectives of the Family Assistance } \\
\text { programmes changed since their establishment in } 1986 ? \text { What use } \\
\text { has been made of work effort and age of children as criteria for } \\
\text { targeting? }\end{array}$ \\
\hline & $\begin{array}{l}\text { What agencies are responsible for administering the Family Assistance } \\
\text { programmes to different client groups (such as people in and people } \\
\text { out of work)? How do recipients register for assistance? }\end{array}$ \\
\hline & $\begin{array}{l}\text { How is Family Assistance entitlement calculated? In particular, what is } \\
\text { the unit of assessment, how is a primary caregiver defined, and what is } \\
\text { the period of assessment? What incidence is there of over-payments } \\
\text { and under-payments? What are programmes' rates of take up? }\end{array}$ \\
\hline & Chapter Seven: Anglo-American Tax-Benefit Systems \\
\hline & $\begin{array}{l}\text { How do the five Anglo-American tax-benefit systems differ? What } \\
\text { emphasis do they place on spending on family cash benefits and } \\
\text { spending on active labour market programmes? }\end{array}$ \\
\hline & $\begin{array}{l}\text { How are family and employment tax credits designed? Is emphasis } \\
\text { placed on providing tax relief to breadwinners or to caregivers? What } \\
\text { structure and level of assistance is provided to representative families? }\end{array}$ \\
\hline \multirow[t]{5}{*}{ Part Three } & Chapter Eight: Income Adequacy \\
\hline & $\begin{array}{l}\text { What broad changes in the income distribution have taken place since } \\
1984 \text { ? Do Gini coefficients indicate an increasing income inequality in } \\
\text { New Zealand? What have the key drivers of income inequality been? } \\
\text { What other evidence is there on income changes in New Zealand } \\
\text { since 1984? }\end{array}$ \\
\hline & $\begin{array}{l}\text { Within these broad changes, how have the incidence and depth of } \\
\text { poverty changed from } 1984 \text { to } 2001 \text { ? How has the poverty reduction } \\
\text { effectiveness of the tax-benefit system changed? Who are the key } \\
\text { population groups in poverty? How do New Zealand's poverty rates } \\
\text { compare with those internationally? }\end{array}$ \\
\hline & $\begin{array}{l}\text { Are data on poverty rates consistent with data on living standards? } \\
\text { Who are the population groups with low living standards? }\end{array}$ \\
\hline & $\begin{array}{l}\text { What is the relationship between income adequacy outcomes and } \\
\text { financial incentives to supply labour? }\end{array}$ \\
\hline
\end{tabular}


Chapter Nine: Financial Incentives to Supply Labour

- What is the distribution of EMTRs from main benefits and the Family Assistance programmes among the population as a whole?

- What family types face the most serious poverty traps? What budget constraints and EMTR profiles do representative families face? What impact does other assistance, such as accommodation assistance and childcare subsidies, have?

- How do the financial incentives for labour supply in New Zealand compare with those in other Anglo-American countries?

Part Four Chapter Ten: Evaluating the Current Direction of Reform

- What impact will Working for Families have on child poverty? How will the static financial gains from Working for Families be distributed?

- What impact will Working for Families have on the distribution of EMTRs over the population as a whole? What impact will Working for Families have on EMTR profiles and budget constraints of representative families? What impact will Working for Families have on the labour supply of different demographic groups?

- How will Working for Families impact on the relative generosity of New Zealand's family and employment tax credits?

- What impact will Working for Families have on the administration and costs of complying with of the tax-benefit system?

- What further reforms could be recommended?

Chapter Eleven: Conclusion

- What are the key findings of the study?

- What future directions should reform and evaluation take?

\subsection{Conclusion}

A number of policy settings and assumptions regarding family structures underpinned the origins of New Zealand's tax-benefit system. Following the 1984 election of the fourth Labour government there was an ideological shift favouring retrenchment of the welfare state. This retrenchment included a shift towards targeted social assistance expenditure on the working-aged, which reflected the increasing market-based setting of wage rates and the decline of full employment. This greater targeting of assistance has resulted in increasing poverty traps facing low-wage families with children. Although the social assistance and income tax systems were largely devised as separate systems large proportions of the population are now affected by both systems simultaneously.

The origins of New Zealand's social assistance system were in an economic and social environment of low and generally short-term 
unemployment and where couples with children and a single male breadwinner were the most common family type. Over the past two decades work patterns and family structures have changed significantly. New Zealand has had one of the highest rates of increase in income inequality in the world over the last two decades and concerns have increasingly been expressed regarding the need to alleviate child poverty. Yet increasing population heterogeneity and the growth in part-time and part-year work are making redesigning the tax-benefit system to respond to poverty more complex. Many jurisdictions have responded to such issues through establishing or redesigning family and employment tax credits and such reforms are now underway in New Zealand with the Working for Families reforms. Expanding the social policy role of the income tax system in this way will further increase the degree to which the social assistance and income tax systems simultaneously affect the same people.

This study reviews methods for measuring the effectiveness of family and employment tax credits, evaluates the Working for Families reforms, and considers possible improvements to Working for Families. The focus of this study is on the effect of tax-benefit programmes on families with children. There are a wide range of policies that governments use to influence policy outcomes. The focus in this study is on the main tax-benefit programmes in general and family and employment tax credits in particular.

Part one of this study considers frameworks for evaluating tax-benefit programmes and then, based on this discussion, develops the criteria and methodology for evaluating these programmes. Part two of this study discusses the changing policy settings in New Zealand's tax-benefit system. Part two also contains a comparison of the tax-benefit systems in New Zealand and other Anglo-American countries, which illustrates similarities and differences in the designs and roles of family and employment tax credits in these countries. The criteria and methodology developed in part one and the policy context identified in part two are then used to evaluate the taxbenefit system, the Working for Families reforms, and a number of changes to these reforms in parts three and four of this study. 
Frameworks, Criteria, AND METHODOLOGY 


\section{Frameworks for Evaluating Tax- Benefit Programmes}

\subsection{Introduction}

The following three chapters evaluate frameworks for evaluating tax-benefit programmes and then, based on this discussion, develop the criteria and methodology for evaluating these programmes. These criteria and methodology are used to evaluate the New Zealand tax-benefit system and the Working for Families reforms in parts three and four of this study.

This chapter considers frameworks for evaluating tax-benefit programmes. Emphasis is given to illustrating the interaction between policy frameworks, policy settings, and policy problems. In section two of this chapter the horizontal equity and vertical equity principles, which underpinned universal provision and progressive tax scales, are discussed. These principles emphasise income as a proxy for utility and treat the taxation and expenditure sides of government budgets as largely separate. However, following increasing unemployment and governments' fiscal deficits emphasis increasingly shifted towards the greater targeting of social assistance and the development of broad based and low rate tax policies. As a corollary of this shift in policy direction greater emphasis was placed upon the optimal design of a tax-benefit system and upon theories integrating the taxation and expenditure sides of government budgets.

Optimal tax theory, which emphasises utility not income, explicitly considers trade-offs in the design of tax-benefit systems between behavioural responses to taxation and social disutility from inequality in individuals' utility. 
In section three of this chapter the key findings of optimal income tax (both non-linear and linear) models are discussed. Reflecting the increasing concern with alleviating child poverty and increasing caregivers' labour supply, the chapter then discusses implications for tax-benefit design of changing the assumed policy objective in these models (from welfarist to poverty reduction models) and of shifting from a labour-leisure model to a labour-domestic production model (attributing greater value to time outside of the labour market). The implications of two perspectives that integrate the taxation and expenditure sides of government budgets (the benefit principle and public choice theory) for tax-benefit design are then considered.

\subsection{Horizontal Equity and Vertical Equity}

Before discussing horizontal equity and vertical equity it is necessary to first define progressivity of the tax-benefit system. Progressivity indicates the degree to which income taxes paid and transfers received vary by income. In practice a range of tax-benefit programmes influence the progressivity of the tax-benefit system. However, for illustrative purposes progressivity is discussed in relation to only income tax systems in the section below. Income tax systems may be progressive, proportionate, or regressive. Progressive income tax systems are those where average tax rates increase over all income ranges. The average tax rate is the total tax paid as a proportion of the taxpayer's total tax base, such as taxable income. With progressive taxation income taxes take a higher proportion of higher incomes than they do from lower incomes. Taxes may take more in absolute terms from higher incomes than they do from lower incomes and still not be progressive if they do not take a higher proportion of higher incomes. Proportional tax systems are those where the marginal tax rate is equal to the average tax rate. The marginal tax rate is the rate of taxation on the additional unit of the taxpayer's taxable income. Thus proportional taxes take the same proportion of incomes however large or small they are. Regressive tax systems are those where the marginal tax rate is less than the average tax rate. Regressive taxes take a higher proportion of low-incomes than they do from higher incomes. Taxes 
may still be regressive even if they take more in an absolute sense from taxpayers on higher incomes [Creedy, 1999, pp. 411-412].

Until the early 1980s emphasis in New Zealand was placed upon funding the provision of social security and social assistance through progressive tax scales, which reflected the prominence of the vertical equity principle [Boston, 1999b, p. 21]. Further, although social assistance was generally provided on an income tested basis in New Zealand, until the early1980s much social security and some social assistance (including family benefits) were provided on a universal basis, which reflected the prominence of the horizontal equity principle. These principles of horizontal equity and vertical equity are discussed below.

\section{Horizontal Equity and Families' Cost Structures}

The classical definition of horizontal equity is that people with equal ability to pay taxes or grounds for receiving assistance should face the same tax burden or should receive the same level of public assistance [Musgrave, 1976, p. 4; Feldstein, in Kaplow, 1985, p. 5]. A second and widely used definition of horizontal equity is based on the ranking of the income distribution and argues that horizontal equity requires the tax-benefit system to leave the ranking of individuals on the basis of pre-tax income unaltered [Duclos, Jalbert, and Araar, 2000, p. 1]. Conceptually, ability to pay (underpinning the classical definition of horizontal equity) differs from the distribution of income (underpinning the re-ranking criterion). Ability to pay is, however, often defined in terms of annual monetary income.

A comprehensive base for assessing an individual's ability to pay would be all resources over which the individual has control. Resources could include monetary income, non-monetary income, such as the imputed income from domestic production and assets such as housing, consumption, and endowments, including financial and human capital endowments. These resources could be measured over an individual's lifetime, so that at any point in time taxes would reflect the net present value of lifetime resources. Differences in individuals' abilities to smooth resources over time could also be taken into account. 
Unfortunately it is not possible to quantify many forms of income, consumption, and endowments. For example, the Haig-Simon measure of annual income, which is the annual change in the family's wealth plus the market value of consumption over the year, requires information on flows of income, stocks of assets, and uncertain or one-off events, such as inheritances. Even where resources can be quantified there may be difficulties in collecting and evaluating data. These difficulties intensify when the period for assessment increases to greater than a year. Difficulties in quantifying ability to pay also arise due to variations in the income definitions and time periods for assessment and entitlement employed in different taxbenefit programmes, with income taxes based on annual income and social assistance generally based on more immediate income needs [Stephens, 1997, p. 483].

Assuming income is regarded as the measure of ability to pay then under the horizontal equity principle two families with the same income should pay the same amount of tax or receive the same amount of assistance. Further, families' ability to pay not only reflects income but also reflects their cost structures, with, for example, families with children facing additional costs to families without children. Differences in cost structures facing families with and without children have been central to many arguments underpinning the provision of family benefits. Given these additional costs families with children have lower ability to pay taxes then families without children and consequently should face relatively lower tax burdens or receive higher levels of assistance (assuming that the benefits to these families from having children do not outweigh these costs (this is discussed in greater detail in the discussion on equivalence scales in chapter three)). The provision of family benefits to all families with children irrespective of their incomes reflects a horizontal equity goal of accounting for the greater income needs of families with children relative to families without children.

There is wide support for the principle of horizontal equity or the equal treatment of equals [Auerbach and Hassett, 1999, p. 1]. Yet while this principle sounds straightforward it can be difficult to apply in practice. A workable definition of horizontal equity has been elusive. Auerbach and 
Hassett [1999, pp. 1-2] identify three key issues that have arisen in the construction of measures of horizontal equity. The first issue is establishing whether there is a need for an independent horizontal equity criterion or whether horizontal equity can be implied in the assumed aversion to inequality in the income distribution. Horizontal equity may simply represent a component of the overall measure of welfare. A second issue is justifying the criteria for horizontal equity if an independent horizontal equity criterion is required. For instance, one measure of horizontal equity is the assessment of whether re-ranking in the income distribution occurs. This criterion has, however, been criticised as giving undue weight to the status quo income distribution.

A third issue in defining a measure of horizontal equity is establishing the characteristics of the groups of people that are to be treated as equals (i.e., the extent that family's cost structures should be taken into account), what equal treatment entails, and how deviations are to be evaluated. As Musgrave has argued:

The basic meaning of 'equal position' must be that people enjoy equal levels of welfare, somehow defined; and that of 'equal treatment' that people in equal pre-tax positions should also be left in post-tax equality. But this is only a statement of the problem, not its solution. As a first step, operational meaning must be give to the concept of equal position [Musgrave, 1976, pp. 4-5].

Thus under a progressive personal income tax system that bases tax liability on the basis of individual incomes a two-income couple will generally pay less in personal income taxes than a single-income couple with the same total income. There is thus a disparity between the taxes faced by partnered families. Yet introducing tax relief to reduce disparities in the taxation of partnered families would, for example, create new disparities between partnered and single workers, with single workers facing higher tax burdens than partnered workers. Disparities would also be created between families of similar sizes, as some single workers have dependents while some partnered workers do not. With increasing population heterogeneity (particularly the breakdown of the breadwinner model of social arrangements) these difficulties in designing policies to achieve horizontal equity have increased. 


\section{Vertical Equity and Tax Scale Progressivity}

Horizontal equity is a prerequisite for the achievement of vertical equity. Vertical equity is the principle that those with higher ability to pay should pay more than those with lower ability to pay. Vertical equity deals with the treatment of unequal individuals and thus requires differentiation between people who have first been grouped on horizontal equity grounds [Musgrave, 1976, p. 4; Kaplow, 1985, p. 6].

Edgework undertook an early analysis of the optimal degree of progressivity of the tax system using utilitarian principles [Boskin, 2000, p. 15]. Edgeworth assumed that the objective in designing the tax system was to maximise a utilitarian social welfare function, which was the sum of individual utilities. The marginal utility of income was assumed to decline with income and be interpersonally comparable [Boskin, 2000, p. 15]. It was argued that individuals should pay taxes or receive transfers so as to result in their marginal utilities of income being equalised (this is the equal marginal sacrifice condition). When all incomes are reduced to the point where the marginal utility of income is equal for everyone the last dollar of income given in taxes and abatement by each person involves the same level of sacrifice. When tax payments are set so that that individuals' marginal sacrifices are equal the total sacrifice (society's total loss of utility) due to tax payments would be minimised, as it would not be possible to reallocate the existing tax burden from one person to another person with identical preferences without the increase in one person's sacrifice in terms of utility exceeding the decrease in the sacrifice in terms of utility of the other person [Pigou, 1929, p. 91; Marshall, 1949 (1920), p. 16; Mill, in Musgrave, 1985, p. 18]. The tax system was therefore required to transfer income from a high-income individual with a low marginal utility of income to a low-income individual with a high marginal utility of income.

Thus, totally ignoring incentives effects, the Edgeworth solution to the optimal degree of progression was the tax and transfer system, which equalised incomes. Except in the unlikely case of everyone having the same pre-tax incomes, this implied a 100 percent rate of taxation for incomes above the average and using the proceeds to transfer incomes

\footnotetext{
- Horizontal equity is also often a prerequisite for efficiency objectives through ensuring neutral treatment of similar economic resources.
} 
to those below the average, with everyone winding up with the average post-tax income [Boskin, 2000, p. 15].

Yet (again reflecting increasing population heterogeneity) the assumption of objectively measurable, comparable, and similar utility functions became increasingly contested [Musgrave, 1976, p. 15]. Further, the prescriptions for the degree of progression in the tax scale prescribed by sacrifice theory were shown to depend on the assumed marginal utility of income function and the definition of equal sacrifice [Musgrave, 1976, pp. 1415]. For example, as Brown and Jackson [1982, p. 64] argue, two other possible meanings of the concept of equal sacrifice other than equal marginal sacrifice are:

- equal absolute sacrifice, which occurs when each person sacrifices the same amount of total welfare (each individual experiences the same loss in total utility) in taxes and abatement; and

- equal proportionate sacrifice, which occurs when each person sacrifices the same proportion of total welfare (the ratio of utility lost to total utility is equal for each individual) in taxes and abatement.

Different concepts of equality of sacrifice have implications for the degree to which the tax schedule should tax those people with a higher ability to pay at a higher rate. As discussed above, the equal marginal sacrifice condition implies the equalising of all incomes through progressive taxation. The equal absolute sacrifice and equal proportionate sacrifice notions imply that the absolute level of taxes should rise as income increases. However, neither the equal absolute nor the equal proportionate conditions are definitive on whether the resulting schedule of taxation should be progressive, proportional, or regressive, as this would vary depending on the assumed marginal utility of income function [Brown and Jackson, 1982, p. 66].

Two other limitations to the arguments for progressive taxation also became apparent. First, the assumption that progressivity could be defined in terms of the formal structure of the tax-benefit system (or legal incidence) became increasingly contested. Defining progressivity in terms of legal incidence would be likely to provide a misleading view on the actual redistributive effect of the tax-benefit system as "this ignores tax incidence effects whereby increased marginal tax rates on higher incomes are offset by 
even larger salaries, or tax avoidance activities, to maintain the real value of after-tax income" [Stephens, 1997, p. 484]. Second, it also became more difficult to assume that progressive taxation would have no incentive effects, particularly on labour supply [Musgrave, 1976, p. 13]. As levels of unemployment increased policymakers and academic researchers increasingly placed attention on labour supply and the incentives for unemployment from tax-benefit programmes [Atkinson and Micklewright, 1991, p. 1679; Bradbury, 2004, pp. 305-306]. Attention thus increasingly

turned to theories that could evaluate both value judgements regarding the income distribution and the behavioural responses to taxation.

\subsection{Optimal Tax Theory}

Optimal tax theory evaluates the conditions for maximising a social welfare function reflecting value judgements regarding the income distribution while taking into account behavioural responses to financial incentives from taxbenefit systems and levying a level of government tax revenue [Mirrlees, 1971]. Optimal tax theory is based on the concept of utility defined as a function of consumption and leisure. Heady [1993, p. 27] argues that there are three reasons for using utility and not income. First, if people increase their work effort in response to a tax change their income may not change but their overall utility may due to the disutility from change in work effort. Second, utility inequality is likely to be less than income inequality as some people may choose to have low incomes. Third, when consumption goods are taxed relative prices and consumer preferences, which are represented by a utility function, will change.

An important tradition in welfare economics is the judging of the allocation of resources in an economy against the two fundamental theorems of welfare economics. The first fundamental theorem of welfare economics states that a perfectly competitive market economy leads to a Pareto optimum, where it is impossible to improve the position of one person without worsening the position of another [Rosen, 1998, p. 47]. The second fundamental theorem states that any Pareto efficient allocation may be achieved by a suitable choice of lump sum transfers. However, in optimal tax 
theory lump-sum taxes, where tax liability is independent of economic behaviour, are often ruled out, governments lack information on ability, and important goods, such as leisure, are outside the tax base. Consequently optimal tax theory is concerned with the second-best nature of optimal tax systems [Slemrod, 1990, pp. 73-74].

\section{Structure of Optimal Tax Models}

The optimal structure of a tax-benefit system is one that would minimise the excess burden associated with levying a level of government revenue and achieving a desired redistribution of income [Cullis and Jones, 1999, p. 426]. Optimal income taxation models involve a dual decision process. The government observes wage incomes but not the potential wages of individuals and levies taxes and provides transfers based on these observed incomes [Bradbury, 1999b, p. 13]. Taxation and grant levels are set subject to a government budget constraint or revenue requirement, which reflects individuals' behavioural responses to taxation and the provision and abatement of the grant. Individuals choose the combination of income and leisure that maximises their utility subject to their budget constraints, which depend on taxation and the provision and abatement of the grant [Creedy, 2001, p. 193]. As well as the government revenue requirement, assumptions are made regarding the economy's production structure (e.g., whether taxes affect pre-tax wages) [Bradbury, 1999b, p. 15]. Assumptions are also made regarding the social welfare function, the distribution of endowment, which is assumed to determine the income distribution, and the behavioural response function [Slemrod, 1993, p. 362]. These three later assumptions of optimal income tax models have been a prominent focus of the optimal tax literature and are discussed below.

The first stage in specifying the social welfare function is to determine individual utility functions. Utility functions are generally taken to be identical

\footnotetext{
- Lump sum taxes are often ruled out due to their regressive nature. This was, for example, one argument made against the British poll tax (community charge levied on all adults living in a jurisdiction) that replaced a residential property tax to finance local government in Scotland in 1989 and England and Wales in 1990. Backlash against the poll tax was instrumental in ending Margaret Thatcher's leadership of the Conservative Party in 1990 [Smith, 1991, p. 431].
} 
over all individuals. Thus individuals are assumed to have identical preferences for income and labour supply. This assumption eliminates problems of defining horizontal equity as there is no need to group individuals into identical categories [Musgrave, 1976, p. 15]. The second stage is then to aggregate the individual utility functions to form the social welfare function [Heady, 1993, p. 28]. Utilitarian social welfare functions define social welfare as the sum of each individual's utility and aim to maximise the total sum of utility through equalising marginal sacrifice irrespective of its distribution. Utilitarian social welfare functions are unconcerned with inequalities in individuals' total utilities [Heady, 1993, p. 29]. However, if a goal of the taxbenefit system is to reduce utility inequality then the social welfare function should put greater weight on the utility gains of low income people than on the gains of high income people. As the strength of the preference for utility equality approaches infinity only the utility of the worst-off person in society has any weight in the social welfare function. This is Rawls's maxi-min criterion [Heady, 1993, p. 29]. The maxi-min criterion is based on the principle that if rational individuals were to make decisions regarding a particular income distribution behind a 'veil of ignorance', so that they do not know what position they would have in the final income distribution, they would have a preference for, depending on their risk aversion, improving the situation of the worst off individual due to a risk that those circumstances could apply to them [Brown and Jackson, 1982, p. 20]. With a more egalitarian social welfare function the more progressive is the optimal income tax system [Slemrod, 1993, pp. 362-363].

While individuals are assumed to have identical preferences they are also assumed to differ in their abilities. Wage rates are assumed to be proportional to ability. As it is also assumed that the only source of income is labour income more able individuals attain higher levels of wellbeing than less able individuals. Thus in the absence of a tax-benefit system the distribution of ability determines the distribution of welfare. With a more unequal distribution of ability the potential social welfare gain from a redistributive tax system is greater [Slemrod, 1993, pp. 362-363]. Thus if income inequality increases then the social welfare gain from reducing poverty also increases. 
The elasticity of labour supply plays an important role in the determination of the optimal marginal income tax rate because this elasticity helps determine welfare losses [Cullis and Jones, 1999, p. 430]. The greater the labour supply response to taxation the greater the efficiency cost perdollar of revenue raised. The greater efficiency cost will imply a less redistributive optimal tax system [Slemrod, 1993, pp. 362-363]. If it is assumed that tax changes are revenue neutral, so that an increase in the tax rate is offset by an increase in the grant, the average taxpayer continues to pay the same amount of tax. This revenue neutrality assumption means the substitution effect dominates the income effect and that compensated elasticities of supply and demand are emphasised [Heady, 1993, pp. 31-32].

\section{Key Results from Optimal Income Tax Theory}

Optimal income tax theory evaluates the designs of hypothetical tax-benefit systems given variations in the assumptions discussed above. Key findings of these optimal tax models for the optimal design of tax-benefit systems are discussed below. This discussion first considers the literature on optimal nonlinear income taxation before discussing linear models of optimal income taxation.

Mirrlees [1971] investigated the design of an optimal non-linear income tax (with a marginal tax rate that can vary with income) given various assumptions about the social welfare function, the distribution of endowments, and the behavioural response function. As Akerloff has written:

However complicated the equations or the mathematics, the basic tradeoff in the choice of an optimal Mirrlees-Fair style income tax can be explained as follows. As taxes are raised and incomes are redistributed, there is a gain in welfare, because income is distributed to those who have a greater need of it (higher marginal utility). But this gain must be balanced against a loss: as tax rates rise in relatively productive jobs and as subsidies rise in relatively unproductive jobs, workers are less willing to take the productive (and more willing to take the unproductive) jobs. Such switching, per se, results in a loss of [the utility of the population] because each worker is choosing the amount of work, or kind of job, which maximises his private utility rather than the amount of work or kind of job which maximises social utility. In general, the redistributive gains versus the losses caused by tax/transfer induced switching is the major tradeoff in the theory of optimal income taxes and welfare payments [Akerloff, 1978, p. 11]. 
Mirrlees [1971] illustrated this trade-off between the gain in welfare from redistribution and the loss of welfare from tax-induced switching with a nonlinear income tax. With a non-linear income tax it would be possible for the tax to have an effect over a short range of incomes only. People whose incomes remain below the range of a tax increase would, for example, be unaffected by the change. People with incomes within the range would experience an income effect from higher taxes encouraging labour supply and a substitution effect discouraging labour supply. (Income and substitution effects are discussed in greater detail in chapter three.) People with incomes above the range would experience an income effect only, encouraging their labour supply. As Heady [1993, p. 36] argues the Mirrlees model demonstrated that overall the net effect on social welfare would depend on:

- "The compensated elasticity of labour supply: a high elasticity will mean that the net revenue gain is either small or negative, so the tax increase is less likely to increase social welfare" [Heady, 1993, p. 36].

- "The degree of concern for inequality [....] The higher the [concern for inequality] the smaller is the relative weight placed on the utility losses of the losers from the tax increase, and so the tax increase is more likely to increase social welfare" [Heady, 1993, p. 36].

- "The degree of income inequality: a high level of inequality implies a greater income difference between the (relatively poor) gainers and the (relatively rich) losers from the tax change, implying that a greater weight should be attached to the gains, and that the tax increase is more likely to increase social welfare" [Heady, 1993, p. 36].

- "The proportion of the population above the range of the tax increase: the higher is this proportion, the greater is the amount of gain to the poorest, and so the tax increase is more likely to increase social welfare" [Heady, 1993, p. 36].

An implication of these factors is that marginal tax rates at the lowest levels of income should be low in order to encourage participation in the labour market. However, for a fixed revenue requirement the reduction in marginal tax rates facing low-income people to encourage their participation in the labour market creates a revenue loss requiring an increase in the marginal tax rates facing higher-income people. These higher marginal tax 
rates facing higher-income people have associated economic costs. Further, in these models the utility that low-income people receive from leisure (nonwork) is given a positive weight. For both of these reasons it is thus optimal to have some low-income people choosing not to work.

As Heady [1993, p. 36] argues an implication of a higher proportion of the population above the range of a tax increase leading to greater social welfare from this increase is that the marginal tax rate at the top of the income scale should be zero. This result is drawn from Sadka [1976, in Cullis and Jones, 1999, pp. 431-432] and reflects the ability to reduce the marginal tax rate of the highest income earner to zero without a decrease (and possibly an increase) in tax revenue. Taxing the very top income of the highest income earner would discourage them from earning an additional unit of income. This taxation distorts their labour supply but raises no tax revenue. Removing the tax on this additional income would encourage the top income earner to increase their work effort while paying no less in taxation [Slemrod, 1993, p. 363]. The practical significance of this result is limited as the zero marginal tax rate should apply only at the very top of the income scale. Yet this result highlights the possibility that egalitarian social goals may be best served by tax systems that are less levelling than intuition suggests [Slemrod, 1993, p. 363].

The principles that emerge - that marginal tax rates should be low at both the highest and lowest levels of income - contrast sharply with what most people have previously believed. [....] But the arguments that lie behind them are in fact rather familiar [....] High marginal tax rates on the largest incomes bring in very little revenue, and are not worth pursuing if they have adverse consequences. Measures of support for low income families achieve rather less than nothing if their receipts are recouped by marginal rates of tax [Kay and King, in Cullis and Jones, 1999, p. 431].

These prescriptions also contrast with the function of current effective marginal tax rates to income, which would appear U-shaped with high effective marginal tax rates at both the top and the bottom of the income distribution [Cullis and Jones, 1999, p. 431].

Mirrlees's [1971] study also found that the optimal non-linear income tax system could be approximated by a linear optimal income tax rate structure with a single marginal tax rate and a demogrant to low-income individuals. 
This demogrant "can either be a lump-sum grant of money to each individual, in which case it provides a guaranteed income to each individual, or a lump sum tax" [Gentry, 1999, p. 308]. Mirrlees's conclusion allowed the optimal tax literature to focus on analysing the simpler and linear forms of optimal income taxes [Heady, 1993, p. 38]. Stern [1976, in Heady, 1993, p. 38] investigated the optimal linear income tax rates that correspond to a range of values for the compensated elasticity of labour supply, the aversion to income inequality, and the government's revenue requirement. Stern's estimates showed that the optimal linear tax rate was higher the lower the compensated elasticity of labour demand, the higher the aversion to income inequality, the greater the inequality in pre-tax wages, and the higher the government revenue requirement [Stern, 1976, in Heady, 1993, p. 39]. Thus differences in the aversion to income inequality can generate a range of optimal tax rates.

Optimal tax models are, however, subject to a number of limitations. Optimal tax models are normative models and, as Gentry has argued, the "degree of abstraction in models of optimal nonlinear income taxes has limited the policy relevance of their results" [Gentry, 1999, p. 307]. For instance, the finding that the marginal tax rate applying to the top income earner should be zero provides no information about the optimal marginal tax rate immediately below the top of the income distribution [Gentry, 1999, p. 307]. Further, optimal tax models generally assume simple population heterogeneity, model hypothetical tax-benefit systems, and pay little attention to the interaction of the demand and supply sides of the labour market. These models also generally assume that the government's revenue requirement is set optimally. Yet in actual tax-benefit systems greater allowance has to be made for variations in administration of different taxbenefit systems and administrators would be likely to lack the knowledge of factors such as individual's utility functions and the distribution of skill levels that would be required for calculating optimal income tax rates [Cullis and Jones, 1999, p. 437]. Policymakers also often face issues in the design of actual tax-benefit systems that optimal tax models do not address [Slemrod, 1990, p. 157; Bradbury, 1999a, p. 30; Creedy, 2001, p. 193]. In particular: 
Political considerations ensure that policy makers take a more holistic perspective on policy objectives than conventional economic literature. Policy makers are also aware of transitional costs, which means that consideration is given to tax reform (i.e., improving an existing tax system) rather than tax design (or achieving an optimal tax system, starting de novo) [Stephens, 1997, p. 477].

\subsection{Non-Welfarist Models and the Valuation of}

\section{Labour}

The discussion of optimal income taxes above was based on the assumption that social welfare is a function of individuals' welfare, which depends on their preferences for income and leisure. More recent optimal income tax research has replaced this welfarist objective with an objective of poverty minimisation (expressed in terms of the poverty gap) [Bradbury, 1999b, p. 23]. As Bradbury [1999b, p. 23] argues this poverty minimisation objective differs from the welfarist objective in two ways. First, as poverty is a function of income no value is assigned to the consumption of leisure by the poor. (In some cases a negative value can be assigned to this leisure.) Second, a poverty minimisation objective involves a tighter focus on individuals at the bottom of the income distribution. Consequently this poverty minimisation objective can be seen as being relatively consistent with values often expressed in policy discourse.

\section{Poverty Alleviation Optimal Tax Models}

Poverty alleviation (non-welfarist) optimal tax models treat poverty alleviation and time in paid employment as intrinsically important public policy outcomes and thus attribute little importance to the foregone utility from foregone leisure time [Bradbury, 1999a, pp. 14-15, 20-23]. As a corollary of this objective these poverty alleviation models are more likely than welfare models to view unemployment as being involuntary rather than voluntary. If leisure has a low value, as a non-welfarist model would be likely to assume, then unemployment would be more likely to be due to factors external to the individual rather than being due to the individual's utility for leisure exceeding that for employment. This assumption appears consistent with research on 
unemployment in New Zealand and overseas. In New Zealand qualitative research on sole-parents has found that sole-parents out of work would often like to work but are discouraged from doing do by financial penalties contained in the tax-benefit system [Gerritsen, 2004, p. 66]. In Britain research has estimated that only one-tenth of unemployment in a sample of the British Family Panel Survey was unambiguously voluntary and a further one-tenth was indeterminate [Burchardt and Le Grand, 2002, pp. 23-24].

The shift from a welfarist to a poverty alleviation objective has implications for the prescriptions generated by optimal income tax models. Overall the pattern of optimal marginal tax rates in a non-welfarist optimal tax model is similar to the optimal pattern in a welfarist model. However, the lower value of leisure in non-welfarist optimal tax models tends to support optimal marginal tax rates higher than those in welfarist optimal tax models (particularly at the bottom of the income distribution) due to the increased emphasis upon focusing resources on individuals below the poverty line [Bradbury, 1999a, p. 28].

- If incentive effects are ignored, minimising the poverty gap requires a guaranteed minimum income with 100 percent effective marginal tax rate on income up to the poverty threshold (lifting all poor to the poverty threshold with no spill-over to the poor or non-poor).

- If labour supply effects are considered then there is a case for relatively lower marginal tax rates on the poor to encourage them to increase their earnings. However, as there is no social benefit from the leisure the poor consume there is a greater need for grants to the poor to redistribute social welfare. This increase in grants creates a revenue effect requiring higher marginal tax rates. These higher marginal tax rates will discourage some individuals from working. It thus remains optimal to have some low-income people not working.

Consequently non-welfarist optimal income tax models tend to lead to higher optimal marginal tax rates than welfarist models. The higher the poverty line the higher these optimal marginal tax rates. Often these higher marginal tax rates are supported by mandatory work schemes or labour demand policies [Bradbury, 1999b, pp. 24-25]. 


\section{Domestic Production and Optimal Tax Models}

A further alternative variation to standard optimal income tax models would be to place a relatively high value on the utility received from leisure time (such as in domestic production models). In a traditional labour-leisure model of labour supply an individual's labour supply behaviour reflects a trade-off between income from work and leisure time. Thus if an unemployed or nonparticipating worker undertakes employment and this does not reduce output or employment elsewhere in the economy all that is foregone when this person enters employment is some of the leisure that he or she was consuming [Rosen, 1988, p. 243]. Yet this time spent outside the labour market not only includes time spent in unemployment or leisure activities but also time spent in domestic production, education and training, voluntary work, and retirement and incapacity [Atkinson and Micklewright, 1991, pp. 1681-1682; Wilson, 1996, p. 7]. While optimal tax theory, particularly in relation to optimal commodity taxes, has systematically evaluated the implications of leisure being excluded from the tax base [Cullis and Jones, 1992, p. 417], less emphasis has been placed upon the exclusion of domestic production from the tax base [Apps and Rees, 1999, p. 14].

In the labour-leisure framework the efficiency of tax changes reflects the labour supply elasticities for primary and secondary workers. Labour supply elasticities are relatively low for primary workers and relatively high for secondary workers. Taxing the more elastic labour supply at a lower rate reduces efficiency costs. Yet as well as distorting the labour-leisure trade-off, tax-benefit programmes also distort the labour-domestic production trade-off. Labour is taxed while domestic production is untaxed. Under individual

\footnotetext{
Key features of a labour-leisure framework are as follows. The extent to which income from a tax-benefit programme compensates for lost or potential market wages is the replacement rate [Brosnan, Wilson, and Wong, 1989, p. 19]. The wage that the individual will not supply labour below is the reservation wage. Increasing the level of assistance of a tax-benefit programme increases the replacement rate and this in turn increases the reservation wage of those receiving assistance. As well as the gross wage rate the replacement rate is influenced by the taxation and the abatement of social security programmes. In a labourleisure model these financial incentives influence people's decisions to enter employment or remain employed and the duration of benefit receipt [Brosnan, Wilson, and Wong, 1989, $p$. 19]. When financial incentives lead to tax-benefit programmes' recipients placing themselves in positions of greater need than would have been the case in the absence of assistance moral hazard is said to have occurred.
} 
taxation in a progressive tax system primary and secondary earners tend to face different tax rates on labour supply. This variation creates a welfare loss by distorting the cost of labour inputs into domestic production relative to labour [Piggot and Whalley, 1996, p. 410]. Apps and Rees [1999] argue that progressive tax systems that tax secondary earners at lower rates achieve a more efficient EMTR structure as the tax difference between domestic and market consumption is reduced relative to regressive tax systems. However, social assistance programmes are often assessed on the basis of the joint incomes of both caregivers in a partnered family. In comparison to individual assessment, under a system of joint income assessment the effective marginal tax rates of secondary earners are raised and the effective marginal tax rates of primary earners are lowered. The combination of individual based income taxes and jointly assessed social assistance programmes means primary earners tend to face higher effective marginal tax rates than secondary earners but secondary earners face higher effective marginal tax rates at lower hours of work.

Gottfried and Richter [1999, p. 408] argue the size of the distortion to domestic production not only reflects the tax induced distortion but also the ability of families to substitute primary and secondary earners' labour inputs into domestic production.

- If the two labour inputs into domestic production can be easily substituted, there is little distortion to domestic production even if there is a large dispersion between primary and secondary tax rates. The distortion to domestic production when a secondary earner is encouraged to enter the labour market is reduced if the primary earner can increase his or her supply of domestic production and the primary earner's domestic production is equivalent to that of the secondary earner.

- In contrast, if it is assumed that secondary earners have a particular advantage in domestic production, reducing the dispersion of tax rates will reduce the distortion to domestic production [Gottfried and Richeter, 1999, p. 408].

Gottfried and Richeter [1999, p. 408] also argue that because domestic production uses marketed inputs as well as primary and secondary labour, 
the size of the distortion to family production also reflects the ability to substitute technological inputs for domestic production. Thus implications of domestic production models for tax-benefit systems depend on the labour supply elasticities of primary and secondary earners and the distribution of effective marginal tax rates between primary and secondary earners. The size of the distortion to domestic production from excluding this production from the income tax base also depends on the ability to substitute primary domestic production for secondary domestic production and technology for domestic production.

\subsection{Integrating Taxation and Expenditure Decisions}

The models discussed above largely assumed that the government's revenue requirement was set optimally. Thus when determining the optimal degree of progressivity of the tax scale, for example, it was assumed that "sensible spending decisions were being made perhaps optimally by some other part of the government, or at least it was exogenous to the tax problem" [Boskin, 2000, p. 16]. This assumption was underpinned by further assuming that the taxation and expenditure sides of the government budget were largely separate. This separation between the two sides of government budgets was consistent with the development of taxation theory, which largely developed in isolation from expenditure theory [Musgrave, 1985, $\mathrm{p}$. 16]. The following section discusses two approaches to integrating taxation and spending and tax decisions. The first relates to the benefit principle (achieving the optimal level of public spending through assigning tax prices to achieve the revelation of preferences). The second draws from public choice theory and relates to the relationship between taxes and incentives for the growth of government [Boskin, 2000, p. 16].

\section{The Benefit Principle}

The benefit principle is derived from the idea of fairness in exchange. This principle links the tax and expenditure sides of a government's budget and argues that people who benefit from the use of a particular good or service 
should pay for it. The development of the benefit principle reflected the development of the general theory of value by Menger and Jevons and of the economic theory of public goods [Musgrave, 1985, p. 8]. In relation to private goods it is often assumed that individuals adjust their consumption until their marginal benefit from or willingness to pay for consumption equals their marginal cost from consumption. It is also often assumed that (also assuming that markets are perfectly competitive) for private goods this allocation will lead to an outcome that is both efficient and fair, since consumers of the goods will pay a price that reflects the goods' economic costs. The benefit principle treats government expenditure as analogous to private goods through basing tax liability on willingness to pay for government expenditure [Wicksell, in Musgrave, 1985, p. 9].

Given the preferences of individuals, welfare is maximised by having each equate marginal utility with price. This basic efficiency rule applies to both public and private goods. To be sure, there is a difference: In the private good case, goods are sold at a uniform price, with individual consumers equating price and marginal utility by quantity adjustment. In the case of public goods the critical feature of indivisibility [...] requires the same quantity to be available to all consumers. Since the marginal utility of the same quantity differs among them, the equating process calls for differential prices to be charged. Thus benefit taxation - greatly broadened from its Hobbesian origin as payment for protection becomes the supreme law of fiscal economy [Musgrave, 1985, pp. 8-9].

The benefit principle can also reflect concerns with inter-generational equity. A contributory social insurance system, for instance, "can be seen as a mechanism that provides a life cycle redistribution from periods of work to periods of retirement as well as one that allows individuals to offset the risks and contingencies of unemployment and sickness" [Stephens, 1997, p. 485].

However, there are a number of limitations to the application of the benefit principle to the design of tax-benefit systems. In particular, two concerns expressed regarding the use of this principle are the difficulty of determining and valuing an individual's consumption of a public good and the justice of its application [Musgrave, 1985, p. 9; Stephens, 1997, p. 471].

Applying the benefit principle to public or merit goods is less straightforward than applying the principle to private goods [Hines, 2000, p. 483]. Public goods are goods that are non-rival and non-excludable, such as national defence. Merit goods are goods that, although not public goods, 
ought to be provided even though members of society may not demand them [Rosen, 1998, p. 55]. For public and merit goods it is not always possible to establish a direct link between the benefits a person receives from them and the contributions they should pay due to information asymmetries and transaction costs [Stephens, 1997, p. 486]. People may also excessively discount the future costs of their actions. There are many public and merit goods and the benefits derived from them vary from person to person. These variations may be unobservable by the tax-benefit system. In such cases it is difficult to calculate taxes based on the individual benefits that each taxpayer derives.

Given these problems one way to determine and value an individual's consumption of a public or merit good would be to discover what that person would be willing to pay for that good given their income and preferences [Musgrave, 1985, p. 17]. Willingness to pay is often seen as the basis for market transactions. The application of this approach is, however, constrained by the difficulty of getting individuals to accurately reveal their willingness to pay for a public or merit good (the free-rider problem). With large numbers of consumers of a public or merit good the offer made by any one individual would have no significant effect on the total supply of the good. An individual would thus have an incentive to understate the benefits they receive from a public or merit good in order to reduce their tax liability [Musgrave, 1985, pp. 10-11]. Further, a person's willingness to pay may not reflect the true value of a public or merit good because this willingness may not necessarily accurately reflect what is in the person's best interests. A person may, for instance, excessively discount the value to them from a public or merit good if there is an inter-temporal separation of tax payments from the receipt of the benefit.

An alternative to willingness to pay would be to determine and value the benefit to an individual from a public or merit good according to the fiscal cost of the good provided to them [Musgrave, 1985, p. 17]. It could, for instance, be possible to impose a user charge or a tax that is closely related to the benefits individuals derive from the use of some public or merit good. However, such an approach may overlook a number of economic costs (i.e., induced changes to behaviours) associated with receipt that may affect 
recipients' utility. In applying the benefit principle in this way it would be necessary to establish that fiscal cost is an appropriate proxy for the total benefit from a public good that an individual receives.

The benefit principle provides little guidance on the desirable degree of progressivity of tax-benefit systems. Under this principle the desirable degree of progressivity reflects the income elasticity of demand. It is often assumed that an individual's utility increases with income but by less with each successive dollar. In the case of normal goods the quantity of the good demanded by an individual does not fall as income increases. Consequently the price that a person would be willing to pay for a public or a merit good would rise as their income increases. Thus if a public or merit good is a normal good a higher income person should contribute more than a lower income person to the cost of providing this good. Yet the benefit principle offers no precise guidance on the extent of this extra contribution. The benefit principle also gives little weight to distributional concerns. Under this principle contributions made to the funding of public or merit goods would reflect willingness to pay for these goods. This willingness to pay and subsequent allocation of goods would be likely to reflect the initial distribution of endowments. Objectives for redistribution aside from smoothing income and consumption over the lifecycle would not be taken into account.

The benefit principle largely limits the scope of government intervention to allocating the duties that ensure a system of natural liberty according to people's previous contributions. Thus this notion of justice in taxation presupposes justice in the existing distribution of endowments [Wicksell, in Musgrave, 1985, p. 9]. Justice in taxation as payment for the cost of public services can thus be separated from distributive justice [Musgrave, 1985, $p$. 9]. This separation is consistent with Musgrave's [1959] distinction between allocative and distributive functions of government intervention. The allocative function of government intervention includes the satisfaction of public desires not met by markets alone and contains greater scope for the use of the benefit principle to guide public policy [Musgrave, 1959]. Thus where markets have failed to reach an optimal equilibrium government intervention could improve social welfare, unless the utility loss from this market failure is exceeded by the utility loss from any government or 
intervention failure. The distributive function of government intervention includes the redistribution of income and wealth to achieve distributive justice. The allocative function of government intervention provides little guidance for the distributive function. Reaching a view on progressivity thus requires reaching a view on the government's distributive function, which cannot be guided solely by the benefit principle.

\section{Public Choice Theory}

As discussed above welfare economics and optimal tax theory largely developed in isolation from the theory on the expenditure side of government budgets [Musgrave, 1985, p. 16]. These theories assume that the level of taxation is largely exogenous of the tax system [Holcombe and Mills, 1994, p. $65]$. This assumption has been challenged by public choice theorists such as Brennan and Buchanan [in Holcombe and Mills, 1994, p. 65]. Public choice theory arose out of a concern with persistent fiscal deficits [Buchholz, 1990, p. 241]. Public choice theory applies rational choice behavioural assumptions to voters, interest groups, and politicians [Le Grand, 1997, p. 149]. This theory is sceptical of the motivations of these actors and prescribes a reduced role for the state, the decoupling of different functions of government (particularly the provision of policy advice and the purchasing of services), and reducing barriers to contestability of these functions. A broad base of support for social assistance programmes is not seen as desirable under this theory.

Early work in the area of public choice theory saw each tax base as a space over which the state could exercise its power to tax. The broader the tax base the more the state would use its power to tax.

The conventional wisdom notes that a given amount of revenue can be raised at a lower cost with a broader tax base that allows lower tax rates and therefore a lower excess burden. But Brennan and Buchanan argue that the total amount of tax revenue will be a function of the tax base, and that a broader tax base will allow more revenue to be collected. Their argument is based on a revenue-maximizing government that is not effectively constrained by electoral competition as such [Holcombe and Mills, 1994, pp 69-71].

Thus imposing taxes on narrow bases would restrict the growth of government and ensure greater efficiency. 
However, more recent work in public choice theory has emphasised that a system of general taxation, i.e., general uniform rates, would minimise the capture of cash concessions and their proceeds to interest groups.

The reason why general taxation is constitutionally preferred to differential or discriminatory taxation in political democracy is that the very structure through which political decisions are made prevents any attainment, even approximately, of the type of tax differentiation that might be defined to be 'optimal' or 'ideal' in a stylised setting of benevolence. That is to say, majoritarian decision processes cannot, by their nature, be expected to generate patterns of outcomes that embody the tax discrimination among persons and groups or over goods that corresponds to that which might be yielded through some economists' exercise of proffering advice to a despot [Buchanan, in Sautet, 2000, p. 9].

Thus broad based taxes are seen as enhancing efficiency. Sautet argues this change in conclusion is due to change in a view of the policy process from "a revenue maximising Leviathan" model to a model of majoritarian politics, "in which the majority determines the outcome of policy irrespective of whether its actions maximise revenue" [Sautet, 2000, p. 12].

As well as the setting of levels of taxation the principles of public choice theory can also be applied to governments' expenditure decisions. The degree of targeting of an expenditure programme can, for example, impact on the programme's support and consequently the volume of public resources for which it accounts [Saunders, 1994, pp. 26-27]. For instance, as Boston and St John have argued:

People are often more willing to pay taxes to fund programmes that benefit them personally than those that assist only the poor. Politically, it is much more difficult to reduce expenditure on social programmes that benefit a large proportion of the population, particularly if the beneficiaries are well equipped to defend their interests [Boston and St John, 1999, p. 96].

Yet taxation and expenditure decisions may also enjoy public support for reasons other than the distribution of their financial benefits. If targeting increases the legitimacy of a programme (possibly by increasing the extent that the direct financial benefit goes to the needy) it could also lead to sustainable or expanding expenditures, as was seen with the expansion of the Earned Income Tax Credit in the United States due to its support for work activity. Further, as well as narrow concerns for the distribution of public 
largesse citizens are also often concerned with broader issues, such as population growth and the changing structures of families. Concerns with fertility and population growth were, for instance, influential in the early growth in expenditure on the universal Family Benefit in New Zealand [McClure, 1998, p. 100]. Thus the implications of public choice theory for the optimal design of a tax-benefit system largely depend on assumptions made about the operation of the government sector (e.g., whether government maximises tax revenue or votes).

\subsection{Conclusion}

This chapter illustrated the interaction between policy frameworks, policy settings, and policy problems. Although social assistance was generally provided on an income tested basis in New Zealand, until the early-1980s much social security and some social assistance (particularly family benefits) were provided on a universal basis. This provision was funded through progressive tax scales [Boston, 1999b, p. 21]. Emphasis in the social security system until the early-1980s was also on the desirability of a broad base of support for programmes [McClure, 1998, pp. 238-239; Boston and St John, 1999, pp. 95-96]. These policy settings reflected a strong emphasis upon the horizontal equity and vertical equity principles. The expenditure and taxation sides of the government budget were also largely seen as separate.

In section two of this chapter the horizontal equity and vertical equity principles, which underpinned universal provision and progressive tax scales, were discussed. These principles emphasise income as a proxy for utility and treat the taxation and expenditure sides of government budgets as separate. Following important social and economic changes (particularly increasing unemployment and governments' fiscal deficits) emphasis increasingly shifted towards the greater targeting of social assistance and the development of broad based and low rate tax policies. Concern over the behavioural effects of progressive taxation and social assistance programmes increased. Concern over increasing and persistent government fiscal deficits also increased. As a corollary of this shift in policy direction greater emphasis was placed upon the optimal design of a tax-benefit system 
and upon theories integrating the taxation and expenditure sides of government budgets.

Optimal tax theory, which emphasises utility not income, explicitly considers trade-offs between behavioural responses to taxation and social disutility from inequality in individuals' utility. Optimal tax models generally assume simple population heterogeneity, model hypothetical tax-benefit systems, and pay little attention to the administrative features of tax-benefit systems and to the interaction of the demand and supply sides of the labour market. Further, as Gentry argues, this "degree of abstraction in models of optimal nonlinear income taxes has limited the policy relevance of their results" [Gentry, 1999, p. 307]. Yet these models can nevertheless help to identify the key elements for evaluating real-world tax-benefit systems.

If not an answer, what can we expect to glean from the academic literature? Generally speaking, we might hope to understand how the optimal tax system depends on the assumptions of the analytic model. [....] Once the relationship between the model and the resulting optimal tax system is understood, we can, for any particular policy question, hope to isolate the key elements on which the debate ought to focus [Slemrod, 1993, p. 361].

Optimal income tax models prescribe a broadly linear personal income tax scale with rates lower at the top and bottom of the income distribution. Optimal income tax arguments for reduced marginal tax rates at high incomes have, however, been more influential than the arguments for reducing marginal rates at low incomes. The implications for tax-benefit design of changing the assumed policy objective in these models (from welfarist to poverty reduction models) were then considered. Poverty reduction (or non-welfarist) optimal tax models generally prescribe higher marginal tax rates than welfarist optimal tax models. As a contrast to poverty reduction models other models have attributed greater value to time outside of the labour market and in domestic production. Domestic production models emphasise lower tax rates on low incomes (as these are the rates most likely to face secondary income earners).

The chapter then evaluated the implications of theories integrating the taxation and expenditure sides of government budgets. The benefit principle treats public and merit goods as analogous to market goods and argues that 
taxes should reflect the benefit that individuals receive from these goods. Difficulties in identifying the benefits received by individuals mean that this principle is of limited value for the design of a tax-benefit system. Further, reaching a view on tax-benefit progressivity requires reaching a view on the government's distributive function, which cannot be guided solely by the benefit principle. Public choice theory illustrated the implications of the structure of tax-benefit systems for the growth of government. However, the implications of these theories for the optimal design of a tax-benefit system largely depend on assumptions made about the operation of the government sector (e.g., whether government maximises tax revenue or votes). Public choice issues are not directly addressed in this study. 


\section{Criteria for Evaluating Tax-Benefit Programmes}

\subsection{Introduction}

Chapter two analysed a number of frameworks for evaluating tax-benefit programmes. This chapter develops criteria for evaluating tax-benefit programmes based on this discussion. The first of these criteria, income adequacy, is considered in section two of this chapter. This section includes discussions on the poverty threshold, equivalising family incomes, and a range of poverty measures. Section three of this chapter then discusses the criteria that could be used to evaluate financial incentives for labour supply. This section includes discussions on income and substitution effects, uncertainty and administrative incentives, and, in order to assess the significance of these effects, empirical studies of labour supply behavioural responses to tax-benefit programmes. The relationships between labour supply and poverty reduction and excess burden are then discussed. Section four of this chapter discusses administration of and compliance with taxbenefit programmes. This section includes discussions on take-up rates and the interaction and coordination of tax-based and social welfare-based programmes.

\subsection{Income Adequacy}

Poverty can be seen as a lack of adequate command over resources. Resources may include monetary income, non-monetary income, such as the imputed income from domestic production and assets such as housing, consumption, and endowments, including financial and human capital 
endowments. Different population groups may also have varying abilities to smooth income over time. Unfortunately it is not possible to quantify many forms of income, consumption, and endowments. For example, as discussed in chapter two, the Haig-Simon measure of annual income requires information on flows of income, stocks of assets, and uncertain or one-off events, such as inheritances. Even where resources can be quantified there may be difficulties in collecting and evaluating data. Consequently poverty measures often focus on a lack of monetary income. These are input measures.

This use of income measures contrasts with living standards (output) measures [Stephens and Waldegrave, 2001, p. 80]. Living standard measures can illustrate which demographic groups forego consumption of certain items because of their costs. (Living standard measures are discussed in greater detail in chapter eight.) There are significant mismatches in the groups that income and living standards measures identify as experiencing inadequate outcomes [Perry, 2002, p. 101]. Living standards measures can, however, be used to verify analysis based on income measures. An advantage of income measures is that they are relatively easy to measure, are the metric used for income taxes, and illustrate a major policy variable (the level of government financial assistance to families) [Stephens and Waldegrave, 2001, p. 80]. The emphasis in this study is thus on income measures.

\section{The Poverty Threshold}

A poverty threshold defines the level below which a monetary income is deemed inadequate. Different levels of inadequacy are reflected in different income thresholds. The income threshold chosen can make a significant difference to measured poverty [Perry, 2004, p. 26]. A relative (distributional) poverty threshold terms people poor if their incomes are judged inadequate in relation to those of other people in society. Relative poverty thresholds indicate the extent that people "are, in effect, excluded from ordinary living patterns, customs and activities" [Hagenaars, in Stephens, 1989, p. 8]. An absolute (nominal) poverty threshold terms people poor if their incomes are below the level necessary to maintain a minimum standard of living that does 
not change over time [Stephens, 1989, p. 8]. Unless an absolute (nominal) poverty threshold is adjusted for economic growth a decreasing proportion of the population will fall below this threshold over time. Economic growth would not lead to a decrease in measured incidence of poverty with a relative poverty threshold, unless economic growth is also associated with a change in income inequality [Jensen and Krishnan, 2001, p. 133].

Stephens, Waldegrave, and Frater [1995, p. 88] argued that a poverty threshold should be both relative to current standards of living and policy parameters and absolute in the sense of representing a standard of living that families should not fall below. They argued [1995, p. 89] that, for example, by the mid-1990s poverty measures based on the Benefit Datum Level, which was initially based on research by the 1972 Royal Commission on Social Security, was no longer related to its original relative conceptualisation due to social, economic, and policy changes since the early 1970s, such as changing family structures and labour market participation rates.

To develop a poverty threshold Stephens, Waldegrave, and Frater [1995] used focus groups to determine an income level that would provide an adequate minimum level of family expenditure that "would enable the family to pay for its own food, clothing, utilities and rent, without either going into debt or taking out special benefits or food parcels" [Stephens and Waldegrave, 2001, p. 80]. These micro studies of families' minimum income requirements were then used to derive a macro poverty measure based on a percentage of median disposable income. Basing the poverty measure on these micro foundations ensured that the measure reflected the experiences of people on low incomes [Stephens, Waldegrave, and Frater, 1995, pp. 8990]. The focus group average minimum adequate family expenditure gave a base poverty measure of 60 percent of median equivalent family disposable income. A lower poverty measure of 50 percent of median equivalent family disposable income was also developed to indicate a more modest level of expenditure [Stephens, Waldegrave, and Frater, 1995, p. 99]. This research provided empirical support for the wide international use of the poverty measures of 60 percent and 50 percent of equivalised median family disposable income. 
Policy is often evaluated on the basis of annual income. Yet annual income may provide both too long and too short a perspective on control over resources. The use of an annual income measure may fail to illustrate the effectiveness of the tax-benefit system in responding to urgent need due to fluctuations in job status, hours worked, and family status. An annual measure may also fail to illustrate the degree to which the tax-benefit system smoothes resources over people's lifecycles. A proportion of the population identified as being below a poverty threshold may only be poor for a relatively short period due to income mobility in the population and changes in the costs they face over time. Lifetime incomes are often more equally distributed than annual incomes. An annual measure may also fail to illustrate factors such as variations in costs due to the need to replace consumer durables and the erosion in the ability to earn income due to long-term unemployment [Wilson, 1996, p. 2; Creedy, 1999, p. 411]. Decisions on the time period for analysis are also linked with decisions on the income-sharing unit, as the composition of these units will change over time (when, for example, children age and become economically independent).

\section{The Income-Sharing Unit}

People deemed poor on the basis of their individual incomes may reside in and have access to the incomes of other family members. Income may also flow across family boundaries. Measured poverty thus reflects the incomesharing unit used in defining the poverty threshold, e.g., individuals, families, or households [Perry, 2004, p. 24]. These three ways of defining incomesharing units are discussed in greater detail below:

- Family units: single adults with no dependents or multiple people related to each other by blood, registered marriage, common law, or adoption. A family unit can include dependent children and elder dependents. Family units may include people who are related to each other but do not share resources, such as an absent parent.

- Statistical households: single adults living alone or multiple people who usually reside together and share facilities, e.g., eating facilities, cooking facilities, bathroom and toilet facilities, living areas [Perry, 2004, 
p. 24]. This is the Statistics New Zealand definition for the Household Economic Survey and the Census.

- Economic family units: single adults or multiple people who usually reside together, share facilities, and are financially interdependent. Children are dependent while aged under 15 or while aged 15 to 18 and neither employed full-time nor on a benefit. Children older than 18 are defined as separate economic family units irrespective of their income or employment status. The economic family unit is generally the unit of eligibility for income-tested social welfare benefits in New Zealand [Jensen and Krishnan, 2001, p. 131].

As many statistical households contain more than one economic family unit a population based on economic family units is larger than a population of statistical households. Perry [2004, p. 45] estimated that, based on the 2001 Household Economic Survey, the 1.4 million statistical households in New Zealand were equivalent to 1.8 million economic family units. This population increase included a 500,000 (1,500 percent) increase in single economic family units, who were mostly income-poor 18 to 25 year olds residing in households with higher incomes. Further, as 70 percent of single economic family units had incomes below the household median this change in the composition of the population also lowered the median income [Perry, 2004 , p. 46]. The choice of income-sharing unit thus has implications for the use of statistical measures based on population means, such as relative poverty lines.

Jensen and Krishnan [2001, p. 130] argue that historically statistical households have been used as the base units for analysis as their members could be "assumed to have commingled their financial affairs to function as an economic unit whose members have a common standard of living". However, as they go on to argue, this assumption has become increasingly doubtful with the increasing heterogeneity in the composition of statistical

\footnotetext{
New Zealand's tax-benefit system employs a range of income sharing units for assessment. Personal income taxes are levied on an individual basis. Family Assistance Tax Credits are assessed on the basis of joint (caregiver) income. Main social welfare benefits are assessed on measures more closely reflecting economic family unit income and assets. Student support is assessed on the basis of family income for students up to the age of 25 .
} 
households [Jensen and Krishnan, 2001, pp. 130-131]. The economic family unit is also the unit of assessment for the majority of social assistance programmes in New Zealand.

\section{Equivalising Household Income}

As well as in their sharing of resources families also differ in their relative income needs (their cost functions). Families in different circumstances require different incomes to achieve similar standards of living. Failing to account for these differences when evaluating tax-benefit policies would be likely to lead to a misleading picture of the nature of policy problems and the effectiveness of government responses. Yet many standard measures of policy outcomes, such as those relating to income inequality, e.g., Gini coefficients and Lorenz curves, are designed for homogeneous populations [Creedy and Scuttella, 2003, p. 3]. To use these measures it is therefore necessary to convert the actual heterogeneous population into a hypothetical homogenous population. This conversion needs to capture forms of income sharing as well as economies of scale derived from sharing resources and durable goods. Otherwise, for instance, if people who share resources and economies of scale are categorised as single-person families they may appear as less well-off than they really are [Smeeding and Weinberg, 2001, p. 2].

Variations in families' costs structures can be accounted for by basing policy evaluation on families' hypothetical equivalised incomes, which are families' actual incomes scaled to reflect their different cost functions. It is often assumed that the costs of childrearing are an important consideration in assessing families' ability to pay taxes or need for assistance [Bradbury, 2003b, p. 771]. However, equivalence scales differ in the ways in which they treat the presence of children in the family. Conditional equivalence scales measure the costs of children but not their benefits. Conditional equivalence scales assume that demographic structures are fixed (so that fertility decisions are exogenous). Unconditional scales take full account of choice of family formation and assume that people choose to have children when the benefits to them of doing so outweigh the costs [Bradbury, 2003b, p. 771]. Thus, for instance, "if a family chooses to have three children and $\$ 12,000$ 
when it could have two children and $\$ 12,000$, then a revealed preference argument implies that the family prefers the alternative it chose" [Pollack and Wales, in Bradbury, 2003b, p. 770].

Unconditional equivalence scales are based solely on adults' preferences towards their children whereas conditional scales directly include the welfare of children [Bojer and Nelson, 1999, p. 531]. In comparison to a conditional scale an unconditional equivalence scale would undercompensate families for the costs of childrearing and produce a lower estimate of the number of children in poverty [Bojer and Nelson, 1999, p. 532]. Yet as Bradbury has argued:

From the perspective of children, however, the revealed preference issues considered above are not relevant. A child's living standard is related to that of its parents but children do not experience the "joys of parenthood". Since the living standards of the children can only be compared with that of their parents in the context of the family, the conditional equivalence scale is thus the relevant scale to use when comparing the welfare of children with that of adults [Bradbury, 2003b, p. 784].

It could also be argued that compensation to parents for the costs of their children could breach horizontal equity, which Atkinson and Stiglitz defined as requiring taste differences to not be taken into account when formulating policy so that taxes and transfers would only be based on the opportunity sets facing different individuals and not their behaviour [Bradbury, 2003b, p. 773]. However, to the degree that opportunity sets differ between families with and without children, conditional equivalence scales would not be inconsistent with a concern for horizontal equity [Bradbury, 2003b, p. 773].

A further important consideration in the use of equivalence scales is whether or not these scales should take housing costs into account. Jensen and Krishnan [2001, p. 127] compared the findings of an equivalence scale that takes housing costs into account with one that does not. Both equivalence scales displayed similar trends in New Zealand data on living standards between 1988 and 1999, although equivalised income taking housing costs into account showed less year-to-year fluctuation. Equivalised income taking housing costs into account also showed a larger impact of economic changes on the living standards of children [Jensen and Krishnan, 2001, p. 127]. The authors thus reached a provisional conclusion that the 
approach of measuring equivalent incomes after removing housing costs was preferred. They also concluded, however, that further research would be required before a preference for such an approach could be authoritatively supported [Jensen and Krishnan, 2001, pp. 146-148].

Equivalence scales effectively re-rank the income distribution [van de Ven and Creedy, 2003, p. 2]. These scales often increase the cost functions of families with multiple children and shift them to lower levels in the hypothetical equivalised income distribution. Thus, when evaluating assistance that varies by the numbers of children in families, the measures of poverty reduction and targeting efficiency based on an equivalised poverty threshold would partly reflect this downwards re-ranking of families with multiple children.

The equivalence scale used in this study is the Whiteford Geometric Scale. This scale is widely used and understood and is the scale used by the New Zealand Treasury. This scale provides similar results to the revised Jensen scale used by the Ministry of Social Development [Johnson, 2005, p. 49]. The Whiteford scale accounts for the number of adults and children in the family and for the ages of the children. The scale is constructed so that a two-adult family has a rating of one. Families with fewer members have a rating of less than one and families with more members have a rating of more than one. The scale also accounts for the fact that children are likely to require less income than adults to achieve a similar standard of living. The scale does not account for the age of children or for housing costs.

\section{Poverty Measures}

The simplest poverty measures are headcount measures, which state the number or proportion of families below the poverty threshold. However, these measures ignore the actual incomes of the poor. They are only concerned with the fact that these incomes fall below the poverty line. Yet two societies may have the same headcount poverty rate but the total cost of bringing all 
the poor up to the poverty line may differ in each society [Creedy, 1998, pp. 82-83]. A poverty measure reflecting the actual incomes of the poor is the poverty gap, which measures the difference between families' incomes and the poverty threshold. The extent to which families fall below the poverty threshold is the poverty depth. Further, poverty reduction effectiveness is the ratio of benefits going to the pre-transfer poor to the total benefits needed by that group and targeting efficiency is the extent that expenditure goes to the poor [Creedy, 1998, p. 83; Stephens and Waldegrave, 2001, pp. 83-85].

\section{Figure 3.1: Hypothetical Pre-Transfer and Post-Transfer Income Distributions}

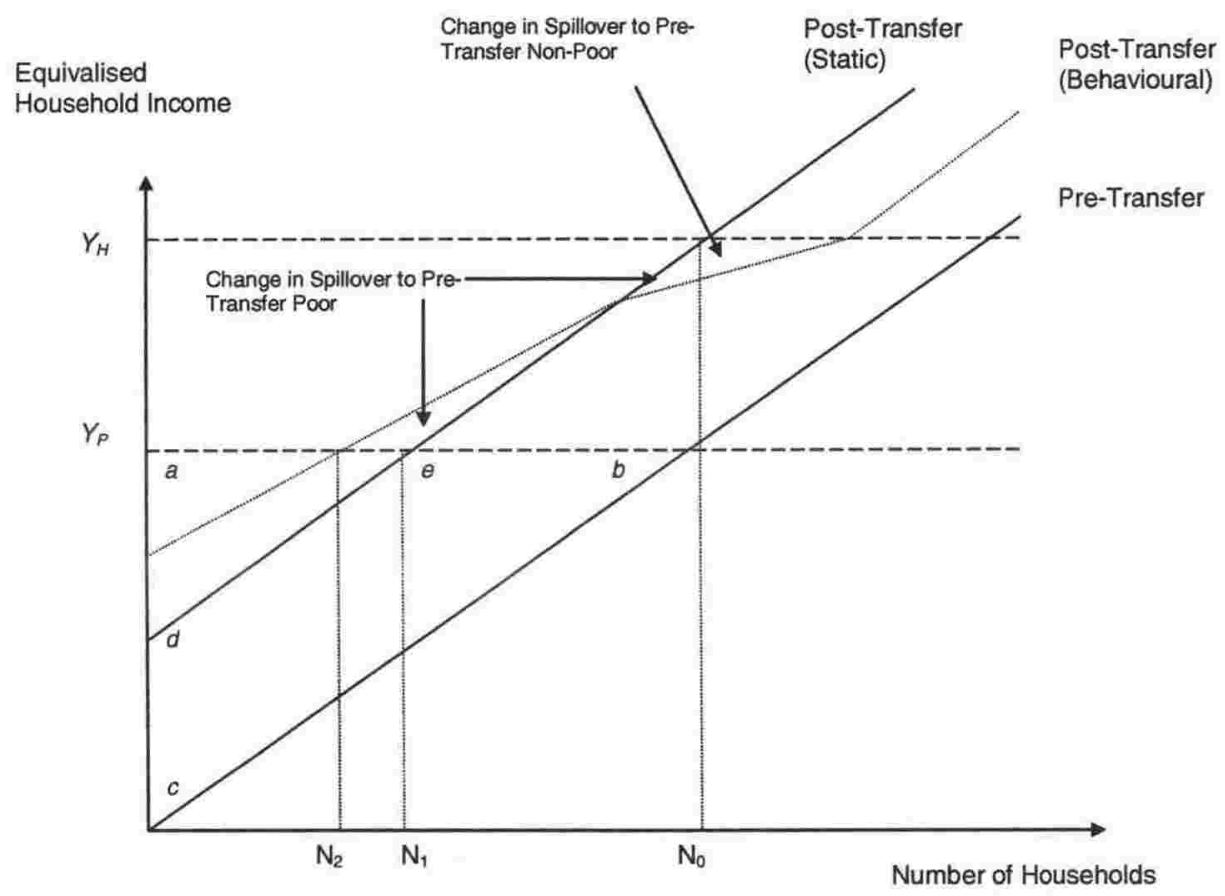

Source: Based on Creedy, 1996, p. 103

Poverty reduction effectiveness, headcount poverty rates, and targeting efficiency are illustrated with hypothetical income distributions in figure 3.1. The ordinate of the figure expresses equivalised family incomes and the abscissa expresses numbers of families. Illustrated in the figure are hypothetical post-transfer income distributions both without (static) and with (behavioural) labour supply effects and a pre-transfer income distribution.

\footnotetext{
The weights used in this equivalence scale are: one adult, 0.64; one adult one child, 0.9; one adult two children, 1.1; one adult three or more children, 1.31; two adults, 1 ; two adults one child, 1.2; two adults two children, 1.38; two adults three children, 1.59; two adults four or more children, 1.74; three adults, 1.22; three or more adults plus children, 1.75; and four or more adults no children, 1.65 .
} 
The comparisons between the pre-transfer and post-transfer distributions are for the same calendar year. $Y_{p}$ is the poverty threshold. $Y_{H}$ is a hypothetical point at which a particular transfer is fully exhausted, creating a notch in the behavioural post-transfer line at this point. The lines remain apart due to the likely behavioural responses from other income tax and welfare programmes in operation.

Poverty reduction effectiveness is the ratio of benefits going to the pretransfer poor to the total benefits needed by that group [Stephens and Waldegrave, 2001, p. 85]. The total benefits needed by the poor are the area bounded by the poverty threshold, the pre-transfer income distribution, and the ordinate (the area abc in the figure). The benefits that go to the pretransfer poor are the area bounded by the poverty threshold, the pre-transfer income distribution, the ordinate, and the post-transfer income distribution (in the static case the area ebcd). Pre-transfer headcount poverty is the number of families at the point where the poverty threshold and the pre-transfer income distribution intersect $\left(\mathrm{N}_{0}\right)$. Post-transfer headcount poverty is the number of families at the point where the poverty threshold and the posttransfer income distribution intersect (in the static case $\mathrm{N}_{1}$ ). Targeting efficiency indicates the extent that expenditure goes to the poor. Targeting efficiency is reduced by spill-over. Spill-over to the pre-transfer non-poor occurs when families with pre-transfer incomes above the poverty line receive some financial assistance. Spill-over to the pre-transfer poor occurs when the transfers received by the pre-transfer poor are greater than those needed to lift their incomes to the poverty threshold [Creedy, 1996, pp. 102, 104; Stephens and Waldegrave, 2001, p. 85].

\subsection{Labour Supply and Excess Burden}

As Blundell [1992, p. 16] argues labour supply can be difficult to define. The impact of tax-benefit programmes on labour supply is often seen in terms of transitions between employment and unemployment. The labour force participation rate is the proportion of the population willing to work (the employed and unemployed). The rate of work effort (the number of hours worked each week and the number of weeks worked per year) is narrower 
than participation in the labour force. The labour force participation rate is thus an indicator of potential labour supply while the rate of work effort is an indicator of actual labour supply [Brosnan, Wilson, and Wong, 1989, p. 19]. However, the full impact of tax-benefit programmes also depends upon transitions between employment and unemployment and the third labour market state of non-participation. The state of non-participation includes people undertaking education and training, domestic and voluntary work, leisure, retirement, and facing discouragement and incapacity [Atkinson and Micklewright, 1991, pp. 1681-1682; Wilson, 1996, p. 7]. A significant proportion of the people who enter employment do so from the state of nonparticipation.

Each of these labour market states can be measured in a number of ways. Measures of unemployment can, for example, be based upon administrative conditions, such as the registration for or receipt of assistance, or upon observed or reported labour market behaviour, such as job search activity [Atkinson and Micklewright, 1991, p. 1683]. All measures are likely to contain some degree of inaccuracy, however. For instance, measures based upon numbers of people receiving assistance would fail to measure those people seeking work but not eligible for or receiving a benefit. Further, measures of the numbers of people receiving assistance would include a number of people not actively seeking work [Atkinson and Micklewright, 1991, p. 1683]. There is also significant heterogeneity within each of the three labour market states. Within the unemployed there are discouraged workers (who have ended their search for employment), those who have already secured a future job, part-time workers, and temporary lay-off workers (who intend to return to their previous employer). Within the employed there are the self-employed, wage and salary earners, full-time workers, part-time workers, those in permanent jobs, and those in temporary jobs. Within the non-participants there are people sick or disabled, caring for children and other dependents, engaged in unpaid work, retired, and engaged in education and training [Atkinson and Micklewright, 1991, pp. 1684-1686]. 


\section{Income and Substitution Effects}

Transitions between labour market states are influenced by financial incentives to supply labour. These financial incentives occur on two margins. The extensive margin relates to choices about labour-force participation and the intensive margin relates to choices about hours or weeks of work [Blundell, 1992, p. 16; Heckman, 1993, p. 116]. The strength of incentives on the extensive margin reflects the income effect of the tax-benefit system. The income effect is the income available for consumption that is independent of the labour supply decision itself. The strength of incentives on the intensive margin reflects the impact of the tax-benefit system on the net hourly wage rate [Blundell, 1992, p. 20]. Budget constraints show the net income after taxation and the payment of abated assistance that is received at different levels of time in paid employment [Prebble and Rebstock (eds.), 1992, p. 11]. Net income when out of work is the height of the budget constraint at zero hours of work. The height of the budget constraint illustrates the income effect. The slope of the budget constraint is equal to the marginal rate of substitution between time in paid employment and time in other activities. The slope of the budget constraint illustrates the substitution effect. Whether these two effects reinforce or offset each other depends on the case at hand and requires empirical analysis [Blundell, 1992, p. 20; Heady, 1993, p. 31].

Income and substitution effects are illustrated with stylised budget constraints and indifference curves for an individual in figure 3.2. The abscissa of the figure is expressed in hours of leisure time, which is time in activities other than paid employment. The line $\mathrm{Y}_{A} \mathrm{~B}$ is the individual's pre-tax budget constraint. It is assumed that a small amount of income is unearned income (such as a demogrant). The individual's utility is illustrated with indifference curves, which show different combinations of the ways that they could spend their time that they would be indifferent between. The slopes of these curves reflect factors such as in-work costs and the availability of childcare and thus vary between different family types. The further from the origin the indifference curve the greater the individual's utility. The slope of the indifference curve is equal to the marginal utility from one additional unit of paid employment. 
In figure 3.2 the indifference curve $\mathrm{U}_{0}$ is the individual's pre-tax indifference curve. The time in paid employment that would maximise a person's utility is that where the additional utility from an additional hour in work is equal to the rate at which this person could substitute this hour of work for an hour in other activities [Creedy, 2003, p. 3]. People are at this point when they have an indifference curve that just touches their budget constraint. If the indifference curve was within the budget constraint then the person would not be maximising their utility and an indifference curve above the budget constraint would be unobtainable. The point of tangency between the indifference curve and budget constraint is at $F_{1}$ in figure 3.2.

Figure 3.2: Income and Substitution Effects with Stylised Indifference Curves and Budget Constraints

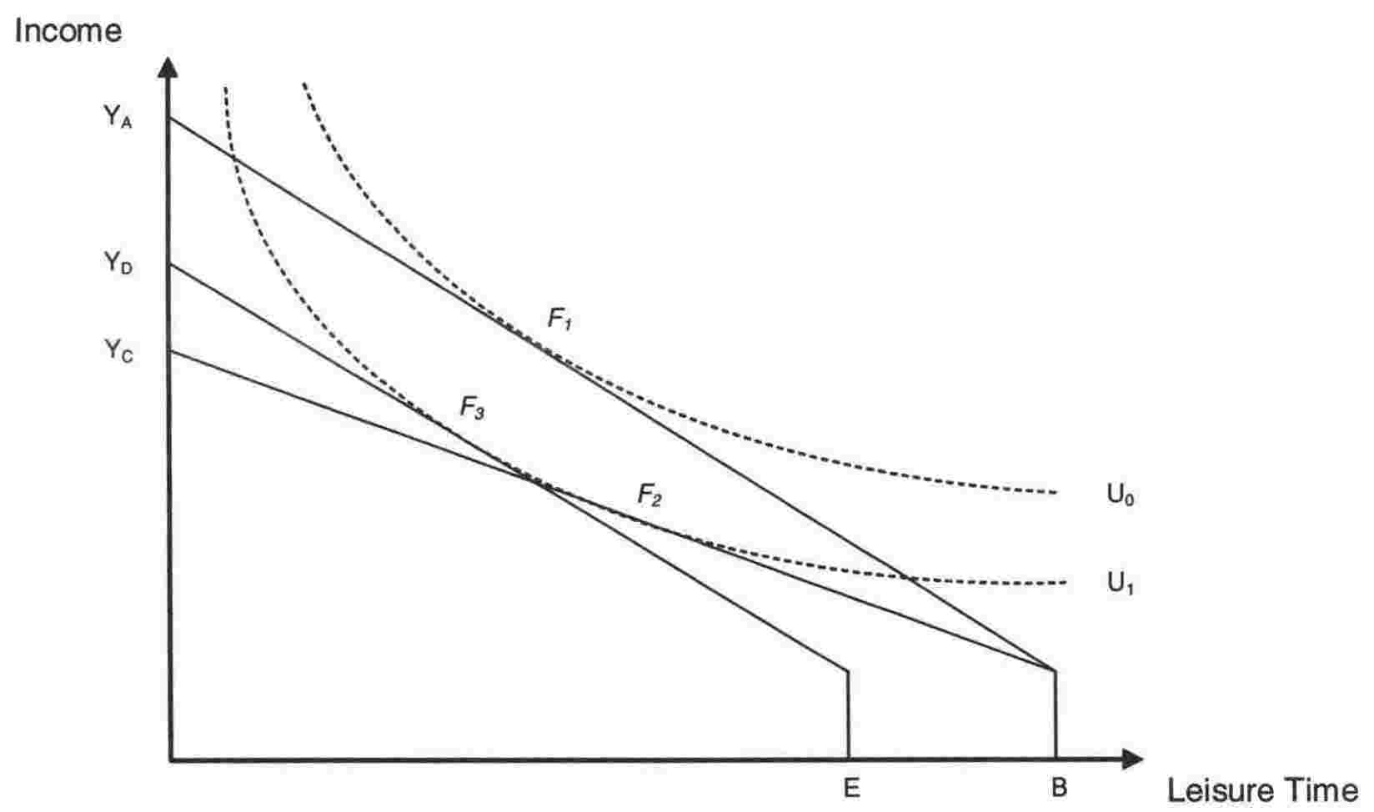

If an income tax is only imposed on earned income the individual's budget constraint pivots and falls to $Y_{C} B$. The new optimal position along this budget constraint is the new tangency with the highest attainable indifference curve. The new budget constraint is tangential to the indifference curve $U_{1}$ at point $F_{2}$, which indicates that this person consumes more leisure and has a lower income as a result of the tax. The hypothetical budget constraint $Y_{D} E$ illustrates the point at which the individual receives the same utility as the post-tax position but at the pre-tax prices. The shift from $F_{1}$ to $F_{3}$ illustrates the income effect and the shift from $F_{3}$ to $F_{2}$ the substitution effect. There is thus a 
reduction in the individual's welfare as a result of the move to the lower indifference curve. Not all people face the same income and substitution effects from this tax change. People with incomes below the change would be unaffected. People with incomes within the range of the change would face a fall in income encouraging work effort and a change in the relative financial return from work discouraging work effort. Whichever effect would dominate is an empirical question. People with incomes above the range over which the change applies would face an income effect and no substitution effect and thus would be encouraged to work more.

The overall effect of the change would therefore be to (a) reduce the labour supply of people facing the higher tax rate and (b) increase the labour supply of people above the range of the change. If the reduction in labour supply from group (a) exceeds the increase in labour supply from group (b) then the total effect on labour supply would be negative. Likewise, if the increase from group (b) exceeds the reduction from group (a) then the total effect on labour supply would be positive. The sizes of the responses of the two groups depend on the uncompensated elasticity of labour supply and the numbers of people in the groups. Thus when the uncompensated elasticity of labour supply (the concern is with uncompensated elasticity as both income and substitution effects are in operation) is high and the number of people above the abatement increase is low, the total labour supply would be likely to fall from an increase in a tax rate.

The discussion above was based on stylised budget constraints and indifference curves. In practise budget constraints are usually highly complex, reflecting the complexity of the interaction of personal income tax policies, main welfare benefits, and supplementary welfare assistance such as the Family Assistance Tax Credits. A consequence of this complexity is that marginal tax rates will often vary by hours of work, so that individuals with the same gross income (reflecting both gross wage rates and hours of work) may face different labour supply incentives. Differences in labour

\footnotetext{
- In some cases a decrease in an individual's tax may encourage a decrease in work effort. For example, a "decrease in work effort in [the case of a tax reduction] is commonly referred to as 'backward-bending' labour supply and is explained by the income effect (from the extra
} 
supply responses may thus reflect differences in individuals' preferences or differences in the marginal tax rates that individuals face [Blundell, 1992, $\mathrm{p}$. 24]. Modelling changes in budget constraints by hours of work for fixed gross wage rates can isolate the impact of marginal tax rates on financial incentives for labour supply decisions.

As Blundell [1992, p. 22] has argued, if "individuals can exert some degree of choice over their labour supply, the characteristics of a tax and benefit system should have implications for observed labour supply behaviour. For instance, if the tax and benefit system does not lead to a proportional tax, in which the effective marginal tax rate is constant, we should observe bunching in the hours distribution." This bunching will tend to take place where there is a discontinuity or notch in an individual's budget constraint. Choice theory suggests that if the notch is moved then the hours at which bunching occurs would also change. Nolan [2003] illustrated that bunching in the distribution of hours of work in New Zealand for various family types could be explained by discontinuities in these family types' budget constraints. This bunching reflects both increases and decreases in hours of work.

Binder and Rosen [1985] analysed the consequences of notches for a number of issues, including welfare reform. They emphasised that while linear taxes impose relatively small excess burdens on everyone a notch imposes a relatively large excess burden on a smaller number of people. The aggregate excess burden thus depends on the distribution of individual tastes and endowments [Binder and Rosen, 1985, p. 738].

Unlike linear incentives, notch schemes do not distort the behaviour of every person. Rather, if properly designed, they induce individuals to self select so that those who are most willing to change their behaviour are the ones who receive the subsidy (or avoid the tax) [Binder and Rosen, 1985, p. 745].

This requires, however, notches to be located in the correct position in the distribution of hours of work, which is likely to be difficult to identify and 1992, p. 23]. 
implement given the degree of population heterogeneity and the difficulty in accurately establishing the distribution of individual tastes and endowments.

\section{The Role of Uncertainty and Administrative Incentives}

People's decisions to supply labour are influenced by more than the financial incentives associated with the tax-benefit system. As well as these financial incentives, changes in people's labour supply also reflect the tax-benefit system's administrative incentives (such as work tests and stand-down provisions), uncertainty people may feel about the level or stability of their likely work or tax-benefit income, and any non-financial considerations for entering or remaining in the work force, including self-esteem and fear of damage to future employment prospects [Barr, 1999, p. 13; Wilson, 1996, pp 13-15].

Financial incentives and administrative incentives should be seen in conjunction. A weakening of administrative incentives for encouraging labour supply could, for instance, increase the significance of financial incentives for encouraging labour supply. For example, when administrative incentives increase the compliance costs facing beneficiaries or when they increase the expected income from work by, for example, assisting an individual to find higher paying work, they increase the relative return from work. However, when they provide services or opportunities to beneficiaries that are not available to people in work they reduce the relative return from work and thus can weaken financial incentives.

Uncertainty and non-financial considerations can also interact with financial incentives to influence labour supply [Wilson, 1996, pp 13-15]. For instance, while a stand-down period for eligibility for an unemployment benefit could make employment more attractive by reducing expected net income on unemployment, for some beneficiaries who face uncertain incomes in work this stand-down period may also increase the perceived costs of re-entering the welfare system in the future and thus create some reluctance to initially leave welfare. Responses to financial incentives may also reflect the timing of payments or abatement, as people may not be aware or may discount the impact of financial incentives when making 
decisions that, for instance, effect entitlements paid on an annual rather than a more frequent basis, such as fortnightly [Barr, 1999, p. 18].

\section{Empirical Studies of Labour Supply Effects}

In order to assess the significance of financial incentives to supply labour the following section considers the results of empirical studies of labour supply behavioural responses to tax-benefit programmes. The section below thus first discusses New Zealand studies of the labour supply behavioural responses. This is then followed by discussion of the results of international studies, with an emphasis on studies evaluating the labour supply effects of family and employment tax credits.

Maani [1989] examined the effect of the Unemployment Benefit on the reservation wage (the wage that the individual will not supply labour below), the probability of reemployment, and the post-benefit wage of the unemployed job seekers. The paper found that the unemployment benefit decreased the probability of re-employment during a given period but, for those who became reemployed, was also associated with a higher postemployment wage. It was estimated that a 10 percent increase in the benefit replacement ratio was associated with a mean probability of re-employment 4.3 percent lower but a ratio of post-unemployment wage to last market wage 4.6 percent higher [Maani, 1989, p. 14].

Brosnan, Wilson, and Wong [1988] reviewed empirical evidence on the relationship between labour supply decisions and the level, duration, and eligibility requirements of income support provisions such as the Unemployment Benefit and Domestic Purposes Benefit. They argued that in general empirical links between disincentives to work in the social assistance system and labour supply behavioural responses were not substantial. However, they did identify that labour force participation and work activity of prime aged men was least sensitive to benefit provision. Teenage men were the most sensitive to the level of benefits and the duration of eligibility and that the labour supply of women was sensitive to the supply of family income assistance.

Chiao and Walker [1992, p. 145] presented econometric estimation of the labour force participation of prime age (16 to 59 ) individuals and used 
these estimates to simulate labour supply effects of changes in the personal income tax scale in 1988 and the 1991 benefit reductions. They estimated an overall market wage labour supply elasticity at 0.38 , a wage elasticity for females at 0.64 , and a wage elasticity for males at 0.22 . They also estimated that changes in the tax scale in 1988-89 increased labour market participation by non-beneficiaries by 1.2 percent and beneficiaries by 0.64 percent. The 1991 benefit reductions were estimated to increase labour participation of beneficiaries by 2.2 percent and non-beneficiaries by 0.9 percent [Chiao and Walker, 1992, pp. 165, 173-174]. Stephens [1999, p. 242] argues that these estimates of labour supply elasticity are very high by international standards and they seem contrary to the earlier findings of Brosnan, Wilson, and Wong [1988]. Further, a review of Chiao and Walker [1992] by Stroombergen and O'Brien [2003, p. 3] argued that the econometric approach taken was likely to have introduced large measurement errors and the estimates were unlikely to be robust.

Maloney [1997, in Stephens, 1999, p. 242; 2000, pp. 447-448] found that reforms to social welfare programmes between 1990 and 1995 increased labour force participation and the supply of weekly hours of labour. The demographic group that experienced the largest increase in labour supply was people aged 60 to 64 , reflecting the gradual increase in the age of eligibility for New Zealand Superannuation to 65. The rise in age of eligibility for the Unemployment Benefit and Domestic Purposes Benefit decreased labour force participation but increased participation in educational among those aged 16 or 17 . Overall Maloney [2000, pp. 447448] estimated the benefit reforms increased aggregate labour force participation by 1.57 percentage points, with a slightly smaller effect for hours of labour supplied and a slightly larger effect for participation in either the labour force or education.

Stroombergen and O'Brien [2003, p. 1] demonstrated the importance of factors such as age, ethnicity, and the presence of dependent children in the family in influencing labour supply. They found a high degree of explanatory power for these non-monetary variables in determining whether an individual was in or out of the workforce. Financial variables, such as wage rates, non- 
labour income, and social assistance income, were statistically significant but their contribution to explaining labour market status was relatively small

International literature on the employment rate of sole-parents also indicates the limited influence of financial incentives on labour supply. Bradshaw et al [1996, in Stephens, 1999, p. 250] found that replacement rates did not appear to influence sole-parent's employment rates. There was little correlation between low replacement rates and high sole-parent labour participation rates. They concluded that the most important factor in influencing sole-parents' labour participation was the availability of good quality childcare. Labour market conditions, the level of incomes and benefits, and cultural attitudes towards mothers in employment were also important [Bradshaw et al, 1996, in Stephens, 1999, p. 250].

In contrast, however, evidence on employment tax credits in the United States and United Kingdom indicates that the financial incentives associated with these programmes have led to an overall increase in employment. This research has differed from that of Bradshaw et al [1996, in Stephens, 1999, p. 250] as rather than looking for a relationship between financial incentives and employment outcomes over different jurisdictions this research has compared employment outcomes within jurisdictions before and after policy changes. Within the overall increase in employment from employment tax credits there have been notable increases in employment of sole-parents, smaller increases in employment of males in partnered families, and decreases in employment among women in couples [Ellwood, 2000; Blundell, Brewer, and Shephard, 2004; Eissa and Hoynes, 2004]. This decrease for women in couples reflects the use of joint income as the basis for assessing entitlement. With the exception of the Family Tax Benefit Part B in Australia (which abates against secondary earners' incomes only), all Anglo-American family and employment tax credits are assessed on joint income. Assessing entitlement on joint income encourages some secondary earners to drop out of the labour market, rather than working or registering for unemployment assistance, and leads to some families choosing to reduce their earned incomes. Basing entitlement on joint income means secondary earners generally face higher effective marginal tax rates from their first dollar of income than primary earners and when secondary earners reduce their 
earned incomes there is little reduction (or an increase) in joint income [Stephens, 1997, p. 480]. Some secondary earners are effectively subsidised to stay at home [Eissa and Hoynes, 2004].

Similar behavioural responses have been estimated for the Working for Families reforms in New Zealand (discussed in greater detail in chapter 10 below). Using a newly-developed behavioural component (TaxMod-B) of the Treasury's microsimulation model of the tax-benefit system (TaxMod-A), Kalb, Cai, and Tuckwell [2005] estimated that the changes to the Family Assistance programmes as part of the Working for Families reforms will increase the labour supply of sole-parents by on average 0.71 hours perweek and decrease the labour supply of partnered men by 0.09 hours and women by 0.18 hours per-week. The Accommodation Supplement changes in the Working for Families reforms were estimated to have a small negative effect on the labour supply of single men and women, although limitations in the modelling of the Accommodation Supplement in TaxMod-A mean this component of the change was not modelled well [Kalb, Cai, and Tuckwell, 2005]. Overall sole-parents were identified as the population group most likely to have the strongest increase in labour market participation and hours of work and married women with and without children were identified as the population group who would be likely to have the strongest reduction in labour market participation and hours of work as a result of the Working for Families reforms. These findings were consistent with the international evidence on employment tax credits.

\section{Labour Supply Behavioural Responses and Poverty Reduction}

Financial incentives to supply labour have implications for income adequacy outcomes. Previous behavioural responses, such as changes in hours of work and family structures, to government assistance will be reflected in poverty measures based on historical data. However, forecast poverty measures based on estimated data often do not consider future behavioural responses. To illustrate this relationship between labour supply behavioural responses and poverty reduction the effects of behavioural responses to a tax-benefit policy change on headcount poverty rates are discussed below. The impact of behavioural responses on poverty reduction and targeting 
efficiency can be illustrated with the case of increasing labour supply of soleparent families and decreasing labour supply of secondary earners. In order to simplify discussion this section of the study uses headcount poverty as a proxy for poverty reduction effectiveness. This assumption does not affect the conclusions of the section.

In figure 3.1 the reduction in the headcount rate of poverty without taking behavioural responses into account is a movement from $N_{0}$ to $N_{1}$. If sole-parents are concentrated at lower levels of family incomes, reflecting their relatively low median wages and hours of work, even after these family incomes are equivalised, their labour supply responses would reduce the numbers of families at low incomes. This behavioural response would mean that the reduction in the headcount rate of poverty would be the larger shift from $\mathrm{N}_{0}$ to $\mathrm{N}_{2}$ in figure 3.1. If secondary income earners are concentrated in families at higher levels of family incomes, even after these family incomes are equivalised, their labour supply responses would reduce the numbers of families at higher incomes. The spill-over of assistance to the pre-transfer poor both increases and decreases. For those pre-transfer poor families who increase their labour supply the spill-over increases if their post-transfer static incomes are above the poverty threshold or if behavioural changes lift them from below to above the poverty threshold. For those pre-transfer poor families whose labour supply decreases the spill-over decreases. The overall change in spill-over to the pre-transfer poor would thus depend on the size and responsiveness of labour supply of the different groups. Spill-over to the pre-transfer non-poor unambiguously decreases when behavioural considerations are taken into account.

\section{Labour Supply and Excess Burden}

As well as income adequacy outcomes, changes in labour supply also have an impact on the excess burden of the tax-benefit system. Excess burden arises as when:

choosing to work less on average, workers will have lower incomes and thus will pay less taxes. Thus a change that would have been revenueneutral for a fixed level of labour supply will, as a result of the reduction in work, produce a revenue loss. It is this revenue loss that represents the 'excess burden' of taxation [Heady, 1993, p. 32]. 
The excess burden results from the higher taxes required to offset the reduced tax revenue from reductions in labour supply. Any gain in social welfare from redistribution would be reduced by the efficiency costs created by this need to increase tax rates [Heady, 1993, p. 32; Slemrod, 1993, p. 362; Creedy, 2003, p. 3]. Excess burden is a cost that is additional to the government revenue generated by taxation (which is a resource transfer) and reflects the extent to which individuals are made worse off in terms of utility through distortions in their decision-making [Hines, 1999, p. 175].

Excess burden can be illustrated with the fall in utility from a tax increase illustrated in figure 3.2. This figure illustrated the fall in an individual's welfare (moving the individual to a lower indifference curve) as a result of the imposition of a tax on labour. However, the difference between the indifference curves:

does not provide a useful measure of welfare change because utility is regarded as an ordinal concept: the utility levels themselves are entirely arbitrary, and the utility function provides simply a preference ordering of alternative bundles with standard properties (such as transitivity and decreasing marginal rates of substitution) [Creedy, 2003, p. 4].

The excess burden can instead be illustrated with the equivalent variation. Equivalent variation holds utility at the post-tax level [Hines, 1999, p. 172]. To explain the equivalent variation, in figure 3.2 the utility level $\mathrm{u}_{1}$ could be attained at the pre-tax prices if the individual faced budget line $D E$, which was parallel to $A B$. The point where the highest obtainable indifference curve was tangential to this hypothetical budget constraint was $F_{3}$. The individual would be indifferent between this variation in their budget at the old prices and the tax. This equivalent variation is measured in terms of a quantity of income by $Y_{A} Y_{D}$, which is the vertical distance between the two budget lines $Y_{A} B$ and $Y_{D} E$ [Creedy, 2003, p. 5].

The excess burden is approximated by one half of the Hicksian elasticity, multiplied by the initial expenditure, and multiplied by the square of the proportional tax-inclusive rate of tax. Thus, for example, a doubling of the tax rate approximately quadruples the excess burden [Creedy, 2003, pp. 11$12]$. This result is consistent with the results of research on the marginal

\footnotetext{
In contrast, compensating variation holds utility at the pre-tax level [Hines, 1999, p. 172].
} 
excess burden of taxation in New Zealand, which have illustrated that the marginal welfare costs of labour taxes increase with labour supply elasticities and with marginal tax rates [Diewert and Lawrence, 1994; McKeown and Woodfield, 1995]. Diewert and Lawrence [1994], for example, estimated that the marginal excess burden of labour taxation rose from five to 18 percent over the 20 years to 1991 although in this period the average tax rate on labour less than doubled. The authors attribute the more than proportionate growth in the marginal excess burden to the increasing flexibility of factors in the New Zealand economy [Diewert and Lawrence, 1994, p. 78].

\subsection{Administration and Compliance}

Income taxes, family and employment tax credits, and main welfare benefits can be seen as different components of a unified tax-benefit system. However, differences between tax-based and welfare-based programmes in relation to administration and compliance limit potential integration of the taxation and social welfare systems and the practical application of concepts such as a negative income tax [Alstott, 1994, p. 609; Alstott, 1995, p. 564; Stephens, 1997, p. 491-501]. The design of income tax programmes reflects the primary objective of the taxation system to raise tax revenue with minimum economic cost while meeting equity objectives. The design of social welfare programmes reflects the primary objective of the social welfare system to ensure a minimum adequate living standard while incurring minimum economic and fiscal costs. The design of tax-based social assistance programmes needs to strike a balance between the primary objectives of the taxation and social welfare systems.

Administration costs are the costs that the government incurs in administering tax-benefit programmes. Total administration costs are all the fiscal costs incurred by the government when delivering a tax-benefit programme. The targeting administration costs are the costs incurred during the process of screening which people should receive assistance [Grosh, 1995, pp. 454-458]. Compliance costs are the costs incurred by taxpayers or third parties in complying with the tax-benefit system over and above the revenue paid and the economic costs of the system [Sandford, in Tan, 1995, 
p. 3; Alexander, Bell, and Knowles, 2004, p. 1]. Compliance costs include monetary, time, and psychic costs associated with complying with the taxbenefit system [Stephens, 1997, p. 489]. Administration and compliance costs reflect factors such as the administrative agency's capacity for assessing need or income streams and current contact with or information on the client group. Administration and compliance costs can be segmented into start-up costs, ongoing costs, and change costs [Stephens, 1997, p. 490].

Compliance costs are treated differently in the taxation and welfare systems. Emphasis in the taxation system is on minimising such costs, while in the welfare system compliance costs may be a feature of the targeting of entitlement. In some cases high compliance costs for recipients may be justified by the benefits these costs provide. For example, high compliance costs may be required when the programme requires intensive contact with recipients, so that these recipients receive support (case management) and the information that makes them aware of their entitlement. The taxation system (which emphasises telephone-based support) provides less administrative contact than the welfare system (which emphasises face-toface contact).

As well as their direct costs, administration and compliance issues also influence other policy objectives (such as the ability to effectively target assistance). For instance, a tax deduction (i.e., a reduction in taxable income by some proportion of a claimed expense) reduces a person's taxable income, so the assistance they receive depends on their marginal tax rate. $\mathrm{A}$ tax credit or rebate (i.e., a reduction in tax paid by some proportion of a claimed expense) helps all eligible taxpayers equally, regardless of their income level and exposure to targeting of tax-benefit programmes. The level of a non-refundable tax credit is constrained by the amount of tax that the recipients pay. Tax assistance can be used to provide income assistance to low-income individuals when it is provided as a direct outlay (a refundable tax credit). Otherwise it tends to be difficult to use the tax system to target assistance to low-income individuals as these recipients usually pay little tax and the level of a (non-refundable) tax credit is constrained by the amount of tax that the recipients pay. Further, in comparison to tax rebates, tax deductions tend to benefit higher income earners under a progressive 
personal income tax scale (as higher income earners receive a greater reduction in their tax liability from the reduction in their assessable income) [Pallot, 1993, p. 127; Nolan and Fairbrother, 2005]. In the discussion below the emphasis is on refundable tax rebates (often referred to as tax credits).

\section{Unit and Period of Assessment}

The ability of different tax-benefit programmes to effectively target assistance reflects the different units of assessment (e.g., individual, family, or family), periods of assessment (e.g., weekly, monthly, or annually), and definitions of income and treatment of assets in use [Whitehouse, 1996, p. 137]. The ability to utilise a comprehensive income definition in income tax and social assistance programmes is limited by efficiency objectives, equity objectives, and objectives for reducing administration and compliance costs. As a result, and reflecting differences in different programmes' objectives, different definitions of income are used for determining liability for personal income taxes, entitlement to social welfare benefits, and entitlement to Family Assistance programmes in New Zealand. Differences in the definitions of income arise in relation to the unit of and time period for assessment, the treatment of assets, and the treatment of different sources of income.

Income tax liability is assessed on the basis of annual individual taxable income. Social welfare benefits are assessed on the basis of an economic family unit definition of income. This definition of income includes wealth indicators, which indicate potential income, as well as actual income received [Stephens, 1997, p. 491]. The definition of income for Family Assistance purposes is a compromise between taxable income and the social welfare definition of income and is based on annual taxable income but using joint incomes of the caregivers rather than individual income as the unit of assessment. There are also a number of income adjustments that apply to the Family Assistance income definition that do not apply to taxable income, such as for child support payments.

The different units of assessment and definitions of income create a number of anomalies in the treatment of different family types. For individuals without children and sole-parents the interaction of income taxes, welfare programmes, and family and employment tax credits is relatively 
straightforward. The integration of these programmes for partnered people is more complex and can create high effective marginal tax rates, particularly for secondary earners, and financial disincentives for entering into or remaining in a partnered relationship. However, using individuals as the unit of assessment for all tax-benefit programmes would increase fiscal costs through increasing the number of eligible recipients, particularly income-poor individuals with wealthy spouses, unless the generosity of assistance was reduced [Whitehouse, 1996, p. 137]. Using individuals as the unit of assessment for all programmes would also increase administration and compliance costs (as both partners in a couple would be required to apply for assistance) and would be likely to lead to moral hazard (through partnered families reallocating incomes and assets within the couple to minimise taxes or maximise assistance) [Stephens, 1997, pp. 492-493]. Levying taxes on an individual rather than joint basis also increases the personal income tax base and allows personal income tax rates to be reduced (shifts towards individual income tax bases partly funded reductions in personal income tax rates in a number of OECD countries during the 1980s and 1990s [OECD, 2001a, p. 142]).

In partnered families it is also necessary to allocate child-based assistance to either the primary income earner or the primary caregiver or to split entitlement between the caregivers. Providing assistance to primary caregivers can emphasise that payments are assistance to compensate families for the costs of children, rather than a contribution to the general family budget, and provide an independent source of income for caregivers. Providing assistance to the primary earner can emphasise assistance as a financial reward for their increased work effort. When separated caregivers share responsibility for the care of a child it is also necessary to allocate assistance between these caregivers. In such cases it is necessary to define how and under what circumstances assistance should be split between these caregivers and what treatment should apply to income transferred between the separated caregivers, such as whether assistance should be reduced by payments of formal and informal child support by non-custodial parents [Stephens, 1997, p. 496]. 
Programmes based on annual periods may be appropriate for people with regular incomes or long-term beneficiaries. However, these programmes may not be appropriate for those people whose circumstances fluctuate (for example, due to changes in job status, hours worked, and family status). Responsiveness to fluctuations in need is influenced by the interval for the measurement of income. Tax-based assistance, which is based on annual income, is less responsive than social welfare programmes, which employ definitions of income based on a shorter time period. Consequently the failure to adjust tax-based assistance during the year may lead to recipients experiencing periods of hardship. Advance-payment schemes (that pay assistance during the year) may increase the ability of tax-based assistance to respond to changing needs. However, administrative and compliance issues, particularly gaps in awareness of entitlement and potential recipients' aversion to incurring debts from overpayments, may reduce the effectiveness of advance-payment schemes (which generally have low levels of take-up in the United States and United Kingdom but not New Zealand). Under an advance payment scheme with a year-end square-up, over-payments or under-payments may arise if incomes fluctuate during the income tax year and the level of assistance does not adjust. To minimise the problems of people incurring tax-debts some small levels of debt could be waived and small levels of income changes could be disregarded in the year-end squareup process. Basing entitlement on income at time of application and disregarding future changes in income during the income tax year could avoid these difficulties. This approach could, however, lead to moral hazard through encouraging recipients to suppress their income around time of application through altering the timing of income streams.

\section{Participation and Compliance}

Administration and compliance issues may also be reflected in non-take up of assistance, take-up of assistance by ineligible recipients, and overpayments of assistance. Non-take-up occurs when, for a number of people, the amount they receive from programmes is less than the amount they are entitled to receive. An individual will often take-up assistance if over the expected length of eligibility the gain in utility from receiving the income transfer exceeds the 
costs of participation [Riphahn, 2001, pp. 381-382]. Consequently take-up tends to increase as the proportion of total net income that could be received as a transfer and expected duration of receipt increase. Yet potential recipients may choose not to claim assistance because there are costs as well as benefits associated with receiving assistance. These costs of participation include any perceived stigma or loss of dignity associated with the application for and receipt of assistance, which may, for instance, harm future employment prospects and wage rates [Atkinson, 1989a, p. 192; Wilson, 1996, pp. 13-15; Creedy, 2002, pp. 151]. Potential recipients may also fail to take-up assistance if they are unaware or uncertain of the extent of benefits and qualifying conditions or because of administrative error [Atkinson, 1989a, p. 192; Creedy, 2002, p. 151]. For any tax-benefit programme there are likely to be people who deliberately receive assistance that they are not entitled to receive. It is also likely that there will be other people who engage in opportunistic behaviour due to scope for moral hazard and alter their circumstances in ways viewed as undesirable by policymakers, i.e., by putting themselves in positions of greater need than would have been the case in the absence of assistance in order to be eligible for assistance for which they would have otherwise been ineligible [Sen, 1995, p. 11].

Reflecting the different approaches to compliance, tax-based and welfare based programmes differ in their ability to evaluate criteria for entitlement, monitor and enforce these criteria, and review entitlement. The taxation system uses annual taxable income and straightforward criteria (e.g., number and ages of children). The welfare system uses a shorter time period and different definition of income and can base eligibility on more complex criteria (like behaviour and family composition) that have greater discretion over how they are applied. Due to the relatively higher administrative intensity involved in applying for welfare programmes, the welfare system is more able to make entitlement conditional on certain types of behaviour (like job search effort). Yet there is less stigma associated with applying for tax-based assistance. The taxation system reviews entitlement less often than the social welfare system and this is generally done ex post while the social welfare system tends to review entitlement ex ante. Due to 
the relatively large reliance upon voluntary compliance in the income tax system, programmes provided through the tax system are particularly prone to fraud and non-compliance. Research on the Earned Income Tax Credit in the United States has estimated that in 1999 from 27.0 to 31.7 percent of claims paid should not have been [Inland Revenue Service, 2002, p. 3].

The take-up rate is the number of actual recipients divided by the total entitled population [Atkinson, 1989a, p. 197]. There are a number of difficulties in calculating take-up rates [Scholz, 1994, p. 64]. Applications for assistance may be received and paid after the period of eligibility and payments may be contained in administrative data for later years. Where payments are made to more than one member of a family during an income tax year the number of recipients may include some double counting. When estimating the total entitled population (families who would receive the benefit if they were to claim) it is often necessary to use survey data, which may not contain accurate income data. There may be cases where people have recorded receipt but are calculated as being not eligible. Further, the complexity of administrative rules for programmes is reflected in the complexity of modelling take-up, with changes in take-up rates potentially being influenced by changes in modelling assumptions and differences between administrators' and modellers' views on who is eligible for assistance.

As well as the overall level of take-up, also significant are the characteristics of recipients failing to receive their full entitlement, changes in take-up over time, changes in amounts not claimed, and significance of different reasons for non-participation [Atkinson, 1989a, p. 194]. Take-up rates show the proportion of the eligible population who receive assistance; they do not show the proportion of the financial entitlement that is received. There may be less reason to be concerned with low take-up rates if the dollar amount that eligible families miss out on is low or if families choose not to take-up assistance for rational reasons, such as high-income earners not wanting to risk triggering tax audits by applying for tax-based assistance. Scholz [1994, p. 79] estimated that, for example, in 1990 the take-up of the Earned Income Tax Credit in the United States was in the range of 80 to 86 percent. It was also estimated that factors correlated with non-take-up were 
consistent with rational or voluntary explanations for non-participation, such as being eligible for a small level of assistance, having a greater proportion of self-employed income, working in states without state income taxes at low income levels, working in family service occupations, and having higher levels of education. Research on the Family Credit in the United Kingdom has produced much lower estimates of take-up. Yet these estimates have also shown that non-take up tends to be correlated with voluntary explanations for non-take-up, such as being eligible for a small amount of assistance, having self-employed status, and being in a partnered family [Clark and McCrae, 2001, p. 19].

\subsection{Conclusion}

This chapter discussed criteria for evaluating tax-benefit programmes. The first key criterion for evaluating these programmes discussed was their effect on poverty. Poverty thresholds can be defined both relative to current standards of living and policy parameters and absolute in the sense of representing a standard of living that families should not fall below. Poverty thresholds can also be based on a number of income sharing units (e.g., statistical families and economic family units), income levels (e.g., 60 percent or 50 percent of equivalised disposable family income), and equivalence scales, which can be used to adjust joint incomes to reflect variations in their cost structures. Success in achieving objectives for poverty relief can be measured in terms of headcount poverty measures and other measures such as the poverty gap and poverty reduction effectiveness.

A second key criterion for evaluating tax-benefit programmes is financial incentives for labour supply. The effect of a tax-benefit reform on financial incentives for labour supply reflects the income and substitution effects that the reform creates. These effects can be illustrated with changes in families' budget constraints. In practise budget constraints are complex and non-linear. As well as income and substitution effects people's labour supply decisions also reflect uncertainty and administrative incentives.

Empirical studies of the labour supply effects of tax-benefit programmes illustrate that caregivers are relatively responsive to financial incentives to 
work. These studies, however, provide differing views on the strength of caregivers' responses to financial incentives to supply labour. International evidence on the relationship between replacement rates and sole-parents' labour supply showed little correlation between the two. However, more recent evidence on the labour supply response to employment tax credits in the United Kingdom and the United States has shown that sole-parents have increased their labour supply and secondary earners have decreased their labour supply in response to these programmes. Preliminary findings on New Zealand's Working for Families reforms have produced similar results. The impact of tax-benefit programmes on caregivers' financial incentives for labour supply is thus a key criterion for evaluation.

The poverty reduction and financial incentives for labour supply criteria should not be seen in isolation as labour supply responses to tax-benefit programmes have implications for poverty reduction effectiveness. Improving financial incentives to supply labour can improve the opportunities for lowwage groups, such as sole-parents, to participate and belong in society. These labour supply effects also have implications for a third criterion, the excess burden of the tax-benefit system, through affecting the size of the tax base. This excess burden results from the higher taxes required to offset the reduced tax revenue from reductions in labour supply.

Section four of this chapter discussed criteria for evaluating tax-benefit programmes relating to administration and compliance issues. Tax-based and welfare-based programmes differ in the degree to which they can accurately assess entitlement, respond to recipients' changing circumstances, and ensure compliance and participation in programmes. Non-take-up occurs when, for a number of people, the amount they receive from programmes is less than the amount they are entitled to. Growing international support for tax-based programmes reflects the belief that assistance provided through the tax system avoids some of the limitations of traditional social welfare programmes. There are, however, a number of limitations to the use of tax-based social assistance, such as the relatively low flexibility in responding to recipients' changing circumstances, the requirement for relatively narrow definitions of income and the income sharing unit, the requirement for relatively clear-cut and non-discretionary 
eligibility criteria, and the vulnerability to taxpayer fraud. These are all factors against which tax-benefit programmes could be evaluated. 


\section{Methodology for Evaluating Tax- Benefit Programmes}

\subsection{Introduction}

This chapter develops a methodology for evaluating tax-benefit programmes. There is a large literature on income inequality, poverty, and living standards in New Zealand. The approach taken in this study is thus to review and synthesise this literature. In comparison to research on income inequality, poverty, and living standards, since the release of Prebble and Rebstock (eds.) [1992] there has been little comprehensive non-government research undertaken on the financial incentives to work contained in New Zealand's tax-benefit system (with the exceptions of St John [1996], Maloney [1997, 2000], St John and Rankin [2002], and Nolan [2003]). This lacuna reflects the complexity of the financial incentives for labour supply created by the interaction of tax-benefit programmes and a lack of independent microsimulation modelling resources. This study aims to help address this lacuna and consequently issues relating to measuring the labour supply financial incentives of tax-benefit programmes are given emphasis in this study and chapter. Further, although reforms to family and employment tax credits have been at the heart of tax-benefit reforms throughout the AngloAmerican world there has been relatively little comparative public policy research on these prominent programmes. Consequently this study and chapter also emphasise issues relating to comparing the design and generosity of family and employment tax credits in different jurisdictions.

Section two of this chapter discusses evidence based policy in New Zealand. Section three explains the method for calculating average tax rates 
and effective marginal tax rates. In section four the chapter then discusses how the effects of tax-benefit reforms on individual families can be estimated and what characteristics these families should be assumed to have. Approaches for estimating the effects of reform on the population as a whole are then discussed in section five. This section includes discussion of arithmetic and behavioural microsimulation modelling and the use and integration of administrative and survey data. Comparative policy analysis is discussed in section six.

\subsection{Evidence Based Policy}

Evidence on what works to achieve desirable social outcomes is increasingly being demanded as an input into policy processes [Lunt and Davidson, 2002, p. 2]. Such evidence can identify, measure, and compare the outcomes (the impacts on the community) of alternative policies [Sefton, 2000, p. 3; Nutley, Walter, and Davies, 2002, p. 2]. This process can inform decisions regarding policy priorities and the best use of resources in a number of ways. Evaluation can feed directly into decision-making and lead to changes to behaviour and practise. While this direct and instrumental use of evaluation is undoubtedly important, evaluation can also have a broader conceptual influence through changing levels of knowledge, understanding, and attitudes [Nutley, Walter, and Davies, 2002, p. 4]. Both the instrumental and conceptual roles of evaluation require the development of partnerships and understanding between researchers, policymakers, and the broader public [Atkinson, 1989b, pp. 1-2; Lunt, 2001, p. 199; Nutley, Walter, and Davies, 2002, p. 10].

The demand for instrumental and conceptual research has increased in New Zealand over the last decade. Following a binding referendum in 1993 New Zealand underwent reform to its electoral system with the change from a First Past the Post (FPP) to a Mixed Member Proportional (MMP) electoral system." This change institutionalised proportional representation, increased the probability of coalition and/or minority governments, and consequently 
reduced the power of the political executive. As a result this change also increased the potential role of independent evaluation as a tool for mobilising political support or as an instrument of persuasion [Mulgan, 1997, pp. 265271].

Further, following the Fiscal Responsibility Act 1994, which established the principles for formulating fiscal policy in New Zealand, governments have been required to regularly publish their short-term and long-term fiscal intentions [Boston, Martin, et al, 1996, p. 263; Treasury, 1996, p. 11]. This legislation increased the transparency of and accountability for fiscal policy outcomes. In the budget documents, for example, refundable tax rebates are listed with social welfare expenditure rather than as reduced tax revenue figures.

The transparency of fiscal outcomes also reflects the development of the Generic Tax Policy Process after 1995, which aims to provide opportunities for substantial external input and increased transparency in the development of tax policy. ${ }^{\dagger}$ Although the Generic Tax Policy Process has largely been a success [Oliver, 1999, p. 1], the 2001 Ministerial Inquiry into the Tax System (the McLeod report) identified three areas for improvement. These were to introduce greater transparency into measuring the success of tax policy, establish forums for independent policy analysis, and to increase participation of stakeholders [McLeod, Chatterjee, et al, 2001a, p. 18]. Following the recommendations of the 2001 Ministerial Inquiry into the Tax System the Public Finance Amendment Act 2004 established further requirements for further reporting of tax expenditures. New Zealand last published such a statement as part of the opening of the books in 1988 [McLeod, Chatterjee, et al, 2001a, p. 19]. However, aside from fiscal

\footnotetext{
The first general election under the MMP electoral system was held in 1996 [Boston, Levine, McLeay, and Roberts, 1996, pp. 20-23].

t The Generic Tax Policy Process has strategic, tactical, operational, legislative, and implementation and review phases. The Treasury is primarily responsible for the earlier stages and the Inland Revenue Department is primarily responsible for later stages. Broad objectives are set and priorities are established with a three-year revenue strategy. Departments and Ministers determine where comparative advantage lies and allocate roles and responsibilities accordingly. Ministers develop protocols establishing their respective policy roles [Oliver, 1999].
} 
outcomes there is still little transparent measurement of tax policy outcomes, such as the impact of the tax-benefit system on labour supply.

Following the 1991 benefit reductions issues of poverty measurement became the focus of academic, political, and media scrutiny in New Zealand [Stephens, 1999, p. 252]. Initially a number of community-based studies of poverty were produced. These studies were discredited by politicians because of their limited statistical basis. The New Zealand Poverty Measurement Project then developed independent estimates of the incidence and severity of poverty based on the Household Economic Survey [Stephens, 1999, p. 251]. There is, however, no equivalent to the Fiscal Responsibility Act 1994 that would require governments to report on social policy outcomes [Boston, Dalziel, and St John, 1999, p. 315]. This led commentators to argue that a strengthening of the government's reporting and monitoring responsibilities in relation to social policy outcomes is required [Boston, St John, and Stephens, 1996; Boston, Dalziel, and St John, 1999, p. 315].

In recent years there has been greater emphasis placed on government reporting on social outcomes. The Ministry of Social Development now issue the Social Report, increased funding has been made available for independent social policy research, and the Social Policy Evaluation and Research committee has been established to align the purchase of social policy research with the government's social policy priorities. The Ministry of Social Development has also developed Knowledge Theme Areas and Key Knowledge Questions to enhance the production and dissemination of knowledge underpinning social policy by encouraging research that takes a cross-sector focus rather than simply reflecting government social sector domains [Hong, 2001, pp. 9-14].

However, the focus and utility of this social reporting and research in New Zealand has been increasingly questioned. The transparency of outcomes in the social development policy domain remains limited by the lack of tax and transfer microsimulation models independent from the government of the day and restricted access of researchers to administrative data. These limitations reduce the supply and variety of tax-benefit modelling, 
public scrutiny on modelling, and understanding of the constraints upon policy [Creedy, Duncan, et al, 2002, pp. 6-7].

[Although] government departments will probably wish to develop some internal modelling capacity, there is a major role for independent tax modellers, or researchers who are independent of government or special-interest groups. However, in view of the high costs of model building, it is likely that they need strong financial support from research grants or government departments. A strong advantage is that independent modellers are obliged to publish full details of models. This public knowledge can help to stimulate a wider assessment of approaches as well as imposing a constraint on the inappropriate use of models. Indeed a strong case can be made for the support of several models so that the benefits of alternative strategies are obtained and the abuse of a single model can be controlled [Creedy, Duncan, et al, 2002, pp. 6-7].

The social development policy process, particularly the role of evidence in policy development, also lacks transparency. Some commentators have argued that the social development policy domain would benefit from a generic policy process such as that used in the tax domain [Shaw and Eichbaum, 2005]. The social development policy process also lacks a formal requirement for identifying policy objectives, identifying trade-offs between policy objectives, and evaluating alternative policy instruments, although formal requirements of this kind are present in other policy domains in New Zealand, such as the requirement to prepare regulatory impact statements for regulatory proposals that increase business compliance costs under the oversight of New Zealand's Regulatory Impact Analysis Unit.

\subsection{Average and Effective Marginal Tax Rates}

This chapter develops a methodology for evaluating tax-benefit programmes. A key feature of this methodology relates to financial incentives to supply labour, particularly average tax rates and effective marginal tax rates. Average tax rates (ATRs) illustrate the change in the income available for consumption and are reflected in the height of the budget constraint. ATRs show the ratio of taxes paid and benefits received to income [Creedy, 1999, p. 411]. Effective marginal tax rates (EMTRs) show the proportion by which a dollar increase in gross income is reduced by income taxes and the abatement of welfare transfers. An EMTR is one minus the change in net 
income after taxation and abatement of income transfers resulting from earning an additional gross dollar [Prebble and Rebstock (eds.), 1992, pp. 713; Nolan, 2003, p. 53]. EMTRs are reflected in the slope of the budget constraint.

Whether changes to ATRs and EMTRs reinforce or offset each other depends on the case at hand and requires empirical analysis [Blundell, 1992, p. 16; Heady, 1993, p. 31]. The size of the responses of different groups depends on the uncompensated elasticity of labour supply and the numbers of people in the groups. Further, different families with the same gross wage may face different ATRs and EMTRs [Blundell, 1992, p. 24]. ATRs and EMTRs reflect the complex interaction of income tax and welfare programmes. Different programmes use different entitlement and abatement schedules, eligibility criteria, definitions of what counts as income, incomesharing units (individual, family, or family), income periods (weekly, fortnightly, or annually), and implementation agencies (the Inland Revenue Department or the Ministry of Social Development). ATRs and EMTRs thus differ among people with different characteristics, depending on factors such as hours of work, wage rates received, marital status, numbers and ages of children, availability of childcare, accommodation needs, and receipt of other assistance.

With real-world tax-benefit systems the calculation of ATRs and EMTRs can be complex. For example, in New Zealand EMTRs cannot always simply be calculated as the sum of the personal income tax rate, the Low Income Earner Rebate, ACC earner levy, net benefit abatement rate, and the Family Assistance abatement rate. This is because net welfare benefits abate against increases in gross income and the personal income tax rate applying to benefit income may differ from the rate applying to non-benefit income. Also complicating the calculation of EMTRs is that while personal income taxes are levied on individual income, social welfare benefits and the Family Assistance Tax Credits abate against joint income. The EMTRs in this study are calculated for adults in single and partnered families. When calculating the EMTRs of a person in a partnered family, his or her partner's income is assumed to remain constant. 
The calculation of EMTRs can be illustrated with the following algebraic approach, which was developed by Ivan Tuckwell and Matthew Bell of the New Zealand Treasury [Treasury, 1999; Nolan, 2002, pp. 17-21; Nolan 2003]. The net social welfare benefit is abated against gross non-benefit earnings. Thus when a family earns an extra dollar in gross non-benefit earnings the total gross income (which includes the gross benefit) does not rise by the full dollar because of the benefit abatement. The gross benefit abatement $\left(r_{b}\right)$ equals the net benefit abatement $\left(r_{B}\right)$ divided by one minus the marginal tax rate on benefit income $\left(t_{\mathrm{B}}\right)$.

$$
r_{b}=r_{B} /\left(1-t_{B}\right)
$$

In this study the change in the tax on gross non-benefit earnings is calculated as the marginal personal income tax rate on earnings $(t)$ multiplied by the change in gross income. While, in practise beneficiaries' non-benefit earnings are generally taxed under the secondary tax regime at 21 percent, this tax is a withholding tax and so excessive tax withheld during the year is returned when taxes are reconciled at the end of the income tax year. Further, the tax on the gross abated benefit and the non-benefit earnings are calculated separately as the tax rate applying to the benefit income may differ from the tax rate applying to non-benefit earnings. In a couple, an individual's total gross income is the total of their gross non-benefit income and one half of the family's gross benefit income.

The change in gross income $\left(y_{\mathrm{G}}\right)$ is one minus the gross benefit abatement.

$$
\Delta \mathrm{y}_{\mathrm{G}}=1-\mathrm{r}_{\mathrm{b}}
$$

The change in disposable income $\left(\mathrm{y}_{\mathrm{D}}\right)$ is the change in gross income multiplied by the changes in tax liability $(\mathrm{t})$ and Family Assistance abatement $\left(r_{p}\right)$ minus the ACC earner account levy.

$$
\Delta y_{D}=\Delta y_{G}\left(1-t-r_{P}\right)-A C C
$$

The EMTR is one minus the change in the disposable income.

$$
\text { EMTR }=1-\Delta y_{D}
$$

When people are faced with a decision on whether or not to make relatively small changes in income, e.g., from working a few extra hours, EMTRs are likely to illustrate the financial incentives applying to their 
decisions. Yet when people are considering relatively large changes in income, e.g., whether to work part-time or full-time, or when they are constrained in the degree to which they can change their hours of work, e.g., when they have employment contracts containing fixed hours, EMTRs are less likely to illustrate the financial incentives applying to their decisions. Also, the hourly wage rate that a person can earn influences the number of hours of work over which they face particular ATRs or EMTRs. If, for example, a benefit recipient's hourly wage rate fell from $\$ 15$ to $\$ 10$ the numbers of hours of work over which they may face EMTRs created by the abatement of welfare programmes would increase.

Estimating ATRs and EMTRs of people in partnered families pose particular difficulties. In partnered families labour supply decisions are generally joint decisions. In these families when either the primary or secondary earner changes his or her labour supply total joint income changes. As social welfare benefits and Family Assistance programmes abate against total joint income the individual incentives facing primary and secondary earners are thus influenced by the earnings of their partners. However, due to the difficulty of modelling joint decisions, in this study changes in joint income are modelled as individual decisions where only one person makes a labour supply decision and the rest of the labour supply decisions in the family are held constant [Prebble and Rebstock (eds.), 1992, pp. 37-38].

There are limits to the usefulness of ATRs and EMTRs. First, as well as financial incentives, labour supply reflects the uncertainty that people feel about the level of their likely work or tax-benefit income, non-financial considerations for entering or remaining in the work force (including selfesteem and fear of damage to future employment prospects), and tax-benefit programmes' administrative incentives (such as work tests) [Wilson, 1996, pp 13-15; Barr, 1999, p. 13]. Further, although people may appear to not face particular financial incentives, e.g., people located above or below the income levels at which incentives occur, they may still be affected by these incentives when making decisions, e.g., by being discouraged from locating at income levels associated with high disincentives to supply labour. 


\subsection{Model-Family Approach}

Illustrating financial incentives for labour supply from changes to tax-benefit programmes requires illustrating the effects of these changes on net wages. These effects can be shown through calculating EMTR profiles and budget constraints for fixed wage rates by hours of work. As budget constraints facing individuals are likely to be non-linear the effective net hourly wage rate facing individuals will be likely to vary with hours of work [Blundell, 1992, p. 24].

In this study financial incentives to supply labour are modelled by hours of work with fixed gross wage rates and not by incomes in order to separate the distribution of hours of work from the distribution of wage rates. Although thresholds contained in tax-benefit programmes are often expressed in terms of gross incomes, modelling financial incentives against gross incomes could be misleading as the same level of income can be achieved through different combinations of hours and wage rates. Consequently two individuals with identical gross incomes may face different financial incentives. A high-wage part-time worker could, for example, face lower EMTRs when increasing their hours of work than a low-wage worker with the same income (as with a higher wage the abatement of social assistance programmes occurs over a shorter range of hours of work). Further, modelling financial incentives by hours of work can illustrate which financial incentives are most likely to affect individuals of interest. For example, given the relatively low median wage of sole-parents, financial incentives to supply labour that apply at very high incomes are not likely to affect these people (as reaching these incomes could require working for an unlikely number of hours per-week) unless they have an unusually high gross wage rate for this family type.

This study focuses on the provision of social assistance to families with children. A model capable of producing accurate budget constraints and EMTRs profiles has been developed to model the impact of tax benefit programmes on scenario family types. A model capable of modelling the levels of assistance provided by family and employment tax credits in five Anglo-American countries (in New Zealand dollars) by hours of work for scenario family types has also been developed. The provision of assistance 
has been illustrated for three family types. The first family consisted of a soleparent earning an hourly gross wage rate of $\$ 10.00$ and with two children aged three and five. The second family consisted of a partnered person earning an hourly gross wage rate of $\$ 15.00$ and with a non-working spouse and two children aged three and five. The third family consisted of a partnered person earning an hourly gross wage rate of $\$ 15.00$ and with a working spouse and two children aged three and five. The working spouse was assumed to earn a fixed income of $\$ 600$ gross per-week (at a wage rate of $\$ 15.00$ per-hour and 40 hours of work per-week). Families were assumed to have two children as this is a relatively common structure for partnered families and, although sole-parents tend to be in single-child families, the incidence of poverty and significance of poverty traps increase with the number of children in the family. These wage rates have been chosen as they closely approximate the median wage rates for these family types.

Nolan [2004c, p. 8] contained Treasury estimates of median gross wage rates for different family types for 2003-04. To calculate wage rates individuals' income data were divided by their reported hours of work contained in the Household Economic Survey and these rates were then aggregated to give a median for the family type by TaxMod-A. The Treasury estimates were:

- Partnered people with working spouses and multiple children, $\$ 18.18$;

- Partnered workers with non-working spouses and multiple children, $\$ 17.65$;

- Single workers with children, $\$ 12.67$;

- Dual-income and single-income partnered people without children, $\$ 17.34$; and

- $\quad$ Single people without children, $\$ 15.78$.

A key finding from this modelling was thus that workers in sole-parent families tended to have lower median wages than workers in partnered

\footnotetext{
'Where one income earner earned 80 percent or more of a household's private income the household was categorised as having only one income earner. If the household's private income was less than half of the household's gross taxable income (e.g., the majority of household income was from an income tested social welfare benefit or from New Zealand Superannuation) then the household was assumed to have no income earners. This latter assumption was necessary as people may work for less than the full income tax year.
} 
families. Therefore in this study the assumed wage rates of sole-parent families are lower than the assumed wage rates of partnered families.

This study also draws upon Treasury estimates of the distribution of hours of work of different family types calculated with TaxMod-A and using Household Economic Survey data. Estimates were calculated for a range of family types [Nolan, 2004c, p. 8]. Because there were small numbers of some family types in the Household Economic Survey data there were few observations of these family types at certain wage rates. Thus in order to provide a useful number of observations in this modelling it was necessary to use wage bands of below and above median wages for different family types rather than single wage rates. Due to the small numbers of certain family types in the sample this modelling was based upon, some distributions of hours were not able to have data calculated for them. For the majority of family types data on the distributions of hours of work (for above and below the median wages) show a general pattern of around 25 to 30 percent of those people earning below median wage working for less than 30 hours perweek and around 15 percent of those people earning above median wage working for less than 30 hours per-week. The key exception to this distribution was the category of sole-parents, where much larger proportions were estimated to work for less than 30 hours per-week ( 45 percent of the group earning below the median wage and 25 percent earning above the median). Thus for lower wage groups the distribution of hours of work was more heavily skewed towards lower hours of work [Nolan, 2004c, p. 8].

\subsection{TaxMod-A and the Household Economic Survey}

To model the interaction of the tax-benefit system with the income distribution a large-scale tax-benefit microsimulation model is required. The construction and maintenance of large-scale tax-benefit models requires teamwork and significant data handling and computer programming requirements [Creedy, 2001, p. 196; Brown and Harding, 2002, p. 3; Creedy and Kalb, 2005, p. 3].

The approach of this study has thus been to draw on an existing 
microsimulation model (Treasury's TaxMod-A) for modelling on the interaction of the tax-benefit system with the income distribution.

\section{TaxMod-A}

The emphasis in TaxMod-A is on population heterogeneity and accurate representation of the tax and transfer system. TaxMod-A calculates income tax liabilities and social assistance entitlement based upon characteristics of the population and rules regarding eligibility and abatement of income tax and social assistance programmes [Smith and Euller, 1992, pp. 29-44; Kalb, Cai, and Tuckwell, 2005, pp. 35-36]. A population of families is derived from demographic, income, and expenditure data contained in the Household Economic Survey. TaxMod-A allocates some people who may be classified in family relationships in the Household Economic Survey into separate families if this is the treatment that applies under income tax and social assistance rules. TaxMod-A calculates benefit receipt based on data on benefit duration (not benefit income) contained in the Household Economic Survey and assumes complete participation (100 percent take-up) in programmes. The model contains incomplete information on wealth and does not model entities such as companies or trusts or people's behavioural responses to income tax and social assistance programmes. TaxMod-A is a partial equilibrium model. Thus this model focuses on only one side of the relevant market (tax and transfer payments and incomes of individuals and families) [Creedy, 2001, p. 197].

As the Household Economic Survey needs to be weighted up to estimate the entire New Zealand population, in TaxMod-A each surveyed family is given a weighting representing the degree to which families of that type occur in the total population. This re-weighting process has recently undergone revision. In 2003 a comparison of administrative data on benefit expenditures for a variety of demographic groups with TaxMod-A estimates identified that these data differed substantially when Statistics New Zealand weights were used. As a result revised population weights were developed [Creedy and Tuckwell, 2003, p. 3]. TaxMod-A also re-weights the Household Economic Survey sample to allow for changing rates of unemployment and 
adjusts income data for inflation, with separate inflators for wage, selfemployed, and interest income.

Microsimulation models are powerful tools. However, as Brown and Harding [2002, p. iii] argue, the "key to effective modelling is to recognise what type of model is required for a given task and to build a model that will meet the purposes for which it is intended. The results then have to be interpreted within the boundaries and limitations of the model." In particular when modelling the effects of a policy change it is important to recognise the limitations of estimates of outcomes based on survey data with relatively small sample sizes. This modelling risk was illustrated in New Zealand in the case of the Parental Tax Credit, where estimates of the cost of the Parental Tax Credit prepared during its establishment differed significantly from the programme's actual expenditure due to the small number of eligible families contained in the Household Economic Survey data used to prepare these estimates [Smith, 1999, p. 2]. Initial estimates used during the development of the Parental Tax Credit were based on 1995-96 Household Economic Survey data, which contained 66 families potentially eligible for the proposed programme. This sample was scaled up to give an estimate of an eligible population of 26,000 . In contrast, later estimates based on 1997-98 Household Economic Survey data contained a sample of 51 potentially eligible families, which was scaled up to give an estimate of an eligible population of 20,000 families [Smith, 1999, p. 1].

\section{Arithmetic and Behavioural Microsimulation Modelling}

TaxMod-A is a non-behavioural (arithmetic) model so no allowance is made for the possible effects of tax changes on individuals' consumption or labour supply [Creedy, 2001, p. 197]. This makes the model relatively straightforward to build, maintain, and use and as no econometric estimation is required the model retains the full heterogeneity of the basic survey data used [Creedy, 2001, p. 197]. In order to estimate financial incentives for the 2003-04-income year TaxMod-A takes data on observed hours of work from the most recent Household Economic Survey (2000-01) and applies this data to the 2003-04 tax-benefit system. However, these hours of work are likely to reflect the tax-benefit system that was in existence in the year of the survey. 
There may thus be some expected variation between the observed hours of work and the hours that actually correspond to the 2003-04 system.

A behavioural component has recently been developed for TaxMod-A. In contrast to a non-behavioural model a behavioural model would estimate financial incentives to supply labour using a two-step procedure. First, changes in the hours of work between the survey year and the year of the policy change would be estimated. Second, the effects of a policy initiative would then be modelled using these new estimated hours.

Behavioural microsimulation models generally treat family formation, marriage, births, retirement, and labour training and higher education decisions as exogenous. Interdependence between commodities and leisure consumptions is assumed. Labour supply in just one job is examined and it is assumed the individual does not work additional hours at a different wage rate. The wage rate is calculated by dividing total earnings by the total number of reported hours of work [Creedy, 2001, p. 198]. For individuals who do not work an imputed wage is calculated based on estimated wage functions [Creedy and Kalb, 2005, p. 8]. The net income corresponding to any given number of hours worked by each individual is calculated in order to produce precise budget constraints relating net income to hours worked for each individual. Fixed or child-related costs can then be factored into the model [Creedy, Duncan, et al, 2002, p. 70]. The model then evaluates which part of each individual's budget constraint is optimal [Creedy, 2001, p. 198].

Behavioural microsimulation models have a lower degree of population heterogeneity than non-behavioural models because economic estimation of the important relationships involves the use of a limited range of categories [Creedy, 2001, p. 198]. Further, due to constraints on the Household Economic Survey data and TaxMod-A some tax-benefit reforms are less likely to be accurately modelled than other reforms. The underestimation of Accommodation Supplement coverage based on Household Economic Survey data by TaxMod-A [Kalb, Cai, and Tuckwell, 2005, p. 4], for example, means that reforms involving this programme are less likely to be accurately modelled by TaxMod-B. In contrast, due to the large proportion of people paying personal income taxes issues of sample size are less likely to impact 
on income tax data based on the Household Economic Survey and so the modelling of income tax reforms is likely to be relatively accurate.

\section{The Household Economic Survey}

Parts of this study draw on data from the Household Economic Survey, which was established to measure the Consumers' Price Index [Gordon, 1997; Talbut, 2004]. The Household Economic Survey was conducted annually from 1983-4 to 1997-98. The Household Economic Survey is now conducted every three years and the last survey available for this study was completed in June 2000-01.

Household Economic Survey data is cross-sectional and not longitudinal as the sample for the survey differs each year [Mowbray, 2001, p. 11]. The Household Economic Survey collects demographic, income, and expenditure data from approximately 3,000 families over the course of a year [Talbut, 2004]. Four questionnaires are used in the survey.

- Information on family composition and social and demographic characteristics of each family member are collected in the family questionnaire [Gordon, 1997, p. 6]. Blood relationships between people in each family are recorded.

- Information on housing expenditure, home maintenance, family operations, transport, holidays, health, and education is collected in the expenditure questionnaire [Gordon, 1997, p. 6]. Each family is asked to record all items of expenditure over $\$ 200$ that occurred in the previous twelve months. Both the location and cost of accommodation are recorded. Some expenditure items (particularly alcohol and tobacco consumption) tend to be inaccurately reported (understated).

- In the income questionnaire each person aged 15 or above is asked to record income from various sources received over the previous 12 months [Gordon, 1997, p. 6]. These income sources include up to three current jobs, six jobs that ended in the previous 12 months, social

\footnotetext{
In comparison the Household Labour Force Survey has a sample size of approximately 15,000 households.
} 
assistance payments, interest income, dividends, and income from other sources.

- Each member of the family aged over 15 is asked to keep an expenditure diary recording all expenditure for two weeks. These expenditures are multiplied by 26 to provide annual expenditure figures [Gordon, 1997, p. 6].

Although the Household Economic Survey collects a large amount of data from each family the survey is designed to measure CPI accurately and so the sample design does not always provide accurate results on social assistance entitlement. For example, in comparison to administrative data collected by the Ministry of Social Development the Household Economic Survey data consistently contains relatively low numbers of ex-beneficiaries [Kalb, Cai, and Tuckwell, 2005, p. 36]. Consequently both Statistics New Zealand and Treasury use integrated weighting, which adjusts the statistical output of the survey to population benchmarks, on the Household Economic Survey data [Statistics New Zealand, 2001, p. 4; Creedy and Tuckwell, 2003].

\section{Survey and Administrative Data}

Difficulties arise when using family surveys designed for other purposes to model tax-benefit systems. For example, information on incomes may be missing, the time period over which incomes are measured may not be appropriate, and surveys may contain non-representative numbers of some types of family so grossing up factors may need to be applied [Creedy, 2001, p. 196]. It may not be possible to fully replicate realistic tax-benefit systems. Features of tax-benefit systems unable to be fully replicated include the administration of means test and the discretion in their application by case managers [Creedy, 2001, pp. 196].

One approach to address the limitations of survey data is to draw on a combination of both survey and administrative data sources. Survey data and administrative data both have their areas of relative strength [Atkinson, 1989a]. Administrative data on programmes contain little information on the large number of people who do not participate in programmes but who may nevertheless be affected by a policy change. Administrative data on 
recipients of programmes may also be incomplete. For instance, the Inland Revenue Department has demographic information for only approximately two thirds of total Family Assistance recipients, as approximately a third of Family Assistance recipients are social welfare beneficiaries who do not provide information to the department [Nolan, 2003, p. 56]. For these people the only information that the Inland Revenue Department holds is the amount of Family Assistance and the monthly social welfare benefits they receive. Based on data on beneficiaries who do file with the department, the Inland Revenue Department are able to develop assumptions regarding the demographics of non-filing beneficiaries and then estimate characteristics of these beneficiaries.

Detailed information on people not contained in administrative data sources can be generated with estimates based on a general survey of families. These estimates may, however, not provide information on recipients as accurately as the administrative data on these programmes, although at times administrative data is limited in the degree to which the characteristics of individuals (e.g., extent of work effort, level of investment income) are recorded.

In New Zealand there have recently been efforts to integrate different data sources [Dixon, 2002, pp. 26-30; Spittal, 2002, pp. 198-201]. The combination of administrative and survey data can introduce a number of other problems, however. Differences may arise between receipt recorded in administrative data, receipt recorded in survey data, and entitlement estimated with survey data. These differences can occur because while some eligibility conditions for programmes may be relatively straightforward to check, i.e., number of children, some conditions may involve complicated calculations or a degree of discretion in their application, e.g., whether two people are cohabitating [Atkinson, 1989a, p. 194].

\subsection{Comparative Policy Analysis}

Comparative public policy research can be undertaken for a number of reasons. Research comparing public policies in different jurisdictions can allow a deeper understanding of options and constraints though identifying 
positive lessons (what to do) and negative lessons (what not to do), identifying political and cultural assumptions (reflected in, for example, the scope of programmes, uses of policy instruments, distributions of the benefits and costs of programmes, and emphasis given to sanctions versus incentives), and enhancing policy predictions and verifying theories [Bennett, 1991, pp. 33-37; Rose, 1991, p. 22]. Comparative policy research can also satisfy political motivations, by helping to put an issue on the agenda, mollifying political pressure (by finding a ready-made solution), or legitimising conclusions already reached (using, perhaps selectively, the persuasive power of foreign evidence) [Bennett, 1991, pp. 33-37].

Comparative social policy research often compares countries' overall inputs, such as the percentage of spending on social programmes as a proportion of GDP, and outputs, such as the effect of this spending on income inequality [Battle, Mendelson, et al, 2001, pp. 3-4]. However, as Battle, Mendelson, et al [2001, pp. 3-4] argue, these comparison tell us relatively little about programmes' objectives and design. Differences between social security systems also mean that it is necessary to be cautious when categorising social security systems in different jurisdictions into broad categories. The coverage of social security systems may vary with the characteristics of individual workers. Alternative programmes to which recipients may apply, such as local charities, may vary from country to country and region to region [Atkinson and Micklewright, pp. 1693-1694].

This study compares the objectives and designs of family and employment tax credits in five Anglo-American countries. These countries are New Zealand, Australia, Canada, the United Kingdom, and the United States. These countries share a common language and similar cultures, histories, economic structures, and political institutions. They have also all undertaken reform to their family and employment tax credits. Some of these reforms, particularly those to the Earned Income Tax Credit in the United States and the Child Tax Credit and Working Tax Credit in the United Kingdom, have influenced reforms in the other countries. This policy transference has led to a view that there is an emerging international consensus regarding the roles and designs of family and employment tax credits [Duncan, 2002]. To assess whether this view is correct this study 
considers the degree to which the five countries have adopted similar objectives and designs in their family and employment tax credits.

In five Anglo-American countries the levels of the family and employment tax credits provided vary according to wage rates, family types, and family sizes. Thus although entitlement and abatement schedules are often expressed in terms of gross income this study models the financial assistance available to families at different hours of work with a fixed gross wage rate reflecting the median wage rate for these family types. Assistance is modelled against hours of work in order to separate low-wage families from higher-wage families who have low hours of work and thus low incomes. Modelling assistance against gross income could create a misleading picture of the financial assistance provided to families. While particular programmes may appear relatively heavily targeted by income when modelled against gross income this may not be the case when levels of financial assistance are modelled against hours of work for families with relatively common wage rates.

Table 4.1: OECD Purchasing Power Parity Rates (2004)

\begin{tabular}{ll} 
& PPP (NZ\$) \\
New Zealand & 1.00 \\
Australia & 0.94 \\
Canada & 0.82 \\
United Kingdom & 0.43 \\
United States & 0.68 \\
\hline
\end{tabular}

Source: OECD, 2005b

All figures in this study are in New Zealand dollars adjusted using OECD purchasing power parity rates for 2004 [OECD, 2005b]. These rates are shown in table 4.1. Purchasing power parity rates illustrate the differences in the costs of a comparable basket of goods and services in different countries. Converting assistance into New Zealand dollars based on purchasing power parity rates illustrates the purchasing power that a family

\footnotetext{
"In this study the modelled wage rate of sole-parents (of NZ\$10 per-hour) is slightly below minimum wage in Australia and the United Kingdom in purchasing power parity terms. This wage rate is slightly above minimum wage in Canada, New Zealand, and the United States. Nolan [forthcoming] contains a comparison of family and employment tax credits in five Anglo-American countries based on a sole-parent wage above minimum wage in all five countries.
} 
would have if the different programmes were in operation in New Zealand. Purchasing power parity rates are used, rather than modelling assistance provided to a family at a particular point in the income distribution (such as a proportion of average production worker income), as modelling assistance at a point in the income distribution reflects both the distribution of wage rates and of hours of work. In this study assistance is modelled over a range of hours of work for a family type at a fixed wage rate. This approach is taken to illustrate how the structures of assistance and financial incentives to work vary with hours of work. Further, in order to draw lessons for New Zealand from overseas jurisdictions the approach taken emphasises the nature of assistance available to family types as if the overseas programmes were in operation in New Zealand. In the modelling throughout the study it is assumed that wage rates, hours of work, and family structures do not vary during the year.

\subsection{Conclusion}

This chapter discussed the methodology for tax-benefit programmes. The chapter began by discussing the increasing demand for research to contribute to the evidence base for policy in New Zealand. The chapter then explained the method for calculating average tax rates and effective marginal tax rates. Following this the chapter discussed how the effects of tax-benefit reforms on individual families could be estimated and what characteristics these families should be assumed to have. A model family approach is taken in this study and, given the focus in this study on assistance to families with children and caregivers' labour supply, the cases of a sole-parent and a secondary earner are considered.

Approaches for estimating the effects of reform on the population as a whole were then discussed. This section included discussion on arithmetic and behavioural microsimulation modelling and the use of administrative and survey data. Microsimulation modelling based on survey data can be used to model hypothetical reforms and can include groups not contained in administrative data sources. Non-behavioural modelling allows for greater population heterogeneity than behavioural modelling. However, non- 
behavioural models may be inaccurate when estimating labour supply behavioural responses and consequently the fiscal costs (and tax rates required) and poverty reduction effectiveness and targeting efficiency of taxbenefit reforms.

Comparative policy analysis was discussed in section six. The focus of the comparative component of this study is on the objectives and design of family and employment tax credits in five Anglo-American countries. In these countries the levels of family and employment tax credits provided vary according to wage rates, family types, and family sizes. Thus this study models the financial assistance available to families at different hours of work with a fixed wage rate reflecting the median wage rate in New Zealand for the family types. 


\section{Evolution and Operation of New ZEALAND'S TAX-BENEFIT SYSTEM}




\section{New Zealand's Tax-Benefit System}

\subsection{Introduction}

This chapter discusses the evolution and operation of New Zealand's taxbenefit system. The material in this chapter - along with that in the following two chapters - forms the basis for the evaluation of the tax-benefit system and current and proposed tax-benefit reforms in parts three and four of this study. The evolution of New Zealand's tax-benefit system is split into three periods reflecting dominant policy objectives influencing the design of policies. Prior to 1984 an emphasis in policy was placed upon a wage earners' welfare state. Between 1984 and 1999 emphasis changed to give greater weight to reducing the role of government intervention in the economy and improving incentives for beneficiaries to work. Following the election of Labour-led governments after 1999 greater emphasis has been placed on poverty reduction and improving the financial incentives for labour supply ('making work pay') more broadly among the population, including secondary earners in families with children. Separating the 1984 to 1999 period from the period since 1999 does not imply a major break with the policies from 1984 to 1999 , but reflects the focus on evaluating tax-benefit reforms since 1999 in the later parts of this study.

\subsection{The Wage Earners' Welfare State}

\section{Social Assistance, Full Employment, and Wage Policies}

The origins of New Zealand's social assistance system were in an economic and social environment of low and generally short-term unemployment and 
where couples with children and male breadwinners were the most common family type. Early social assistance programmes were developed alongside policies that aimed to attain full employment and to ensure adequate market incomes for breadwinners in families. The Pensions Act 1898 established state funded flat-rate old-aged pensions that were income tested (selective) and provided for a low-level of subsistence living (residual) [Castles, 1985, p. 16]. Following the enactment of this legislation the coverage of the social assistance system gradually expanded through including various additional categories of people in need [Beaglehole, 1993, p. 1; Stephens and Waldegrave, 2001, p. 77]. Governments also engaged in public work schemes and policies that aimed to protect and develop manufacturing in efforts to achieve full employment. The Industrial Conciliation and Arbitration Act 1894 established compulsory mediation of industrial disputes and the setting of national wage awards and in 1908 the Court of Arbitration introduced the concept of a living wage [Goodger, 1998, p. 126], which was a basic wage rate for men set at a level deemed adequate for a breadwinner with a non-working spouse and two children through the arbitration system [Reeves, 1923, pp. 85, 216-242; Condliffe, 1959, pp. 118-119; Castles, 1985, p. 15]. Consequently the role of the social assistance system was generally restricted to dealing with residual pockets of hardship due to temporary spells of unemployment or incapacity [Stephens and Waldegrave, 2001, pp. 77-78].

When the number of unemployed rose dramatically in the 1930s large public work schemes (work relief) were initiated. Due to the large number of the unemployed and the meagre pay and irregularity and generally purposeless nature of work relief there was a growing awareness that income support needed to be more wide-ranging and flexible [McClure, 1998, pp. 5051]. The Social Security Act 1938 extended the range of income tested benefits to invalids, deserted wives, the sick, widows without children, orphans, and the unemployed and introduced an emergency benefit for people ineligible for main benefits. Yet principles that the state should provide employment and that recipients of welfare have a duty to work remained important.

Early social assistance programmes were based on beliefs that men had dependents and women did not and that married women rarely worked 
in paid employment [Beaglehole, 1993, p. 2]. It was assumed that when determining the need for public support a husband and a wife were a single income sharing unit. Thus despite concerns for motherhood and providing for children, when cash benefits were first introduced they were granted to male breadwinners and their dependents [Beaglehole, 1993, p. 2]. Differing levels of public support for the lifestyles of different groups of women also influenced the timing and nature of their support; with widows receiving assistance before deserted wives and deserted wives receiving assistance before sole mothers [Beaglehole, 1993, p. ix]. These differences in the treatment of these groups of women reflected the difficulty of reconciling desires to meet the needs of women and children whose private support had broken down while also avoiding encouraging and affirming family dissolution [McClure, 1998, p. 67].

State-funded and income tested family allowances were first established in New Zealand with the enactment of the Family Allowances Act 1926 [Campbell, 1927, p. 369]. These family allowances were limited to large families on low incomes and were extended in scope (through the creation of an income-tested Family Benefit) during the 1930s and 1940s. Yet during World War Two the income testing of this assistance was seen as a constraint on the expansion of production through discouraging increased work effort [McClure, 1998, pp. 97-98]. Further, following the release in Britain of William Beveridge's 1942 report Social Insurance and Allied Services there was also a shift towards the provision of universal family benefits internationally. ${ }^{\dagger}$ Thus in New Zealand the income tested Family Benefit was replaced with a universal Family Benefit with the enactment of the Social Security Amendment Act 1945.

\footnotetext{
Although a tax exemption for children had been introduced in 1914, at this time few wage and salary earners paid income tax so this tax relief did not affect most households. With the establishment of the universal Family Benefit the tax exemption for children was removed to help fund this programme [McClure, 1998, p. 104, 39-40].

${ }^{\dagger}$ In his 1942 report, Social Insurance and Allied Services, William Beveridge proposed that Britain adopt a system of income transfers that would provide a minimum standard of living from the cradle to the grave below which no one should be allowed to fall [McClure, 1998, pp. 98-99, 105].
} 
The universal Family Benefit was paid to principal caregivers of children and was not targeted by income. This programme was designed to redistribute income to all families with children not only to alleviate poverty. When established the Family Benefit was set at a generous level of 10 shillings per-week, which was equivalent to 8.8 percent of the male nominal wage and 25 percent of the single Unemployment Benefit [Goodger, 1998, p. 126]. This level was considerably higher than the British Family Benefit of five shillings, which was introduced in 1946 [Beaglehole, 1993, p. 2]. However, as the value of the Family Benefit was not indexed to inflation its real value eroded over time. For instance, as the Royal Commission on Social Policy [1988, p. 5] estimated, between 1979 and 1988 the real value of the benefit fell to 35 percent of its 1979 value.

After 1951 supplementary assistance was provided in order to address variations in needs that were unable to be addressed by the main forms of social assistance or that could only be addressed by main forms assistance at high fiscal costs to the government. Payments of supplementary assistance were income tested and at times subject to administrative discretion. Perceived problems with supplementary assistance included stigma associated with the application process and a lack of information on assistance, which discouraged its take-up [McClure, 1988, pp. 134, 140-141]. Nevertheless, this supplementary assistance was the precursor to a range of supplements that would be added on to main benefits in following decades [McClure, 1998, p. 140].

Because of the largely residual role of social assistance there was an extensive use of income testing for the main forms of social assistance except for pensions [Boston, 1999a, p. 8]. There were some exceptions to this residual role of the social assistance system for the working aged. These exceptions occurred where governments aimed to achieve objectives other than solely reducing hardship. The provision of the universal Family Benefit from 1945 to 1991 was, for example, not only influenced by concerns regarding families' financial needs but was also influenced by concerns regarding birth rates and desires to reinforce women's maternal roles in society [Beaglehole, 1993, p. ix]. Overall, however, the origins of New Zealand's social assistance system reflected an emphasis upon residual and 
right-based principles as opposed to insurance or contributory principles [Boston, 1999a, p. 8]. Residual principles emphasise self-reliance and individual responsibility. Right-based principles base entitlement on people's status as citizens. Insurance or contributory principles base entitlement on previous financial contributions. New Zealand's system of income support could thus be classified as a social assistance, as opposed to a social insurance, regime [Atkinson and Micklewright, 1991, pp. 1692-1693].

\section{A Narrow Base and High Rate Tax System}

This development of New Zealand's social assistance system was underpinned by a progressive income tax system which, except for a period between 1939 and 1960, levied personal income taxes on an individual basis. Over the first half of the twentieth century the number of personal income tax thresholds increased (from two in 1900 to 39 in 1940) but then fell after the late 1960s. In 1967 there was a 33-tier personal income tax scale with rates ranging from 15 to 60 percent and by 1978 this was a five-tier scale with rates ranging from 20 to 60 percent, with the 60 percent rate starting at three times average earnings [Stephens, 1993, p. 50; McLeod, Chatterjee, et al, 2001a, p. i]. By 1982 a five-tier personal income tax scale had rates ranging from 20 to 66 percent, with the top rate starting at 2.5 times average earnings [Stephens, 1993, p. 50].

There was a large reliance upon taxing employee income due to the narrowness of the income tax base. By 1984, for example, a wide range of family tax rebates (discussed in chapter six) and other tax rebates had been established, exemptions were available for work-related expenses and for contributions to life insurance and superannuation schemes, and fringe benefits were outside the tax base. There were also a number of

An individual based income tax was first introduced with the Land and Income Tax 1891 [Chan, 1993, p. 61]. The Land and Tax Amendment Act 1939 introduced a system of tax aggregation where income derived by a married woman was deemed to be income derived by her husband and the husband was assessable and liable for income tax on the joint income. Separate assessment was possible but did not affect a couple's total liability as this only meant that the tax payable under the aggregate method would be split between the spouses. This was similar to the system in operation in England at that time. Joint taxation was repealed with the Land and Income Tax Amendment Act 1960 on the grounds that this would improve the financial incentives to work facing both spouses and consequently increase private savings [Chan, 1993, pp. 61-62]. 
concessions for the self-employed and companies [McLeod, Chatterjee, et al, $2001 \mathrm{~b}, \mathrm{pp} .5,10]$. In relation to the taxation of companies, the classical system of company taxation taxed the income of companies at 45 percent and then again in the hands of shareholders at their marginal tax rates upon distribution [McLeod, Chatterjee, et al, 2001a, p. i]. Disparities between the company tax rate and personal income tax rates (particularly the top personal rate of 66 percent) led to incentives to change company organisational form and retain earnings, created a bias to debt finance, and encouraged takeovers of less highly geared companies [Stephens, 1993, p. 48]. Further, the wholesales sales tax, with five rates ranging from 10 to 50 percent, covered only 39 percent of the potential wholesales sales tax base (excluding the service sector and value-added by retailers) and 23 percent of total consumption. These gaps in the wholesale sales tax base were generally a result of political lobbying or justified on income distributional grounds (e.g., lower rates on goods accounting for high proportions of low-income families' consumption, such as food and clothing) rather than Ramsey taxation principles (for taxing goods with relatively elastic demands at lower rates) [Stephens, 1993, p. 48].

\section{The Overload Debate}

By the early 1980s New Zealand had experienced a growth of per-capita income less than that being experienced overseas and a fall in relative living standards [Hawke, 1985, p. 213; Mascarenhas, 1996, p. 71]. Factors that constrained economic growth in New Zealand included the collapse in the price of cross-bred wool after the 1966-1967 season, the entry of Britain into the European Economic Community in 1973, increases in oil prices by the Organization of the Petroleum Exporting Countries in 1973 and 1979, and persistently high inflation and interest rates. The low effectiveness of the tax system at raising revenue and increasing fiscal cost of government expenditure were reflected in government deficits. The narrow tax base was failing to raise tax revenue sufficient to meet the government's expenditure

\footnotetext{
The effective rate for companies varied from -50 percent for forestry to 39 percent for drugs, chemicals, and the retail trade [Bevin, in Stephens, 1993, p. 48].
} 
requirements as high tax rates and uneven tax rules contributed to poor rates of economic growth and tax avoidance was commonplace [McLeod, Chatterjee, et al, 2001b, p. 6]. Government expenditure requirements increased due to the lack of income testing for much social security expenditure, including education, healthcare, and some forms of social assistance (such as student allowances) by the early 1980s [Boston, 1999a, p. 9]. Government expenditure also increased due to government policies such as Supplementary Minimum Prices for primary products, Think Big industry development schemes, the universal National Superannuation, and increasing take up of the income-tested Domestic Purposes Benefit and Unemployment Benefit.

The numbers of recipients of the Domestic Purposes Benefit and Unemployment Benefit had grown from 4,000 at the beginning of the 1970s to over 100,000 in 1984 [McClure, 1998, p. 204]. The take-up of the Domestic Purposes Benefit, which grew gradually between 1968 and 1973 while the benefit remained discretionary and then more rapidly after 1973 when this benefit became non-discretionary, led to anxiety that it was encouraging negative social changes, particularly a decline in the traditional two-parent basic family unit, and a doubling of its annual cost between 1980 and 1984 [McClure, 1988, pp. 179, 185]. Further, by 1981 the numbers of registered unemployment had reached three percent of the labour force and by 1983 it was over five percent [Boston, 1999a, p. 9]. This increase reflected worldwide shifts in the structures of economies away from secondary sectors (i.e., manufacturing) to tertiary sectors (i.e., services) and consequent reductions in blue-collar employment and a marked rise in unemployment in most OECD countries during the 1970 s and 1980s. As a consequence of this increase in unemployment policymakers and academic researchers gave greater attention to the effect of social assistance on financial incentives to supply labour [Atkinson and Micklewright, 1991, p. 1679].

Thus by the early 1980 s the combination of declining economic growth, high inflation and interest rates, increasing costs of state intervention, falling confidence in the tax system, increasing financing costs for large fiscal deficits, and increasing unemployment and take-up of main welfare benefits led to an overload debate and a policy response centred around reducing 
public expenditure [Evans, Grimes, et al, 1996; Mascarenhas, 1996, p. 104; Silverstone, Bollard, and Lattimore, 1996]. These fiscal, economic, and social pressures were matched by an ideological shift away from a rights-based approach to a more targeted or residual social assistance regime [Boston, 1999a, p. 9].

\subsection{Neo-Liberal Policy Settings}

After the 1984 election of the fourth Labour government there was increased emphasis on redesigning the social assistance system to constrain fiscal costs, reduce scope for moral hazard, and encourage labour supply and human capital acquisition [Stephens and Waldegrave, 2001]. The previous National government had reduced the rate of the unemployment benefit by making it taxable and increased the stand-down period for the Unemployed Benefit from one to two weeks [McClure, 1998, p. 221]. The Labour government maintained this stringency. However, in response to poverty among working families with children the Family Care wage supplement for non-beneficiary families with children was introduced in 1984. Family Care was subject to problems of take up and the exclusion of beneficiaries was contentious. In 1986 the income-tested and in some cases work-tested Family Assistance Tax Credits were established.

The Family Support Tax Credit was available to beneficiaries, although the base adult benefit level was reduced to keep the total payment to beneficiaries similar and to improve benefit replacement rates. Family Support was provided at a higher rate than Family Care to also compensate low-income families for the introduction of the Goods and Services Tax [McClure, 1998, pp. 216-217]. The Guaranteed Minimum Family Income (GMFI) was introduced for working families with children and who satisfied hours-based work tests. In 1986 benefit abatement thresholds were increased. Liberalisation of the economy and corporatisation and privatisation of state owned enterprises lead to an increase in unemployment and the numbers of people receiving the Unemployment Benefit continued to grow. Growth also took place in take-up of the Sickness Benefit, Invalids Benefit, and Special Benefit and in 1990 proposals were made for a single core 
benefit. After the early 1980 s there were changes in the overall tax mix and the structure of the personal income tax system (discussed below).

After the November 1990 general election the newly elected Bolger National government discovered that their fiscal position was worse than they had anticipated due to large increases in the forecast deficit and the need for funds to stop the collapse of the Bank of New Zealand [McClure, 1998, p. 234; McKinnon, 2003, p. 347]. Reflecting this fiscal position the National government took the restructuring of the social assistance system further than the previous Labour government through pursuing greater targeting of expenditure, liberalisation of the labour market, and reductions in benefit levels. These three policy settings are discussed below.

\section{Greater Targeting of Expenditure}

The government budget in July 1991 brought major changes to social services and social security. There was greater emphasis on the user charges for tertiary education and health services. Universal benefits were removed. The aims were reduced fiscal costs, greater targeting efficiency, and a more modest safety net, which would support people at a level sufficient for needs when necessary [Shipley, 1991, p. 13; McClure, 1998, p. 235]. This shift in policy objectives reflected an increasing concern that middle-class groups were large financial beneficiaries of (had captured) the welfare state although they had relatively low needs [Stephens, 1997, p. 475; Bertram, 1988].

In 1991 the universal Family Benefit was removed and all unabated Family Support rates were increased by the value of the Family Benefit ( $\$ 6$ per-week). As Family Support was targeted on the basis of joint income, lowincome families retained their support, average-income families received more limited help, and higher-income families became fully responsible for their children's upbringing [McClure, 1998, p. 235]. Only 42 percent of the fiscal savings from the removal of the Family Benefit went into Family Support [Stephens, 1999, p. 247]. Combined expenditure on the Family Benefit and Family Support of $\$ 695$ million in 1990-91 fell to expenditure of $\$ 618$ million on Family Support in 1991-92. However, there was little public protest at the removal of the Family Benefit. The lack of indexation had 
meant that the value of the programme had reduced to being a token amount and the large number of recipients (approximately 900,000 children) meant that the fiscal savings to the government in abolishing the programme were significant [McClure, 1998, pp. 238-239]. Yet some critics argued that the loss of even token membership of the system by middle-class families meant that the community lost able advocates with a stake in the system [McClure, 1998, pp. 238-239]. Further the removal of the Family Benefit marked the end of provision of social assistance on the basis of family structure regardless of income and need. The removal of the Family Benefit also meant the loss of an independent income for non-working caregivers in families not eligible for targeted assistance [McClure, 1998, pp. 238-239].

\section{Liberalised Labour Markets}

The Bolger National government coordinated reform of social security for working-aged beneficiaries with labour market reform. The nature of employment in New Zealand underwent dramatic change with the corporatisation and privatisation of a number of state trading enterprises that began under the fourth Labour government. Changes in the nature of employment increased with the shift towards an industrial relations framework emphasising increasing wage flexibility [Brosnan, Rea, and Wilson, 1995, p. 17]. The Employment Contracts Act 1991, which applied to all employment contracts, broke the historical link between union membership and negotiating authority. This Act overturned the century-old labour arbitration and award system and formalised the growing deregulation of the labour market. Trade union membership, which had already begun to decline, fell significantly. The loss of legislative props, such as compulsory unionism, led to a fall in trade union density of 69 percent in the first 18 months of the Act (May 1991 to December 1992) [Walsh and Brosnan, 1999, pp. 125-126]. Parallel to these labour market changes were reductions in benefit levels and tightening of benefit regulations in efforts to shift people from benefits to paid employment [McClure, 1998, p. 235].

Alongside these policy changes were trends in the labour market such as increasing part-time and casual work, variations in weekly hours of work, variations in wage rates, and participation rates of women [Callister, 2000, 
pp. 6-16]. Between December 1985 and December 2001 the labour-force grew by 20 percent to reach approximately two million [Statistics New Zealand, 2002a]. The numbers of people classified as working part-time grew by 62 percent and accounted for an increasing percentage of total employment (of 22.7 percent up from 16.6 percent). There was a decline in employment rates of working-aged men, particularly low-skilled workers, and an increase in women's employment rates and representation in managerial and professional occupations. Between December 1985 and December 2001 the number of women in the labour force increased by almost one-third and the number of men in the labour force increased by 5.4 percent [Statistics New Zealand, 2002b, p. 14]. At the family level work became more polarised with a growth in both work-rich families, including dual-earner couples, and work-poor families, including couples where neither partner is in paid work [Singley and Callister, 2003].

\section{Reduced Benefit Levels and Greater Use of Supplementary Assistance}

In 1991 stringent cuts in benefit levels were introduced for working-age beneficiaries. These cuts were motivated by concerns regarding the rise in the numbers of people receiving a main welfare benefit. After the early 1970 s the steady increase in receipt of the Domestic Purposes Benefit reflected the increasing proportion of sole-parent families, increasing take-up rates of the benefit, and declining employment of sole-parents between 1976 and 1991 [Stephens, 1999, pp. 242-243]. After the late 1980s there was a marked rise in the numbers of people receiving the Unemployment Benefit, which reflected a low rate of economic growth and a significant increase in potential labour supply, particularly with growth in the population aged 15-19 [Stephens, 1999, p. 242]. The 1991 benefit cuts were also motivated by Treasury concerns that benefit levels in New Zealand were relatively high by international levels [Stephens, 1999, p. 247]. To create greater incentives for beneficiaries to move from benefits into the workforce all benefits that could be regarded as short-term (e.g., not life-long) were reduced in value [McClure, 1998, pp. 236-237]. 
Table 5.1: Net Main Benefit Rates Before and After 1991 Reforms

\begin{tabular}{|c|c|c|c|c|}
\hline Category & Before Reforms & After Reforms & Difference & $\%$ Difference \\
\hline \multicolumn{5}{|l|}{ Unemployment } \\
\hline Single Adult & $\$ 143.57$ & $\$ 129.81$ & $-\$ 13.76$ & -9.58 \\
\hline Married couple & $\$ 223.22$ & $\$ 216.34$ & $-\$ 6.88$ & -3.08 \\
\hline Single (1 child) & $\$ 213.40$ & $\$ 185.93$ & $-\$ 27.47$ & -12.87 \\
\hline $\begin{array}{l}\text { Married couple } \\
\text { (1 child) }\end{array}$ & $\$ 255.08$ & $\$ 229.88$ & $-\$ 25.20$ & -9.88 \\
\hline \multicolumn{5}{|l|}{ Sickness } \\
\hline Single adult & $\$ 162.26$ & $\$ 135.22$ & $-\$ 27.04$ & -16.66 \\
\hline Married couple & $\$ 270.24$ & $\$ 245.86$ & $-\$ 24.38$ & -9.02 \\
\hline Single (1 child) & $\$ 213.14$ & $\$ 185.93$ & $-\$ 27.21$ & -12.77 \\
\hline $\begin{array}{l}\text { Married couple } \\
\text { ( } 1 \text { child) }\end{array}$ & $\$ 255.08$ & $\$ 245.86$ & $-\$ 9.22$ & -3.61 \\
\hline \multicolumn{5}{|l|}{$\begin{array}{l}\text { DPB and } \\
\text { Widows }\end{array}$} \\
\hline Single adult & $\$ 162.26$ & $\$ 135.22$ & $-\$ 27.04$ & -16.66 \\
\hline Single (1 child) & $\$ 213.14$ & $\$ 185.93$ & $-\$ 27.21$ & -12.77 \\
\hline $\begin{array}{l}\text { Married couple } \\
\text { ( } 1 \text { child) }\end{array}$ & $\$ 228.87$ & $\$ 202.83$ & $-\$ 26.04$ & -11.38 \\
\hline \multicolumn{5}{|l|}{ Invalids } \\
\hline Single adult & $\$ 162.26$ & $\$ 162.26$ & & \\
\hline Married couple & $\$ 270.44$ & $\$ 270.44$ & & \\
\hline Single (1 child) & $\$ 213.14$ & $\$ 213.14$ & & \\
\hline $\begin{array}{l}\text { Married couple } \\
\text { ( } 1 \text { child })\end{array}$ & $\$ 255.08$ & $\$ 270.44$ & $\$ 15.36$ & 6.02 \\
\hline
\end{tabular}

Source: Morrison and Waldegrave, 2002, p. 88. New rates came into effect 1 April 1991

Table 5.1 shows the main net benefit rates before and after the 1991 reforms. The average cut to all benefits was approximately 10 percent. The largest cuts faced young and single beneficiaries. Youth benefit rates were extended from 18 to 24 , representing a 25 percent cut for people these ages [McClure, 1998, p. 237]. In contrast the maximum benefit of married couple without children fell three percent [Morrison and Waldegrave, 2002, pp. 8687]. Domestic Purposes Benefit and Widows Benefit recipients faced benefit reductions between 11.38 and 16.66 percent. Invalids were recognised as long-term beneficiaries who were unlikely to rejoin the workforce and their rates were not reduced. Eligibility for main benefits was also more closely scrutinised and restricted with increased use of work tests and longer standdown periods for some benefit categories [McClure, 1998, pp. 236-237]. 
An immediate outcome of the benefit cuts was an increase in the incidence and severity of poverty [Stephens, 1999, pp. 238-249]. The benefit cuts also led to an increase in the use of food banks and special needs grants. In the first quarter of 1990 the Salvation Army distributed 1,226 food parcels and by the first quarter of 1994 this had increased to 14,906 [Stephens, 1999, p. 251]. Further:

Supplementary benefits became the government's chief means of adjusting benefit levels in cases of extreme hardship, a vital backstop to a more focused benefit system. Supplementary benefits took the principle of targeting those in need one stage further, and meant that the Department [of Social Welfare] could treat people with a range of needs according to their particular circumstances, giving extra help to those short of clothing or paying high rent or medical bills; it also allowed the government flexibility in raising or lowering levels without legislation. To assist beneficiaries who faced severe hardship after the benefit cuts, the gap between income and essential outgoings necessary for special benefits (the most common of the supplementary benefits) was lowered from $\$ 45$ to $\$ 20$ [McClure, 1998, pp. 237-238].

In the five months to May 1995 special needs grants increased by 75 percent and food grants by 142 percent and food bank use fell by 12 percent. However, following the large increase in expenditure on supplementary assistance (in the year to June 1995 expenditure on food grants increased from $\$ 3.4$ million to $\$ 9.8$ million) the criteria for special benefits and special needs grants were tightened. Consequently grants decreased and food bank use increased [Stephens, 1999, p. 251].

This increasing demand for supplementary assistance increased the administration and compliance costs associated with the social assistance system. These costs were reflected in cases of administrative decisions being subject to review by the courts. In the case of Haidi Mai Ankers $v$ Attorney General (1994) the processing of claims for special benefits was reviewed and in the case of Ruka $v$ Department of Social Welfare (1997) the application of the test to be used to determine whether recipients are in a relationship in the nature of marriage was reviewed. However, as supplementary assistance was not indexed for inflation but the main working aged benefits were, over time the balance in the social assistance system shifted back towards the main forms of assistance [Mackay, 1998, p. 16]. The lack of indexation of supplementary assistance also meant that the poverty 
reduction effectiveness of these programmes fell [Waldegrave, Stephens, and King, 2003, p. 207].

In 1998 further reforms to working aged benefits were announced. In this second stage of restructuring emphasis was placed upon complementing financial incentives for labour supply with active case management, tighter eligibility conditions, and work-for-the dole schemes [Stephens, 1999, p. 239; Green, 2001, p. 49].

The perception of why people were on a benefit also altered. Traditionally, being on a benefit was viewed as a consequence of adverse economic conditions or a rigid labour market. The new perception was that individuals were on benefits as a result of their own lack of motivation - a situation permitted by a benefit system that was poorly designed, structured and enforced [Stephens, 1999, p. 239].

Efforts had also been made to improve the financial incentives to work with the Tax Cuts and Social Policy Package (the Hand-Up Package), which was phased in from 1996 to 1998. Central to this package were increases in the generosity of the Family Support Tax Credit and Guaranteed Minimum Family Income (renamed the Family Tax Credit in 1999) and the introduction of a work-based Independent Family Tax Credit (renamed the Child Tax Credit in 1999).

\section{Broad Based and Low Rate Tax Policy}

The 1981 tax system was a narrow base and high rate tax system that was also seen as being unfair and inefficient and unlikely to be able to continue to meet governments' revenue needs [McLeod, Chatterjee, et al, 2001b, p. 5]. The 1981 tax system was heavily reliant upon revenue levied on individuals' incomes. This reliance on taxing individuals' incomes fell over the next 25 years. The proportion of tax revenue received from taxing individuals' incomes fell from two-thirds of total revenue in 1984 to around half in 2001. The proportions of tax revenue received from taxing consumption and companies increased. By 2001 a broad based consumption tax (the Goods and Services Tax) generated 25 percent of total revenue [McLeod, Chatterjee, et al, 2001b]. As well as changes in the overall tax mix the structure of the personal income tax system also changed after the early 1980s. Between 1981 and 1999 the number of personal income tax 
thresholds including the Low Income Earner Rebate fell from five to three, real income levels at which high marginal tax rates applied increased, and the top personal income tax rate reduced from 60 to 33 percent [Stephens, 1993, p. 51]. In 1999 a new top personal income tax rate of 39 percent was introduced. The 1981 and 2001 personal income tax scales are illustrated in table 5.2.

Table 5.2: Flattening of New Zealand's Personal Income Tax Scale (1981 to 2001)

\begin{tabular}{llllll}
\hline 1981 Personal Income Tax Scale & \multicolumn{3}{l}{ 2001 Personal Income Tax Scale } \\
\hline $\begin{array}{l}\text { Taxable Income } \\
\text { (1981 Dollars) }\end{array}$ & $\begin{array}{l}\text { Taxable Income } \\
\text { (2001 Dollars) }\end{array}$ & Statutory Rate & $\begin{array}{l}\text { Taxable Income } \\
\text { (2001 Dollars) }\end{array}$ & Statutory Rate & $\begin{array}{l}\text { Statutory Rate } \\
\text { Including Low } \\
\text { Income Earner } \\
\text { Rebate }\end{array}$ \\
\hline$\$ 1-\$ 5,000$ & $\$ 1-\$ 11,600$ & $14.5 \%$ & $\$ 1-\$ 9,500$ & $19.5 \%$ & $15.0 \%$ \\
$\$ 5,001-$ & $\$ 11,601-$ & $35.0 \%$ & $\$ 9,501-$ & $19.5 \%$ & $21.0 \%$ \\
$\$ 11,683$ & $\$ 27,000$ & & $\$ 38,000$ & & \\
$\$ 11,684-$ & $\$ 27,001-$ & $48.0 \%$ & $\$ 38,001-$ & $33.0 \%$ & $33.0 \%$ \\
$\$ 16,266$ & $\$ 37,600$ & & $\$ 60,000$ & & \\
$\$ 16,267-$ & $\$ 37,601-$ & $55.0 \%$ & Over $\$ 60,000$ & $39.0 \%$ & $39.0 \%$ \\
$\$ 22,000$ & $\$ 50,900$ & & & & \\
$\begin{array}{l}\text { Over } \\
\$ 22,000\end{array}$ & Over $\$ 50,900$ & $60.0 \%$ & & & \\
\hline
\end{tabular}

Source: McLeod, Chatterjee, et al, 2001b, p. 9

This flattening of the personal income tax scale took place with (and was financed by) a broadening of the tax base. The income tax base was broadened through changes to taxation of fringe benefits and superannuation and the introduction of resident withholding tax. Personal income taxes were broadened through the removal or consolidation of complex systems of personal income tax deductions and rebates for single-income families and families with dependents.

In 1986 a range of tax rebates for single-income families and families with dependents were replaced with the Family Assistance Tax Credits. The Family Assistance programmes were established to compensate for the loss of personal income tax deductions and rebates for single-income families and families with dependents and the introduction of the Goods and Services Tax. In 1991 the Family Benefit was removed. In the mid-1990s the work focus of the Family Assistance programmes was strengthened with the introduction of an Independent Family Tax Credit, which provided $\$ 15$ perweek per-child to families who were independent from forms of main income- 
tested benefits. In 1999 the objectives of the Family Assistance programmes were extended to also include providing a Parental Tax Credit, which provides up to eight weeks of assistance for families independent from main income-tested benefits with a newborn child.

\subsection{Neo-Liberal Reform and Social Assistance Expenditure}

It has been argued that following the 1984 election of the fourth Labour government there was an ideological shift favouring retrenchment of the welfare state in New Zealand [Boston, 1999a, p. 9]. This retrenchment is illustrated below with expenditure-based measures of the welfare state. Internationally the use of expenditure-based measures of welfare state retrenchment has been subject to debate. Esping-Andersen has argued that expenditure is epiphenomenal to the theoretical substance of welfare states [1990, p. 19]. If, for example, there is an increase in the level of unemployment in an economy then total expenditure on assistance to the unemployed could increase while expenditure per unemployed person decreases. Further, as well as changes in expenditure, welfare state expansion or contraction also reflects changes to the level of public sector employment, the extent of direct and non-profit service provision by the state, and state support for the charitable sector [Clayton and Pontusson, 1998, p. 90]. Nevertheless, as Pierson has argued, an expenditure measure can illustrate important features of welfare state retrenchment, such as the stability of programmes due to political sensitivity and constituencies of support for established welfare programmes [Pierson, 1996, pp. 174-175].

Figure 5.1 shows total net social assistance expenditure and social assistance expenditure by type from 1980-81 to 1999-2000 as proportions of GDP. Figure 5.2 shows total net social assistance expenditure excluding pensions by type from 1980-81 to 1999-2000 as proportions of GDP. In figure 5.2 pensions are included in the calculation of total expenditure but are not shown in the graph. Figure 5.3 shows total social assistance net expenditure by type from 1980-81 to 1999-2000. Again pensions are included in the 
calculation of total expenditure but are not shown in the graph. These figures draw on net social assistance expenditure data provided by the Inland Revenue Department and the Ministry of Social Development. Net expenditure data for later years were not available for this study. These data do not include the Low Income Earner Rebate or tax exemptions. The Low Income Earner Rebate is a tax rebate paid on all wage and salary income below the bottom statutory personal income tax threshold and can thus be seen as a feature of the personal income tax scale and not a tax rebate. Tax exemptions were distinct from the tax-benefit programmes considered in this study as they were largely provided to support activities such as the purchasing of life insurance.

Figure 5.1: Social Assistance Net Expenditure by Type 1980-81 to $1999-2000$ (\% of GDP)

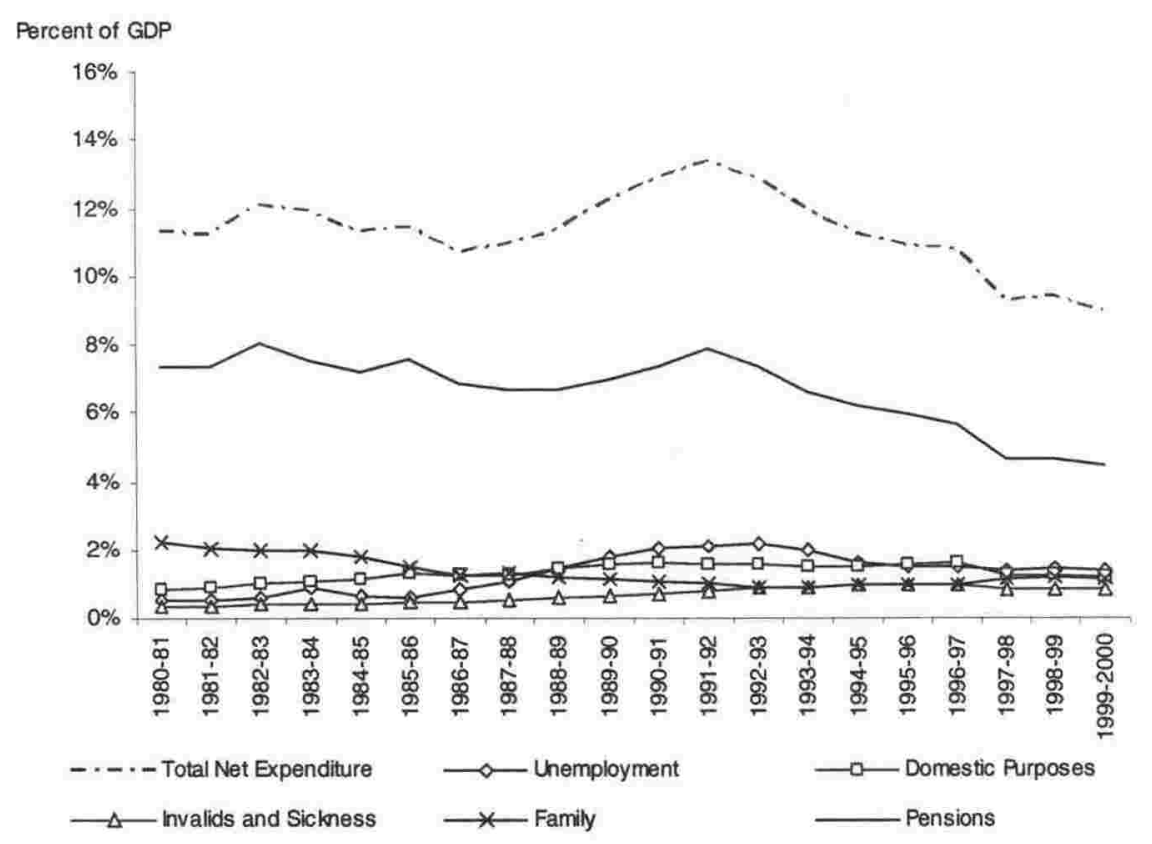

Sources: Inland Revenue Department, 2001, estimates of tax expenditures 1980-81 to 19992000; Ministry of Social Development, 2001, Social Services Statistical Report, Table 14; Ministry of Social Development, 2002, estimates of net social assistance expenditure 1997-98 to 2005-06; Nolan, 2002, p. 25; Claus and Scobie, 2002, appendix A2 
Figure 5.2: Social Assistance Net Expenditure by Type (Excluding Pensions) $1980-81$ to $1999-2000$ (\% of GDP)

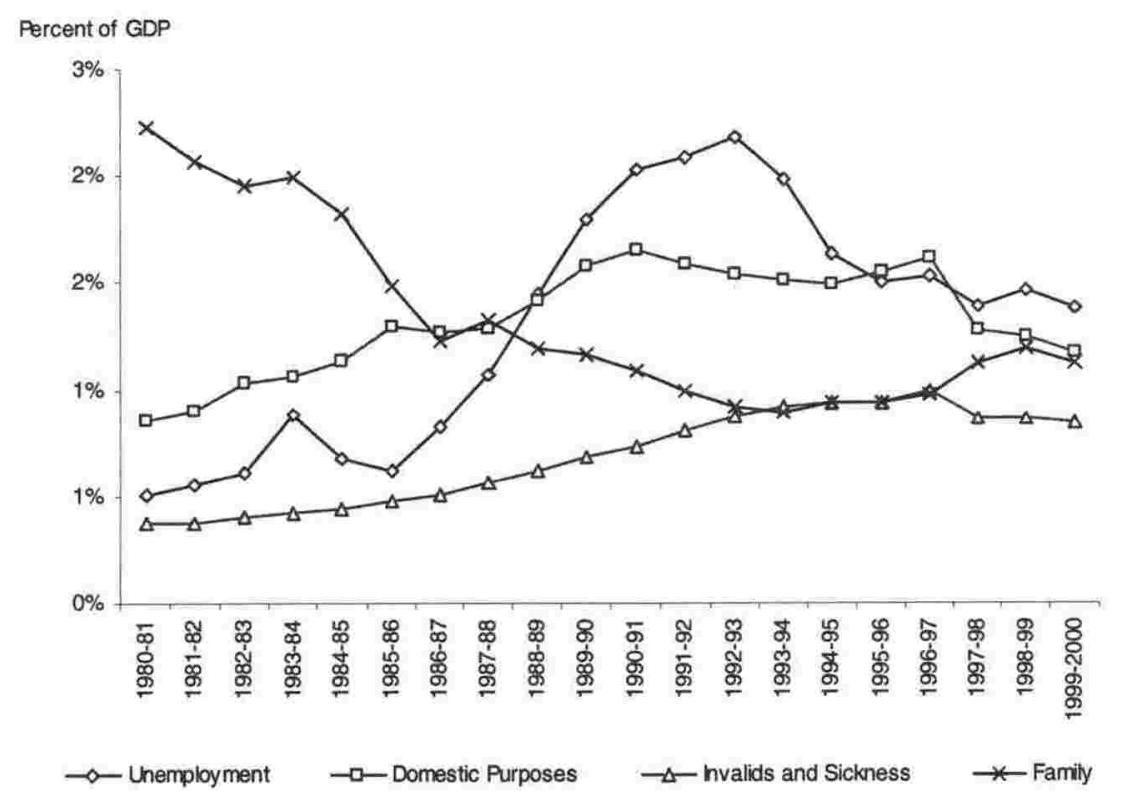

Sources: Inland Revenue Department, 2001, estimates of tax expenditures 1980-81 to 19992000; Ministry of Social Development, 2001, Social Services Statistical Report, Table 14; Ministry of Social Development, 2002, estimates of net social assistance expenditure 1997-98 to 2005-06; Nolan, 2002, p. 25

These expenditure figures illustrate the change in welfare state priorities in New Zealand after 1984. Total net social assistance expenditure declined from 11.3 percent of GDP in 1980-81 to 8.5 percent in 1999-200. This was largely due to the fall in expenditure on pensions, which fell from 7.4 percent of GDP in 1980-81 to 4.3 percent in 1999-2000, following the phased increase in age of eligibility to 65. Pensions include New Zealand Superannuation, War and Veterans Pensions, Widows Benefits, and Transitional Retirement Benefits. After 1980-81 the proportions of expenditure on income-tested Unemployment Benefits, Domestic Purposes Benefits, and Invalids and Sickness Benefits all increased.

The proportion of expenditure on dependent children in families had fallen over the early part of this period due to the declining real value and 1991 removal of the universal Family Benefit and the removal of family tax rebates in the mid-1980s. Some forms of expenditure targeted towards families with dependent children, such as the higher rates of main benefits paid to such families, are not included in these figures. In 1986 the Family Assistance Tax Credits were introduced. The introduction of and later 
expenditure in the form of family tax rebates (excluding the Low Income Earner Rebate) through the income tax system remained relatively stable during these decades. Figure 5.4 shows tax expenditures as a proportion of GDP from $1980-81$ to $1999-2000$. Figure 5.5 shows the proportion of social assistance expenditure through the tax system from 1980-81 to 1999-2000. While total expenditure through the tax system fell from 3.8 percent to 1.8 percent of GDP over this period, expenditure on family tax rebates (excluding the Low Income Earner Rebate) accounted for a relatively stable proportion of GDP, accounting for 0.9 percent of GDP in 1980-81 and 1.1 percent in 1999-2000. These rebates were largely provided to families as assistance to offset the costs of dependent children. In 1980-81, 6.5 percent of total social expenditure was provided through the tax system. In this year the combination of expenditure on the Family Benefit and expenditure on family tax rebates accounted for 16 percent of total social assistance expenditure. Following 1992-93 expenditure through the tax system accounted for increasing proportions of social assistance expenditure. By 1999-2000, 11.3 percent of total social assistance expenditure was provided through the tax system. In this year the social expenditure through the tax system accounted for 22 percent of total social assistance expenditure excluding pensions.

Figure 5.4: Tax Expenditures 1980-81 to $1999-2000$ (\% of GDP)

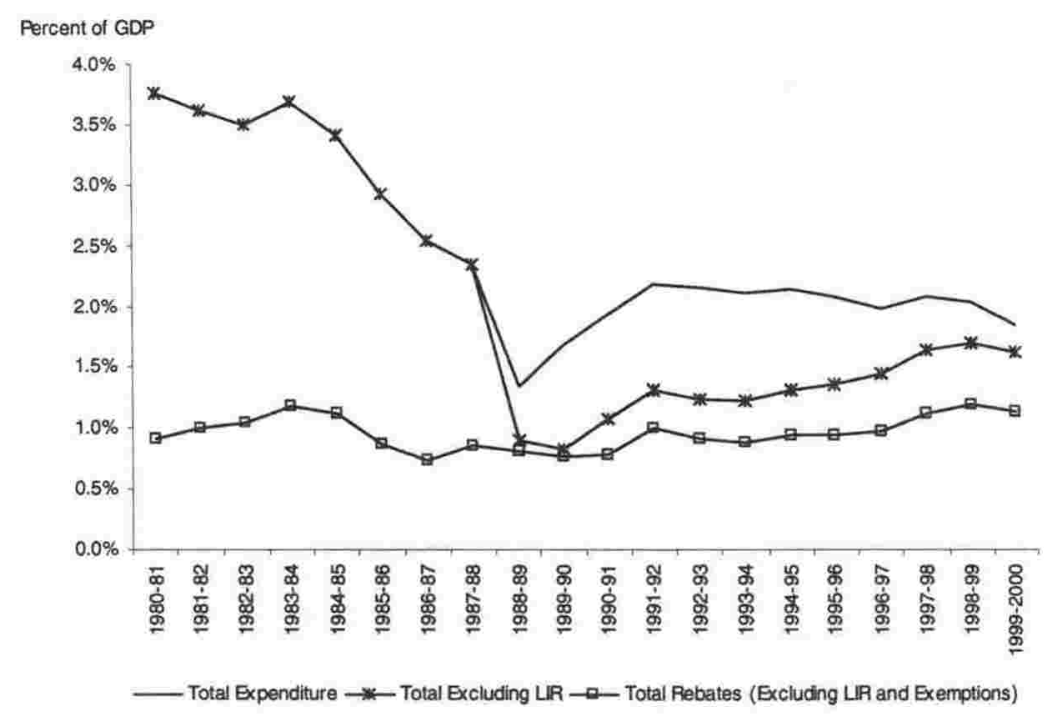

Sources: Inland Revenue Department estimates of tax expenditures 1980-81 to 1999-2000; Nolan, 2002, p. 25; Claus and Scobie, 2002, appendix A2 
Figure 5.5: Proportion of Social Assistance Expenditure through the Tax System 198081 to $1999-2000$

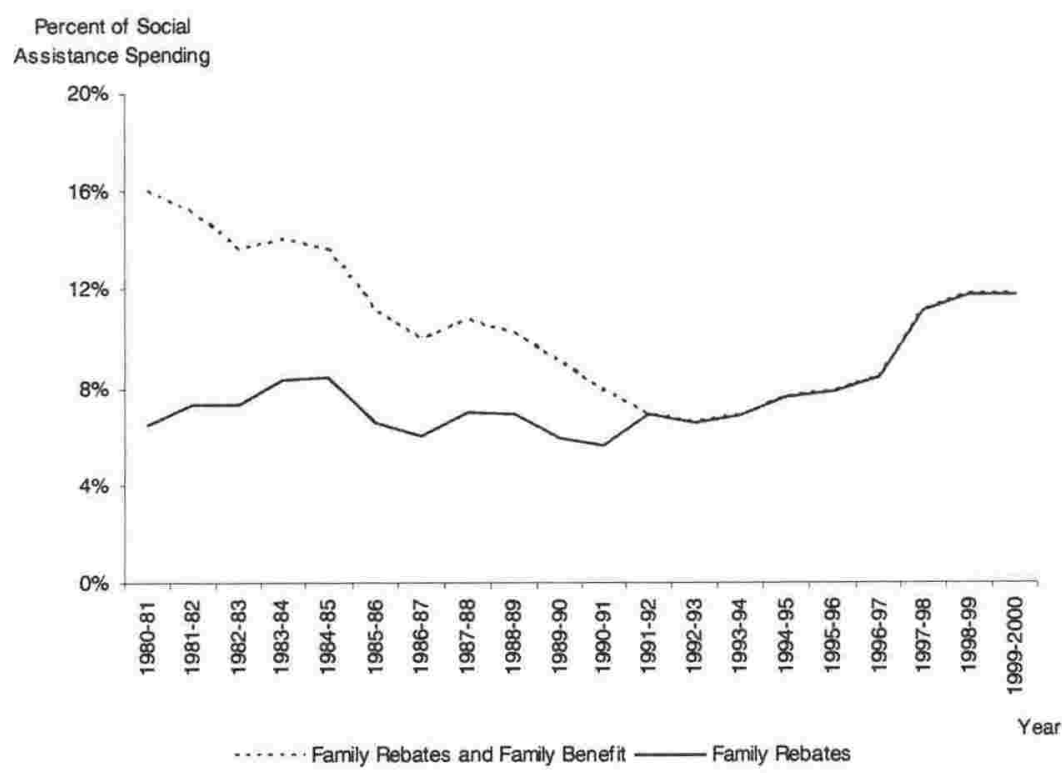

Sources: Inland Revenue Department, 2001, estimates of tax expenditures 1980-81 to 19992000; Ministry of Social Development, 2001, Social Services Statistical Report, Table 14; Ministry of Social Development, 2002, estimates of net social assistance expenditure 1997-98 to 2005-06; Nolan, 2002, p. 25

\subsection{Social Development and Making Work Pay}

Since 1999 in New Zealand there has been a greater focus on improving the financial incentives for labour supply facing low-wage caregivers (including secondary earners) and not just recipients of main welfare benefits. This emphasis on low-wage caregivers' labour supply has been part of a broader strategy for reducing child poverty. This shift in emphasis has been termed a social development strategy for social assistance [Clark and Maharey, 2001, p. 5]. Efforts to develop a social development strategy have taken place within constraints such as the number of social welfare beneficiaries, limits to the level of taxation, the effect of programmes on incentives to work, and social attitudes towards social security [Stephens and Waldegrave, 2001, pp. 78-79]. Further, exclusion of families receiving main welfare benefits from some social assistance has been contentious and is currently being challenged as discriminatory and breaching the Human Rights Act 1993 [St John and Craig, 2004, p. 54]. 


\section{Social Assistance Expenditure by Benefit Type}

The total numbers of people in receipt of a main benefit have fallen since 1999. The numbers of people receiving the Unemployment Benefit have declined. There were on average 167,200 recipients on the Unemployment Benefit in 1999. In 2004 this had fallen to 89,600 , reflecting strong economic and employment growth [Cullen, 2004, p. 1195]. The numbers of people receiving the Domestic Purposes Benefit has remained steady. In 1999 the number of recipients of the Domestic Purposes Benefit averaged 110,900. This fell to 108,800 in 2002 and increased to 111,200 in 2004 [Cullen, 2004, p. 1195]. There has been an increase in people receiving the Invalids Benefit and other disability-related benefits. The numbers of Invalids Benefit recipients have been estimated to have increased from 53,200 in 1999 to 74,500 in 2004 and Sickness Benefit recipients from 32,700 to 45,300 [Cullen, 2004, p. 1195]. Recipients of the supplementary Disability Allowance have been estimated to have increased from 181,700 in 1999 to 241,900 in 2004 [Cullen, 2004, p. 1194].

The New Zealand Government was estimated to collect approximately $\$ 48.26$ billion in tax revenue in 2004-05. This revenue represented approximately 33.4 percent of GDP [Cullen, 2004]. The New Zealand Government was estimated to have total expenses of approximately $\$ 44.5$ billion. Expenditure on New Zealand Superannuation, Domestic Purposes Benefits, Unemployment Benefits, and other benefits was estimated to account for 36 percent of this total. These estimates included the personal income taxes levied on benefits and departmental expenses. Other areas of key expenditure included health expenditure of 20 percent of total expenditure and education expenditure of 18 percent of total expenditure.

Table 5.3 shows the major areas of expenditure in the New Zealand social assistance system for 2004-05. These figures are gross of personal income taxes and are for the year ended 30 June. Total social assistance expenditure was estimated at $\$ 13,599$ million for this year. This expenditure included $\$ 6,176$ million on New Zealand Superannuation and the Widows Benefit and other pensions. Expenditure on pensions was the largest single area of expenditure in the social assistance system and a key determinant of total social assistance expenditure. Current projections are for significant 
increases in the costs of pensions due to the impact of demographic changes after 2011 [Creedy and Scobie, 2002].

Table 5.3: Social Assistance Expenditures by Benefit Type (2004-05)

\begin{tabular}{lll}
\hline Benefit Type & $\begin{array}{l}\text { Estimated } \\
\text { Expenditure }(\$ \mathrm{~m})\end{array}$ & $\begin{array}{l}\text { Пroportion of GDP } \\
(\%)\end{array}$ \\
\hline Main Benefits & & \\
\hline $\begin{array}{l}\text { New Zealand Superannuation } \\
\text { (Including Widows Benefits) }\end{array}$ & 6,176 & 4.28 \\
$\begin{array}{l}\text { Domestic Purposes Benefit } \\
\text { Unemployment Benefit }\end{array}$ & 1,577 & 1.09 \\
Invalids Benefit & 939 & 0.65 \\
Sickness Benefit & 1,044 & 0.72 \\
& 514 & 0.36
\end{tabular}

\begin{tabular}{lll}
\hline Supplementary Assistance & & \\
\hline Family Support Tax Credit & 918 & 0.64 \\
Accommodation Supplement & 754 & 0.52 \\
Income Related Rents & 366 & 0.25 \\
Disability Allowance & 274 & 0.19 \\
Special Benefit & 164 & 0.11 \\
Childcare Assistance and & 85 & 0.06 \\
OSCAR Programmes & & \\
Paid Parental Leave & 74 & 0.05 \\
Special Needs Grants & 54 & 0.04 \\
Child Tax Credit & 150 & 0.10 \\
Parental Tax Credit & 15 & 0.01 \\
Family Tax Credit & 14 & 0.01 \\
& & \\
Other* & 481 & 0.33 \\
& & \\
\hline Total Welfare Benefits & 13,599 & 9.41 \\
Total Welfare Benefits & 7,423 & 5.14 \\
(Excluding NZS)
\end{tabular}

$\Pi \quad$ Year ended 30 June

* Student Allowances, Benefits Paid in Australia, Orphans Benefits, Handicapped Child Allowances, Training Incentive Allowances, Independent Youth Benefits

Sources: Vote: Housing, Vote: Revenue, and Vote: Social Development, The Estimates of Appropriations 2004-05, Treasury, Wellington

By excluding expenditure on New Zealand Superannuation and the Widows Benefit and other pensions the expenditure on the working aged can be estimated at $\$ 7,423$ million. This expenditure on the working aged included expenditure of $\$ 1,577$ million on the Domestic Purposes Benefit, $\$ 939$ million on the Unemployment Benefit, $\$ 1,045$ million on the Invalids 
Benefit and $\$ 514$ million on the Sickness Benefit, and $\$ 1,120$ million on the Accommodation Supplement and Income Related Rentals. Expenditure on the Family Support Tax Credit was $\$ 918$ million, the Child Tax Credit $\$ 150$ million, the Parental Tax Credit $\$ 15$ million, and the Family Tax Credit $\$ 14$ million.

Working-aged benefits differ in the emphasis they place upon addressing short-term fluctuations in need, such as temporary loss of employment and support for childrearing, as opposed to longer-term incapacity to work, due to invalidity or sickness. The Domestic Purposes Benefit and the Unemployment Benefit are the largest areas of expenditure on income-tested assistance to working-aged and work-capable people. There have been concerns at the rates at which, in response to increases in the work requirements associated with the Unemployment Benefit and Domestic Purposes Benefit, recipients have switched to the Invalids Benefit and Sickness Benefit in order to remain eligible for assistance. The Invalids Benefit and Sickness Benefit account for significant levels of expenditure.

Significant levels of expenditure are also made through the Family Assistance Tax Credits. The Family Support Tax Credit is the largest single area of social assistance expenditure provided through the tax system. The Family Support Tax Credit is provided to all low-income families with dependent children irrespective of work status. The Child Tax Credit, Family Tax Credit, and Parental Tax Credit are only provided to low-income working families with dependent children. Only a small proportion of social assistance expenditure is provided through the tax system for these low-income working families. Estimated expenditure on all the Family Assistance programmes of $\$ 1,097$ million for 2004-05 was approximately 14.8 percent of total welfare spending on the working aged. Further, the expenditure on the Child Tax Credit, Family Tax Credit, and Parental Tax Credit accounted for 16.3 percent of the total Family Assistance expenditure. Little more than 2.4 percent of total welfare spending on the working aged was assistance provided through the tax system that was only available for families with children in work.

At an estimated total of $\$ 1,120$ million the two major forms of accommodation assistance, the Accommodation Supplement and Income 
Related Rentals, accounted for a proportion of total social assistance expenditure similar to that of the Family Assistance programmes. The Accommodation Supplement remains the main instrument for delivering housing assistance. For both the Accommodation Supplement and Income Related Rentals the majority of assistance goes to recipients of main social welfare benefits [Roper and Greenland, 2002, pp. 47, 55-56].

\section{Working for Families}

On 27 May 2004 the Minister of Social Development, the Hon. Steve Maharey, announced a number of tax-benefit reforms (collectively know as Working for Families) targeting low-wage families with children. These reforms include increases in the rates of the Family Assistance programmes, removal of abatement of the Family Assistance programmes below $\$ 27,500$, the introduction of an hours-based eligibility threshold for the Child Tax Credit (which will also be renamed the In-Work Payment), removal of the child component of main benefits (so that partnered people with children, for example, will receive the same Unemployment Benefit rate as partnered people without children), increases in the Accommodation Supplement, reductions in the abatement of the Accommodation Supplement and the introduction of a new Accommodation Supplement region, and increases in childcare subsidies. (These reforms are described in greater detail in chapter 10.) The government has also announced an intention to introduce single core benefit reforms. Under such a system recipients would receive supplementary assistance on the basis of their need rather than benefit category. Few details are currently available on the single core benefit proposal. This proposal has been signalled for implementation after 1 April 2007.

\subsection{Conclusion}

This chapter considered the evolution of New Zealand's tax-benefit system. The evolution of New Zealand's tax-benefit system was split into three periods, reflecting dominant policy objectives present in the design of policies. Before 1984 an emphasis in policy was placed upon a wage 
earners' welfare state. The shift in policy after 1984 reflected declining economic growth, increasing unemployment and take up of main welfare benefits, falling confidence in the tax system, increasing financing costs for large fiscal deficits, and an ideological shift towards a more residual and targeted social security regime.

Between 1984 and 1999 emphasis changed to reflect a desire for a reduced role of government intervention and improving incentives for beneficiaries to work. Greater emphasis was given to expenditure on targeted assistance for working-aged people. Following reductions in main benefits in 1991 there was a shift in the structure of the system towards supplementary assistance. Indexation of main benefits and not supplementary assistance meant that this shift was not permanent. There were changes in the tax-mix (away from income and towards consumption taxes) and the flattening of the personal income tax scale. However, social assistance expenditure through the tax system has played an increasingly important role in the social assistance system.

Following the election of Labour-led governments since 1999 greater emphasis has been placed on reducing poverty and 'making work pay' more broadly among the population, including secondary earners in families with children. This shift in policy reflected a greater political consensus for alleviating child poverty and improved rates of economic growth. Following the Working for Families reforms and the single core benefit reforms, which are proposed for implementation in 2007, there will be a shift in the structure of the social assistance system towards supplementary assistance. This shift will increase the proportions of social assistance expenditure for which the Family Assistance programmes account, which in 2004-05 had a combined total greater than expenditure on the Unemployment Benefit. 


\section{New Zealand's Family Assistance Tax Credits}

\subsection{Introduction}

The previous chapter discussed the evolution of New Zealand's tax-benefit system. A feature of this evolution was the increasing proportion of total social assistance expenditure provided through the tax system over the last two decades. This chapter discusses the evolution and operation of the major forms of social assistance expenditure through the tax system, which are the Family Assistance Tax Credits. In comparison to other tax-benefit instruments in New Zealand little previous research has been undertaken on these programmes. Section two of this chapter discusses the evolution of the Family Assistance programmes and considers the designs and objectives of the Family Assistance programmes and their antecedents. This is then followed by a discussion on the changing levels of aggregate expenditure on Family Assistance. Section three of the chapter then considers the administration of these programmes. This section includes discussions on calculating entitlement, under-payments and over-payments, and rates of take-up of support. The material in this chapter - along with that in chapters five and seven - forms the basis for the evaluation of the tax-benefit system and current and proposed tax-benefit reforms in parts three and four of this study.

\footnotetext{
* New Zealand has a small number of other tax expenditures, including the Housekeeper Rebate and the Transitional Tax Allowance. These programmes account for low levels of government expenditure and are not discussed in this study.
} 


\subsection{Evolution of the Family Assistance Programmes}

\section{Antecedents to the Family Assistance Programmes}

A system of family allowances was first introduced in New Zealand in 1926 [Campbell, 1927, p. 369]. During the 1930s and 1940s these family allowances were extended in scope. In 1946 the universal Family Benefit was established. This programme was designed to redistribute income to all families with children, not only to alleviate poverty [Royal Commission on Social Policy, 1988, pp. 5-6]. The level of the benefit was not indexed for inflation and so the real value of the benefit was vulnerable to erosion. The Royal Commission on Social Policy [1988, p. 5] estimated that by 1988 the real value of the benefit was 35 percent of its 1979 value. The operation of the benefit is described in table 6.1. The Family Benefit was paid to principal caregivers.

As well as the Family Benefit a number of small tax rebates that aimed to assist low-income breadwinners with the costs of maintaining a family preceded the introduction of the Family Assistance Tax Credits [KoopmanBoyden and Scott, 1984, pp. 63-65, 144-145]. Table 6.1 describes the tax rebates that were in operation during the ten years prior to the introduction of Family Assistance. Until 1984 these rebates were limited to working families, paid to principal income earners, and did not vary according to the number of children in the family. These rebates sought to compensate breadwinners both for the cost of children and for the withdrawal of the secondary earner from the labour market. Rebates abated against a mixture of the primary earner's income, secondary earner's income, and joint caregivers' income. Families with children but who received social welfare benefits, and thus were not eligible for these rebates, could receive supplementary assistance in the form of a Family Maintenance Allowance. 

universal (not targeted by income). In 1976 the value of the payment was $\$ 3$ per-week ( $\$ 156$ per-annum) per-child. The value increased to $\$ 6$ per-week ( $\$ 312$ per-annum) in 1979 and remained at this level until 1991, when the benefit was merged with Family Support. Between 1976 and 1989 eligibility was automatic for children sixteen years or under. The benefit could also be received for older children undertaking schooling. Between 1 January 1989 and 1 April 1991 the automatic qualifying age was lowered to fifteen.

The Young Family Rebate

The Spouse Rebate

The Single-Income Family Rebate

The Low-Income Family Rebate

The Family Rebate

The Principal-Income Earner Rebate

Family Care
Established in 1976. Paid to principal income earners of lowincome families with a child under five. In 1976 the maximum value was $\$ 6$ per-week ( $\$ 312$ per-annum). The value was increased to $\$ 9$ per-week ( $\$ 468$ per-annum) in 1977. Abated against the principal income earner's income in excess of $\$ 13,710$. The level of the rebate did not vary with the number of children.

Established in 1976 (replacing the Dependent Spouse Tax Exemption). Paid to principal income earners. The maximum value was $\$ 3$ per-week ( $\$ 156$ per-annum). Abatement began once secondary earners' incomes reached $\$ 10$ per-week ( $\$ 520$ perannum). The level of the rebate did not vary with the number of children.

Established in 1977. Paid to income earners of low-income and single-income families with a child under ten. Extended to qualifying families with a child under twelve in 1978. The value of the payment was $\$ 4$ per-week ( $\$ 208$ per-annum). The level of the rebate did not vary with the number of children.

Established in 1981 (replacing the Single-Income Family Rebate). Paid to principal income earners and sole-parents. The rebate abated against total joint income. Abatement began once joint income reached $\$ 9,800$. The level of the rebate did not vary with the number of children.

Established in 1983 (replacing the Spouse Rebate, the Young Family Rebate, and the Low-Income Family Rebate). Paid to principal income earners of working families with a dependent child. The maximum value was $\$ 27$ per-week ( $\$ 1,404$ per-annum). Abatement began when joint income reached $\$ 9,800$. The level of the rebate did not vary with the number of children.

Established in 1983. Paid to principal income earners of families without children and families with children (if the level of this rebate exceeded the value of the Family Rebate). Families could not receive both the Principal Income Earner Rebate and the Family Rebate. Abatement began when the individual assessable income of the principal earner reached $\$ 6,118$.

Established in 1984. Paid to principal caregivers of working families. The maximum value was $\$ 10$ per-week ( $\$ 520$ perannum) per-child. Eligible parents had to work a total of 30 hours per-week. Abatement began once joint income exceeded $\$ 20,470$.

Source: Koopman-Boyden and Scott, 1984; Nolan, 2002 
Following increasing concern with poverty among families with children the Family Care programme was established in 1984. As with the Family Benefit, assistance was provided to caregivers to emphasise that this was assistance to compensate for the costs of children, rather than a contribution to the general family budget, and to provide an independent source of income for primary caregivers. The greater costs facing larger families were recognised through providing assistance for every child in the family, although there was no differentiation between older and younger children or between the first and additional children. This programme was subject to problems of take up and the exclusion of beneficiary families was contentious. As well as not receiving a main income-tested benefit families were required to work a total of 30 hours per-week to be eligible for the programme [McClure, 1998, pp. 216-217].

\section{The Family Assistance Programmes}

In 1986 a wide range of tax rebates for families with dependents were replaced with the Family Assistance Tax Credits. The changing levels of assistance, abatement regimes, and eligibility criteria for each of the Family Assistance programmes are discussed below. These refundable tax rebates can be paid either at the end of the income tax year or in fortnightly instalments during the year. In some years policy changes to annual figures came into effect during the income tax year. Figures on the levels of assistance and abatement regimes are provided as annual amounts for the income tax year (1 April to 31 March) as this is the period over which entitlement is calculated. Where policy changes came into effect during the income tax year composite rates (composites of the proportion of the year at the old rate and the proportion at the new rate) are provided. (Levels of assistance and abatement regimes at the dates of policy change can be found in Nolan [2002, pp. 35-36]).

In the tables below figures on the levels of assistance and abatement regimes are provided below in both nominal and inflation adjusted (real) levels. The inflation adjusted figures have been calculated using the Statistics New Zealand CPI index with April 2004 as the base. As this index is influenced by changes to consumption taxes (such as those following the tax- 
mix switch in New Zealand in the 1980s) it has been argued that it is inappropriate for deflating gross incomes, which should be deflated using the CPI index excluding GST [O'Dea, 2000]. However, as the Family Assistance programmes are added to net income the $\mathrm{CPI}$ index is appropriate to use for deflating these levels of assistance. Further, although the Family Abatement thresholds are expressed in gross incomes these thresholds have been deflated with the CPI index to ensure consistency in the index used for both the levels of assistance and thresholds for abatement.

Assistance is paid to the principal caregiver rather than the primary income earner. A principal caregiver is a person deemed to have responsibility for the day-to-day care of a dependent child other than on a temporary basis. A dependent child is someone who is 15 years or younger, 16 or 17 and not working full-time (more than 30 hours per-week) or receiving a main welfare benefit, student allowance, or other government assistance, or 18 years of age and still at secondary school or a tertiary institution. The principal caregiver does not have to be the child's parent [Income Tax Act $2000 s$ OB1]. In a shared custody arrangement there can be more than one principal caregiver. For instance, both parents of a dependent child can qualify as a principal caregiver if they are living apart, they are both qualifying persons, and they care for the dependent child for at least one third of the time throughout the year (or eligible period) [Income Tax Act 2000 s KD2AA]. For Family Assistance purposes the concept of care is based on having responsibility for the child. To be a qualifying person a person has to be aged 16 years or over, a principal caregiver of a dependent child, and satisfy residency requirements. The residency requirements can be met in two ways. Firstly, a person can satisfy these requirements if he or she has been in New Zealand continuously for at least 12 months at any time, is a tax resident, and is present in New Zealand when he or she applies for a

\footnotetext{
Where there is a dispute between separated caregivers, such as over the length of time for which a person is the principal caregiver, the Inland Revenue Department bases the payment to the caregivers on the allocation of responsibility under a custody order or the previous allocation of the payment to the caregivers. It is the responsibility of the caregiver who contests this split of the payment to provide additional factual information to the Inland Revenue Department that demonstrates that the previous allocation no longer applies.
} 
payment. A person can also satisfy these residency requirements by caring for a dependent child who is both a tax resident and present in New Zealand.

\section{Family Support}

Family Support replaced Family Care, the Family Rebate, the Principal Income Earner Rebate, and the Family Maintenance Allowance on 1 October 1986. Family Support is a refundable tax rebate available to low-income and middle-income families irrespective of their work status. The level of the unabated entitlement is based on the number and ages of children in the family. Table 6.2 describes changes in the level of the unabated entitlement and the abatement regime of Family Support. For partnered families this programme abates against joint income of the caregivers. This income is adjusted for the proportion of the income tax year that the family is eligible for the programme (the eligible period). For sole-parent families Family Support abates against the income of the caregiver adjusted for the eligible period. What is counted as income for the purposes of calculating Family Support entitlement and abatement differs from the definitions of income used to calculate social welfare benefit entitlement and abatement and income tax liability.

Since establishment Family Support has provided greater assistance for the eldest child in a family than for additional children. This structure reflects an assumption that due to economies of scale each additional child in the family incurs a lower marginal financial cost to the family. Since 1 April 1989 Family Support entitlement has also reflected the ages of children in the family, with entitlement for older children being greater than that for younger children. This structure reflects an assumption that families' costs increase with the age of children. Since 1986 the degree to which assistance varies with the ages of children has increased. Where a child's age group changes during the income tax year the annual Family Assistance entitlement is a weighted average reflecting the proportions of the eligible period the child is at the younger and older ages. 
Table 6.2: Family Support Unabated Entitlement and Abatement Regime

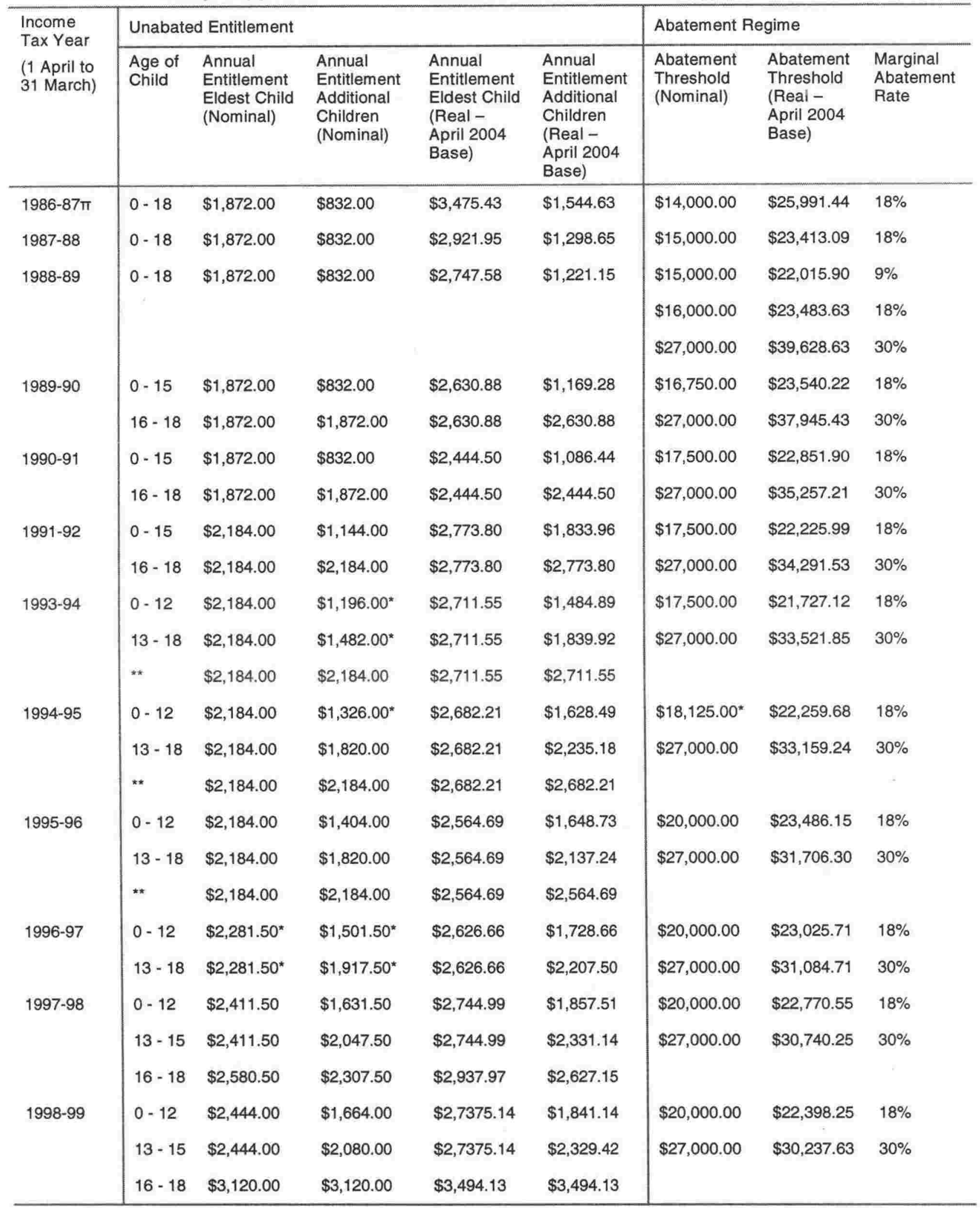


Table 6.2: Family Support Unabated Entitlement and Abatement Regime (Year to 31 March)

\begin{tabular}{|c|c|c|c|c|c|c|c|c|}
\hline \multirow{2}{*}{$\begin{array}{l}\text { Income } \\
\text { Tax Year } \\
\text { (1 April to } \\
31 \text { March) }\end{array}$} & \multicolumn{5}{|c|}{ Unabated Entitlement } & \multicolumn{3}{|c|}{ Abatement Regime } \\
\hline & $\begin{array}{l}\text { Age of } \\
\text { Child }\end{array}$ & $\begin{array}{l}\text { Annual } \\
\text { Entitlement } \\
\text { Eldest Child } \\
\text { (Nominal) }\end{array}$ & $\begin{array}{l}\text { Annual } \\
\text { Entitlement } \\
\text { Additional } \\
\text { Children } \\
\text { (Nominal) }\end{array}$ & $\begin{array}{l}\text { Annual } \\
\text { Entitlement } \\
\text { Eldest Child } \\
\text { (Real - } \\
\text { April 2004 } \\
\text { Base) }\end{array}$ & $\begin{array}{l}\text { Annual } \\
\text { Entitlement } \\
\text { Additional } \\
\text { Children } \\
\text { (Real - } \\
\text { April 2004 } \\
\text { Base) }\end{array}$ & $\begin{array}{l}\text { Abatement } \\
\text { Threshold } \\
\text { (Nominal) }\end{array}$ & $\begin{array}{l}\text { Abatement } \\
\text { Threshold } \\
\text { (Real - } \\
\text { April } 2004 \\
\text { Base) }\end{array}$ & $\begin{array}{l}\text { Marginal } \\
\text { Abatement } \\
\text { Rate }\end{array}$ \\
\hline \multirow[t]{3}{*}{ 2004-05 } & 0.12 & $\$ 2,444.00$ & $\$ 1,664.00$ & $\$ 2,444.00$ & $\$ 1,664.00$ & $\$ 20,356.00$ & $\$ 20,356.00$ & $18 \%$ \\
\hline & $13-15$ & $\$ 2,444.00$ & $\$ 2,080.00$ & $\$ 2,444.00$ & $\$ 2,080.00$ & $\$ 27,481.00$ & $\$ 27,481.00$ & $30 \%$ \\
\hline & $16-18$ & $\$ 3,120.00$ & $\$ 3,120.00$ & $\$ 3,120.00$ & $\$ 3,120.00$ & & & \\
\hline \multirow[t]{3}{*}{ 2005-06 } & $0-12$ & $\$ 3,744.00$ & $\$ 2,444.00$ & $\$ 3,640.36$ & $\$ 2,376.35$ & $\$ 20,356.00$ & $\$ 19,792.51$ & $18 \%$ \\
\hline & $13-15$ & $\$ 3,744.00$ & $\$ 2,860.00$ & $\$ 3,640.36$ & $\$ 2,710.49$ & $\$ 27,481.00$ & $\$ 26,720.28$ & $30 \%$ \\
\hline & $16-18$ & $\$ 4,420.00$ & $\$ 3,900.00$ & $\$ 4,188.94$ & $\$ 3,696.12$ & & & \\
\hline \multirow[t]{3}{*}{$2006-07$} & $0-12$ & $\$ 3,744.00$ & $\$ 2,444.00$ & $\$ 3,548.28$ & $\$ 2,316.24$ & $\$ 27,500.00$ & $\$ 26,062.39$ & $30 \%$ \\
\hline & $13-15$ & $\$ 3,744.00$ & $\$ 2,860.00$ & $\$ 3,548.28$ & $\$ 2,710.49$ & & & \\
\hline & $16-18$ & $\$ 4,420.00$ & $\$ 3,900.00$ & $\$ 4,188.94$ & $\$ 3,696.12$ & & & \\
\hline \multirow[t]{3}{*}{$2006-07^{\star \star *}$} & $0-12$ & $\$ 3,744.00$ & $\$ 2,444.00$ & $\$ 3,548.28$ & $\$ 2,316.24$ & $\$ 35,000.00$ & $\$ 33,170.31$ & $20 \%$ \\
\hline & $13-15$ & $\$ 3,744.00$ & $\$ 2,860.00$ & $\$ 3,548.28$ & $\$ 2,710.49$ & & & \\
\hline & $16-18$ & $\$ 4,420.00$ & $\$ 3,900.00$ & $\$ 4,188.94$ & $\$ 3,696.12$ & & & \\
\hline \multirow[t]{3}{*}{ 2007-08 } & $0-12$ & $\$ 4,264.00$ & $\$ 2,964.00$ & $\$ 3,944.64$ & $\$ 2,742.00$ & $\begin{array}{l}\$ 27,500.00 \\
\text { or }\end{array}$ & $\begin{array}{l}\$ 25,440.33 \\
\text { or }\end{array}$ & $\begin{array}{l}30 \% \\
\text { or }\end{array}$ \\
\hline & $13-15$ & $\$ 4,264.00$ & $\$ 3,380.00$ & $\$ 3,944.64$ & $\$ 3,126.85$ & $\underset{\star \star \star \star}{\$ 35,000.00}$ & $\underset{* \star \star \star}{\$ 32,378.60}$ & $20 \%{ }^{\star * \star}$ \\
\hline & $16-18$ & $\$ 4,940.00$ & $\$ 4,420.00$ & $\$ 4,570.01$ & $\$ 4,088.95$ & & & \\
\hline
\end{tabular}

$\pi \quad$ Only applied for the six months of the 1986-87 income tax year for which Family Support was in place

* Composite annual rate based on the proportions of the income tax year for which the old and the new rates applied

** Provision for those born on or before 30 September 1977 (aged sixteen at the time of the change in policy)

*** Labour Party election proposal (not enacted at completion of study)

Sources: Income Tax Acts (various years), Statistics New Zealand CPI Index (April 2004 base)

In the United Kingdom research has shown that while parents' average spending increases with the age of children this increase was less than that assumed in the age-related scales in benefits and allowances. This research estimated that, for instance, spending on eleven year olds was 86 percent of spending on 16 year olds [Middleton, Ashworth, and Braithwaite, 1997]. Australian research, in contrast, has shown that that the estimated average cost of a child increases with age and with gross joint income. The precise estimates differ according to the methodology employed (e.g., expenditure 
surveys or basket-of-goods approaches) [Saunders, 1999, p. 2]. There is a lack of equivalent research on families' spending on children by age of child in New Zealand. However, spending on younger children is often less discretionary than spending on older children and families with younger children often face particular costs that do not have as great an impact on families with older children (such as funding the withdrawal of a caregiver from the labour market (in New Zealand caregivers tend to re-enter the labour market when children are older)).

In New Zealand's Family Assistance programmes in 2004 the rate for the eldest child aged up to 12 was approximately 78 percent of the rate for a 16 to 18 year-old eldest child. The rate for an additional child aged up to 12 was approximately 53 percent of the rate for an additional child aged 16 to 18. The rate for an additional child aged 13 to 15 was approximately 67 percent of the 16 to 18 rate. In the light of the research in the United Kingdom and the particular costs that face families with younger children, the agerelated scales in the Family Support programme could overcompensate families with older children (particularly for additional children in the family).

Between 1 October 1986 and 1 April 1990 Family Support payments were split equally between spouses in two-spouse families. Since 1 April 1990 Family Support payments have been paid to principal caregivers only. A principal caregiver is a person who is deemed to have responsibility for the day-to-day care of a dependent child other than on a temporary basis. Before 23 June 1987 where spouses were separated only one spouse could receive the Family Benefit and thus Family Support. After this date provision was made for the Family Benefit and thus Family Support to be split between spouses. With the discontinuation of the Family Benefit from 1 April 1991 new criteria for the splitting of Family Assistance Payments were established. Between 1 April 1991 and 1 April 1993 spouses were eligible for these payments provided they were the principal caregiver for four out of every twelve weeks. On 1 April 1993 this provision changed to one third of the income-tax year.

The marginal abatement rates listed in table 6.2 apply for each dollar of gross income for Family Assistance purposes above the corresponding threshold until the entitlement is fully abated. Since 1 April 1989 the Family 
Support abatement rates of 18 and 30 percent have not changed (although the 18 percent rate will be removed on 1 April 2006). Although were a number of changes to the lower abatement threshold, the top abatement threshold applied from incomes in excess of $\$ 27,000$ from 1 April 1988 until 1 April 2004, at which point the threshold increased to $\$ 27,481$. The lower abatement threshold applied to incomes in excess of $\$ 20,000$ from 1 April 1995 until 1 April 2004, at which point the threshold increased to $\$ 20,356$. There have thus been long periods of little change in these rates and thresholds.

Table 6.2 also shows the level of the unabated entitlement and the abatement regime of Family Support adjusted for inflation. The real levels of Family Support and abatement thresholds illustrate the consequences of the long periods of little policy change to these programmes. In real terms the $\$ 27,000$ threshold for 30 percent abatement in $1988-89$, for example, was equivalent to approximately $\$ 40,000$ in 2004-05. This effective shift in the threshold increased the numbers of people facing higher abatement of their Family Assistance entitlement. A second way that inflation impacts on families' Family Assistance entitlement is through eroding the real value of assistance [St John and Craig, 2004, pp. 40-41]. Over the period from 1991 to 1999 the Family Support levels largely retained their real value due to the Hand Up package, which was phased in from 1 April 1996, and in real terms the rates for children aged 16 to 18 increased. In the period from 1999 to 2005 there was a notable drop in the value of the assistance.

Following Working for Families, however, the value of assistance will increase in real terms. On 1 April 2005 the Family Support rate for the eldest child increased by $\$ 25$ per-week and the rate for additional children by $\$ 15$ per-week. From 1 April 2006 Family Support will only abate against income in excess of $\$ 27,500$ at a rate of 30 percent. The final component of the Working for Families reforms is a $\$ 10$ per-week per-child increase in Family Support from 1 April 2007. However, some of this increase will be eroded by inflation between 1 April 2005 and 1 April 2007 due to the delay in implementing the inflation adjustment of the programmes. From 1 April 2007 the Family Assistance rates and thresholds will be increased in line with the 
CPI whenever inflation increases reach a total of 5 percent or more. Yet no account will be made for inflation between 1 April 2005 and 1 April 2007.

\section{Family Tax Credit}

The Guaranteed Minimum Family Income was introduced with Family Support on 1 October 1986. The Guaranteed Minimum Family Income was renamed the Family Tax Credit on 1 October 1999. This refundable tax rebate is one of the Family Plus Tax Credits (along with the Child and Parental Tax Credits), which are only available to working families. This rebate ensures a minimum net income before Family Assistance for working families with dependent children and abates dollar-for-dollar against the combined net income of both caregivers or, for sole-parent families, the income of the caregiver adjusted for the eligible period. The structure of the programme is similar to that of a negative income tax and provides an income guarantee for working families. Reflecting the design of the rebate as an income guarantee for low-income workers the rebate was paid to the primary earner until 1 April 2003. Since this date the rebate has been paid to the principal caregiver, as this is the approach taken for the other Family Assistance programmes.

Between 1 October 1986 and 1 April 1991 to be eligible for the rebate a family needed to satisfy the conditions for the receipt of the Family Benefit (see table 6.1), have a joint income below the guaranteed minimum income, be independent from income-tested benefits, and satisfy a work test. Incometested benefits include the Domestic Purposes Benefit, Widows Benefit, Transitional Retirement Benefit, Invalids Benefit, Independent Youth Benefit, Emergency Benefit, and Unemployment Benefit. Recipients of assistance under the public accident compensation scheme (ACC) became ineligible for the rebate once they received ACC payments for three months or more. The work test required sole-parents to work at least twenty hours per-week and two-parent families a combined total of at least thirty hours. Families were eligible for the rebate only for the proportion of the year for which they satisfied this work test. Information on hours and weeks of work was not audited independently of the general taxpayer audit process. With the removal of the Family Benefit from 1 April 1991 additional eligibility criteria for 
the rebate were introduced based on principal responsibility for the day-today care of dependent children.

Table 6.3: Family Tax Credit Unabated Entitlement and Abatement Regime

\begin{tabular}{llll}
\hline Income Tax Year & $\begin{array}{l}\text { Annual } \\
\text { (1 April to 31 March) } \\
\text { Muaranteed } \\
\text { Familym } \\
\text { (Nominal) }\end{array}$ & $\begin{array}{l}\text { Annual } \\
\text { Guaranteed } \\
\text { Minimum } \\
\text { Family Income } \\
\text { (Real - April } \\
\text { 2004 Base) }\end{array}$ & $\begin{array}{l}\text { Marginal } \\
\text { Abatement } \\
\text { Rate }\end{array}$ \\
\hline $1986-87^{\pi}$ & $\$ 10,816.00$ & $\$ 20,080.25$ & $100 \%$ \\
$1987-88$ & $\$ 11,856.00$ & $\$ 18,505.71$ & $100 \%$ \\
$1988-89$ & $\$ 13,416.00$ & $\$ 19,691.02$ & $100 \%$ \\
$1989-90$ & $\$ 13,936.00$ & $\$ 19,585.47$ & $100 \%$ \\
$1990-91$ & $\$ 14,456.00$ & $\$ 18,876.97$ & $100 \%$ \\
$1996-97$ & $\$ 14,690.00^{*}$ & $\$ 16,912.38$ & $100 \%$ \\
$1997-98$ & $\$ 14,768.00$ & $\$ 16,813.78$ & $100 \%$ \\
$1998-99$ & $\$ 15,002.00^{*}$ & $\$ 16,821.08$ & $100 \%$ \\
$1999-2000$ & $\$ 15,080.00$ & $\$ 16,949.92$ & $100 \%$ \\
$2006-07$ & $\$ 17,000.00$ & $\$ 15,726.75$ & $100 \%$ \\
\hline
\end{tabular}

"Only applied for the six months of the 1986-1987 income tax year for which the Family Tax Credit was in place

* Composite annual rate based on the proportions of the income tax year for which the old and the new rates applied

Sources: Income Tax Acts (various years), Statistics New Zealand CPI Index (April 2004 base)

What is counted as income for the purposes of calculating the Family

Tax Credit entitlement and abatement differs from the definitions of income used to calculate social welfare benefit entitlement and abatement and income tax liability. The guaranteed minimum income is the net income before the payment of Family Support, the Child Tax Credit, and the Parental Tax Credit. Table 6.3 shows the guaranteed minimum family income. Since 1 October 1986 the level of the guaranteed minimum family income has been the same for all families with children and assistance has abated at a marginal abatement rate of 100 percent above this threshold. The annual guaranteed family income was increased annually from 1 October 1986 until 1 April 1990. The guaranteed income was next increased regularly from 1 April 1996 until 1 April 1999. From 1 April 2006 the guaranteed minimum income will increase to $\$ 17,000$ per-annum after a period of erosion in the real value of the programme. 


\section{Child Tax Credit/ln-Work Payment}

The Independent Family Tax Credit was introduced on 1 July 1996. The Independent Family Tax Credit was renamed the Child Tax Credit on 1 April 1999. This refundable tax rebate is one of the Family Plus Tax Credits (along with the Parental and Family Tax Credits), which are only available to working families. The rebate is paid to low-income families that are independent from state assistance (not receiving an income-tested benefit). Families are only eligible for the Child Tax Credit for the proportion of the income tax year for which they are independent from main income-tested benefits. The rebate is paid to principal caregivers. If custody is shared the rebate may be split according to the proportion of the income tax year that each spouse is the principal caregiver. To be eligible for a payment a spouse must be the principal caregiver for at least one third of the income tax year. The levels of the unabated entitlement are listed in table 6.4.

Table 6.4: Child Tax Credit/In-Work Payment Unabated Entitlement and Abatement Regime

\begin{tabular}{llll}
\hline $\begin{array}{l}\text { Income Tax Year } \\
\text { (1 April to 31 March) }\end{array}$ & $\begin{array}{l}\text { Annual Entitlement } \\
\text { Per-Child/Family } \\
\text { (Nominal) }\end{array}$ & $\begin{array}{l}\text { Annual Entitlement } \\
\text { Per-Child/Family (Real } \\
- \text { April 2004 Base) }\end{array}$ & $\begin{array}{l}\text { Abatement } \\
\text { Regime }\end{array}$ \\
\hline $1996-97^{\pi}$ & $\$ 390.00$ & $\$ 449$ & $\begin{array}{l}\text { Family Support } \\
\text { regime }\end{array}$ \\
$1997-98$ & $\$ 682.50^{*}$ & $\$ 777.05$ & $\begin{array}{l}\text { Family Support } \\
\text { regime }\end{array}$ \\
$1998-99$ & $\$ 780.00$ & $\$ 873.53$ & $\begin{array}{l}\text { Family Support } \\
\text { regime }\end{array}$ \\
$2006-07$ & $\begin{array}{l}\$ 3,120.00 \text { Per-Family } \\
\$ 780.00 \text { Fourth+ } \\
\text { Child }\end{array}$ & $\begin{array}{l}\$ 2,886.32 \text { Per-Family } \\
\$ 721.58 \text { Fourth+ } \\
\text { Child }\end{array}$ & $\begin{array}{l}\text { Family Support } \\
\text { regime }\end{array}$ \\
\hline
\end{tabular}

"Only applied for the nine months of the 1996-97 income tax year for which the Child Tax Credit was in place

* Composite annual rate based on the proportions of the income tax year for which the old and the new rates applied

Sources: Income Tax Acts (various years), Statistics New Zealand CPI Index (April 2004 base)

The level of the Child Tax Credit remained unchanged from 1 April 1998. An increase planned for 1 April 1997 was phased in over two years due to changes in the Government's fiscal position following an economic downturn [Boston and Church, 2002, p. 30]. For abatement purposes the Child Tax Credit is added to Family Support and the Parental Tax Credit (if applicable). This total amount abates following the thresholds and rates in 
table 6.2 and using the same definition of income as Family Support. Under the Working for Families reforms, from 1 April 2006 the Child Tax Credit will be paid at a rate of $\$ 60$ per-week per-family with a top-up of $\$ 15$ for the fourth and every additional child. Eligibility will require independence from main forms of state assistance and satisfying an hours based work test of 20 hours per-week for sole-parents and 30 hours per-week for partnered families. The programme will be renamed the In-Work Payment. In real terms the add-on for the fourth and additional child will be less than the 1998 perchild rate. However, the unabated assistance for the first three children will be greater than the 1998 per-child rate.

\section{Parental Tax Credit}

The Parental Tax Credit was introduced on 1 October 1999. This programme was a response to increasing political pressure for the introduction of publicly funded paid paternal leave [Liebschutz, 1999], which was later introduced in 2002. This refundable tax rebate is one of the Family Plus Tax Credits (along with the Child and Family Tax Credits) that are only available to working families. The rebate is paid to low-income families that are independent from state assistance (not receiving an income-tested benefit) for the first eight weeks after the birth of the child. Families are only eligible for the Parental Tax Credit for the proportion of the eight-week period that they are independent from main income-tested benefits. Families cannot receive both the Parental Tax Credit and publicly funded paid parental leave.

Table 6.5: Parental Tax Credit Unabated Entitlement and Abatement Regime

\begin{tabular}{llll}
\hline $\begin{array}{l}\text { Income Tax Year } \\
\text { (1 April to 31 March) }\end{array}$ & $\begin{array}{l}\text { Annual Entitlement } \\
\text { Per-Family } \\
\text { (Nominal) }\end{array}$ & $\begin{array}{l}\text { Annual Entitlement } \\
\text { Per-Family (Real - } \\
\text { April 2004 Base) }\end{array}$ & $\begin{array}{l}\text { Abatement } \\
\text { Regime }\end{array}$ \\
\hline $1999-2000$ & $\$ 1,200.00$ & $\$ 1,348.80$ & $\begin{array}{l}\text { Family } \\
\text { Support } \\
\text { regime }\end{array}$ \\
\hline
\end{tabular}

Sources: Income Tax Act (2000), Statistics New Zealand CPI Index (April 2004 base)

The rebate is paid to principal caregivers. If custody is shared the rebate may be split according to the proportion of the eight-week period that each spouse is the principal caregiver. To be eligible for a payment a spouse must be the principal caregiver for at least one third of the eight-week period. Where the eight-week period occurs over two income tax years the rebate is 
split between the two years and each instalment is assessed against the specified income for the appropriate year [Income Tax Act 2000 s KD 2 (6)].The unabated rebate provides an end-of-year sum of $\$ 1,200$ or $\$ 150$ perweek for the eight weeks following the birth of a child. For abatement purposes the Parental Tax Credit is added to Family Support and the Child Tax Credit. This total amount abates following the abatement thresholds and rates in table 6.2 and using the same definition of income as Family Support.

\section{Aggregate Expenditure on the Family Assistance Programmes}

Table 6.6 presents data on the fiscal cost of the Family Assistance programmes and the Family Benefit. The entire Family Assistance Vote goes to the Inland Revenue Department. The Ministry of Social Development makes a weekly request to Inland Revenue Department for a cash transfer to fund Family Assistance payments to beneficiaries. The Family Assistance programmes are treated as expenditure in the national accounts.

The Family Benefit was paid until 1991-92, at which point the benefit was integrated with Family Support payments. Reflecting the greater targeting of the Family Support programmes the increase in Family Support from 1990-91 to 1991-92 was less than the reduction in the Family Benefit. Family Support payments were estimated to have a fiscal cost of $\$ 918$ million in 2004-05. Family Support payments were available to low-income families irrespective of their work status. The Family Plus Tax Credits were estimated to have a fiscal cost of $\$ 179$ million in 2004-05. The largest Family Plus Tax Credit was the Child Tax Credit.

Illustrating the effect of credit corrosion due to inflation (discussed above) the real level of expenditure on Family Assistance declined during the early 1990s and then increased following the Hand-Up package of tax reductions and increases in Family Assistance from 1996 to 1998. Since 1 April 1999 there has been little change to the parameters of the Family Assistance programmes and consequently real Family Assistance expenditure has declined since this date. 
Table 6.6: Family Benefit and Family Assistance Fiscal Cost (\$ Million)

\begin{tabular}{llllllll}
\hline Year $\pi$ & $\begin{array}{l}\text { Family } \\
\text { Benefit }\end{array}$ & $\begin{array}{l}\text { Family } \\
\text { Support }\end{array}$ & $\begin{array}{l}\text { Family } \\
\text { Tax } \\
\text { Credit }\end{array}$ & $\begin{array}{l}\text { Child } \\
\text { Tax } \\
\text { Credit }\end{array}$ & $\begin{array}{l}\text { Parental } \\
\text { Tax } \\
\text { Credit }\end{array}$ & $\begin{array}{l}\text { Total } \\
\text { Nominal }\end{array}$ & $\begin{array}{l}\text { Total } \\
\text { Real }\end{array}$ \\
\hline $1986-87$ & $\$ 273.3$ & $\$ 186.9$ & N/A & N/A & N/A & $\$ 460.2$ & $\$ 854.4$ \\
$1987-88$ & $\$ 290.6$ & $\$ 403.4$ & N/A & N/A & N/A & $\$ 694.0$ & $\$ 1083.3$ \\
$1988-89$ & $\$ 258.4$ & $\$ 439.3$ & N/A & N/A & N/A & $\$ 697.7$ & $\$ 1024.0$ \\
$1989-90$ & $\$ 284.4$ & $\$ 465.0$ & N/A & N/A & N/A & $\$ 749.4$ & $\$ 1053.2$ \\
$1990-91$ & $\$ 223.0$ & $\$ 472.0$ & N/A & N/A & N/A & $\$ 695.0$ & $\$ 907.6$ \\
$1991-92$ & N/A & $\$ 618.0$ & N/A & N/A & N/A & $\$ 618.0$ & $\$ 784.9$ \\
$1992-93$ & N/A & $\$ 577.3$ & N/A & N/A & N/A & $\$ 577.3$ & $\$ 725.8$ \\
$1993-94$ & N/A & $\$ 609.4$ & N/A & N/A & N/A & $\$ 609.4$ & $\$ 857.2$ \\
$1994-95$ & N/A & $\$ 700.1 * *$ & N/A & N/A & N/A & $\$ 700.1$ & $\$ 859.8$ \\
$1995-96$ & N/A & $\$ 748.3$ & N/A & N/A & N/A & $\$ 748.3$ & $\$ 878.7$ \\
$1996-97$ & N/A & $\$ 777.0$ & $\$ 8.2$ & $\$ 40.5$ & N/A & $\$ 825.7$ & $\$ 950.6$ \\
$1997-98$ & N/A & $\$ 874.4$ & $\$ 6.6$ & $\$ 121.4$ & N/A & $\$ 1002.4$ & $\$ 1141.3$ \\
$1998-99$ & N/A & $\$ 906.5$ & $\$ 8.2$ & $\$ 161.9$ & N/A & $\$ 1076.6$ & $\$ 1205.7$ \\
$1999-$ & N/A & $\$ 899.0$ & $\$ 10.6$ & $\$ 167.0$ & $\$ 6.8$ & $\$ 1083.4$ & $\$ 1217.7$ \\
2000 & & & & & & & \\
$2000-01$ & N/A & $\$ 860.7$ & $\$ 17.3$ & $\$ 161.3$ & $\$ 17.2$ & $\$ 1056.5$ & $\$ 1164.2$ \\
$2001-02$ & N/A & $\$ 870.0$ & $\$ 12.0$ & $\$ 159.0$ & $\$ 19.0$ & $\$ 1060.0$ & $\$ 1131.5$ \\
$2002-03$ & N/A & $\$ 922.0$ & $\$ 13.0$ & $\$ 156.0$ & $\$ 17.0$ & $\$ 1108.0$ & $\$ 1151.0$ \\
$2003-04$ & N/A & $\$ 805.0$ & $\$ 14.0$ & $\$ 152.0$ & $\$ 14.0$ & $\$ 985.0$ & $\$ 1008.3$ \\
$2004-$ & N/A & $\$ 918.0$ & $\$ 15.0$ & $\$ 150.0$ & $\$ 14.0$ & $\$ 1097.0$ & $\$ 1097.0$ \\
$05^{\star * * ~}$ & & & & & & & \\
\hline
\end{tabular}

$\pi$ Prior to $1989-90$ the year ended 31 March; from 1989-90 onwards the year ended 30 June

* The Family Tax Credit was recorded together with Family Support until 1996-97

** The increase from 1993-94 to 1994-95 partly reflected the shift from cash to accrual accounting after 30 June 1994

*** Contained in the 2004-05 Estimates of Annual Appropriations. Actual out-turns may differ from the figures listed

Sources: Government of New Zealand, various years, Estimates of Annual Appropriations and Departmental Budgets of the Government of New Zealand; Inland Revenue Department, various years, Inland Revenue Annual Report, Ministry of Social Development, 2001, Social Services Statistical Report, Table 14; Statistics New Zealand CPI Index (April 2004 base) 


\subsection{Estimating Entitlement and Take-Up}

\section{Taxation and Abatement of Social Welfare Benefits}

Due to the interaction of the Family Assistance programmes with main welfare benefits and the personal income tax system, calculating entitlement to the Family Assistance programmes can be complex. Social welfare benefit levels are set and paid to recipients as net amounts. Personal income tax on the benefit income is then calculated to give gross benefit levels. Income tax is calculated on benefits to ensure that the full costs of benefits are reported in government accounts and that beneficiaries face similar tax rates on additional earnings as low-income earners not receiving a benefit.

When beneficiaries receive non-benefit earnings their net unabated benefit ( $b$ ) abates against gross non-benefit earnings $\left(e_{G}\right)$. Abatement of the net benefit $\left(b_{A}\right)$ is based on gross earnings and equals the net benefit abatement rate $\left(r_{\mathrm{B}}\right)$ multiplied by the level of the gross non-benefit earnings above the gross threshold at which abatement begins (the level of the earnings disregard $\left(d_{B}\right)$ below which non-benefit earnings do not reduce the net benefit).

$$
b_{A}=\left(e_{G}-d_{B}\right) r_{B}
$$

Subtracting benefit abatement from the net unabated benefit results in the net benefit after abatement $\left(b_{N}\right)$.

$$
b_{N}=b-b_{A}
$$

The net benefit after abatement is then increased for personal income taxes on the benefit $\left(t_{B}\right)$ to give the level of the gross abated benefit $\left(b_{G}\right)$.

$$
b_{G}=b_{N} /\left(1-t_{B}\right)
$$

The gross non-benefit earnings $\left(e_{G}\right)$ are reduced by personal income tax on non-benefit income $(t)$ and the ACC earner account levy (ACC) to give the net non-benefit earnings $\left(e_{N}\right)$.

$$
e_{N}=e_{G}(1-(t+A C C))
$$

For beneficiaries, non-benefit earnings are taxed under the secondary tax regime at 21 percent. The secondary tax is a withholding tax so any excessive tax withheld during the year is returned at the end of the income 
tax year. The tax on the gross abated benefit and the non-benefit earnings are calculated separately as the tax rate applying to the benefit income may differ from the tax rate applying to non-benefit earnings. Differences in the tax rates applying to benefit and non-benefit income occur when a beneficiary's annual gross benefit income is below a personal income tax threshold yet non-benefit earnings increase total gross income to above the threshold. Under the current personal income tax scale such a difference would occur if a beneficiary receives a gross abated benefit below $\$ 9,500$ along with nonbenefit income that increases total gross income to above $\$ 9,500$.

\section{Entitlement to the Family Assistance Programmes}

Net income before Family Assistance (y) equals the net benefit after abatement $\left(b_{N}\right)$ plus net non-benefit earnings $\left(e_{N}\right)$.

$$
y=b_{N}+e_{N}
$$

For Family Assistance purposes a number of income adjustments $\left(\mathrm{y}_{\mathrm{F}}\right)$ are made to net income before Family Assistance. Some income that is exempt from income tax is not exempt for Family Assistance purposes, such as child support transfers and maintenance payments. Conversely some deductions that are allowable under the general income tax rules are not allowed for Family Assistance purposes, such as business adjustments. The income adjustments are made on application for Family Assistance and are also part of the end-of-year square-up process. Inland Revenue have estimated that, based on data for part of the 2000-01 income tax year, business adjustments accounted for a large majority of the adjustments ( 76.2 percent of the total adjustments), followed by child support (13.6 percent), and maintenance payments (9.9 percent) [Inland Revenue Department, 2002]. These income adjustments lead to net specified income for Family Assistance purposes ( $\left.y_{s}\right)$.

$$
y_{S}=y-y_{F}
$$

\footnotetext{
"The Family Assistance registration form collects information on the receipt and payment of child support payments. This includes both payments made via the Inland Revenue Department and payments made by private arrangement. The Inland Revenue Department checks child support payments made via the Inland Revenue Department automatically. Payments made by private arrangements are not audited separately from the general taxpayer audit process. Child support payments made are subtracted from income for Family Assistance abatement purposes. Child support payments received are added to income for Family Assistance abatement purposes.
} 
Both entitlement for and abatement of Family Assistance is adjusted for the number of days of eligibility during the income tax year (the eligible period $\left.\left(\mathrm{p}_{\mathrm{F}}\right)\right)$. There are two periods of the income tax year, which may or may not differ, for Family Assistance purposes. The specified period is an unbroken period where the recipient is eligible for some form of Family Assistance. The eligible period is an unbroken period where the applicant meets all four of the following criteria:

- the applicant is a qualifying person;

- the applicant is a principal caregiver;

- the applicant has an unchanging marital status during the period; and

- the applicant is making the claim in relation to a dependent child or dependent children [Income Tax Act 2000 s OB 1].

For example, the specified period for a family that is eligible for some form of Family Assistance during the full income tax year would be the full income tax year. However, if the nature of the family's entitlement changes during the year due to, for example, a change in the number of dependent children in the family the specified period would be made up of more than one eligible period. If a family with one child adopts an additional child during the year they will have two eligible periods; one period where entitlement is based on one child and one period where entitlement is based on two children.

The criteria used to calculate the eligible period differ among the four Family Assistance programmes. For Family Support purposes the eligible period is based on the four standard criteria above. As well as these four standard criteria the eligible period for the Child Tax Credit and the Parental Tax Credit is also based on the number of weeks the recipient's family is independent from main income-tested benefits. For the Family Tax Credit the eligible period is based on the four standard criteria, the number of weeks the recipient's family is independent from main income-tested benefits, and the number of weeks the recipient's family satisfies an hours-based work test of a total of 30 hours for partnered families and 20 hours for sole-parents.

The assessment period for the Family Assistance programmes is the income tax year adjusted for the proportion of the year that the recipient is eligible for the programmes. This allows taxable income, subject to a number of income adjustments, to be used for calculating entitlement and abatement. 
However, over-payments and under-payments of Family Assistance can arise for families paid during the year because the entitlement is based on income at time of application and then projected forward until the end of the tax year, at which time payments made during the year and actual entitlement are reconciled.

The full year abatement rate $\left(r_{F}\right)$ is adjusted for the eligible period $\left(p_{F}\right)$ to give the abatement rate for the eligible period $\left(r_{\mathrm{p}}\right)$.

$$
r_{P}=r_{F}\left(p_{F} / 365\right)
$$

Implications of basing abatement rates as well as the level of entitlement on the eligible period are that the programmes are received by higher income earners who are eligible for short periods of the income tax year (if, for example, a child is born late in the year) and the entitlement can vary significantly from year to year.

There are two Family Assistance entitlement and abatement regimes; that applying to the Family Tax Credit and that applying to the Family Support Tax Credit, the Child Tax Credit, and the Parental Tax Credit. The Family Tax Credit pays the difference between net specified income and the net guaranteed minimum income. The rebate abates dollar for dollar against increases in family net specified income. Family Support, the Child Tax Credit, and the Parental Tax Credit are added together and this total figure abates against gross specified income. Family Support is the first payment to abate, followed by the Child Tax Credit and then the Parental Tax Credit. Family Support, the Child Tax Credit, and the Parental Tax Credit entitlements equal the unabated rebates minus abatement. This abatement is the abatement rate multiplied by the level of the gross specified income, which is the net specified income increased for personal income taxes, above the gross abatement threshold. The four abated rebates are added together to give the total Family Assistance (FA) entitlement.

$$
\mathrm{FA}=\mathrm{FS}+\mathrm{CTC}+\mathrm{PTC}+\mathrm{FTC}
$$

This Family Assistance entitlement is then added to net specified income giving a net income including Family Assistance ( $\left.\mathrm{y}_{\mathrm{N}}\right)$.

$$
\mathrm{y}_{\mathrm{N}}=\mathrm{y}_{\mathrm{S}}+\mathrm{FA}
$$


Income from the Family Assistance Tax Credits does not increase gross taxable income for the person to whom the rebate is paid [Income Tax Act $2000 s \mathrm{KD} 8]$. Thus the marginal tax rates applying to additional benefit income and non-benefit earnings are those applying to gross income excluding Family Assistance.

\section{Family Assistance Payment Periods and Under-Payments and Over- Payments}

Family Assistance payments can be received fortnightly during the year or as a lump sum at the year-end. Around half of the Family Support payments made by the Inland Revenue Department (a quarter of the total Family Support payments) are paid at year-end [Nolan, 2002]. Payment during the year can be by cheque or bank transfer. A year-end payment can take the form of a cheque or bank transfer or through a reduction in the tax payable by the recipient. The taxpayer may also elect for any end of year payment to be offset to another taxpayer.

The assessment period for the programmes is the income tax year adjusted for the proportion of the year that the recipient is eligible for the programmes. This allows taxable income to be used for calculating entitlement and abatement. People receiving their entitlement from the Inland Revenue Department have their entitlement reconciled when their taxable income is known at year-end. Beneficiaries who receive their entitlement from the Ministry of Social Development can have their Family Assistance entitlement reconciled at year-end by requesting an income tax reconciliation.

Over-payments and under-payments of Family Assistance can arise for families paid during the year because the entitlement is based on income at time of application and then projected forward until the end of the tax year. Families can be underpaid or overpaid Family Assistance during the year if, for example, they change their income, caregiver status, or marital status and do not inform the Ministry of Social Development or the Inland Revenue Department. Families who are overpaid during the year incur a debt with the Inland Revenue Department. Families who are underpaid during the year can receive their additional entitlement in a year-end payment. To reduce the extent of overpayments, legislation contains an uplift factor, where the 
previous year's income is increased to account for the likely increase in the family's income. The uplift factors are contained in schedule 12 of the Income Tax Act 2000.

Table 6.7 contains data compiled by the Inland Revenue Department on the numbers of recipients underpaid and overpaid during the year to March 2001. Data from more recent years were not available for this study. These figures lack information on some recipients paid during the year by the Ministry of Social Development. This lack of information is due to both the failure of some of these people to file tax returns and to the incomplete nature of the information on these people provided to the Inland Revenue Department when tax returns are filed. The table shows that numbers of taxpayers underpaid and overpaid are roughly equal. Table 6.7 also shows that the majority (85 percent) of the recipients of the Family Assistance programmes chose to take-up assistance at during the year. Of all Family Assistance recipients, 56 percent were paid by the Ministry of Social Development, 22 percent by the Inland Revenue Department, and seven percent by both the Ministry of Social Development and the Inland Revenue Department at different times during the year (these were people who moved between benefit and work within the income tax year).

Administrative changes made by the Inland Revenue Department since 2001 are likely to mean that the incidence of underpayments and overpayments (and consequently taxpayer debt) is likely to have fallen. Since October 2002 the Inland Revenue Department has developed the Proactive Actions programme. This programme monitors the incomes of Family Assistance recipients contained in monthly schedules provided by employers and reconciles this against income estimates provided upon application for Family Assistance. Where discrepancies are identified the income estimates for Family Assistance are revised [Inland Revenue Department, 2003, p. 3]. The Inland Revenue Department has also developed new debt and hardship rules, which allow the agency to write-off debt where its enforcement would lead to hardship or require an inefficient use of departmental resources [Inland Revenue Department, 2003, p. 3]. 
Table 6.7: Timing and Accuracy of Family Assistance Payments (Year to 31 March 2001)

\begin{tabular}{|c|c|c|c|c|}
\hline $\begin{array}{l}\text { Agency and } \\
\text { Timing of } \\
\text { Payment }\end{array}$ & $\begin{array}{l}\text { Payment } \\
\text { accurate to } \\
\text { within } \$ 100\end{array}$ & $\begin{array}{l}\text { Underpaid during } \\
\text { the year } \\
\text { (more than } \$ 100 \text { ) }\end{array}$ & $\begin{array}{l}\text { Overpaid during } \\
\text { the year } \\
\text { (more than } \\
\$ 100 \text { ) }\end{array}$ & Total \\
\hline $\begin{array}{l}\text { MSD Paid During } \\
\text { Year (No Tax } \\
\text { Return Filed) }\end{array}$ & $117,450 \pi$ & 0 & 0 & 117,450 \\
\hline $\begin{array}{l}\text { MSD Paid During } \\
\text { Year (Tax Return } \\
\text { Filed) }\end{array}$ & 31,260 & 12,960 & 9,780 & 54,000 \\
\hline $\begin{array}{l}\text { IRD Paid During } \\
\text { Year }\end{array}$ & 9,490 & 28,660 & 28,780 & 66,930 \\
\hline $\begin{array}{l}\text { Both MSD and } \\
\text { IRD Paid During } \\
\text { Year }\end{array}$ & 2,120 & 6,440 & 12,400 & 20,960 \\
\hline $\begin{array}{l}\text { Total Paid During } \\
\text { Year }\end{array}$ & 160,320 & 48,060 & 50,960 & 259,340 \\
\hline Paid at Year-End & 46,100 & 0 & 0 & 46,100 \\
\hline Total & 206,420 & 48,060 & 50,960 & 305,450 \\
\hline \multicolumn{5}{|l|}{ Percentages } \\
\hline $\begin{array}{l}\text { MSD Paid During } \\
\text { Year (No Tax } \\
\text { Return Filed) }\end{array}$ & 100.0 & 0.0 & 0.0 & 100.0 \\
\hline $\begin{array}{l}\text { MSD Paid During } \\
\text { Year (Tax Return } \\
\text { Filed) }\end{array}$ & 57.9 & 24.0 & 18.1 & 100.0 \\
\hline $\begin{array}{l}\text { IRD Paid During } \\
\text { Year }\end{array}$ & 14.2 & 42.8 & 43.0 & 100.0 \\
\hline $\begin{array}{l}\text { Both MSD and } \\
\text { IRD Paid During } \\
\text { Year }\end{array}$ & 10.1 & 30.7 & 59.2 & 100.0 \\
\hline $\begin{array}{l}\text { Total Paid During } \\
\text { Year }\end{array}$ & 57.0 & 18.5 & 19.7 & 100.0 \\
\hline Paid at Year-End & 100.0 & 0.0 & 0.0 & 100.0 \\
\hline Total & 67.6 & 15.7 & 16.7 & 100.0 \\
\hline
\end{tabular}

$\pi$ Includes 12,510 recipients whose entitlements could not be reconciled at year-end due to insufficient information

Source: Inland Revenue Department estimates (based on a sample of March 2001 tax returns, personal tax summaries and IR348s)

\section{Estimates of Family Assistance Participation Rates}

Measures such as eliminating the need for the majority of personal taxpayers to file annual tax returns (IR5 forms) reduced the costs facing taxpayers of complying with the tax system. However, the annual tax returns process also played a role in indicating Family Assistance entitlement to potential recipients and to the Inland Revenue Department. Reducing the Inland 
Revenue Department's contact with personal taxpayers has therefore potentially increased the importance of the Family Assistance application process for the take-up of the rebates. Non take-up occurs when, for some number of people, the amount they receive from social assistance programmes is less than the amount they are entitled to receive. There are also a number of people who receive more than their entitlement (due to factors such as administrative error and taxpayer fraud). Non take-up and overpayments have implications for both the design and evaluation of social assistance programmes [Riphahn, 2001, p. 379; Creedy, 2002, p. 151].

There are few estimates of the level and causes of non-take-up of Family Assistance. The Inland Revenue Department has calculated estimates of the take-up of Family Assistance by comparing numbers of recipients with approximations of numbers eligible from the 2001 Census [Ministry of Social Development, 2003]. The eligible population is difficult to estimate due to limitations to the Census data, particularly as income bands are only available in $\$ 10,000$ increments. From the 2001 Census data the Inland Revenue Department estimated that some 174,000 families were eligible to receive Family Assistance payments from the Inland Revenue Department. This compares with approximately 160,000 families who were assessed for Family Assistance, giving a figure of about 92 percent take-up. From this data there were no identifiable sub-group of the population who were excluded from Family Assistance coverage. This relatively high estimate of Family Assistance take-up can be explained by the design and administration of the programmes.

- Only one application form is required for the Family Assistance programmes. Annual reapplications are not required. The Family Support programme is targeted on the basis of relatively straightforward criteria. Full-year beneficiaries receive their Family Support automatically from the Ministry of Social Development. Family Support accounts for the majority of spending on the Family Assistance programmes. High take-up rates for Family Support are likely to be reflected in high take-up rates for Family Assistance.

- Overpayments, underpayments, or non-take-up are most likely to arise when a person moves on and off a main social welfare benefit. The 
Inland Revenue Department and the Ministry of Social Development have recently enhanced their exchange of information. Thus, for example, when a person exits a main benefit the Inland Revenue Department is informed, up to date income information is obtained from the person, and interim payments of the Child Tax Credit may be made [Inland Revenue Department, 2003, p. 4]. This exchange of information is likely to ensure higher take-up of the Child Tax Credit.

- The use of hours-based thresholds for the Family Tax Credit could, however, affect take-up for this programme. The Inland Revenue Department can update information on incomes and benefit receipt without the taxpayer filing additional information. Informing the Inland Revenue Department of changes in hours of work, in contrast, requires a taxpayer to file additional information (unless this change in hours is reflected in the exit or entry of a main benefit). Generally information on hours of work is provided on a voluntary basis and is not audited independently of the general taxpayer audit process. As the Family Tax Credit accounts for only a small proportion of total Family Assistance expenditure low take-up of this programme is not likely to significantly change overall rates of take-up of Family Assistance.

\subsection{Conclusion}

This chapter reviewed the evolution and operation of New Zealand's Family Assistance Tax Credits. Since their 1986 establishment the Family Assistance programmes have provided assistance targeted on the basis of family structure and income (the Family Support Tax Credit) and targeted on the basis of family structure, income, and work effort (first the Family Tax Credit and then the Child Tax Credit and Parental Tax Credit). In relation to total expenditure on Family Assistance the expenditure on the work-based programmes has been marginal in comparison to expenditure on Family Support. All Family Assistance programmes, including the work-based programmes, are only available to families with children. Since 1 April 2003 all Family Assistance programmes have been paid to the primary caregiver (providing caregivers with an independent source of income). 
There have been long periods of little change in the design of the Family Assistance programmes. Apart from increases in levels of assistance and abatement thresholds, the Family Tax Credit is largely identical to the programme established in 1986. The rationale for the Family Tax Credit was to provide an income guarantee (that abates at 100 percent) for working families. In the design of the Family Support Tax Credit since 1986 greater emphasis has been placed on targeting assistance by the numbers and ages of children in families. Since 1986 assistance has increased with the ages of children. Failure to increase the levels of the Family Assistance programmes in line with inflation has been well documented. Also important are the long periods of little change in the abatement thresholds and abatement rates for the programmes. For instance, the top threshold at which Family Support abatement begins remained unchanged for the twelve years prior to 1 April 2000 and the abatement rates of 18 and 30 percent have been in place since 1 April 1989.

In the 1990s an extension of the work-focus of the Family Assistance programmes took place with the introduction of the Child Tax Credit and the Parental Tax Credit. The Parental Tax Credit also represented an attempt to extend the objectives of the Family Assistance programmes to include the provision of support to working families with newborn children. Both the Child Tax Credit and the Parental Tax Credit abate under the Family Support abatement regime. The current Family Assistance programmes are summarised in table 6.8 .

Due to the interaction of the Family Assistance programmes with main welfare benefits and the personal income tax system, calculating entitlement to the Family Assistance programmes can be complex. Family Assistance entitlement is based on projected annual income and the period of the income tax year for which the caregiver is primarily responsible for the child. Application for the Family Assistance programmes is relatively straightforward. However, for non-beneficiaries application for assistance does require the family to file a Family Assistance application form with the Inland Revenue Department and the child and caregiver to have Inland Revenue Numbers. In the majority of cases the Inland Revenue Department can identify changes in entitlement during the year. Take-up of the Family 
Assistance programmes (particularly Family Support) is likely to be relatively high. Assessment of entitlement is largely based on voluntary compliance and is only audited as part of the general process of auditing income tax returns.

Table 6.8: Family Assistance Programmes (1 April 2005)

\begin{tabular}{|c|c|}
\hline $\begin{array}{l}\text { Family Support Tax } \\
\text { Credit }\end{array}$ & $\begin{array}{l}\text { Entitlement depends on number and ages of children. Entitlement } \\
\text { per-child ranges from } \$ 47 \text { to } \$ 85 \text { per-week. The entitlement abates } \\
\text { against gross specified joint income. }\end{array}$ \\
\hline Family Tax Credit & $\begin{array}{l}\text { Guarantees a minimum after-tax income for families with children } \\
\text { and who are independent from main income-tested benefits and } \\
\text { working more than } 30 \text { hours per-week if a couple or } 20 \text { hours per- } \\
\text { week if a sole-parent. The entitlement abates dollar for dollar } \\
\text { against increases in net specified income above the guaranteed } \\
\text { minimum family income. }\end{array}$ \\
\hline Child Tax Credit & $\begin{array}{l}\text { Entitlement is } \$ 15 \text { per-child per-week. Only families who are } \\
\text { independent from main income-tested benefits are entitled. The } \\
\text { entitlement abates together with Family Support. }\end{array}$ \\
\hline Parental Tax Credit & $\begin{array}{l}\text { Payment for the first eight weeks after the birth of a child. } \\
\text { Entitlement is } \$ 150 \text { per-baby per-week. Only families who are } \\
\text { independent from main income-tested benefits are entitled. The } \\
\text { entitlement abates together with Family Support and the Child Tax } \\
\text { Credit. }\end{array}$ \\
\hline
\end{tabular}

Increasing the reliance in the social assistance system on the Family Assistance programmes is likely to place increasing pressure on these application, assessment, and auditing processes. This is particularly the case if there is a greater emphasis on the work-based credits, particularly when they employ complex targeting criteria such as hours of work. Increasing the role of the Family Assistance programmes in the tax-benefit system will also place increasing pressure on the joint administration of these programmes by the Inland Revenue Department and the Ministry of Social Development. 


\section{Anglo-American Family and Employment Tax Credits}

\subsection{Introduction}

The previous chapters discussed the evolution and operation of New Zealand's tax-benefit system and Family Assistance Tax Credits. This chapter continues to establish the context for the Working for Families reforms and compares New Zealand's tax-benefit system and family and employment tax credits with those in four other Anglo-American countries. This comparative public policy research illustrates distinctive and important features of New Zealand's social assistance system and potential lessons for New Zealand from social assistance reform internationally.

In section two of this chapter the tax-benefit systems in five AngloAmerican countries are compared. Particular attention is paid to the proportions of spending on family cash benefits and active labour market programmes. Family and employment tax credits are then compared in section three of the chapter. This section first discusses the directions of reform to family and employment tax credits in the countries. The section then models the structures and generosity of assistance to three representative families and compares the goals designs of family and employment tax credits in the five countries.

\subsection{Comparison of Tax-Benefit Systems}

Policies of adopting tax credits to reduce child poverty and to improve financial incentives to work have almost solely been limited to the liberal or Anglo-American welfare states [Adler, 2004, p. 103]. These countries have 
been classified as liberal or residual welfare states on the basis of their degree of welfare effort, reliance upon targeting, strict entitlement rules, and emphasis on work for poverty relief [Esping-Andersen, 1990]. Of these countries New Zealand and Australia place heavy reliance upon noncontributory social assistance programmes provided without time limits for eligibility for assistance. Canada, the United Kingdom, and the United States all use a mixture of contributory social insurance and non-contributory social assistance programmes, with the United States placing the greatest emphasis on time limits for eligibility for assistance. As Whiteford [2001, p. $46]$ argued the absence of contributory programmes in the New Zealand and Australian social assistance systems means that the mean-tested noncontributory programmes have to perform the functions that would be performed by social insurance programmes in other countries.

In New Zealand and Australia there has been a growing consensus for reforming personal income tax schedules to place a greater focus on economic efficiency and improved financial incentives rather than a concern with distributional goals. In these countries personal income tax scales have been flattened through reductions in marginal income tax rates and the numbers of income tax thresholds. Tax bases have been broadened through removing or consolidating complex systems of tax deductions and rebates for single-income families and families with dependents. In recent years emphasis has been placed on developing family and employment tax credits to reduce poverty and improve financial incentives for labour supply. Family and employment tax credits are able to provide tax relief on a more targeted basis than changes to personal income tax scales and, as they are generally provided through personal income tax systems, are seen to more strongly reinforce work effort than traditional welfare programmes [Alstott, 1995; Nolan and Fairbrother, 2005].

In the five Anglo-American countries the unit of assessment for assessing personal income taxes is generally the individual, except for those families who opt for joint taxation in the United States. Welfare programmes are assessed on the basis of definition of income that presumes intra-family income sharing and includes wealth indicators, which indicate potential income as well as actual income received [Stephens, 1997]. Family and 
employment tax credits are assessed on a compromise between taxable income and the welfare definition of income, using joint annual taxable income of the caregivers and with a number of income adjustments that do not apply to taxable income, such as for child support payments.

Table 7.1: Expenditure on Family Cash Benefits and Total Public Social Expenditure (2001)

\begin{tabular}{lllll}
\hline & $\begin{array}{l}\text { Family Cash } \\
\text { Benefits } \\
\text { Cost Per-Annum } \\
\text { (Billions - National } \\
\text { Currencies) }\end{array}$ & $\begin{array}{l}\text { Total Public } \\
\text { Social } \\
\text { Expenditures } \\
\text { Cost Per-Annum } \\
\text { (Billions - National } \\
\text { Currencies) }\end{array}$ & $\begin{array}{l}\text { Percentage of } \\
\text { Public Social } \\
\text { Expenditures }\end{array}$ & $\begin{array}{l}\text { Percentage of } \\
\text { GDP }\end{array}$ \\
Australia & 20,314 & 128,337 & 15.8 & 2.8 \\
Canada & 9,756 & 196,425 & 5.0 & 0.9 \\
New Zealand & 2,661 & 22,655 & 11.7 & 2.2 \\
United Kingdom & 22,432 & 219,627 & 10.2 & 2.2 \\
United States & 38,145 & $1,470,967$ & 2.6 & 0.4 \\
\hline
\end{tabular}

Sources: OECD, 2004, 'Public Social Expenditure by Main Category at Current Prices in National Currency (1980-2001)'. OECD, 2004, 'Public Social Expenditure by Main Category as a Percentage of GDP (1980-2001)'

The five countries differ in the emphasis they place upon spending on family cash benefits in their tax-benefit systems. Table 7.1 shows data on expenditure on family cash benefits and total public social expenditure for 2001 from the OECD's Social Expenditure Database. The OECD defines family cash benefits as expenditures that support families, e.g., excluding one-person families, and are associated with the costs of raising children. This database does not include expenditure on family cash benefits where the family receives this expenditure as a reduction in tax liability. Only the refundable component of tax assistance is included in this database. Thus, for example, in 1997 US $\$ 24.4$ billion of the US $\$ 30.5$ billion of the expenditure on the Earned Income Tax Credit in the United States was refundable and included in these figures [Adema, 2001, p. 21]. In 2001 the United States spent the lowest proportion of total public social expenditures on family cash benefits. Canada had the second lowest proportion. New Zealand and Australia had the highest levels of expenditure on family cash benefits both as a proportion of total public social expenditures and of GDP, although the United Kingdom spent a similar proportion of GDP on these programmes. Among OECD countries New Zealand and Australia provided two of the four 
highest levels of family benefits relative to GDP, along with Luxembourg and Austria (2.4 percent) [Dwyer, 2005, p. 17]. The United States provided one of the four lowest levels of expenditure on family benefits relative to GDP, along with Korea, Japan, and Spain [Dwyer, 2005, p. 17].

Table 7.2: Expenditure on Family Cash Benefits and Active Labour Market Programmes (2001)

\begin{tabular}{llll}
\hline & $\begin{array}{l}\text { Family Cash Benefits } \\
\text { Cost Per-Annum } \\
\text { (Billions - National } \\
\text { Currencies) }\end{array}$ & $\begin{array}{l}\text { Active Labour Market } \\
\text { Programmes } \\
\text { Cost Per-Annum } \\
\text { (Billions-National }\end{array}$ & Proportion \\
Australia & 20,314 & 3,185 & $6.38: 1$ \\
Canada & 9,756 & 4,683 & $2.08: 1$ \\
New Zealand & 2,661 & 644 & $4.13: 1$ \\
United Kingdom & 22,432 & 3,517 & $6.39: 1$ \\
United States & 38,145 & 14,947 & $2.55: 1$ \\
\hline
\end{tabular}

Sources: OECD, 2004, 'Public Social Expenditure by Main Category at Current Prices in National Currency (1980-2001)'. OECD, 2004, 'Public Social Expenditure by Main Category as a Percentage of GDP (1980-2001)'.

As well as the provision and design of tax-benefit programmes the management of programmes' recipients through active labour market programmes can have an important influence in determining policy outcomes and shaping how recipients perceive their opportunities and obligations to change their recipient status [Stephens, 1997, p. 502]. The five countries differ in the emphasis they place upon spending on active labour market programmes as opposed to family cash benefits in their tax-benefit systems. Table 7.2 shows data on expenditure on family cash benefits and active labour market programmes for 2001 from the OECD's Social Expenditure Database. Active labour market programmes are social expenditures other than education that are aimed at improving beneficiaries' prospect of employment or increasing their earnings' capacity. These expenditures include public employment services and administration, labour market training, and programmes to provide or promote employment for the unemployed, disabled, and youth [OECD, 2002, p. 32]. These programmes

\footnotetext{
"Although, as Dwyer [2005, p. 18] argues, New Zealand's ranking is inflated because of the inclusion of the Domestic Purposes Benefit in the New Zealand data and the exclusion of comparable assistance in other countries.
} 
do not include family cash benefits that are structured to encourage financial incentives to work.

The United States and Canada were similar in their expenditures on family cash benefits as a proportion of active labour market programmes. These countries both placed relatively equal weights upon active labour market programmes and family cash benefits. Australia and the United Kingdom placed less weight upon expenditure on active labour market programmes. Spending in New Zealand was between these two groups.

The figures in table 7.2 do not capture the greater emphasis placed upon active labour market programmes since 2001. In the United Kingdom, for instance, the New Deal policy, which was first established in 1997, distinguishes able people who require encouragement to work and people unable to work who require relatively unconditional support. These different groups have different administrative points of contact (JobCentre Plus for the able group and the Pensions Agency for the second group) [Adler, 2004, p. 96]. Case management is used to provide (encourage) employment opportunities for the group able to work. As much of the available work is low paid tax credits are used to "demonstrate that work pays and to persuade people to accept poorly paid employment" [Adler, 2004, p. 103]. This approach is similar, but not identical, to that taken in the United States [Adler, 2004, p. 103].

Expenditure in the New Zealand social assistance system is tightly targeted. Targeting in the other four countries is less severe. A 1992 analysis of 18 OECD countries (not including Canada) ranked child-benefit packages into four tiers, with the first tier the most generous and the fourth the least. Australia and the United Kingdom were ranked as having second tier levels of assistance over a range of income levels and family types. New Zealand and the United States were seen as laggards with fourth tier levels of assistance [Stephens and Bradshaw, 1995]. Since then Australia, Canada, the United Kingdom, and the United States have introduced new policy initiatives and extended existing ones to address poverty and make work pay. Equivalent initiatives in New Zealand are not due to be fully implemented until 2007. In a 2002 analysis of 22 countries New Zealand remained in the laggard category (ranked eighteenth after housing costs). 
Canada (ranked eleventh) and the United States (ranked seventh) were in the third tier and Australia (ranked fourth) and the United Kingdom (ranked second) were in the second [Bradshaw and Finch, 2002].

\subsection{Comparison of Family and Employment Tax Credits}

The following section of this chapter discusses the use of family and employment tax credits in New Zealand, Australia, Canada, the United Kingdom, and the United States. The programmes that are discussed are:

- New Zealand: the Family Assistance Tax Credits, comprising the Family Support Tax Credit and the Family Plus Tax Credits (the Child, Parental, and Family Tax Credits);

- Australia: the Family Tax Benefit Part A and Family Tax Benefit Part B;

- Canada: the Canada Child Tax Benefit, comprising the Basic Benefit and the National Child Benefit Supplement, and, as an example of provincial-level assistance, the British Colombia Family Bonus and Earned Income Credit;

- United Kingdom: the Child Tax Credit, comprising the Family Element and the Child Tax Credit, the Working Tax Credit, and the universal Child Benefit; and

- United States: the federal Earned Income Tax Credit, Child Tax Credit, and, as an example of state-level assistance, the Wisconsin Earned Income Credit.

Generally family tax credits are paid to families with dependent children irrespective of workforce status, while receipt of employment tax credits is dependent upon work effort. Reforms to family and employment tax credits have been at the heart of tax-benefit reforms throughout the Anglo-American world. Yet there has been relatively little comparative public policy research on these prominent tax-benefit reforms. Mendelson [2001] reviewed cashbenefits for children in Australia, Canada, the United Kingdom, and the United States. This study extends this research to include New Zealand. This study also differs from the approach taken in Mendelson in two ways. First, 
the scope of this paper is family and employment tax credits and not cashbenefits for children. Thus this paper includes the full level of employment tax credits (not just the child-based component of these programmes) but childbased assistance provided through other policy instruments (such as childbased personal income tax exemptions) is not included. Second, in this earlier work levels of assistance were modelled against gross incomes. However, in the five Anglo-American countries the levels of family and employment tax credits provided also vary with wage rates, family types, and family sizes. Thus although entitlement and abatement schedules are often expressed in terms of gross incomes this paper models financial assistance available to families at different hours of work with a fixed wage rate reflecting a low wage rate for these family types. This approach separates low-wage families from higher-wage families who have low hours of work and thus low incomes. Modelling assistance against gross incomes could create a misleading picture of the financial assistance provided to families as while particular programmes may appear relatively heavily targeted by income when modelled against gross incomes this may not be the case when levels of financial assistance are modelled against hours of work for families with relatively low wage rates.

\section{Approaches to Reform in Anglo-American Countries}

To address goals such as reducing relatively high rates of child poverty and increasing caregivers' labour supply (as part of a broader poverty reduction strategy) Anglo-American countries have placed emphasis on redesigning family and employment tax credits [Adler 2004]. Some of these reforms, particularly those to the Earned Income Tax Credit in the United States and the Child Tax Credit and Working Tax Credit in the United Kingdom, have influenced reforms in the other countries, particularly the reforms to New Zealand's Family Assistance programmes currently underway. To provide further context for the comparison of these reforms in later sections of this chapter, this section briefly discussed approaches to reform in the AngloAmerican countries except New Zealand (discussed in chapters five and six). 


\section{Australia}

Australia, like New Zealand, has few contributory social insurance programmes. Social assistance programmes are flat-rate and provided without time limits. Since the early 1980s Australia has reformed its personal income tax scale away from a concern with distributional goals and fiscal constraints and towards a greater concern with economic efficiency and improved financial incentives for labour supply [Beer, 1995; Nolan, 2005, p. 4]. Over the last 25 years general tax assistance for families has also been cashed out and paid as income-tested assistance to caregivers [Whiteford, 2001 , p. 43]. Payments for children in low-income families have been made payable to caregivers rather than as part of beneficiaries' income support payments [Whiteford, 2001, pp. 43-44]. In 1983 a Family Income Supplement was established to provide income-tested assistance for low-income working families at the same rate as income support recipients. By 1998 coverage of this programme had expanded from one percent of children in 1983 to nearly 14 percent [Whiteford, Mendelson, Millar, 2003, p. 3].

In July 2000 the Final Report of the Reference Group on Welfare Reform (the McClure report) was released. This report emphasised five principles of individualised service delivery, simpler income support, better financial incentives and assistance, mutual obligations, and fostering social partnerships. The report recommended extending mutual obligation principles to sole-parents, people on disability pensions, and the matureaged jobless and rolling the plethora of social assistance benefits into one common payment with an incentive bonus to encourage people to move off state support [McClure, Jackson, et al, 2000].

Also in July 2000, the Australian Government integrated a range of tax rebates for single-income families and families with dependents into the Family Tax Benefit Part A, Family Tax Benefit Part B, and Child Care Benefit. These Family Tax Benefit reforms were part of a package of general tax reforms that emphasised simplification and consolidated administration into a single agency (Centrelink). The Family Tax Benefit Part A is designed to assist with the general costs of raising children. The Family Tax Benefit Part $B$ is designed to support single-income partnered and sole-parent families. Entitlement for Family Tax Benefits is assessed on the basis of estimated 
taxable income for the forthcoming income tax year with a reconciliation with taxable income at year-end. To minimise problems of people incurring taxdebts the first A $\$ 1,000$ of debt is waived [Whiteford, Mendelson, Millar, 2003, p. 5]. In 2001, of the 2.6 million families with children in Australia 1.8 million received the Family Tax Benefit Part A and 1.2 million received the Family Tax Benefit Part B [Whiteford, Mendelson, Millar, 2003, p. 4]. However, some concern has been expressed regarding the targeting efficiency of the Family Tax Benefit Parts A and B and the lack of targeting of assistance on the basis of work effort [Ingles, 2001].

\section{Canada}

The Canadian social security system operates at both federal and provincial levels. Social assistance programmes vary between provinces and are generally available to only those people who have exhausted all other sources of income, such as employment earnings, savings, and social insurance benefits [Battle and Mendelson, 2001, p. 108]. In 1978 Canada introduced a Refundable Tax Credit. In 1993 this Refundable Child Tax Credit, a non-refundable Child Tax Credit, and Family Allowances were integrated to create the Child Tax Benefit. This programme was paid by the Canadian tax authority to families on low-incomes and middle-incomes and was complemented by a Working Income Supplement to low-income working families.

In 1998 the Working Income Supplement was abolished and the Child Tax Benefit (renamed the Canada Child Tax Benefit) was expanded to include a more generous supplement to low-income families regardless of employment status. The rates of this credit have since been increased to extend coverage of the credit up to families on relatively high-incomes. In 2002 around 80 percent of Canadian families with children received some benefit from the Canada Child Tax Benefit [Whiteford, Mendelson, Millar, 2003, p. 9]. Entitlement to the Canada Child Tax Benefit is based on net joint income for the previous calendar year. There are no mid-year adjustments for changes in income. Adjustments may, however, be made for changes in family composition. A family whose income falls may be eligible for a top-up of provincial assistance. As the Canadian tax system does not use a pay-as- 
you-earn withholding system the majority of Canadian taxpayers are required to undertake an annual tax reconciliation process. As entitlement is based on earnings in the previous year issues of overpayment and debt do not arise [Whiteford, Mendelson, Millar, 2003, pp. 10-11].

Under the National Child Benefit reform provinces and territories are replacing their social assistance child benefits with increased federal child benefits and provincial income-tested programmes for low-income families with children [Battle and Mendelson, 2001, p. 109]. Under these reforms provincial and territorial governments are expected but not required to reduce their social assistance expenditures for children to take into account increasing federal expenditures on the National Child Benefit Supplement, provided that they reinvest savings in other programmes and services for low-income families with children [Battle and Mendelson, 2001, p. 105]. Most provinces and territories now offer income-tested child benefit programmes and/or employment earnings supplements for families with children. Four provinces have added provincial supplements to the Canada Child Tax Benefit. All the provincial child benefit programmes emphasise anti-poverty objectives and are designed to mesh with the federal system in terms of thresholds and reduction rates [Battle and Mendelson, 2001, pp. 105-106].

\section{United Kingdom}

The first child tax allowances were introduced in 1909 on the grounds of ensuring horizontal equity between taxpayers with children and those without. Family Allowances were introduced in 1946 for second and subsequent children. Family Allowances were intended to contribute to the costs of raising children and it was assumed that wages would cover the cost of the first child. Benefits for child dependants were included in the contributory National Insurance and the non-contributory National Assistance (renamed Supplementary Benefit in 1966 and Income Support in 1988) [Millar, 2001, p. 192]. The Child Benefit Act 1975 created a new system of universal support. Both child tax allowances and Family Allowances were abolished and the Child Benefit was introduced from April 1977 as a universal cash payment for all children [Millar, 2001, p. 192]. In 1977 a supplement to the Child Benefit for sole-parent families was introduced and 
was paid per-family not per-child. This supplement was abolished in July 1998 (although existing claimants can continue to receive it). A higher rate of Child Benefit has been payable for the first child since 1991 [Millar, 2001, p. 193].

Since 1997 Labour governments have pursued welfare and taxation reform with the objectives of making work pay and supporting families with children. Governments have also committed to eradicating child poverty. There has been a growth of a range of tax credits and benefits to address child poverty and poverty among workers and improve incentives to work for the low-waged and disabled. Central to these reforms has been the Working Families' Tax Credit. Under the Working Family Tax Credit families on lowincomes and where the main earner worked more than 16 hours per-week were entitled to a Basic Tax Credit with an add-on if the main earner worked more than 30 hours. The Working Families' Tax Credit was based on a six monthly assessment of means so that once entitlement was established the credit continued to be paid for the six months even if the family stopped working during this period. A Child Tax Credit was also paid on the basis of the ages of children and a childcare tax credit of 70 percent of eligible childcare costs was available.

Following a desire to produce a simpler tax credit system, in 2003 the Working Families Tax Credit and Disabled Persons Tax Credit were replaced by the Child Tax Credit and Working Tax Credit (discussed in greater detail below). The six monthly assessment of need was removed. Entitlement is initially based on the previous year's gross joint income. At year end there is a reconciliation of entitlement. The first $£ 2,500$ increase in gross joint income is disregarded for the current year (but is included in calculating entitlement for future years). Thus if income increases by less than this amount entitlement is not reduced. If gross joint income falls then entitlement is increased. However, backdated payments can only be made for a maximum of three months [Whiteford, Mendelson, Millar, 2003, pp. 14-15]. The establishment of the Child Tax Credit and Working Tax Credit were linked with institutional changes, particularly the creation of the Department for Work and Pensions and merging of the benefits and employment services agency (JobCentre Plus). 


\section{The United States}

The United States has a federal political system with social security provided at federal and state levels. Non-contributory social assistance programmes (welfare) are less generous than contributory social insurance programmes [Meyer, 2001, p. 263]. The United States has a long history of providing assistance to families with children through the tax system. Indirect benefits to families with children have been provided through the tax system for nearly a century. The main mechanism for this support has been a tax exemption for every individual in a family of the same amount for adults and children. This provision was typically not seen as an explicit provision of benefits for children but a response to these families' lesser ability to pay taxes [Meyer, 2001, pp. 259-260].

The Earned Income Tax Credit was established in 1975 and initially provided low levels of assistance. Levels of federal expenditure and assistance per-recipient increased significantly following expansions of the programme in 1986, 1990, and 1993. This expansion reflected bipartisan political support for the programme, as it was seen as helping the working poor rise above the poverty line without increasing the minimum wage or funding to welfare programmes for those out of work. As well as the federal programme, increasing numbers of state Earned Income Tax Credits have been offered. These state programmes are extensions of the federal Earned Income Tax Credit and are generally based on a percentage of the federal programme. In more recent years, however, the Earned Income Tax Credit has been subject to criticism due to a perceived proliferation of fraud and abuse, increased costs, and expansion of the programme beyond working poor families with children.

Expansion of the federal Earned Income Tax Credit has been undertaken in conjunction with broader social security reform. The Personal Responsibility and Work Opportunity Reconciliation Act 1996 removed the 61-year-old Aid to Families with Dependent Children programme and the Jobs Opportunity and Basic Skills Training Programme. In place of these programmes the Temporary Assistance to Needy Families programme was established. Lifetime limits of up to five years for receiving welfare were introduced, work requirements were strengthened, and state governments 
were subject to financial incentives to reduce their welfare rolls. In 1997 a non-refundable Child Tax Credit was established for families with children and in 2001 was extended through being increased in value and being made refundable for families with taxable earnings above a threshold.

\section{Family and Employment Tax Credits Provided to Three Family Types}

Payments of family and employment tax credits vary according to wage rates, hours of work, family types, and family sizes. The family and employment tax credits available to three family types are modelled below. The first family consists of a sole-parent earning an hourly gross wage rate of NZ\$10.00 and with two children aged three and five. The second family consists of a partnered person earning an hourly gross wage rate of NZ\$15.00 and with a non-working spouse and two children aged three and five. The third family consists of a partnered person earning an hourly gross wage rate of $N Z \$ 15.00$ and with a working spouse and two children aged three and five.

Assistance is modelled according to hours of work (rather than income) to separate low-wage families from higher-wage families with low hours of work and thus low incomes. The family and employment tax credits modelled are those in place for 2004-05. This is not a complete picture of all the assistance to which these families would be entitled. Canada and the United States also provide assistance through the personal income tax scale that is not modelled and in these countries the levels of assistance provided at the provincial or state level vary. The provincial-level and state-level assistance modelled in this study are those of British Columbia for Canada and Wisconsin for the United States, which both have relatively ungenerous taxbenefit systems. These systems have been chosen to provide low-level benchmarks against which the New Zealand system can be compared. Emphasis is given to family and employment tax credits because of the prominence of reform to these programmes in the five countries and their importance for the financial incentives to work facing sole-parents and secondary earners. All figures are in New Zealand dollars (adjusted using OECD purchasing power parity rates for 2004) [OECD, 2005b]. 


\section{A Sole-Parent with Two Children}

Figure 7.1 illustrates the family and employment tax credits provided to a sole-parent with two children and earning a wage rate of NZ\$10.00 for up to 50 hours of work per-week. Australia and the United Kingdom generally provide the most generous levels of assistance. Canada and the United States are less generous than Australia and the United Kingdom. In New Zealand the assistance provided is the least generous of the five countries.

Figure 7.1: Family and Employment Tax Credits for a Sole-Parent with Two Children (Aged 3 and 5) and Earning \$10.00 Per-Hour (2004-05)

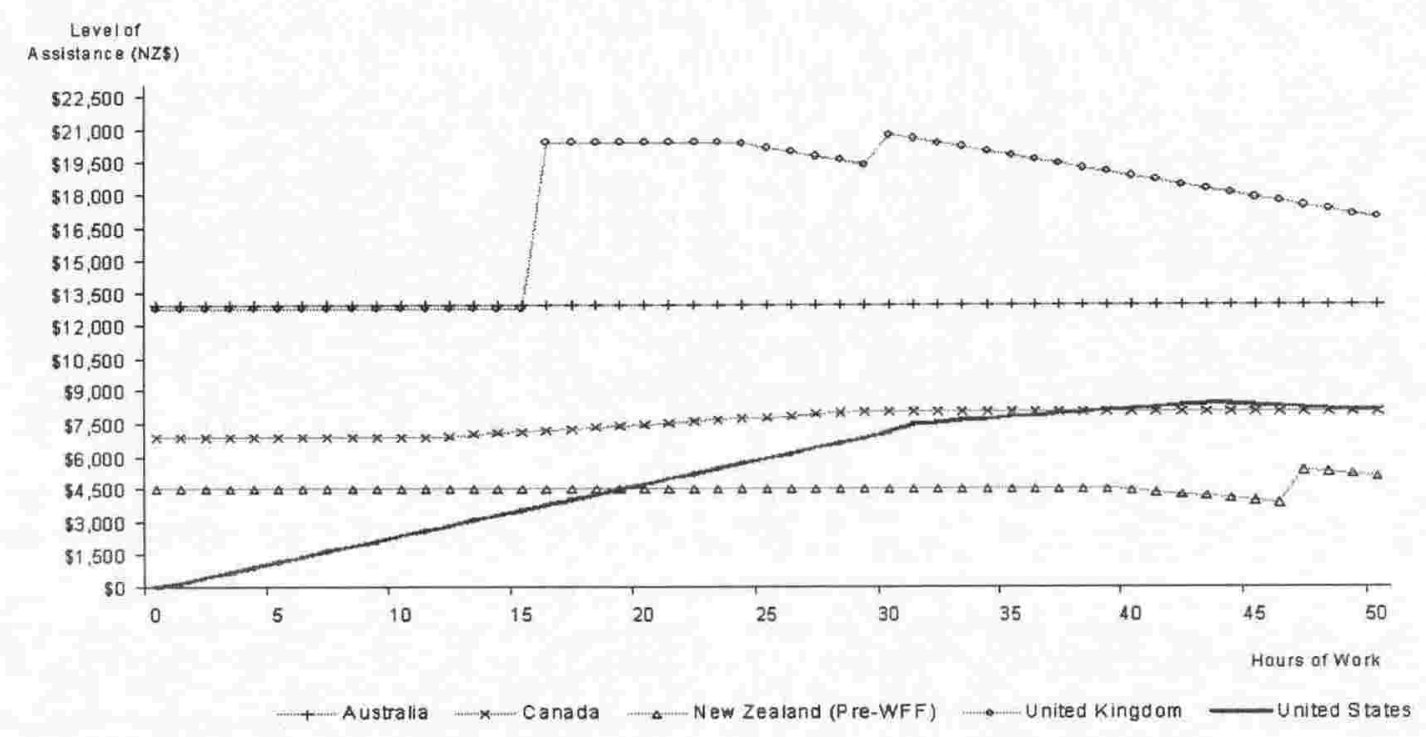

Variations in targeting regimes mean that the effects of changes in hours of work on assistance differed in the five countries. These differences indicate the degree to which the different countries targeted assistance on the basis of family structure as opposed to paid employment. For this soleparent family Australia and Canada largely targeted assistance on the basis of family structure. In Australia there was no change in the level of assistance provided to this sole-parent at this wage rate if their hours of work varied between zero and 50 hours per week. Family tax credits in Canada were also largely targeted by family structure and not paid employment. At this wage rate the sole-parent received similar levels of assistance from not working, working part-time, or working full-time.

The United States placed greater emphasis upon targeting assistance by paid employment. Under the federal Earned Income Tax Credit and state- 
level programme (the Wisconsin Earned Income Credit) the assistance provided to the sole-parent increased with earnings from work until their income reached a threshold. At low hours of work the levels of assistance were low. This phase-in of assistance boosted financial incentives to increase hours of work in this range. At a little over 30 hours a week this family qualified for the Child Tax Credit, which provided assistance to families with earned income above a threshold, and which only began to abate at high-income levels. Above this threshold the level of assistance remained stationary until the sole-parent's earned income reached the threshold for abatement of the Earned Income Tax Credit (creating disincentives to increase hours of work).

The United Kingdom provided a mixture of universal programmes, programmes targeted by family structure, and programmes targeted by paid employment (hours of work). Sole-parents who worked between zero and 16 hours per-week received a universal Child Benefit, a Family Element that only began to abate at very high income levels, and a Child Tax Credit that began to abate at relatively low income levels. At 16 hours of work the soleparent became eligible for a Working Tax Credit, which increased when they became eligible for the Full-Time Premium at 30 hours of work. New Zealand provided a mixture of programmes targeted by family structure and programmes targeted by both family structure and paid employment (hours of work and rules excluding welfare recipients). There was no change in the level of assistance provided to this sole-parent until abatement of the Family Assistance programmes began at just over 39 hours of work per week. In New Zealand at around 47 hours of work the sole-parent exited welfare and increased their entitlement with the work-based Child Tax Credit.

\footnotetext{
- The Child Tax Credit contains a direct reduction in tax liability and a refundable component. Families with earnings above US $\$ 10,750$ may receive up to US $\$ 1,000$ per child. If any credit remains following the direct reduction in tax liability the family may receive the refundable component, which is calculated at a rate of 15 percent on income above the eligibility threshold up to the maximum level of the credit. The graphs show both the direct reduction in tax liability and the refundable component of the credit. The sole-parent's tax liability assumes they received one personal exemption and two dependent exemptions. The credit abates at a rate of 5 percent against income in excess of US $\$ 75,000$ for unmarried individuals and US $\$ 110,000$ for married people who file jointly.
} 
Table 7.3: Structure of Child Benefit Package for Sole-Parent With One Child Earning Average Female Earnings (UK£ Per-Month) (2001)

\begin{tabular}{llllllllll}
\hline & $\begin{array}{l}\text { Income } \\
\text { Tax }\end{array}$ & $\begin{array}{l}\text { Income } \\
\text { Related } \\
\text { Child } \\
\text { Benefit }\end{array}$ & $\begin{array}{l}\text { Universal } \\
\text { Child } \\
\text { Benefit }\end{array}$ & $\begin{array}{l}\text { Net } \\
\text { Rent }\end{array}$ & $\begin{array}{l}\text { Net } \\
\text { Local } \\
\text { Tax }\end{array}$ & $\begin{array}{l}\text { Childcare } \\
\text { costs }\end{array}$ & $\begin{array}{l}\text { Health } \\
\text { Costs }\end{array}$ & $\begin{array}{l}\text { Net after } \\
\text { taxes } \\
\text { and } \\
\text { benefits }\end{array}$ & $\begin{array}{l}\text { Net } \\
\text { after } \\
\text { all }\end{array}$ \\
\hline Australia & 98 & 0 & 0 & 0 & 0 & -125 & 0 & 98 & -27 \\
Canada & 3 & 91 & 0 & 0 & 0 & -324 & 0 & 94 & -230 \\
$\begin{array}{l}\text { New } \\
\text { Zealand }\end{array}$ & 38 & 0 & 0 & 0 & 0 & -322 & 10 & 38 & -275 \\
$\begin{array}{l}\text { United } \\
\text { Kingdom }\end{array}$ & 270 & 0 & 67 & 0 & 12 & -385 & 2 & 338 & -33 \\
$\begin{array}{l}\text { United } \\
\text { States }\end{array}$ & 68 & 0 & 0 & 0 & 0 & -160 & 0 & 68 & -92 \\
\hline
\end{tabular}

Sources: Bradshaw and Finch, 2002, p. 139

This modelling of family and employment tax credits does not provide a complete picture of all the assistance to which these families would be entitled. However, the conclusion that New Zealand's tax-benefit programmes had relatively low levels of generosity among the AngloAmerican countries is consistent with other research on the structure and generosity of child benefit packages in OECD countries. Table 7.3 illustrates the generosity of the child benefit package provided to a sole-parent with one child and earning average female earnings in a selection (five AngloAmerican countries) of the countries contained in this other research. Income tax assistance provided in New Zealand was less generous than the United Kingdom, Australia, and the United States. Canada was alone in providing an income related child benefit to this family and the United Kingdom was alone in providing a universal child benefit to this family. New Zealand was the least generous jurisdiction net after taxes and benefits. Childcare costs were high in all the countries. At low earned income levels Australia and the United States gave substantial assistance to offset childcare costs, New Zealand and Canada less, and the United Kingdom relatively little. Australia and Canada also increased the amount of income-related cash benefits for preschool aged children and the United Kingdom and the United States allowed an offset against taxable income for childcare costs. New Zealand and Canada were the least generous jurisdictions net after all. 


\section{A Partnered Person with a Non-Working Spouse and Two Children}

Figure 7.2: Family and Employment Tax Credits for a Primary Earner with Two Children (Aged 3 and 5) and Earning NZ\$15.00 Per-Hour (2004-05)

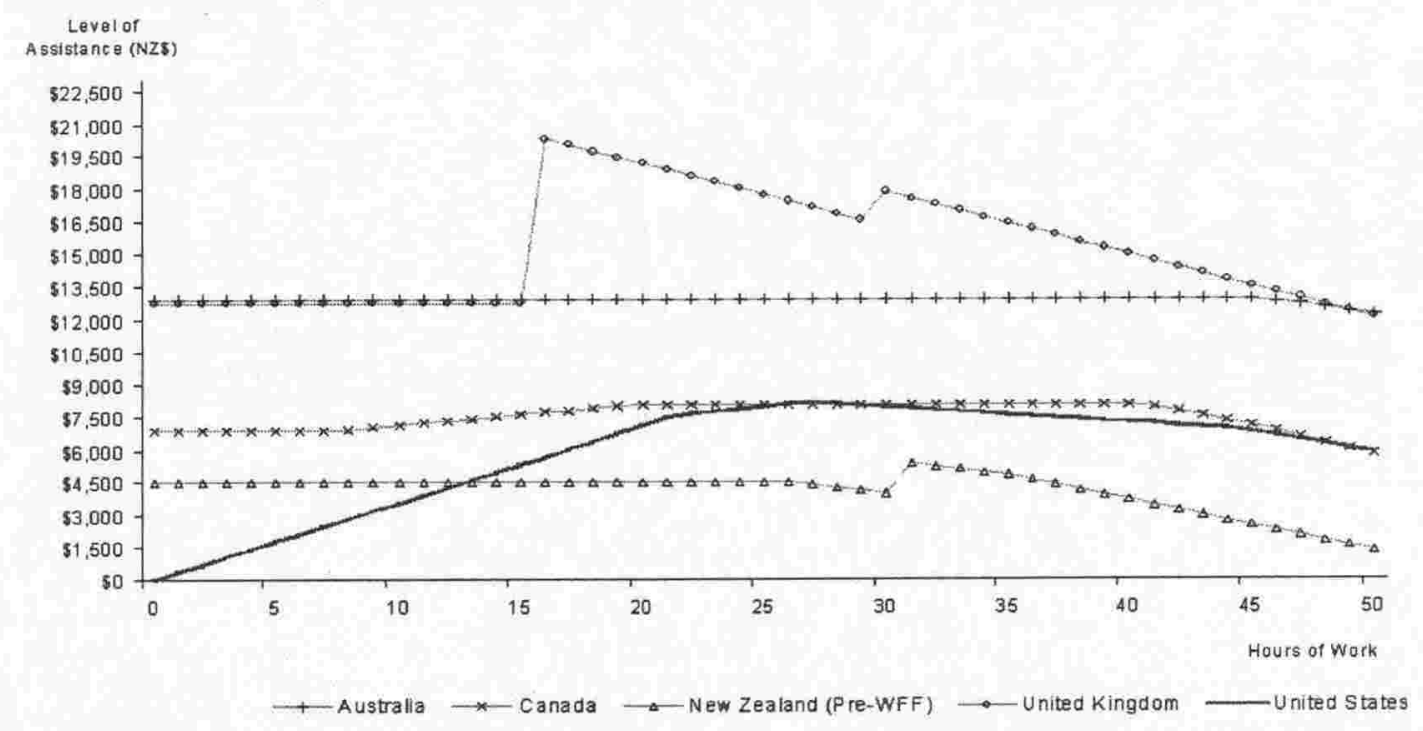

Figure 7.2 illustrates the family and employment tax credits provided to a partnered person earning a wage rate of $\mathrm{NZ} \$ 15.00$ with a non-working spouse and two children. In partnered families when either the primary or secondary earner change their hours of work total joint income changes. As family and employment tax credits generally abate against total joint income the levels of assistance provided to primary and secondary earners are influenced by the hours of work of the other partner. Yet for modelling purposes the levels of assistance below are calculated as individual decisions, where only one person makes a labour supply decision and the rest of the labour supply decisions in the family are held constant [Prebble and Rebstock (eds.), 1992]. Thus while the levels of assistance are those provided to the family as a whole the hours of work are those applying to the one individual who is assumed to be able to vary their hours of work. Australia and the United Kingdom provided the most generous levels of family and employment tax credits. Canada and the United States were generally less generous than these two countries. In New Zealand in 2004-05 the assistance provided was the least generous of the five countries. 
Table 7.4: Structure of Child Benefit Package for Couple With Two Children and One Earner on Average Male Earnings (UK£ Per-Month) (2001)

\begin{tabular}{|c|c|c|c|c|c|c|c|c|c|}
\hline & $\begin{array}{l}\text { Income } \\
\text { Tax }\end{array}$ & $\begin{array}{l}\text { Income } \\
\text { Related } \\
\text { Child } \\
\text { Benefit }\end{array}$ & $\begin{array}{l}\text { Universal } \\
\text { Child } \\
\text { Benefit }\end{array}$ & $\begin{array}{l}\text { Net } \\
\text { Rent }\end{array}$ & $\begin{array}{l}\text { Net } \\
\text { Local } \\
\text { Tax }\end{array}$ & $\begin{array}{l}\text { School } \\
\text { costs/ } \\
\text { benefits }\end{array}$ & $\begin{array}{l}\text { Health } \\
\text { Costs }\end{array}$ & $\begin{array}{l}\text { Net after } \\
\text { taxes } \\
\text { and } \\
\text { benefits }\end{array}$ & $\begin{array}{l}\text { Net } \\
\text { after } \\
\text { all }\end{array}$ \\
\hline Australia & 106 & 0 & 0 & 0 & 0 & 0 & -16 & 106 & 90 \\
\hline Canada & 0 & 60 & 0 & 0 & 0 & 0 & -23 & 60 & 37 \\
\hline $\begin{array}{l}\text { New } \\
\text { Zealand }\end{array}$ & 6 & 0 & 0 & 0 & 0 & -12 & -4 & 6 & -10 \\
\hline $\begin{array}{l}\text { United } \\
\text { Kingdom }\end{array}$ & 43 & 0 & 112 & 0 & -21 & 0 & 0 & 155 & 134 \\
\hline $\begin{array}{l}\text { United } \\
\text { States }\end{array}$ & 107 & 0 & 0 & 0 & 0 & 0 & -184 & 107 & -78 \\
\hline
\end{tabular}

Sources: Bradshaw and Finch, 2002, p. 137

Although this modelling of family and employment tax credits does not provide a complete picture of all the assistance to which these families would be entitled, the conclusion that New Zealand's tax-benefit programmes had relatively low levels of generosity among the Anglo-American countries is consistent with other research on the structure and generosity of child benefit packages in OECD countries. Table 7.4 illustrates the generosity of the child benefit package provided to a couple with two children and one earner on average male earnings in a selection (five Anglo-American countries) of the countries contained in this other research. Income tax assistance provided in New Zealand was less generous than the United States, Australia, and the United Kingdom. Canada was alone in providing an income related child benefit to this family and the United Kingdom was alone in providing a universal child benefit to this family. New Zealand was the least generous jurisdiction net after taxes and benefits. Health costs were highest in the United States. The United States and New Zealand were the least generous jurisdictions net after all.

\section{A Partnered Person with a Working Spouse and Two Children}

Figure 7.3 illustrates the family and employment tax credits provided to a partnered person earning a wage rate of $\mathrm{NZ} \$ 15.00$ with a working spouse and two children. It is assumed the working spouse earned a fixed income of $\mathrm{NZ} \$ 600$ gross per-week (at a wage rate of $\mathrm{NZ} \$ 15.00$ per-hour and 40 hours of work per-week). 
Figure 7.3: Family and Employment Tax Credits for a Secondary Earner with Two Children (Aged 3 and 5) and Earning NZ\$15.00 Per-Hour (2004-05)

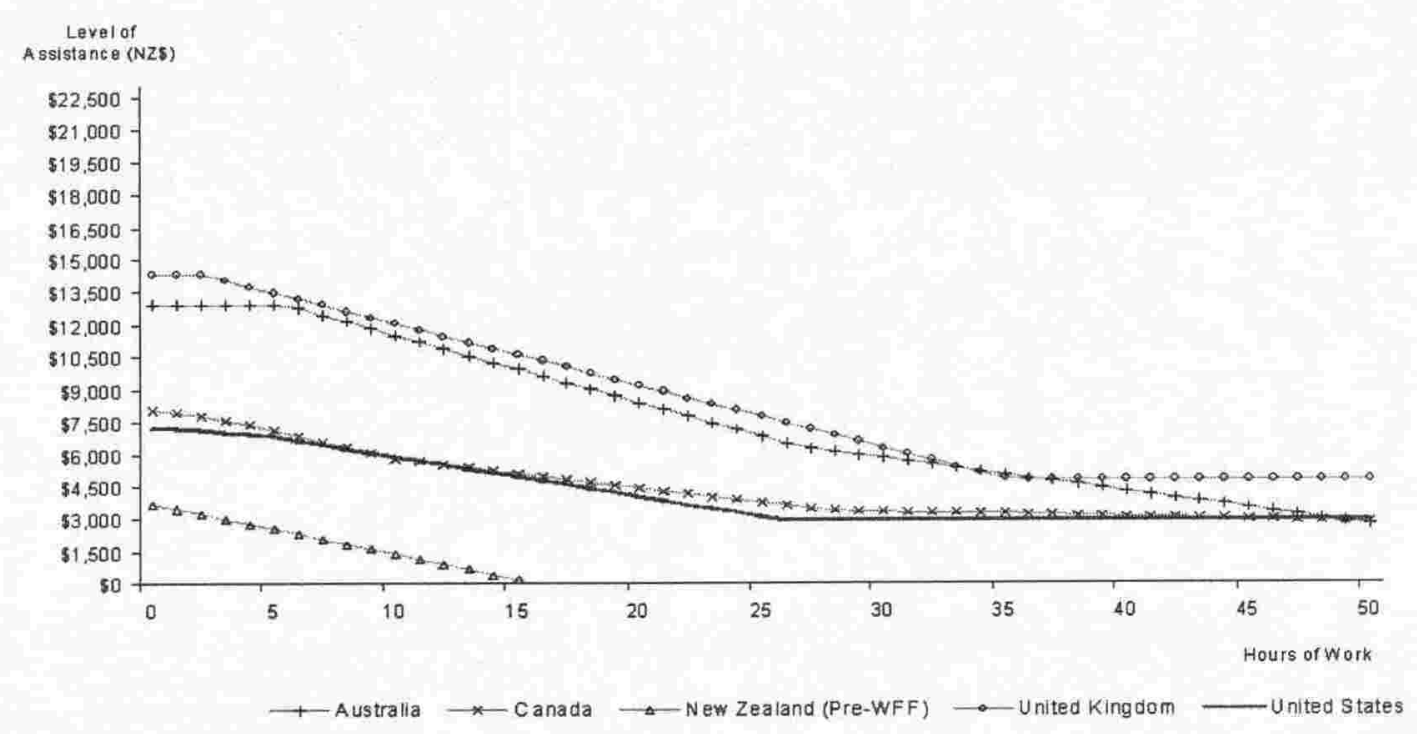

Australia and the United Kingdom provided the most generous levels of family and employment tax credits. Canada and the United States were generally less generous than these two countries. In New Zealand in 2004-05 the assistance provided was the least generous of the five countries. In all of the five countries the secondary earner faced abatement of family and employment tax credits from (or soon after) their first dollar of earnings. New Zealand was the only country not providing base levels of assistance received by families with relatively high joint incomes. In Australia the family received a base rate of the Family Benefit Part A, in the United Kingdom the family received a universal Child Benefit and a Family Element, in the United States the family received a Child Tax Credit, and in Canada the family received a National Child Benefit Supplement up to high hours of work.

Changing the numbers and ages of children in the family had some impact on the structure of assistance identified in the cases above. As the number of children in the family increased, the level of assistance paid to the family also increased. As a consequence of this increase the abatement of assistance took place over a larger number of hours of work. Likewise, in New Zealand and Australia when the ages of children increased the level of assistance paid to the families increased and the abatement of assistance also took place over a larger number of hours of work. In the United Kingdom 
the levels of assistance provided to families with children under one would have been greater than those modelled above.

\section{Goals and Designs of Family and Employment Tax Credits}

The five Anglo-American countries have taken differing approaches to the design of their tax credits. Australia places the strongest emphasis upon targeting assistance by family structures and does not provide employment tax credits, although there have been calls for such programmes [Ingles, 2001]. Since the 1998 removal of the Working Income Supplement (an employment tax credit) the design of tax credits in Canada has also reflected a strong emphasis upon targeting assistance by family structure [Battle and Mendelson, 2001]. Since 1986 New Zealand has provided family and employment tax credits to low-income families with dependent children. The United Kingdom provides a mixture of universal programmes, programmes targeted by family structure, and programmes targeted by paid employment (hours of work) [Millar, 2001]. Since 1975 the United States has provided an employment tax credit to families with dependent children, which was extended to working families without children in 1993 [Meyer, 2001]. In 1997 a Child Tax Credit was established for families with children and with taxable earnings and was extended to include families with children and without taxable earnings in 2001. Earned and family tax credits are also provided at the provincial and state levels in Canada and the United States [Mendelson, 2001].

Designs of family tax credits differ in the five countries, reflecting assumptions regarding the degree to which families' costs reflect the number of children (the degree to which economies of scale in childrearing mean each additional child incurs a lower marginal financial cost to the family) and the age of children.

- In the targeting of this assistance by family structure the United States (Child Tax Credit) takes a simple approach and does not differentiate between additional and older children.

- Australia (Family Tax Benefit Part A) also takes a relatively simple approach and does not differentiate between the first three children (although there is a supplement for the fourth and additional children) 
but varies assistance by ages of children, with additional assistance for older children.

- New Zealand (Family Support Tax Credit) varies assistance by number of children (additional entitlement for the eldest child) as well as ages of children, with additional assistance for older children.

- The United Kingdom (Child Tax Credit, including the Family Premium) targets assistance by ages of children (increased assistance for children under one) and number of children and provides a universal Child Benefit that pays a higher annual rate for the eldest eligible child.

- Canada (Canada Child Tax Benefit, including the National Child Benefit Supplement) places the strongest emphasis on targeting family tax credits by child-based criteria, with assistance varying by ages of children (additional payments made for each child under the age of seven) and number of children. Under the Canada Child Tax Benefit regime additional payments are made for the third and each additional child, rates of abatement vary between single and multiple child families, and the levels of assistance vary between the first child, second child, and additional children (assistance decreases for later children).

The provision of greater assistance for older children in New Zealand and Australia reflects an assumption that families' costs increase with the age of children. In contrast Canada and the United Kingdom provide additional assistance to younger children (under seven in Canada and under one in the United Kingdom) and the United States does not target assistance on the basis of age of children. In the United Kingdom research has shown that while parents' average spending increases with the age of children this increase was less than had previously been assumed in age-related scales in benefits and allowances [Middleton, Ashworth, and Braithwaite, 1997]. Australian research has shown that that estimated average costs of children increase with age and with gross joint income but precise estimates differ according to the methodology employed (e.g., expenditure surveys or basketof-goods approaches) [Saunders, 1999]. There is a lack of equivalent research on families' spending on children by age in New Zealand. However, spending on younger children is often less discretionary than spending on 
older children and families with younger children often face costs that do not have as great an impact on families with older children, such funding the withdrawal of a caregiver from the labour market. It could thus be argued that age-related scales contained in New Zealand's Family Support programme overcompensate families with older children (particularly for additional children in the family).

Designs of employment tax credits also differ. Two approaches taken to designing these programmes have been to base assistance on satisfying hours-based eligibility thresholds (often in conjunction with rules reducing receipt of assistance by welfare recipients) or to provide an earned income subsidy that increases with earnings up to a threshold.

- In New Zealand employment tax credits are only available to families with dependent children and following proposed reforms will largely require satisfying hours-based eligibility criteria (20 hours per week for sole-parents and 30 hours per week for partnered families). In the United Kingdom since 2003 the Working Tax Credit has been paid to people in work both with and without children. Eligibility requires satisfying an hours-based eligibility threshold (at least one income earner in the family working 16 hours per week) and a full-time premium is paid when total family hours of work exceed 30 hours per week. This use of hours-based thresholds in New Zealand and the United Kingdom is likely to lead to distortions in distributions of hours of work and appears inconsistent with the increasing use of employment contracts requiring variations in hours of work, such as for seasonal work.

- Since 1978 in the United States the Earned Income Tax Credit has had a phase-in zone (where assistance increases with earnings), a stationary range (where the level of assistance does not vary with earnings), and an abatement zone. Although providing positive financial incentives for labour supply this phase in of assistance has been criticised on distributional (vertical equity) grounds. The rates for families with two or more children have been increased relative to those

\footnotetext{
*As Johnston [2005] illustrated New Zealand women tend to leave the labour force when they have children and to return strongly to the labour force when their children get older.
} 
for families with a single child. A smaller Earned Income Tax Credit has been made available to childless families. The subsidy rates, thresholds, and abatement rates vary between families with no, one, and multiple children (all increasing with numbers of children) and vary between married and unmarried families.

Employment tax credits are important for the financial incentives to work facing sole-parents and secondary earners in families with children [OECD, 2001]. With the exception of Australia (which had a rate of 58 percent), in 2001 the proportions of married mothers working in Anglo-American countries were all around 70 percent. With the exception of the United States (which had a rate of 68 percent), there were large differences in employment rates between married and single mothers in each of the Anglo-American countries, with single mothers' rates ranging from 46 percent in Australia to 51 percent in Canada [Stephens, 2003; OECD 2004b]. Evidence on employment tax credits in the United States and United Kingdom indicated that it is on this margin of caregivers' participation rates that the labour supply behavioural responses to these programmes are likely to be strongest. This evidence indicates that the overall increase in employment from these programmes was composed of increases in employment of sole-parents, smaller increases in employment of males in partnered families, and decreases in employment among women in couples [Ellwood, 2000; Blundell, Brewer, and Shephard, 2004; Eissa and Hoynes, 2004]. Recent estimates on the Working for Families reforms in New Zealand reached similar conclusions [Kalb, Cai, and Tuckwell, 2005].

This result for mothers in couples reflects the use of joint income as the basis for assessing entitlement. With the exception of the Family Tax Benefit Part B (which abates solely against secondary earners' incomes) in Australia, all Anglo-American family and employment tax credits are assessed on joint income. Assessing entitlement on joint income encourages some secondary earners to drop out of the labour market rather than working or registering for unemployment assistance and leads to some families reducing their earned incomes. Basing entitlement on joint income means secondary earners generally face higher effective marginal tax rates from their first dollar of income than primary earners and when secondary earners reduce their 
earned incomes there is little reduction (or an increase) in joint income. Some secondary earners are effectively subsidised to stay at home [Eissa and Hoynes, 2004]. However, using individuals as the unit of assessment would increase fiscal costs through increasing the number of eligible recipients (particularly income-poor individuals with wealthy spouses) unless the generosity of assistance was reduced, increase administration and compliance costs (as both partners in a couple would be required to apply for assistance), and be likely to lead to moral hazard (through partnered families reallocating incomes and assets within families to minimise taxes or maximise assistance) [Whitehouse, 1996; Stephens, 1997].

In Australia families largely dependent on a single income are eligible for additional assistance (the Family Tax Benefit Part B). Sole-parents are not subject to any abatement of this additional assistance. In partnered families this assistance only abates against the lowest income earner's income. Partnered families face higher abatement of this programme (and larger disincentives for work) when a secondary earner increases their earned income than when a primary earner increases their earned income. In the United States support for single-income partnered families is provided through differences in income tax filing status for married couples and tax exemptions for married spouses and dependants. This continued use of joint taxation contrasts with the trend among OECD countries to move towards separate taxation of couples to reduce disincentives to work facing secondary earners [OECD, 2001]. Non-refundable tax rebates (only available to taxpayers with some level of earned income) for the support of a spouse or common law partner and a dependant are also provided in Canada.

The five countries also take a variety of approaches to adjusting assistance to fluctuations in recipients' circumstances due to, for example, changes in job status, hours worked, and family status. Entitlement to the Canada Child Tax Benefit is based earnings for the previous year, although

\footnotetext{
* Levying taxes on an individual rather than joint basis increases the personal income tax base and allows personal income tax rates to be reduced (shifts towards individual income tax bases partly funded reductions in personal income tax rates in a number of OECD countries during the 1980s and 1990s [OECD 2001a]).
} 
adjustments can be made for changes in family composition. Failure to adjust tax-based assistance during the year may lead to recipients experiencing periods of hardship when incomes fall.

In other jurisdictions assessment based on current year income with year-end square-ups and advance-payment schemes (that pay benefits during the year) are used to increase the ability of tax credits to respond to changing needs. A high proportion of recipients take-up assistance during the year in New Zealand and these payments tend to be relatively accurate, reflecting the largely automated nature of the administration of these programmes with the tax authority adjusting levels of assistance when families' incomes or welfare receipt change. However, administrative and compliance issues, particularly low awareness of entitlements and potential recipients' aversion to incurring debts from overpayments, have reduced the effectiveness and take-up of advance-payment schemes in the United States and United Kingdom [Whitehouse, 1996]. Under an advance payment scheme with a year-end square-up, over-payments or under-payments may arise if incomes fluctuate during the income tax year and the level of assistance does not adjust. To minimise the problems of people incurring taxdebts some small levels of debt are waived in Australia and in the United Kingdom small levels of income changes are disregarded in the year-end square-up process [Whiteford, Mendelson, and Millar, 2003]. Basing entitlement on income at time of application and disregarding future changes in income during the income tax year would avoid these difficulties. This approach could, however, lead to moral hazard through encouraging recipients to suppress their income around time of application through altering the timing of income streams.

\subsection{Conclusion}

This chapter compared the New Zealand tax-benefit system and family and employment tax credits with those in four other Anglo-American countries. Australia, Canada, the United Kingdom, and the United States have all undertaken reform to their family and employment tax credits. Such reforms are currently underway in New Zealand. This chapter illustrated the different 
approaches taken to designing family and employment tax credits in these countries. Of these designs the dual objective approach, particularly of the United Kingdom, appears to offer greater opportunity for both directly addressing relatively high rates of child poverty and increasing low-wage caregivers' labour supply (as part of a broader poverty reduction strategy).

The United States has emphasised encouraging paid employment in the design of family and employment tax credits. Generosity of assistance is relatively low, which indicates a reluctance to subsidise caregivers' withdrawal from the labour market. Labour market participation rates of soleparents and married mothers and poverty rates are relatively high. Reflecting increases in caregivers' employment rates and relatively high rates of economic growth, over the 1990s child poverty rates fell. With flexible labour markets employment tax credits play an important role in reducing child poverty through encouraging low-wage caregivers' employment. The effectiveness of this assistance at reducing poverty would fall should economic growth and rates of caregivers' employment decline. In this context in the United States the growing emphasis on pursuing child-based goals through extending the Child Tax Credit is significant.

Canada and Australia both place emphasis on targeting assistance by family structure. In Canada relatively little emphasis is given to promoting paid employment (except at the provincial level) and assistance strongly differentiates between families on the bases of numbers and ages of children. In Australia emphasis is placed upon maintaining family structures (particularly single-income families with children), as shown by the generous Family Tax Benefits provided to caregivers largely irrespective of employment status and the higher abatement of these credits when secondary income earners work for more than a few hours per week. In these countries greater emphasis could be placed on the potential role employment tax credits (improving financial incentives for low-wage secondary earners' labour supply) as part of a strategy for reducing child poverty, particularly in Australia where rates of caregivers' labour supply tend to be relatively low.

The United Kingdom and New Zealand both aim to balance goals for ensuring income adequacy among families with children and encouraging 
caregivers' labour supply. This approach has partly influenced the relatively large fall in the rate of child poverty in the United Kingdom over the 1990s, although take-up of tax credits has been relatively low. In New Zealand emphasis is also given to reducing programmes' fiscal costs (providing assistance on a more residual basis). In this country employment tax credits are, for example, limited to families with children to both compensate these families for the additional costs they face when working and to ensure that assistance to working families is tightly targeted and fiscal costs reduced. This highly residual nature of assistance in New Zealand was reflected in an increasing rate of child poverty over the 1990s.

Within these broader attempts to reconcile policy goals the AngloAmerican countries have taken different approaches to the designs of family and employment tax credits. In their design of family tax credits, Australia, New Zealand, and the United States have placed relatively little emphasis on additional needs facing families with younger children, particularly the costs of caregivers' withdrawal from the labour market in New Zealand. The United Kingdom and New Zealand both use hours-based thresholds to exclude highwage and low-hour workers from receipt of their employment tax credits, although (as argued in chapters 10 and 11) the use of these thresholds is inconsistent with increasing use of employment contracts requiring flexibility in hours of work. 


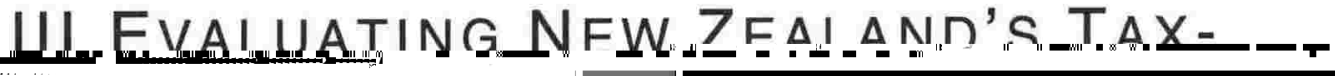
(1) 


\section{Income Adequacy}

\subsection{Introduction}

This chapter discusses income adequacy and aims to identify whether there are particular demographic groups of particular concern for this study. These changes in incomes have taken place within important changes in patterns of family structures and work in New Zealand. Section two of this chapter thus discusses these changes in historical and comparative context. The chapter then discusses the changing distribution of income (particularly income inequality), poverty incidence, poverty gap, and poverty reduction effectiveness of the tax-benefit system, and comparisons between New Zealand poverty rates and rates in other Anglo-American countries. Following this the chapter discusses living standards measures, which can indicate which demographic groups forego consumption of certain items because of their costs and can thus be used to verify analysis based on income measures. Finally the duration of benefit receipt in New Zealand is discussed. These discussions illustrate the interaction of labour market outcomes and income adequacy outcomes and reinforce the need to address low financial incentives for low-income families to supply labour or poverty traps (considered in the following chapter). 


\subsection{Population Heterogeneity and Income Inequality}

\section{Increasing Heterogeneity of Families}

Changes in the income distribution and living standards in New Zealand have taken place within important changes in patterns of family structures. Between 1976 and 2001 the percentage of two-parent families decreased from 62 to 42 percent of all families. In 2001 of the 967,614 families (excluding one-person families) in New Zealand two-parent families numbered 407,793 . In this period there were corresponding increases in the proportions of couples without children from 29 to 39 percent and sole-parent families from 9 to 19 percent [Statistics New Zealand, 2002b, p. 9]. In 2001 sole-parent families numbered 182,919. Since 1976 there has also been a significant increase in one-person families [Statistics New Zealand, 2002b, p. 10]. In 2001 one-person families numbered 307,635.

In 2001 the majority (53 percent) of sole-parent families had one child. Partnered families were more likely to include two children (39 percent) than one child (35 percent). Larger families were less common with 26 percent of partnered families and 18 percent of sole-parent families having three or more children. Among families with children the patterns of family size showed little change between 1991 and 2001. One-child families accounted for an increasing proportion of total families. Beneficiary families tended to have lower numbers of children than the wider population.

These changes in New Zealand can be seen in the light of trends in similar countries. Table 8.1 compares a number of demographic and labour market indicators for New Zealand and four other Anglo-American countries. The other countries are Australia, Canada, the United Kingdom, and the United States. In these countries increases in divorce and non-marital childbearing and shifts in the living arrangements of young adults and families have led to rises in sole-parenthood, single adults living alone, and a decline in extended families [Singley and Callister, 2003, p. 2]. While New Zealand and the United States have the largest proportions of families 
headed by a sole-parent and incidences of teenage births among AngloAmerican countries, all five countries are above the OECD average for these outcomes, which are significant indicators of hardship and poor child outcomes [Jacobsen, Mays, et al, 2002]. There is an ethnic dimension to the results for New Zealand and the United States, with Maori and Pacific in New Zealand and African-American and Hispanics in the United States having higher incidences of sole-parenting and teen births than the dominant European populations, although the results for the predominant European populations are still well above the OECD average [Stephens, 2000].

Table 8.1: Anglo-American Demographic and Labour Market Indicators (2001)

\begin{tabular}{lllllllll}
\hline Country & $\begin{array}{l}\text { Children } \\
\text { Under 16 } \\
(\%)\end{array}$ & $\begin{array}{l}\text { Sole- } \\
\text { Parents } \\
(\%)\end{array}$ & $\begin{array}{l}\text { Married } \\
\text { Mothers } \\
\text { Working } \\
(\%)\end{array}$ & $\begin{array}{l}\text { Sole } \\
\text { Mothers } \\
\text { Working } \\
(\%)\end{array}$ & $\begin{array}{l}\text { Female } \\
\text { Earnings } \\
(\% \text { Male) }\end{array}$ & $\begin{array}{l}\text { Fertility } \\
\text { Rate }\end{array}$ & $\begin{array}{l}\text { Births } \\
\text { Out Of } \\
\text { Marriage }\end{array}$ & $\begin{array}{l}\text { Teen } \\
\text { Births }\end{array}$ \\
\hline Australia & 20 & 21 & 58 & 46 & 81 & 1.7 & 28.7 & 4.7 \\
Canada & 20 & 17 & $70^{*}$ & 51 & 72 & 1.5 & - & 5.7 \\
$\begin{array}{l}\text { New } \\
\text { Zealand }\end{array}$ & 23 & 29 & 68 & 47 & 76 & 2.0 & 42.0 & 8.4 \\
$\begin{array}{l}\text { United } \\
\text { Kingdom }\end{array}$ & 20 & 22 & 68 & 50 & 74 & 1.6 & 40.1 & 7.6 \\
$\begin{array}{l}\text { United } \\
\text { States }\end{array}$ & 21 & 29 & 68 & 68 & 73 & 2.1 & 33.0 & 12.3 \\
\hline
\end{tabular}

${ }^{*}$ All women aged 16 or older

Source: Nolan, Stephens, and Callister, 2005, p. 2

\section{Increasing Polarisation of Work}

As well as patterns of family structures, the Anglo-American countries have also experienced significant changes in labour market outcomes. In the five countries there has been an increase in the labour market participation of females, particularly in managerial professions, and a decrease in labour market participation rates of males, particularly blue-collar workers [Singley and Callister, 2003, p. 3]. In these countries changes in family structures and labour markets have influenced the polarisation of work, with a growth in both work-rich families (including dual-earner couples) and, with the exception of the United States, work-poor families (including couples where neither partner is in paid work) [Singley and Callister, 2003; Gregg, Scutella, and Wadsworth, 2004]. 
With the exception of Australia, which has a relatively low proportion of married mothers working despite a relatively high level of female earnings, proportions of married mothers working in Anglo-American countries are similar. In New Zealand the increasing incidence of dual-income families reflects the strong relationship between age of the youngest child in the family and the labour market status of the mother. As Johnston [2005, p. 14] has illustrated, New Zealand women tend to leave the labour force when they have children and to return strongly to the labour force when their children get older. With the exception of the United States there are large differences in employment rates between married and sole mothers in each of the AngloAmerican countries. Proportions of sole mothers working have risen in the five countries over the last decade with the largest increase occurring in New Zealand, where their employment rate has risen from 27 percent in 1991 [Nolan, Stephens, and Callister, 2005, p. 2].

Singley and Callister [2003] illustrated the incidence of jobless families within family types in New Zealand, the United Kingdom, and the United States in 2000. In all three countries single families had the highest percentages of joblessness, with sole-parents having higher rates of joblessness than single adults. Partnered families had much lower rates of joblessness than single families and partnered families without children had higher rates of joblessness than partnered families with children. New Zealand and the United Kingdom had similar proportions of jobless families within family type. The United States had much lower proportions of soleparent and single adult jobless families. The proportions of jobless partnered with children families were similar in the three countries.

Since the mid 1980s the trends for jobless families have generally followed broader economic trends. New Zealand, Australia, and the United Kingdom experienced both periods of growth and periods of decline in the proportion of prime-aged jobless families. In comparison to these three other countries the United States had a lower proportion of jobless families and relatively little change in the proportion of jobless families until the fall in this rate following sustained economic growth during the 1990s [Singley and Callister, 2003]. 


\section{Income Inequality 1984 to 1998}

Since 1984 the New Zealand income distribution has undergone significant change. When reviewing changes in incomes in New Zealand from 1991 to 1998 , Mowbray [2001, p. 8] identified that family incomes in dollar terms, which fell throughout the 1980s, reached a low point between 1992 and 1994. This fall was associated with the business cycle, with the economy moving into recession at the end of the 1980 s and entering a recovery phase from 1991 [Bakker and Creedy, in O'Dea, 2000]. Mowbray [2001, p. 8] also identified that between 1994 and 1998 family income levels recovered, although not to the levels of the 1980s.

As well as this trend for falling real family incomes there was also a trend for increasing income inequality. To illustrate this changing income inequality the findings of a number of studies of the changing Gini coefficient in New Zealand are presented in table 8.2. The Gini coefficient indicates the extent to which the Lorenz curve deviates from the line of equality. "The Gini coefficient measures the area between the line of equality and the actual income distribution and can have a value of between zero and one, where zero implies total equality (everyone has the same income) and one implies total income inequality (all income is in the hands of one person) [Creedy, 1999, p. 413; O'Dea, 2000].

The studies of the changing Gini coefficient in New Zealand presented in table 8.2 employed a range of different income measures. However, these studies are all based on Household Economic Survey data and show an increase in income inequality from 1983 to 1995 . The bulk of this increase occurred between 1985 and 1990. Gini coefficients based on census data confirm these results [Martin, 1998, in O'Dea, 2000]. The Statistics New Zealand [1999] study allows the increase in income inequality due to changing composition of family structures to be isolated. The increase in the Gini coefficient from 1985 to 1995 on the basis of family market income was 0.077 and of this 0.013 was due to change in family structures. Changes in family structure were thus responsible for 17 percent of the increase in 
income inequality on the basis of family market income. Changes in family structure had a much smaller effect on the increase in inequality of disposable equivalised income. Of this increase, changes in family structure only accounted for 1.5 percent.

Table 8.2: Estimates of Gini Coefficients in New Zealand (1983-84 to 1995-96)

\begin{tabular}{|c|c|c|c|c|c|c|}
\hline & Income Concept & $\begin{array}{c}1983- \\
84\end{array}$ & $\begin{array}{c}1985- \\
86\end{array}$ & $\begin{array}{c}1990- \\
91\end{array}$ & $\begin{array}{c}1991- \\
92\end{array}$ & $\begin{array}{c}1995- \\
96\end{array}$ \\
\hline $\begin{array}{l}\text { Podder and } \\
\text { Chatterjee [1998] }\end{array}$ & Gross Equivalised & 0.353 & & & 0.382 & 0.404 \\
\hline \multirow[t]{2}{*}{$\begin{array}{l}\text { Statistics New } \\
\text { Zealand [1999] }\end{array}$} & $\begin{array}{l}\text { Family Market } \\
\text { Actual }\end{array}$ & & 0.394 & 0.453 & & 0.471 \\
\hline & $\begin{array}{l}\text { - With } \\
\text { Demographic } \\
\text { Adjustment }\end{array}$ & & 0.407 & 0.454 & & 0.471 \\
\hline \multirow[t]{2}{*}{$\begin{array}{l}\text { Statistics New } \\
\text { Zealand [1999] }\end{array}$} & $\begin{array}{l}\text { Disposable } \\
\text { Equivalised }\end{array}$ & & 0.254 & 0.305 & & 0.322 \\
\hline & $\begin{array}{l}\text { - With } \\
\text { Demographic } \\
\text { Adjustment }\end{array}$ & & 0.255 & 0.303 & & 0.322 \\
\hline $\begin{array}{l}\text { Hyslop and Maré } \\
\text { [1999] }\end{array}$ & $\begin{array}{l}\text { Gross Family } \\
\text { Income }\end{array}$ & $\begin{array}{l}0.347 \\
(1983 \\
\text { to } \\
1988)\end{array}$ & & & & $\begin{array}{l}0.398 \\
(1995 \\
\text { to } \\
1998) \\
\end{array}$ \\
\hline
\end{tabular}

Source: O’Dea, 2000

To further illustrate the drivers of this increase in income inequality, O'Dea [2000] reviewed research that isolates the effect of a range of demographic factors (e.g., age, sex, and family type) on rising income inequality in New Zealand. Key findings of this study were that:

- Influencing the change in income inequality at a family level were changes in family composition (such as the relative share of sole-parent and two parent families), the age profile of the population, and qualifications.

- Influencing the change in income inequality at an individual level were age, sex, ethnicity, and qualifications.

* The Lorenz curve graphs the cumulative distribution of income against the cumulative distribution of people. The line where the relative population share equals the cumulative income share (the 45 degree diagonal from the origin) is the line of equality. 
- Falling labour force participation rates for men contributed to income inequality. At a family level rising female labour force participation may have partially masked the effect of falling male participation on changes in income inequality.

- Reflecting life cycle changes (such as increasing earnings with workforce experience and income falling in child-bearing age-groups for women) an individual's age strongly influenced their income.

- Due to difficulty in measuring important contributors to inequality no study could explain more than 60 percent of the increase in income inequality. For example, while studies assume that qualifications can act as a proxy for changes in skill levels there are a range of skills (such as interpersonal skills) not captured by the type of qualifications people hold.

Overall the key drivers of the increase in income inequality included changes in wages and salaries (wages and salaries comprise the large majority of market income), changes in family composition (especially the growth in soleparent families and older families without children), a growing proportion of workers in their prime earning years and with higher educational qualifications, and changes in employment outcomes [O'Dea, 2000].

\section{The Composition of Low-Income Families 1988 to 1998}

The discussion above emphasised changes in the inequality of incomes in New Zealand. The following section, in contrast, focuses only on those families at the bottom of the income distribution. Mowbray [2001] found that in 1998 families with children tended to cluster in the bottom two-fifths of the income distribution. Families with children had lower equivalised disposable incomes than families without children, irrespective of the numbers of adults present in the family [Mowbray, 2001, pp. 21 and 29-31]. Table 8.3 illustrates the percentage of different family types in the lowest income quintile. These data are based on disposable family incomes equivalised with the Revised Jensen Scale [Mowbray, 2001, pp. 12 and 21]. From 1998 to 1990, 19 percent of families with children had incomes in the bottom quintile of equivalised family income. By 1992 this had increased to 29 percent. This incidence of low incomes among families with children remained at around 
this level until 1996, when the incidence fell to 24 percent. In 1998 a quarter of families with children were in the lowest income quintile. Families with three or more children were most likely to be in the lowest quintile than families with one or two children.

Table 8.3: Families in Quintile One by Number of Children (1988-1998)

\begin{tabular}{|c|c|c|c|c|c|c|}
\hline \multirow[t]{2}{*}{ Family Type } & 1988 & 1990 & 1992 & 1994 & 1996 & 1998 \\
\hline & \multicolumn{6}{|c|}{ (Percentage Within Lowest Quintile) } \\
\hline One-Child Family & 11 & 13 & 27 & 22 & 16 & 19 \\
\hline Two Child Family & 16 & 19 & 26 & 30 & 24 & 23 \\
\hline Three-Child Family & 27 & 25 & 31 & 36 & 29 & 19 \\
\hline Four Or More-Child Family & 46 & 42 & 50 & 47 & 39 & 34 \\
\hline $\begin{array}{l}\text { Any Children or Dependent } \\
\text { Young People in Q1 }\end{array}$ & 39 & 38 & 56 & 61 & 48 & 43 \\
\hline $\begin{array}{l}\text { Percentage of Families with } \\
\text { Children or Dependent Young } \\
\text { People in Q1 }\end{array}$ & 19 & 19 & 29 & 30 & 24 & 22 \\
\hline $\begin{array}{l}\text { Percentage of Children or } \\
\text { Dependent Young People in } \\
\text { Q1 }\end{array}$ & 24 & 23 & 31 & 33 & 27 & 24 \\
\hline
\end{tabular}

Source: Mowbray, 2001, p. 31

Sole-parents were more likely to lie toward the lower end of the income distribution. In 1988 and 1989 approximately 20 percent of sole-parents had equivalised disposable incomes that put them in the lowest income quintile. The proportion of sole-parents in the lowest income quintile increased to approximately 34 percent in 1991 and 50 percent in 1992, possibly reflecting the 1991 reductions in main welfare benefits [Mowbray, 2001, p. 35]. The incidence of sole-parents in the lowest income quintile remained at this level until 1994, after which it reduced to 44 percent in 1996 and 38 percent in 1998 [Mowbray, 2001, p. 35].

Factors such as age of youngest child and family size were also correlated with low incomes. The distribution of family incomes by age of youngest child indicated that families with younger children were more likely to have lower incomes and that generally the level of family income rose with the age of youngest child. For sole-parents the age of youngest child was a more significant factor at the low end of the income distribution than it was for couples. There was also some correlation between family size and income, with larger families being less likely to have higher incomes than smaller families. 
The proportion of beneficiary families in the lowest income quintile increased from 28 percent in 1990 to 42 percent in 1991. In 1992 the proportion had increased to 57 percent. The proportion fell to 54 percent in 1994 and 43 percent of families that received a main welfare benefit had disposable incomes that placed them in the bottom quintile of the income distribution in 1998. The mean equivalised income of families that included a recipient of a main welfare benefit was 72 percent of the average disposable family income in 1982. The mean equivalised income of beneficiary families fell to between 65 and 72 percent until 1990. After 1991 the mean equivalised family income of beneficiaries fell to 57 percent [Mowbray, 2001, p. 35].

\subsection{Poverty}

The section above identified that families with children tended to cluster in the bottom two-fifths of the income distribution. Among these families low incomes were also correlated with larger family size, younger children, sole parenthood, and receipt of a main welfare benefit. To assess whether or not the incomes of these low-income families were not only relatively low but also inadequate, the following section summarises research on the changing poverty incidence, poverty gap, and poverty reduction effectiveness from 1984 to 1998 and from 1998 to 2001 . The 1984 to 1993 period saw a large increase in poverty, particularly reflecting the 1991 benefit reductions and declining rates of economic growth. By 1998 rates of poverty had begun to fall but between 1998 and 2001 rates of child poverty had begun to increase again.

\section{Poverty Incidence 1984 to 1993}

The Poverty Measurement Project used a focus group methodology to establish a poverty line related to current economic conditions and social policies. This threshold was then adjusted in line with consumer prices to give an absolute measure [Stephens, 1999, p. 252]. The Poverty Measurement Project calculated that from 1984 to 1993 the percentage of families below the consumer price adjusted poverty line before housing costs 
rose from 4.3 percent of $(42,000$ families and 159,000 people) to 10.8 percent of families (116,000 families and 393,000 people). In 1984 the family types with the highest incidences of poverty were adults with three or more children (with a poverty incidence of 14 percent) and sole-parents (with an incidence of 11.8 percent). By 1993 sole-parents had the highest poverty incidence of all family types of 46.2 percent. The poverty incidence of adults with three or more children had increased to 24.1 percent [Stephens, 1999, p. 252]. Overall, families with dependent children had higher poverty incidences than families without and these incidences rose with the number of children in the family [Stephens, 1999, p. 252].

The increasing incidence of poverty among sole-parents was reflected in a change in the structure of overall poverty. Sole-parents accounted for an increasing proportion of families in poverty, rising from 10.1 to 22.8 percent of all families. Single adults also accounted for a greater proportion of the structure of poverty, increasing from 15.4 in 1984 to 17.4 percent in 1993 and becoming the second most common type of family in poverty. Adults with three or more children and adults with two children accounted for lower proportions of the structure of poverty (falling from 28.2 to 15.7 percent and 18.8 to 11.2 percent respectively) but still accounted for significant proportions of all the families in poverty [Stephens, 1999, p. 253].

The Poverty Measurement Project also estimated changes in a relative poverty measure based on 60 percent of median family disposable income. However, as O'Dea [2000] has argued, from 1985 to 1995 in New Zealand the median income fell but the mean income increased.

This is an unusual situation in that means and medians usually move more or less in parallel. The fact that they [had not moved in parallel between 1985 and 1995] shows in itself that there have been significant changes to the income distribution. These disparate trends have bedevilled discussion of 'poverty' over this period. If a 'poverty line' is defined as some percentage of the median [...] then a decline in the median can result in a lower percentage of families apparently being in poverty', even when the position of those near the bottom end of the distribution is perhaps worsening [O'Dea, 2000, p. 26].

Thus, as median income fell the poverty line benchmarked against median income fell also: 
Between 1984 and 1993, median income fell by 17.1 per cent, with similar declines for each of the bottom five deciles. This dramatic fall in the benchmark poverty level meant that the incidence of poverty remained constant between 1984 and 1991, but then fell from 13.7 per cent to 10.8 per cent in 1993 . This fall was due to the substantial reduction in poverty among single adults, from 25.9 per cent in 1991 to 9.1 per cent in 1993 . The poverty line went from marginally above to marginally below the level of New Zealand Superannuation. Yet most family groups actually had an increase in their incidence of poverty; for example, 35.8 per cent of sole parents were poor in 1991, compared with 46.2 per cent in 1993 [Stephens, 1999, p. 254].

The Poverty Measurement Project also estimated that between 1984 and 1993 the overall effectiveness of the tax-benefit system at reducing poverty had fallen from 88.7 to 73.2 percent. The largest falls were in poverty reduction effectiveness of families with children. The poverty reduction effectiveness rate for sole-parents fell from 85.4 to 46.6 percent, for partnered adults with three or more children from 63.6 to 27.2 percent, for partnered adults with two children from 57.1 to 49.8 percent, and for partnered adults with one child from 73.9 to 54.1 percent [Stephens, 1999, p. 253]. Poverty reduction effectiveness declined as the number of children in the family increased.

\section{Poverty Incidence 1998 to 2000}

In 1998 families without dependent children were the largest single familytype in poverty. The poverty incidence increased with the number of children in the family. The higher poverty incidence for larger families and the ethnic composition of poverty were related (although segmenting the total population into ethnic groups could at times obscure the heterogeneity within such groups [Chapple, 2000, p. 103-106; Baehler, 2002, p. 18]). As well as a higher incidence of poverty, Maori and Pacific Islander groups had, on average, larger families, lower employment rates and lower work incomes [Stephens, 1999, p. 254]. Further, over a third of beneficiaries were below the 60 percent threshold, compared to ten percent of families with one person employed and five percent with two employees in the family. However, although the incidence of poverty was low among working families, almost 30 percent of the families below the 60 percent poverty line were working families [Stephens and Waldegrave, 2001]. 
Table 8.4: Incidence and Severity of Poverty (1997 and 2000)

\begin{tabular}{|c|c|c|c|c|c|c|c|c|}
\hline \multicolumn{9}{|c|}{ (a) Before Adjusting for Housing Costs } \\
\hline \multirow{2}{*}{$\begin{array}{l}\text { Poverty } \\
\text { Incidence }\end{array}$} & \multicolumn{2}{|l|}{ All } & \multicolumn{2}{|c|}{ Adults $18-64$} & \multicolumn{2}{|c|}{ Adults $65+$} & \multicolumn{2}{|c|}{ Children 0-18 } \\
\hline & 1997 & 2000 & 1997 & 2000 & 1997 & 2000 & 1997 & 2000 \\
\hline Market & 28.4 & 27.4 & 18.2 & 18.3 & 76.9 & 71.2 & 30.8 & 29.9 \\
\hline Disposable & 15.7 & 16.3 & 11.0 & 13.2 & 30.0 & 17.9 & 20.5 & 23.9 \\
\hline Efficiency & $44.7 \%$ & $40.5 \%$ & $39.6 \%$ & $27.9 \%$ & $61.0 \%$ & $74.9 \%$ & $33.4 \%$ & $20.1 \%$ \\
\hline \multicolumn{9}{|c|}{ Poverty Gap (\$) } \\
\hline Market & 5,668 & 6,625 & 993 & 1,555 & 3,226 & 3,440 & 1,449 & 1,630 \\
\hline Disposable & 598 & 729 & 235 & 341 & 117 & 34 & 246 & 354 \\
\hline Efficiency & $89.4 \%$ & $89.0 \%$ & $76.3 \%$ & $78.1 \%$ & $96.4 \%$ & $99.0 \%$ & $83.0 \%$ & $86.3 \%$ \\
\hline \multicolumn{9}{|c|}{ (b) After Adjusting for Housing Costs } \\
\hline \multirow{2}{*}{$\begin{array}{l}\text { Poverty } \\
\text { Incidence }\end{array}$} & \multicolumn{2}{|l|}{ All } & \multicolumn{2}{|c|}{ Adults $18-64$} & \multicolumn{2}{|c|}{ Adults $65+$} & \multicolumn{2}{|c|}{ Children 0-18 } \\
\hline & 1997 & 2000 & 1997 & 2000 & 1997 & 2000 & 1997 & 2000 \\
\hline Market & 29.7 & 30.2 & 19.5 & 21.2 & 75.3 & 70.6 & 33.5 & 33.9 \\
\hline Disposable & 20.3 & 21.9 & 16.7 & 18.8 & 12.3 & 10.8 & 33.5 & 35.0 \\
\hline Efficiency & $31.6 \%$ & $27.5 \%$ & $14.4 \%$ & $11.3 \%$ & $83.7 \%$ & $84.7 \%$ & $0.0 \%$ & $-3.2 \%$ \\
\hline \multicolumn{9}{|c|}{ Poverty Gap (\$) } \\
\hline Market & 6,059 & 7,283 & 1,059 & 1,654 & 3,222 & 3,438 & 1,778 & 2,191 \\
\hline Disposable & 1,211 & 1,589 & 422 & 626 & 146 & 115 & 643 & 848 \\
\hline Efficiency & $80.0 \%$ & $78.2 \%$ & $60.2 \%$ & $62.2 \%$ & $95.5 \%$ & $96.7 \%$ & $63.8 \%$ & $61.3 \%$ \\
\hline
\end{tabular}

Source: Waldegrave, Stephens, and King, 2003, p. 207

Table 8.4 presents findings of the New Zealand Poverty Measurement project on the poverty incidence and poverty gap for 1997 and 2000. This table uses data derived from the 1997-98 and 2000-01 HES surveys, which are centred on September 1997 and December 2000. Thus the 2000-01 HES data do not provide complete annual data on policy changes such as the 1 April 2000 increase in the partnered rate of superannuation to above 65 percent of the net average ordinary time weekly earnings. The 1997-98 year is thus listed as 1997 and the 2000-01 year as 2000 [Waldegrave, Stephens, and King, 2003, p. 207]. The poverty threshold has been updated on a relative basis (percentage of median family disposable income).

On the basis of market income the poverty incidence before housing costs for the population as a whole fell from 28.4 to 27.4 percent. There was also little change in the poverty incidence on the basis of disposable income, which increased from 15.7 to 16.3 percent. The population group who had the largest change in their poverty incidence between 1997 and 2000 was adults 65 and older. The disposable income poverty incidence for this group 
fell from 30.0 percent in 1997 to 17.9 percent in 2000 due to the policy of restoring of the pension level to 65 percent of average weekly earnings.

For both adults aged 18 to 64 and children there were little changes to the market income poverty incidence between 1997 and 2000. However, for both of these groups the disposable income poverty incidence increased (from 11.0 to 13.2 percent for adults 18 to 64 and from 20.5 to 23.9 for children), reflecting a decrease in the poverty reduction effectiveness of the social assistance system. The effectiveness of the social assistance system at reducing poverty among adults 18 to 64 fell from 39.6 to 27.9 percent and for children from 33.4 to 20.1 percent. Possible reasons for this fall in the poverty reduction effectiveness for children were the lack of indexation of the Family Assistance programmes and the exclusion of beneficiary families from receipt of the Child Tax Credit [St John and Craig, 2004]. The incidence of poverty was higher for children than for adults aged 18 to 64 . Children's disposable income poverty incidence increased from 20.5 percent to 23.9 percent in 2000.

The poverty incidence and poverty reduction effectiveness for adults aged 18 to 64 and children worsened when housing costs were taken into account. For adults aged 65 and above the poverty incidence and poverty reduction effectiveness improved when housing costs were taken into account, possibly reflecting the relatively high rates of home ownership among this group.

\section{New Zealand's Poverty Incidence Rankings}

As shown in table 8.5, Perry [2004] estimated that, based on a poverty threshoid of 60 percent of the equivalised family median income, in 2000-01 New Zealand's child poverty rate (of 22 percent) was above the European Union average (of 19 percent) but similar to the rates of Canada and the United Kingdom (of 23 and 24 percent). Child poverty was notably less than that of the United States (of 30 percent). Data on Australia was not presented in this study. With the exception of the United States, the listed AngloAmerican countries thus had similar incidences of child poverty. 
Table 8.5: International Estimates of Child Poverty at $60 \%$ Family Median Income (2000-01)

\begin{tabular}{lc}
\hline United States & $30 \%$ \\
Portugal & $27 \%$ \\
Spain & $26 \%$ \\
Ireland & $26 \%$ \\
Italy & $25 \%$ \\
United Kingdom & $24 \%$ \\
Canada & $23 \%$ \\
New Zealand (2001) & $22 \%$ \\
European Union Average & $19 \%$ \\
Greece & $18 \%$ \\
France & $18 \%$ \\
Netherlands & $16 \%$ \\
Germany & $14 \%$ \\
Belgium & $13 \%$ \\
Sweden & $10 \%$ \\
Finland & $6 \%$ \\
Denmark & $5 \%$ \\
\hline
\end{tabular}

Source: Perry, 2004, p. 41

This result that Anglo-American countries, with the exception of the United States, have similar incidences of poverty has been found by other studies. Using the 2000 Luxembourg Income Study and a poverty threshold of 60 percent of family median income, Fritzell and Ritakallio [2004] estimated the incidence of poverty at 23.6 percent in the United States, 19.5 percent in the United Kingdom, and 17.1 percent in Canada. Using a slightly different methodology Waldegrave, Stephens, and King [2003] estimated a poverty incidence of 16.3 percent in New Zealand. In 1994 Australia had a poverty incidence comparable to New Zealand. Based on poverty thresholds of 50 percent of median family equivalised disposable income, the Australian child poverty rate for 1993-94 was estimated at 11 percent, for 1996-1997 was estimated at 13 percent, and for 1997-1998 was estimated at 12 percent [Bradbury, 2003a; Perry, 2004]. The New Zealand child poverty rate at this threshold for 1994 to 1998 was estimated to range from 11 to 14 percent and for 2001 was estimated at 14 percent [Perry, 2004].

Recent UNICEF research on child poverty in OECD countries has ranked New Zealand (with the fourth highest poverty incidence at 16.3 percent) behind Australia (ninth highest at 14.7 percent), Canada (eighth 
highest at 14.9 percent), and the United Kingdom (seventh highest at 15.4 percent) for rates of child poverty based on a poverty threshold of 50 percent of equivalised median income for 2001 [UNICEF, 2005]. At 21.9 percent the United States had the second highest incidence of child poverty in the OECD behind Mexico. These of rates child poverty had fallen from the rates in the early 1990 s by 3.1 percent in the United Kingdom, 2.4 percent in the United States, 1.7 percent in Australia, and 0.4 percent in Canada. In New Zealand over this period child poverty rose 2.0 percent. This study thus confirms that the Anglo-American countries, with the exception of the United States, have similar rates of child poverty, particularly when seen in contrast to Nordic countries such as Denmark (at 2.4 percent), Finland (at 2.8 percent), Norway (at 3.4 percent), and Sweden (at 4.2 percent).

\subsection{Living Standards}

Living standards measures can indicate which demographic groups forego consumption of certain items because of their costs. These measures can thus be used to verify analysis based on income measures. The following section of this chapter thus discusses data on living standards based on an Economic Living Standard Index (ELSI) produced by the Ministry of Social Development. The ELSI scale takes detailed indicators of well-being and aggregates them into a single score of living standards. Indicators of wellbeing are drawn from survey data collected for the purpose of measuring living standards [Jensen, Krishnan, et al, 2003, pp. 72-73]. This scale is an output measure.

The Economic Living Standard Index, or ELSI, is based on what people are consuming, their various forms of recreation and social participation, their family facilities and so on, rather than being calculated from the resources (income, financial and assets) that enable them to do these things [Jensen, Krishnan, et al, 2003, p. 74].

40 items are included on the ELSI scale. Data on these items are combined to give an ELSI score with a range from 0 (very low living standard) to 60 (very high living standard). The range of scores is then converted into seven score intervals (living standard levels) [Jensen, Krishnan, et al, 2003, p. 75]. 


\section{Incidence of Low Living Standards}

Overall a large proportion of the population ( 80 percent) have living standards that place them in the "fairly comfortable" (level 4) to "very good" (level 7) score intervals. However, average living standard scores vary widely between different types of economic family units. Sole-parents have the lowest average living standards of all economic family unit types. This can partly be explained by the high proportion of sole-parents who rely on an income-tested benefit for an income source [Jensen, Krishnan, et al, 2003, pp. 82-83].

In 2000, 13 percent of all dependent children had living standard levels of either category one or two, 16 percent had category three, 41 percent had categories four and five, and 30 percent had categories six and seven. Table 8.6 presents data on the propensity for children to experience constraints in consumption by living standard level. Children in families with ELSI scores at the lower end of the scale were more likely to experience constraints on consumption of child-specific goods and services than children in families with higher ELSI scores.

For those with scores that place them in the "restricted" or "somewhat restricted" categories of the scale, it is at least twice as likely that they will experience postponement of trips to the doctor or dentist or not have suitable wet weather clothing. It is also at least twice as likely that books (including school books) will go unbought, computers or internet access will be unavailable at home, school outings will be skipped, cultural lessons and sports involvement will be foregone, and childcare services will go unpurchased [Jensen, Krishnan, et al, 2003, pp. 82-83].

Overall this research illustrated that beneficiary families, sole-parents, and Maori and Pacific groups were relatively likely to have low living standards. Working families had better living standards than beneficiary families even when family incomes were similar. Employment thus plays an important role in influencing living standards and variations in living standards can only be partly explained by income differences. 


\begin{tabular}{|c|c|c|c|c|}
\hline & $\begin{array}{l}\text { Restricted } \\
\text { Living } \\
\text { Standards } \\
(1 \& 2) \\
\%\end{array}$ & $\begin{array}{l}\text { Somewhat } \\
\text { Restricted } \\
\text { Living } \\
\text { Standards } \\
\text { (3) } \\
\%\end{array}$ & $\begin{array}{l}\text { Comfortable } \\
\text { Living } \\
\text { Standards } \\
(4 \& 5) \\
\%\end{array}$ & $\begin{array}{l}\text { Good Living } \\
\text { Standard } \\
(6 \& 7) \\
\%\end{array}$ \\
\hline \multicolumn{5}{|c|}{ Items not obtained and activities not participated in because of cost } \\
\hline $\begin{array}{l}\text { Suitable wet weather } \\
\text { clothing for each child }\end{array}$ & 31 & 7 & 3 & 0 \\
\hline $\begin{array}{l}\text { A pair of shoes in good } \\
\text { condition }\end{array}$ & 17 & 3 & 1 & 0 \\
\hline Child's bike & 24 & 9 & 4 & 0 \\
\hline Playstation & 29 & 23 & 9 & 1 \\
\hline Personal computer & 59 & 29 & 20 & 2 \\
\hline Internet access & 59 & 30 & 19 & 3 \\
\hline Pay for childcare services & 28 & 13 & 8 & 1 \\
\hline $\begin{array}{l}\text { Have children's friends over } \\
\text { for a meal }\end{array}$ & 13 & 5 & 2 & 0 \\
\hline $\begin{array}{l}\text { Have enough room for } \\
\text { children's friends to stay the } \\
\text { night }\end{array}$ & 15 & 2 & 2 & 1 \\
\hline $\begin{array}{l}\text { Have children's friends to a } \\
\text { birthday party }\end{array}$ & 14 & 3 & 2 & 0 \\
\hline \multicolumn{5}{|c|}{ Items of consumption cut back on (a little or a lot) because of cost } \\
\hline Not gone on school outings & 51 & 23 & 7 & 1 \\
\hline $\begin{array}{l}\text { Not bought school } \\
\text { books/supplies }\end{array}$ & 38 & 18 & 5 & 1 \\
\hline Not bought books for home & 58 & 38 & 17 & 3 \\
\hline $\begin{array}{l}\text { Postponed child's visit to the } \\
\text { doctor }\end{array}$ & 31 & 13 & 3 & 0 \\
\hline $\begin{array}{l}\text { Postponed child's visit to the } \\
\text { dentist }\end{array}$ & 18 & 10 & 4 & 2 \\
\hline Child went without glasses & 9 & 8 & 1 & 0 \\
\hline $\begin{array}{l}\text { Child went without cultural } \\
\text { lessons }\end{array}$ & 54 & 41 & 20 & 4 \\
\hline $\begin{array}{l}\text { Child's involvement in sports } \\
\text { limited }\end{array}$ & 54 & 34 & 13 & 1 \\
\hline $\begin{array}{l}\text { Child wore bad-fitting clothes } \\
\text { or shoes }\end{array}$ & 57 & 31 & 13 & 3 \\
\hline Children share a bed & 21 & 18 & 3 & 0 \\
\hline $\begin{array}{l}\text { Limited space for children to } \\
\text { study or play }\end{array}$ & 45 & 28 & 12 & 5 \\
\hline
\end{tabular}

Source: Jensen, Krishnan, et al, 2003, p. 83 
Perry [2002] argued that internationally there is a mismatch between income-based and outcome-based poverty measures typically in the range of 50 to 60 percent. Perry estimated that, based on a poverty threshold of 60 percent of median equivalised family income, in New Zealand the overlap between income and deprivation measures is 40 percent [Perry, 2002, p. 109]. This mismatch occurs as:

The link between current income and actual living conditions is [...] not straightforward as there are many factors other than current income that significantly affect consumption and therefore current material wellbeing. These factors can differ significantly from family to family, so that even when their current incomes and consumption needs are the same or similar, their living standards differ [Perry, 2002, p. 105].

The overlap between the measures is dependent on the level at which the poverty threshold is set. Increasing the poverty threshold increases the overlap, although at even a generous poverty threshold (of 70 percent of median equivalised family income) the mismatch is still significant (in the order of 50 percent) [Perry, 2002, p. 112]. Measuring income over a longer period also increases overlap [Perry, 2002, p. 113]. Yet in spite of this mismatch research on living standards can help identify priority groups for intervention and be used to verify analysis of the effects of government interventions on the distribution of income.

\subsection{Duration of Benefit Receipt}

Influencing the rate and incidence of jobless families, poverty, and low living standards in New Zealand are trends for the duration of receipt of and repeated spells on main welfare benefits. As Gardiner and Hills [1999, in O'Dea, 2000] have argued:

It is important to distinguish between at least three groups: the persistently poor, the recurrently poor and the temporarily poor. [...] Much current government policy [...] is aimed at getting people who are currently out of work into work. The extent of recurrent poverty [...] suggests that policy needs to pay attention not just to the first transition, off benefit and into work. It also needs to focus on subsequent transitions, stopping the same people simply cycling between benefits and work, much of it low paid [Gardiner and Hills, 1999, in O'Dea, 2000, p. 47]. 
The probability of a person's spell on a social welfare benefit ending decreases as benefit duration increases. This could be due to a wide range of factors, such as reservations employers may have about hiring long-term unemployed workers, discouragement that may arise when a person has been unable to move off a benefit for a long period, or a composition effect, where, as the length of time on benefit increases, people with low probabilities of employment account for greater proportions of those who receive assistance [Wilson, 1999, p. 66; Wilson, 2002, p. 48].

Wilson [1999] examined administrative data on the duration of receipt of and numbers of spells on main working-aged social welfare benefits, excluding supplementary benefits and New Zealand Superannuation, between 1993 and 1998 for a cohort of around 250,000 people who were granted a working aged benefit in 1993. This paper found that:

- For an estimated 54 percent of recipients the duration of receipt of the first observed spell on a benefit was less than 20 weeks.

- For an estimated 79 percent of recipients the duration of receipt for the first spell on a benefit was less than one year.

- For an estimated 93 percent of recipients the duration of receipt for the first spell on a benefit was less than three years.

- For an estimated four percent of recipients the duration of receipt for the first spell on benefit was at least five years [Wilson, 1999, p. 66].

The duration of the first spell on a benefit varied among the benefit types. It was estimated that approximately three percent of Unemployment Benefit recipients spent all of the five years from 1993 to 1998 receiving a benefit. In contrast, it was estimated that approximately 26 percent of Domestic Purposes Beneficiaries, 39 percent of Widows Benefit recipients, 58 percent of Invalids Benefit recipients, and 15 percent of Sickness Benefit recipients spent all of the five years receiving a benefit [Wilson, 1999, p. 68].

For those people who transfer to another benefit or return to a benefit after some period off a benefit, the duration of the first spell on a benefit understates the length of time that they spend on a benefit. In terms of the total time on a benefit an estimated eight percent of the cohort spent all of the five-year period on a benefit, 33 percent spent three or more of the five years 
on a benefit, and 62 percent spent at least one of the five years on a benefit [Wilson, 1999, p. 67].

An alternative view on the duration of benefit receipt is provided by comparing the number of people in a cohort that received a benefit at different points of time. Of those people who entered a benefit in 1993 an estimated 47 percent of Sickness Benefit recipients, 52 percent of Widows Benefit recipients, 57 percent of Domestic Purposes Benefit recipients, and 69 percent of Invalids Benefit recipients were receiving a benefit, whether continuously or not, at the end of a five-year period. Unemployment Benefit recipients were the least likely to have remained on or be back on benefit at the end of a five-year period. However, due to variations in seasonal employment, receipt of the Unemployment Benefit was strongly cyclical [Wilson, 1999, p. 71].

Gobbi and Rea [2002] also found that there were important differences in the unemployment experiences of different groups for the 1993 cohort. Males had higher risk of multiple spells of unemployment and spent more time unemployed in total. Maori and Pacific groups were at risk of prolonged periods of unemployment. Younger workers had higher risk of becoming unemployed and experiencing multiple spells of unemployment. However, duration of unemployment was longer among older workers. Unemployment Benefit recipients tended to spend shorter periods on a benefit than sickness and invalid beneficiaries, with recipients of Domestic Purposes Benefits falling in-between these groups.

\subsection{Conclusion}

Family structures and labour market outcomes have undergone significant change in New Zealand. There has been a decline in the proportion of single income partnered families. There has been an increase in sole-parent families and partnered families without children. At the family level work has become more polarised with a growth in both work-rich and work-poor families. There has been an increase in the labour market participation of females, particularly in managerial professions, and a decrease in labour market participation rates of males, particularly blue-collar workers. There is 
a strong relationship between age of the youngest child in the family and the labour market status of the mother. Participation of mothers increases as the ages of children in families increase.

The increase in income inequality in New Zealand since the early 1980s has been one of the highest rates of increase in the world. Overall the key drivers of the increase in income inequality included changes in wages and salaries (wages and salaries comprise the large majority of market income), changes in family composition (especially the growth in sole-parent families and older families without children), a growing proportion of workers in their prime earning years and with higher educational qualifications, and changes in employment outcomes [O'Dea, 2000]. Changes in income inequality are important for understanding changes to the incidence and depth of poverty. With increasing income inequality it is possible to have both an increase in economic growth and poverty. Further, with a more unequal income distribution the social value of redistribution to those below the poverty line increases due to the assumed diminishing marginal utility of income [Pigou, 1929, p. 98].

In New Zealand families with children tended to cluster in the bottom two-fifths of the income distribution. Among these families low incomes were also correlated with larger family size, younger children, sole parenthood, and receipt of a main welfare benefit. To assess the degree to which the incomes of these low-income families were inadequate, the chapter summarised research by the Poverty Measurement Project on the changing poverty incidence, poverty gap, and poverty reduction effectiveness from 1984 to 1998 and from 1998 to 2001 . The 1984 to 1993 period saw a large increase in poverty, particulariy refiecting the 1991 benefit reductions and declining rates of economic growth. By 1998 rates of poverty had begun to fall but between 1998 and 2001 rates of child poverty had begun to increase again (reflecting falling poverty reduction effectiveness of the tax-benefit system).

Research on economic living standards illustrated that beneficiary families, sole-parents, and Maori and Pacific groups were relatively likely to have low living standards. Working families had higher living standards than beneficiary families even when family incomes were similar. Employment 
thus plays an important role in influencing living standards. Trends for the duration of receipt of main welfare benefits illustrated that sole-parents, incapacitated people, and widows were the people with the highest duration of benefit receipt and could thus persistently face low living standards. This interaction of labour market outcomes and income adequacy outcomes reinforces the need to address low financial incentives for low-income families to supply labour (poverty traps), which are considered in the following chapter. 


\section{Financial Incentives for Labour Supply}

\subsection{Introduction}

The previous chapter discussed income adequacy and New Zealand's taxbenefit system and illustrated the interaction between labour market and income adequacy outcomes. This chapter continues the evaluation of the tax-benefit system and discusses financial incentives to supply labour. In comparison to the large amount of recent research on income inequality, poverty, and living standards, since the release of Prebble and Rebstock (eds.) [1992] there has been little comprehensive non-government research undertaken on the financial incentives to work contained in New Zealand's tax-benefit system (with the exceptions of St John [1996], St John and Rankin [2002], and Nolan [2003 and 2004c])." This lacuna reflects the complexity of the financial incentives for labour supply created by the interaction of tax-benefit programmes and a lack of independent microsimulation modelling resources.

The structure of this chapter is as follows. In section two the financial incentives to supply labour created by main welfare benefits and the Family Assistance programmes are discussed. First the distribution of effective marginal tax rates over the population as a whole are discussed. From this discussion it is possible to identify the key groups that face poverty traps created by the tax-benefit system. The financial incentives facing these key

\footnotetext{
* This chapter draws upon Nolan [2003 and 2004c], which were based on the 2003-04 taxbenefit system, but updates individual EMTR profiles and budget constraints for 2004-05 (the year immediately prior to the introduction of the Working for Families reforms). In this chapter the earlier research is drawn upon where more recent data were not available for this study.
} 
groups are then investigated in greater detail through modelling of the budget constraints and EMTR profiles facing representative families. The financial incentives to supply labour associated with two other forms of assistance, accommodation assistance and childcare supplements, are then discussed in section three. In section four the financial incentives to supply labour in the New Zealand tax-benefit system are compared with those in other AngloAmerican countries.

\subsection{Main Benefits and Family Assistance}

The tax-benefit system tailors different financial incentives to work to different groups in the population. To illustrate the broad variety of financial incentives to work facing different population groups the financial incentives facing different groups of people are discussed below. These financial incentives reflect the proportions by which increases in gross income are reduced by taxes and the abatement of main welfare benefits and the Family Assistance Tax Credits.

\section{Effective Marginal Tax Rates}

Table 9.1 shows Treasury estimates of the numbers of individuals, excluding all people aged under 15 and dependents aged over 15, who faced certain EMTRs and who received main benefits, the Family Assistance Tax Credits, New Zealand Superannuation, and none of these forms of assistance. These estimates were calculated with TaxMod-A based on 2001 Household Economic Survey data inflated to 2003-04. A person could be present in more than one column except when they were in the none column. The EMTR categories were not divided into even ranges but had instead been divided into ranges reflecting the frequency with which certain EMTRs occured. The estimates in table 9.1 were only based on the abatement of major benefits, thus some EMTRs may have been underestimated (e.g., where recipients received Disability Allowances or Special Benefits). 
Table 9.1: Distribution of Individuals by EMTRs and Benefit Receipt (2003-04)

\begin{tabular}{|c|c|c|c|c|}
\hline EMTR & $\begin{array}{l}\text { Income-Tested } \\
\text { Main Benefit }{ }^{\Pi}\end{array}$ & $\begin{array}{l}\text { Family } \\
\text { Assistance }^{*}\end{array}$ & $\begin{array}{l}\text { New Zealand } \\
\text { Superannuation }\end{array}$ & None \\
\hline Less than 16 & 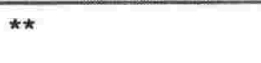 & 2,888 & $\star \star$ & 18,679 \\
\hline 16 to 16.9 & 35,097 & 15,271 & 11,988 & 155,944 \\
\hline 17 to 21.9 & 12,121 & $\star \star$ & ** & 19,861 \\
\hline 22 to 22.9 & 214,288 & 66,148 & 291,101 & 460,802 \\
\hline 23 to 33.9 & 24,488 & 7,290 & $\star *$ & 11,712 \\
\hline 34 to 34.9 & 3,250 & 5,183 & 10,323 & 260,393 \\
\hline 35 to 38.9 & 5,446 & $\star \star$ & ** & 22,712 \\
\hline 39 to 39.9 & ** & $\star *$ & $\star *$ & 46,737 \\
\hline 40 to 40.9 & 7,266 & 13,406 & 7,263 & 116,505 \\
\hline 41 to 45.9 & 13,576 & 5,972 & ** & 3,934 \\
\hline 46 to 46.9 & 3,611 & 13,470 & ** & ** \\
\hline 47 to 47.9 & 54,874 & 22,509 & 18,363 & $\star *$ \\
\hline 48 to 51.9 & ** & ** & ** & ** \\
\hline 52 to 52.9 & 9,578 & 24,475 & ** & $* \star$ \\
\hline 53 to 79.9 & 25,541 & 24,401 & 9,559 & $\star \star$ \\
\hline $80+$ & 20,126 & 12,003 & $\star \star$ & ** \\
\hline All & 431,717 & 215,894 & 357,905 & $1,121,628$ \\
\hline
\end{tabular}

П Unemployment Benefit, Domestic Purposes Benefit, Invalids Benefit, Sickness Benefit, and Widows Benefit

* $\quad$ Family Support Tax Credit, Child Tax Credit, and Family Tax Credit. Excludes Parental Tax Credit

** Too few observations to disclose

Source: Nolan, 2003. Based on 2000-01 HES data inflated to 2003-04 by TaxMod-A

High EMTRs occurred when people paid both personal income taxes and faced abatement of social assistance programmes. People who did not receive social assistance thus generally had lower EMTRs than families who received assistance. The majority of people who received no social assistance had EMTRs below 41 percent. These EMTRs were given by the interaction of the personal income tax scale, the Low Income Earner Rebate, and the ACC earner levy. Further, recipients of New Zealand Superannuation (provided irrespective of income to all qualifying residents) also had generally low EMTRs. New Zealand Superannuation is no longer income-tested and so has no effect on EMTRs. An estimated 87 percent of New Zealand Superannuation recipients faced EMTRs below 23 percent. These EMTRs were given by the interaction of the statutory personal income tax scale, the Low Income Earner Rebate (which applies to all income (both employment 
and passive income) of superannuitants), and, where applicable, the ACC earner levy.

Many working families received the Family Assistance Tax Credits without any other form of assistance so their EMTRs were a combination of the personal income tax scale, the Low Income Earner Rebate, ACC earner levy, and the abatement of the Family Assistance programmes. The distribution of EMTRs among Family Support Recipients was bimodal. Approximately 39 percent of Family Support recipients faced EMTRs below 23 percent, which indicates that these families did not face Family Assistance abatement, while approximately 28 percent of Family Assistance recipients faced EMTRs in the range of 52 percent and above. The Family Tax Credit automatically resulted in very high EMTRs of over 100 percent but very few families qualified for this programme.

For the population who received other forms of government incometested transfers the pattern of EMTRs was more complex due to the range of benefits and supplementary assistance measures, the range of administrative rules and abatement regimes, and variations in family circumstances. The majority (an estimated 61 percent) of recipients of income-tested main benefits faced EMTRs of below 23 percent. These EMTRs were given by the interaction of the personal income tax scale, the Low Income Earner Rebate, the ACC earner levy, and the abatement-free zone for non-benefit earnings. People who faced these EMTRs included both beneficiaries with declared non-benefit income (and whose non-benefit incomes were below the threshold at which the benefit started abating) and beneficiaries without declared non-benefit incomes. The remaining recipients of income-tested main benefits were distributed reasonably evenly among the range of EMTRs, with an estimated 9 percent of recipients facing EMTRs from 23 percent to 40.9 percent, 17 percent facing EMTRs from 41 percent to 51.9 percent, and 13 percent facing EMTRs of 52 percent and above.

Thus for the vast majority of the population the EMTRs created by the interaction of the personal income tax and social assistance systems were less than 48 percent. There were, however, a small number of demographic groups at certain income levels who faced EMTRs in excess of 48 percent. These groups included a number of recipients of income-tested main benefits 
and the Family Assistance programmes. To identify those people who faced high financial disincentives to work in greater detail, the following section of this chapter shows the EMTR profiles and budget constraints that faced different family types at different wage rates in 2004-05 (immediately prior to Working for Families).

\section{Poverty Traps and Family Structures}

The section below discusses the poverty traps facing a sole-parent with two children, a partnered family with two children and one income, and a partnered family with two children and two incomes for 2004-05. (See Nolan [2003, pp. 11-15, 21-23] for an analysis of the poverty traps facing families without children in 2003-04.) The section below first discusses EMTR profiles and budget constraints of a sole-parent with two young children at two wage rates. Profiles for this person at a gross hourly wage of $\$ 10$ and $\$ 15$ are compared to illustrate the impact of variations in the wage rate. The section then discusses the EMTR profiles and budget constraints of partnered people with two children with and without a second income in the family. Profiles are shown for a $\$ 15$ hourly gross wage for the secondary income earner and it is assumed that the primary income earner earns a fixed $\$ 31,200$ gross per-annum (given by 40 hours work per-week at $\$ 15$ gross per-hour), as an example of a low-wage dual-income family. These profiles are all based on the taxation and social assistance systems in place in 2004-05 and include personal income taxes, main welfare benefits, the ACC earner levy, and the Family Assistance programmes. They do not include accommodation and childcare assistance and indirect taxes.

As well as these EMTR profiles and budget constraints this study also draws upon Treasury estimates of estimates of median wages and the distribution of hours of work of different family types calculated with TaxModA and using Household Economic Survey data. Estimates for 2003-04 were calculated for a range of family types [Nolan, 2003, p. 11; Nolan, 2004c, p. 8]. 
Because there were small numbers of some family types in the Household Economic Survey data there were few observations of these family types at certain wage rates. Thus in order to provide a useful number of observations in this modelling it was necessary to use wage bands of below and above median wages for different family types rather than single wage rates. Due to the small numbers of certain family types in the sample this modelling was based upon some distributions of hours were not able to have data calculated for them.

Figure 9.1: EMTR Schedule and Budget Constraint of a Sole-Parent with Two Children (Aged 3 and 5) and Earning \$10 Per-Hour (2004-05)

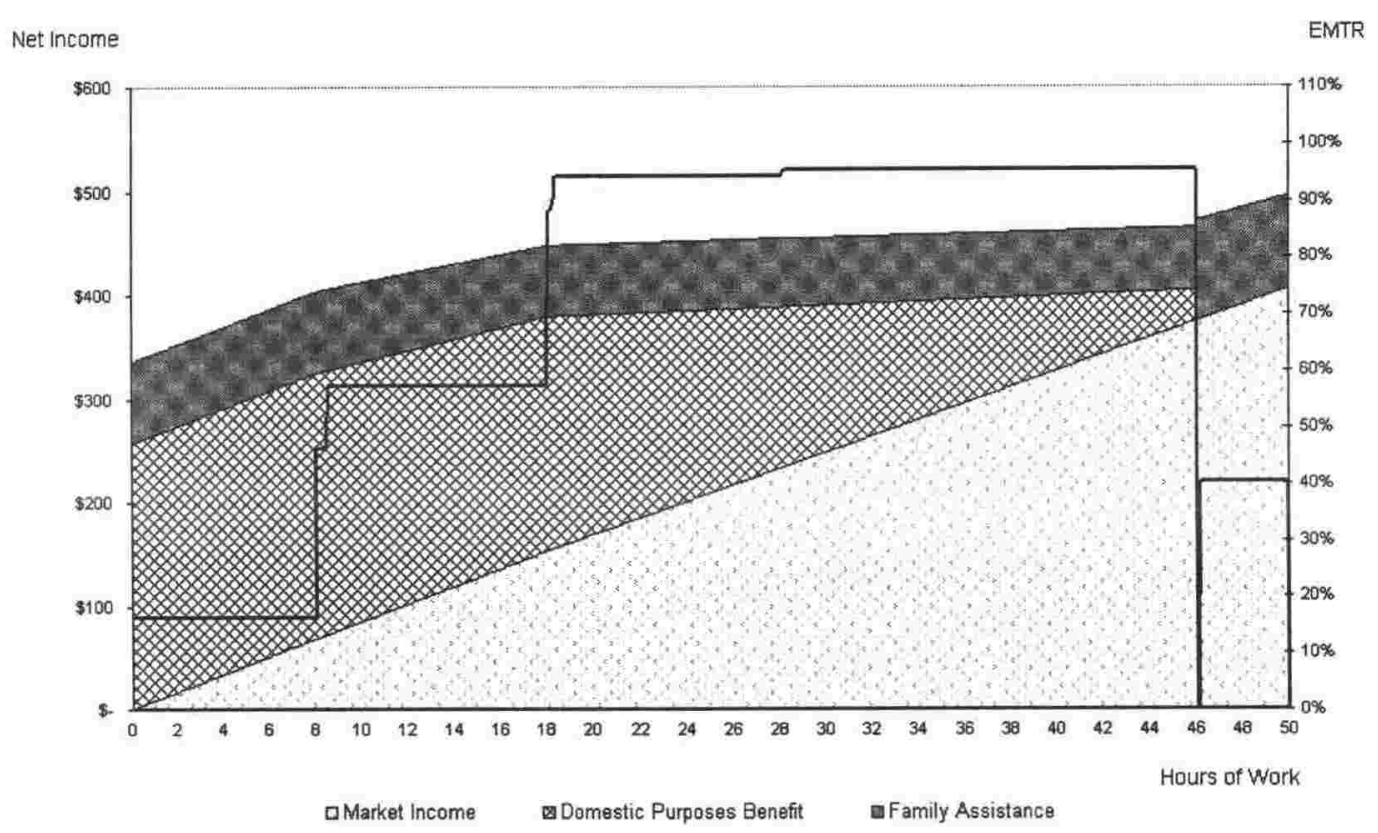

Figure 9.1 shows an EMTR profile and budget constraint of a soleparent with two children and receiving a $\$ 10$ per-hour wage. Initially the EMTRs facing this person were relatively low, due to the $\$ 80$ abatement-free zone for the Domestic Purposes Benefit. Once non-benefit earnings exceeded $\$ 80$ gross per-week the net Domestic Purposes Benefit abated by 30 percent against increases in gross non-benefit income until non-benefit

In 2003-04, for single people without children the social assistance system provided relatively few disincentives for increases in hours of work above 30 hours per-week at $\$ 10$ per-hour (or 20 hours per-week at $\$ 15$ per-week). There were greater disincentives for small increases in hours of work at hours below this level due to the abatement of the Unemployment Benefit. 
earnings increased to $\$ 180$ per-week. This created an EMTR of 46.2 percent, which increased to 57.4 percent when Family Assistance abatement began. Thus for between eight and 18 hours of work the person lost around half of every extra dollar earned in taxes and the abatement of Family Assistance. Gross non-benefit income above $\$ 180$ per-week reduced the net benefit by 70 percent. This, along with Family Assistance abatement, created an EMTR of 94.3 , which increased to 95.4 percent when Family Assistance abatement increased to 30 percent. At 20 hours of work this person had a net income of $\$ 446.70$ and by 40 hours of work this had increased to $\$ 456.40$. For these 20 hours of work the person working for $\$ 10$ gross per-hour received an effective net wage rate of around 50 cents per-hour. Once the benefit was fully abated (or the person chose to exit the benefit) the person received the work-based Child Tax Credit, which created a large negative EMTR and a kink in the budget constraint. Above this point the EMTRs reflected the abatement of the Family Assistance programmes and the personal income tax scale.

This EMTR profile and budget constraint demonstrated relatively good returns from part-time work. However, once the person earned $\$ 80$ gross non-benefit earnings (at 8 hours) there were relatively few financial rewards from increasing hours of work until the person could exit the benefit, which was financially worthwhile at around 46 hours of work. This profile thus illustrates a key trade-off when aiming to improve financial incentives to work through lowering abatement at lower income levels; lowering this abatement comes at the economic cost of increasing abatement further up the distribution of hours of work.

Figure 9.2 shows a similar EMTR profile and budget constraint of a sole-parent but with a $\$ 15$ per-hour wage. At the higher wage rate the number of hours over which social assistance programmes abate was reduced. Thus while the benefit abatement-free zone and the lower level of abatement on non-benefit income between $\$ 80$ and $\$ 180$ were exhausted more quickly, so too was the remainder of the Domestic Purposes Benefit (which became profitable to exit at around 30 hours of work). Thus while there was relatively less of an incentive for this person to work a small number of hours the incentives for this person to work around 30 hours or 
above were greater than was the case at the lower wage rate. However, even at these hours of work the disincentives to supply labour were still strong, with at least half of every dollar earned being lost in taxes and abatement of Family Assistance between 36 and 50 hours of work per-week.

Figure 9.2: EMTR Schedule and Budget Constraint of a Sole-Parent with Two Children (Aged 3 and 5) and Earning \$15 Per-Hour (2004-05)

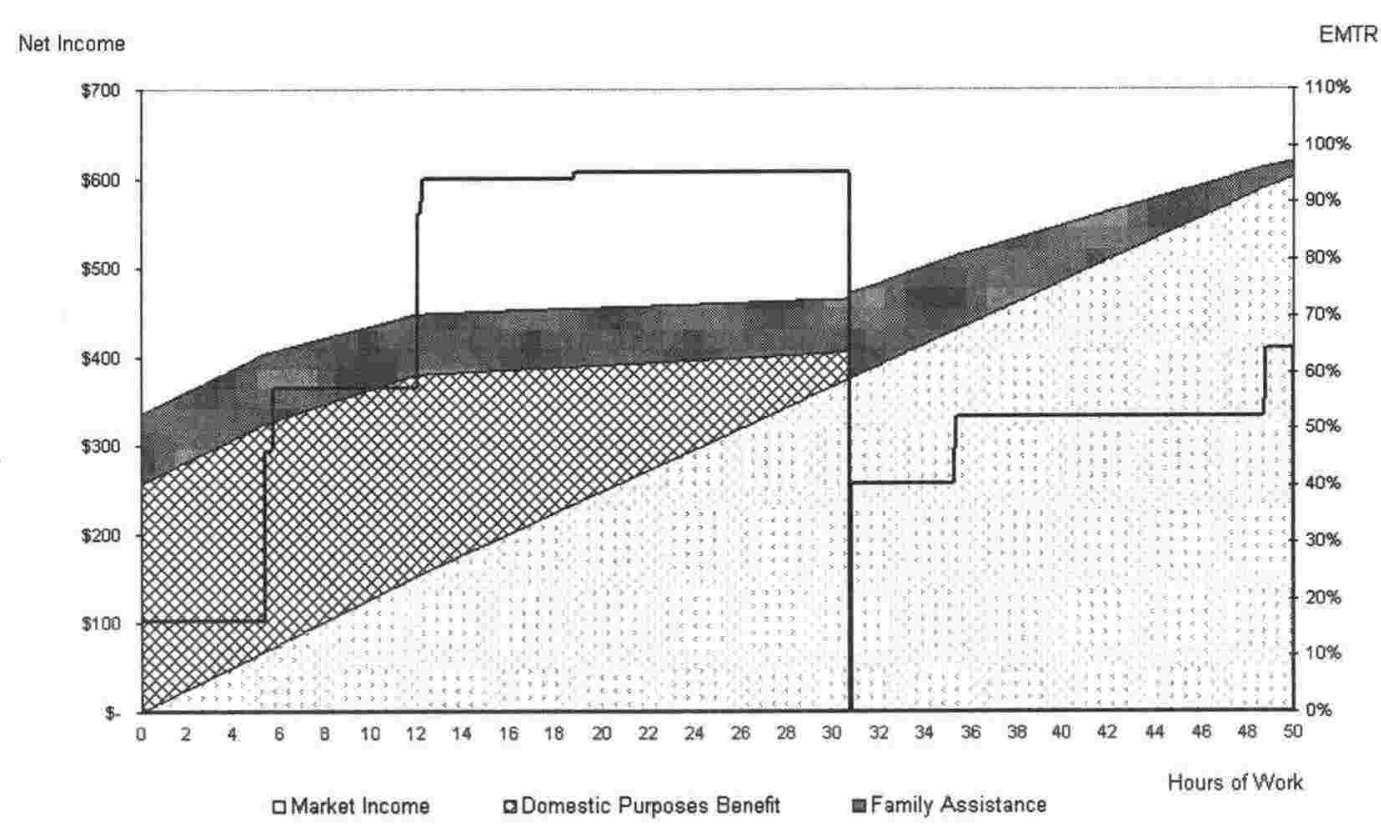

Nolan [2003 and 2004c] contained data on sole-parents' hours of work that demonstrated the importance of these poverty traps. The distribution of working sole-parents earning below median wages was most heavily concentrated at between 10 and 19 hours of work per-week, although due to the small sample size the numbers of working sole-parents in many of the bands of hours of work were unable to be calculated. The distribution of soleparents earning wages above the median was bimodal, with a mode at between 10 and 19 hours and a larger mode between 30 and 50 hours. Such distributions were consistent with the conclusion above that of those soleparents who work financial incentives for part-time work were relatively strong. Further, the higher concentration of sole-parents with wages above the median in work above thirty hours per-week was consistent with the finding that for sole-parents on $\$ 15$ per-week the financial incentives to work improved when exiting the Domestic Purposes Benefit became financially 
worthwhile at around 30 hours of work per-week. As a proportion of total individuals in work the number of sole-parents in work was low.

Figure 9.3: EMTR Schedule and Budget Constraint of a Primary Earner with Two Children (Aged 3 and 5) and Earning \$15 Per-Hour (2004-05)

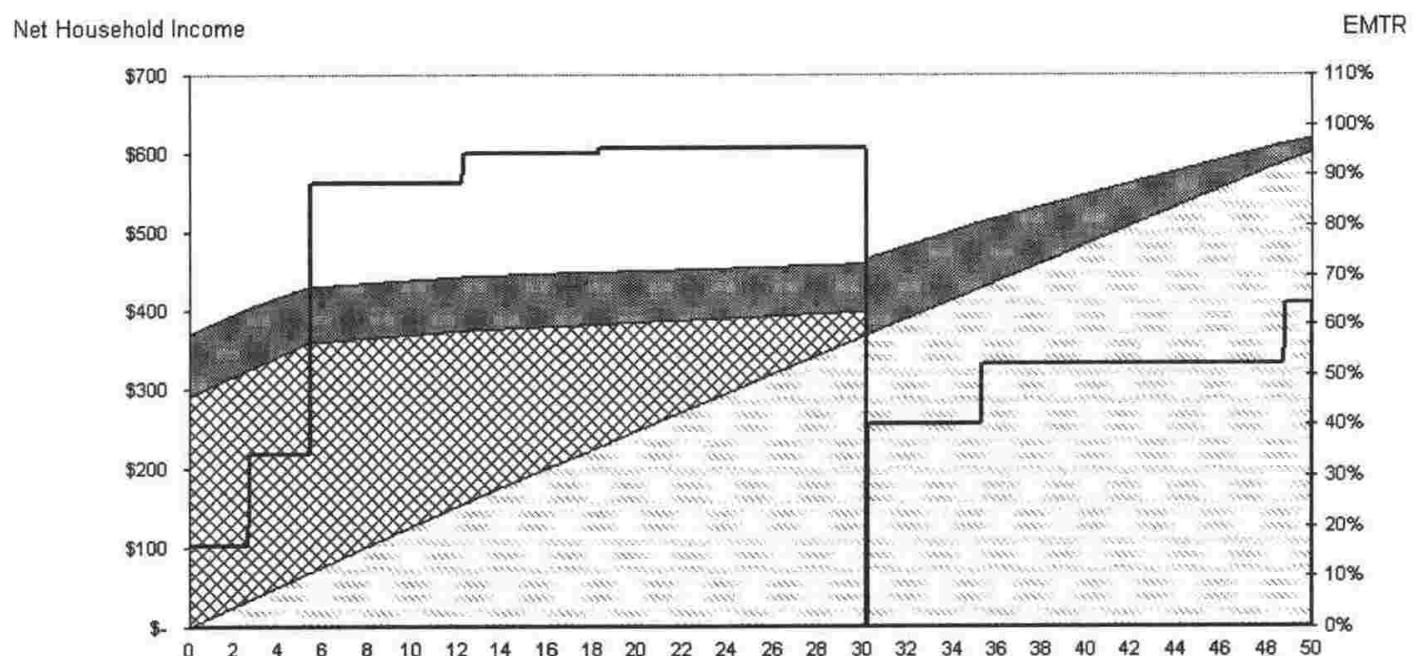

Hours of Work

口Market Income EUnemployment Benefit Family Assistance

Figure 9.3 shows the EMTR profile and budget constraint of a person with a non-working spouse and two children under 13 and with a wage rate of $\$ 15$ per-hour. Initially the EMTRs facing this person were low (due to the abatement-free zone of the Unemployment Benefit). Once the person's total gross income (including benefit income) increased to above $\$ 20,356$ they faced Family Assistance abatement of 30 percent. Due to the failure to index the Family Assistance abatement thresholds and the indexation of main welfare benefits with inflation, recipients of main benefits with even small levels of part-time income increasingly faced Family Assistance abatement. The level of the earnings' disregard had also not been indexed for inflation and so with growth in wage rates over time had provided relief from main benefit abatement for fewer numbers of hours of work. Thus at around six hours of work this person's gross non-benefit earnings exceeded $\$ 80$ and they faced abatement of the Unemployment Benefit and EMTRs of 88.3 to 95.4 percent until the Unemployment Benefit was fully exhausted or the person chose to exit the benefit. At six hours of work this family had a net income of $\$ 430$, which increased to around $\$ 454$ at around 30 hours of work. 
Over these 24 hours of work the person with a gross wage rate of $\$ 15$ perhour received an effective net wage rate of around $\$ 1$ per-hour. Once the person exited the benefit they received the work-based Child Tax Credit, which created a large negative EMTR and a kink in the budget constraint. Above this point the EMTRs reflected the abatement of the Family Assistance programmes and the personal income tax scale.

This EMTR profile demonstrated relatively poor incentives for part-time work (except at small hours of work per-week). For this person increases in income from work from around six hours of work to around 30 hours of work led to little increase in net income. (If the person's wage rate fell to $\$ 10$ perhour, small increases in income from work from around 8 hours of work to around 45 hours of work led to little increase in net income.) Thus for this person at a $\$ 15$ per-hour wage rate there were small incentives for working small numbers of hours and much greater incentives for increasing hours of work when working for more than 30 hours per-week.

Nolan [2003 and 2004c] also contained data on partnered parents' hours of work that demonstrated the importance of these poverty traps. For those workers receiving below median wage and with multiple children and non-working spouses the hours of work were concentrated at between 10 to 19 hours and, more heavily, at between 40 to 49 hours of work. This concentration of hours of work at above 40 hours was consistent with the finding above that financial incentives for this family type improved when the Unemployment Benefit was fully abated. For those workers in this family type and receiving above median wages their hours of work were also concentrated at above 40 hours. Again this was consistent with the finding that financial incentives for this family type improved when the Unemployment Benefit was fully abated. As a proportion of total individuals in work the number of workers with multiple children and non-working spouses was relatively low (although higher than sole-parents).

Figure 9.4 shows the EMTR profile and budget constraint of a person with a wage rate of $\$ 15$ per-hour and with a working spouse (with an assumed fixed income of $\$ 31,200$ ) and two children under 13 . This person faced relatively high EMTRs as soon as they began to work. The level of the spouse's income meant that the family had already exited the Unemployment 
Benefit and so did not face benefit abatement. (With a lower spouse's income the secondary earner may also face benefit abatement.) As the family had already exited the benefit and as the primary earner worked for more than 30 hours per-week, the family already received the work-based Child Tax Credit. The secondary earner's EMTR profile was thus a combination of the abatement of the Family Assistance programmes of 30 percent (based on joint income) and the personal income tax scale (based on individual income).

Figure 9.4: EMTR Schedule and Budget Constraint of a Secondary Earner and Two Children (Aged 3 and 5) and Earning \$15 Per-Hour (2004-05)

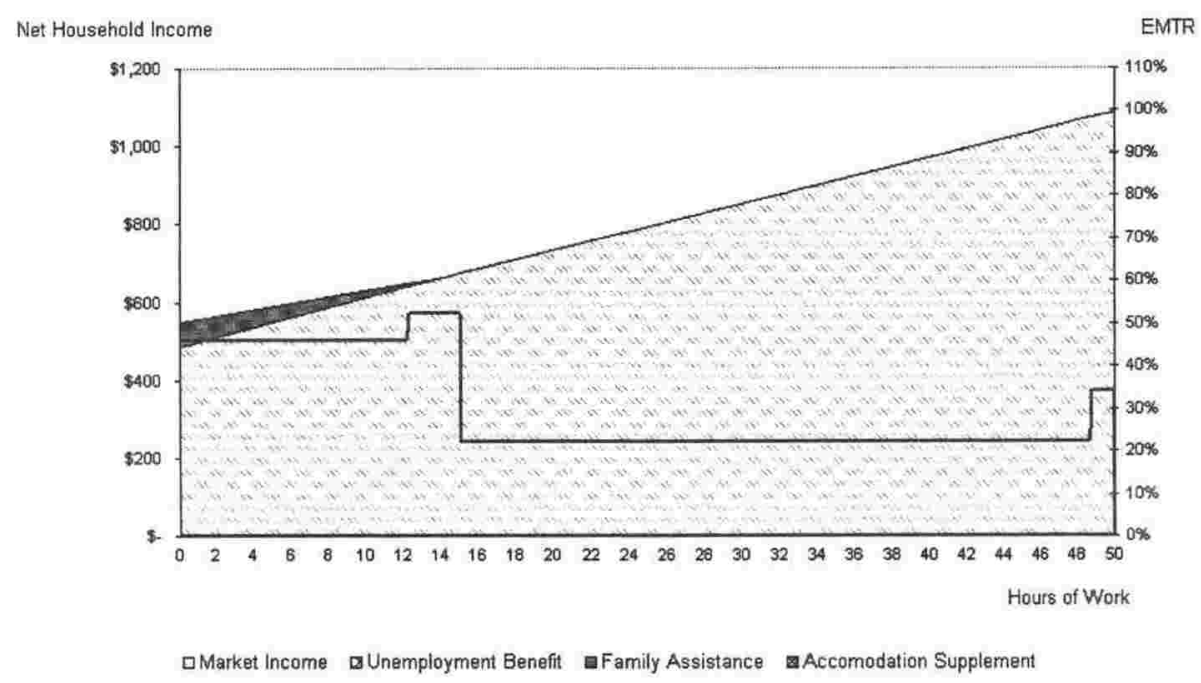

For this person there was relatively little incentive for work at less than 15 hours per-week. Below this point almost half of every dollar earned was lost in taxes and the abatement of Family Assistance. At a $\$ 15$ per-hour wage rate it was only by working around 15 hours per-week that the person could earn an income that exceeded the income levels over which the abatement of the Family Assistance programmes occurred. The person therefore had stronger incentives to increase their hours of work once they were working over 15 hours per-week. There were therefore relatively strong disincentives for part-time work and these disincentives decreased when the person faced full-time work. If the fixed income of the spouse increased then the other worker would have reached the point at which the Family Assistance programmes were fully exhausted sooner. Likewise, if the fixed 
income of the spouse decreased then reaching this point would have taken a larger number of hours of work. Thus as the spouse's income increased the financial incentives for the other person to supply labour increased also.

Again these poverty traps can be seen in the light of data on the distribution of hours of work [Nolan, 2003 and 2004c]. Data show that the distributions of hours of work of partnered workers (both with wages below and above the median) and multiple children and working partners were unimodal, with modes at around 40 to 49 hours. This concentration of hours of work at above 40 hours was consistent with the finding above that financial incentives for this family type improved when the Unemployment Benefit was fully abated. The correlation between high EMTRs and low numbers of people in certain hours of work appeared, however, less clear in the cases of two-income families than in the cases of single-income families because in two-income families the financial incentives facing secondary earners vary according to the incomes of primary earners. The number of workers with multiple children and working spouses was a relatively large proportion of the total individuals in work.

Changing the numbers and ages of children in the family have some impact on the poverty traps identified in the cases above. As the number of children in the family increased the level of assistance paid to the family also increased. As a consequence of this increase the abatement of assistance took place over a larger number of hours of work. Likewise, when the ages of the children increased the level of assistance paid to the family increased and the abatement of assistance also took place over a larger number of hours of work. Poverty traps were, therefore, most likely to affect large families with oider children.

\subsection{Accommodation and Childcare Assistance}

Due to the difficulty of accurately incorporating issues surrounding accommodation and childcare costs into the type of analysis above, these two factors have been treated separately in this chapter. However, this should not be seen as reducing the importance of these factors. Accommodation costs have been identified as an important indicator of 
poverty and low living standards [Stephens and Waldegrave, 2001]. Childcare costs are an important cost associated with working and have particular implications for the labour market participation of caregivers.

Issues surrounding accommodation and childcare costs are difficult to accurately incorporate into the analysis above for two reasons. Firstly, considerable variability exists among the families who face these costs. Accommodation costs, for example, vary widely among and within different regions of the country [Roper and Greenland, 2002, pp. 52, 57-59]. Families also differ in the degree to which they can access informal childcare provided by other family members (such as grandparents). Modelling these costs accurately requires information that is more detailed than that captured by the Household Economic Survey or during routine programme administration. Indeed, it has been estimated that the Treasury's arithmetic microsimulation model (TaxMod-A) under-predicts the number of families who receive the Accommodation Supplement by around 60 percent [Kalb, Cai, and Tuckwell, 2005 , p. 4]. Secondly, the nature of accommodation and childcare costs are such that they are both largely endogenous, which means that their consumption to some degree reflects other factors, such as the degree to which people choose to participate in the labour market.

The following discussion largely focuses on those people who currently receive assistance for accommodation, childcare, or both types of cost. However, the assumption that receipt of income support is an indicator of need is limited as take-up of assistance among the needy population is likely to be less than 100 percent [Atkinson, 1989a, p. 197]. Not all low-income families in need of accommodation assistance would, for instance, receive public assistance for their accommodation costs (income Related Rentals and the Accommodation Supplement). Further, due to fraudulent behaviour and overpayments due to administrative error not all families who take-up assistance would be in need. Receipt of assistance may also reflect the potential for moral hazard associated with the provision of such assistance. For example, some people may alter their circumstances in ways viewed as undesirable by policymakers (e.g., place themselves in positions of need) in order to remain eligible for assistance [Sen, 1995, p. 11]. 
The two main areas of publicly funded accommodation assistance are the Income Related Rentals and Accommodation Supplement programmes. These programmes address different needs (with Income Related Rentals only being available to state house tenants while Accommodation Supplement payments are available for both public and private accommodation) and differ in terms of their generosity (with Income Related Rentals generally being the more generous of the two programmes). The Accommodation Supplement is the main form of accommodation assistance for non-beneficiaries.

Both forms of accommodation assistance tended to be targeted towards beneficiaries. As at March 2002, the largest numbers of people receiving assistance from Income Related Rentals were beneficiaries (as these people make up 88 percent of tenants in state houses) and the large majority (91 percent) of Accommodation Supplement recipients were beneficiaries [Roper and Greenland, 2002, pp. 55-56]. Disincentives associated with the receipt of these programmes therefore mostly faced beneficiaries. Until 1 October 2004, for recipients of main benefits the Accommodation Supplement reduced by 25 cents per dollar for the first $\$ 80$ of non-benefit income. Above the $\$ 80$ threshold the Accommodation Supplement was not reduced until the recipient was no longer a beneficiary. The abatement then followed the abatement rules for non-beneficiaries. Prior to Working for Families, for nonbeneficiaries, the supplement abated at 25 percent when income exceeded the rate of the applicable gross Invalids Benefit plus an add-on of $\$ 17.92$ (which was established to compensate for income tax reductions in 1996 and 1998).

The Childcare Subsidy provides financial assistance to low-income families with a dependent child under the age of five to obtain access to childcare services. The OSCAR Subsidy helps low-income families to pay for before and after school programmes and school holiday programmes for children aged five to 13 . The 2001 Census estimated that approximately 197,000 families had a child under five. The majority (73 percent) of these families were two-parent families but a sizeable number (23.5 percent) were sole mother families. Labour force participation of mothers tended to increase with the age of children, particularly when the youngest child was older than 
one. Half of the partnered mothers with a youngest child over five were employed and 29 percent of sole mothers with a youngest child over five were employed. There was little recorded difference in the hours of work between sole and partnered mothers. The most common hours of work for mothers were recorded as 30 hours or more per-week. As with accommodation assistance, the majority of childcare assistance went to recipients of main benefits. Incentives to work associated with the receipt of these programmes therefore mostly faced beneficiaries (and Domestic Purposes Beneficiaries in particular).

Overall the disincentives associated with the Accommodation Supplement were likely to mostly face childless beneficiaries but a significant proportion of these recipients were also sole-parents (particularly Domestic Purposes Benefit recipients), who were the group that accounted for the majority of (and thus may have mostly received support for work effort from) childcare assistance.

\subsection{Comparison with Other Anglo-American Countries}

Table 9.2 compares financial incentives in New Zealand with those in the other four Anglo-American countries for primary earners (sole and partnered) and secondary earners at various points in the income distribution [Nolan, Stephens, Callister, 2005]. In the five countries replacement rates including housing assistance (based on the ratio of assistance when unemployed to average net income from work) were higher for partnered families than for sole-parent families, with the greatest differences between the sole and partnered rates occurring in Australia and the United Kingdom. For both sole and partnered caregivers replacement rates were highest in the United Kingdom and New Zealand and lowest in the United States. Further, both sole and partnered caregivers earning an income of half the average production worker income faced the highest average tax rates net of tax credits in the United States and lowest in the United Kingdom. At full average production worker income the average tax rates net of tax credits facing sole 
and partnered workers in the United Kingdom were still lowest. At this higher income level the highest average tax rates net of tax credits were those facing families in New Zealand and the next highest were those in Australia.

Table 9.2: Comparison of Anglo-American Financial Incentives for Labour Supply (2002)

\begin{tabular}{|c|c|c|c|c|c|}
\hline & Australia & Canada & $\begin{array}{l}\text { New } \\
\text { Zealand }\end{array}$ & $\begin{array}{l}\text { United } \\
\text { Kingdom }\end{array}$ & $\begin{array}{l}\text { United } \\
\text { States }\end{array}$ \\
\hline \multicolumn{6}{|c|}{ Sole-Parent Family (Two Children) } \\
\hline Replacement Rate & 56 & 55 & 62 & 64 & 35 \\
\hline \multicolumn{6}{|l|}{ Average Tax Rate } \\
\hline $\begin{array}{l}1 / 2 \text { Average Production } \\
\text { Worker Income }\end{array}$ & -44.8 & -35.2 & -38.8 & -69.4 & -21.0 \\
\hline $\begin{array}{l}\text { Average Production } \\
\text { Worker Income }\end{array}$ & 13.6 & 10.4 & 18.8 & 8.8 & 14.7 \\
\hline \multicolumn{6}{|c|}{ Average Effective Marginal Tax Rate } \\
\hline $\begin{array}{l}0 \text { to } 1 / 2 \text { Average } \\
\text { Production Worker } \\
\text { Income }\end{array}$ & 51.2 & 61.7 & 60.4 & 47.0 & 39.4 \\
\hline $\begin{array}{l}1 / 2 \text { to Average Production } \\
\text { Worker Income }\end{array}$ & 72.0 & 56.9 & 76.4 & 82.4 & 50.5 \\
\hline \multicolumn{6}{|c|}{ Partnered Family (Two Children) } \\
\hline Replacement Rate & 66 & 58 & 67 & 73 & 41 \\
\hline \multicolumn{6}{|l|}{ Average Tax Rate } \\
\hline $\begin{array}{l}1 / 2 \text { Average Production } \\
\text { Worker Income }\end{array}$ & -42.7 & -37.9 & -36.7 & -65.4 & -30.3 \\
\hline $\begin{array}{l}\text { Average Production } \\
\text { Worker Income }\end{array}$ & 13.8 & 11.4 & 18.8 & 9.2 & 11.5 \\
\hline \multicolumn{6}{|c|}{ Secondary Earner Average Effective Marginal Tax Rate* } \\
\hline $\begin{array}{l}0 \text { to } 1 / 2 \text { Average } \\
\text { Production Worker } \\
\text { Income }\end{array}$ & 44.5 & 48.2 & 47.3 & 52.0 & 23.0 \\
\hline $\begin{array}{l}1 / 2 \text { to Average Production } \\
\text { Worker Income }\end{array}$ & 31.5 & 39.8 & 30.4 & 32.0 & 26.0 \\
\hline
\end{tabular}

* Primary earner assumed to earn 0.67 percent of Average Production Worker Income Source: Nolan, Stephens, and Callister, 2005. Derived from OECD, 2004b

Average effective marginal tax rates show the proportion of extra earnings lost in direct taxes and abatement of income-related benefits and housing assistance. Along with the lower replacement rates the lower figures for average effective marginal tax rates for the United States provide an explanation for that country's high employment rate for sole-parents. For partnered families in the United States the second earners' marginal tax rates were also relatively low, encouraging labour force participation, whereas in the other four countries roughly half of any earnings of the secondary earner 
were lost on initial entry into the work force, even before childcare and transport costs [Nolan, Stephens, and Callister, 2005].

Reflecting the largely free travel of citizens between New Zealand and Australia (under the Trans-Tasman Travel Arrangement 1973) these countries share large segments of their labour markets. Financial disincentives for labour supply (reflected in replacement rates, average tax rates, and average effective marginal tax rates) at the proportions of average production worker income above were higher in New Zealand than in Australia. Yet New Zealand's labour force participation rates of sole and partnered caregivers were higher than those of Australia. This higher labour force participation was likely to reflect a relatively high proportion of low-wage workers (increasing average replacement rates) and low generosity of family and employment tax credits (increasing average tax rates).

\subsection{Conclusion}

This chapter evaluated the financial incentives to supply labour present in New Zealand's tax-benefit system. In this system financial incentives to supply labour differ among different groups in the population. For the majority of the population the EMTRs created by the interaction of the personal income tax and social assistance systems were less than 48 percent. There were, however, a small number of demographic groups at certain income levels who faced EMTRs of 48 percent or above. These groups included a number of people who received income-tested main benefits, the Family Assistance programmes, or some combination of all of these programmes.

For all family types the lower the hourly wage the greater the significance of the abatement of the social assistance and the abatementfree zone for financial incentives. While previous research has highlighted the low returns from work for sole-parents at low wages [Green, 2001, p. 60] this chapter demonstrated that prior to Working for Families low-wage singleincome couples with children also faced significant discouragement to work.

\footnotetext{
* In New Zealand recent economic growth has been underpinned by growth in labour utilisation, while in Australia economic growth has to a greater degree been driven by increased labour productivity.
} 
Low-wage families with children required two income earners if they were to have market incomes sufficient to allow them to escape the poverty traps present in the social assistance system.

Accommodation and childcare assistance were treated separately in this chapter. The disincentives for small increases in hours of work that faced recipients of the Unemployment Benefit and the Domestic Purposes Benefit would thus have been understated, as disincentives associated with the receipt of the Accommodation Supplement mostly faced recipients of main social welfare benefits. In contrast the support for work effort from the receipt of the Childcare and OSCAR Subsidies also mostly faced recipients of main social welfare benefits. Overall the disincentives associated with the Accommodation Supplement were likely to have mostly faced childless recipients of main social welfare benefits but a significant proportion of these recipients were also sole-parents (particularly Domestic Purposes Benefit recipients) who were the group accounting for the majority of, and thus may have mostly faced any incentives for work associated with, childcare assistance.

Financial incentives for labour supply measured as proportions of average production worker income were weaker in New Zealand than in Australia, yet of these countries labour force participation rates of sole and partnered caregivers were higher in New Zealand. This higher labour force participation in New Zealand was likely to reflect a relatively high proportion of low-wage workers (increasing average replacement rates) and low generosity of family and employment tax credits (increasing average tax rates). 
IV EVALUATING THE WORKING FOR FAMILIES REFORMS 


\section{Evaluating the Working for Families Reforms}

\subsection{Introduction}

This chapter evaluates the Labour-led government's response to the policy issues identified in earlier chapters in the form of the Working for Families reforms. These reforms are summarised below. In section two of the chapter the impact of Working for Families on headcount poverty rates and the distribution of the gains from these reforms are discussed. The impact of Working for Families on the EMTR profiles and budget constraints of three family types and on couples' incentives to work are discussed in section three. In section four the chapter then discusses the impact of Working for Families on the structure and relative generosity of the family and employment tax credits going to these family types. Section five contains a discussion of the administrative implications of the reforms.

\section{The Working for Families Reforms}

On 27 May 2004 the Minister of Social Development announced a number of tax-benefit reforms (collectively know as Working for Families) targeting lowwage families with children. Key features of the package were:

- October 2004: remove abatement of Accommodation Supplement during the $\$ 80$ gross per-week earnings' disregard for main benefit abatement; increase the thresholds at which non-beneficiary families' Accommodation Supplement begins to abate; and increase Childcare and OSCAR Subsidy rates.

- April 2005: increase Family Support Rates (\$25 per-week for the eldest child and $\$ 15$ per-week for additional children); remove child 
component of main benefits; and increase Accommodation Supplement areas from three to four, with increases in the maximum rates of assistance in some areas.

- October 2005: further increases in Childcare and OSCAR Subsidy rates.

- April 2006: replace the $\$ 15$ per-child Child Tax Credit with an In-Work Payment of $\$ 60$ per-week (with $\$ 15$ per-child top-up for the fourth and additional children) available to families not receiving a main benefit and working 30 hours per-week if a couple or 20 hours per-week if single; remove abatement of Family Assistance on incomes between \$20,356 and $\$ 27,500$; and increase the Family Tax Credit, from providing a guaranteed minimum family income of $\$ 15,080$ net to providing $\$ 17,000$ net.

- April 2007: increase Family Support rates by $\$ 10$ per-child per-week.

From 1 April 2007 the Family Assistance programmes are also to be indexed to inflation, with the rates and thresholds increasing when Consumer Price Index increases reach a total of five percent.

The Labour-led government has also announced an intention to introduce single core benefit reforms. The single core benefit was legislated for by Labour in 1989 but not implemented. The idea of a single core benefit was also favoured by the former National Prime Minister Jenny Shipley [Stephens, 1999, p. 257]. Under such a system recipients would receive supplementary assistance on the basis of their need rather than benefit category. This proposal has been signalled for implementation after 1 April 2007. Few details are currently available on the single core benefit proposal. This proposal is thus not discussed in this study.

\subsection{Headcount Poverty Rates}

\section{Working for Families and Headcount Poverty Rates}

A primary objective of the Working for Families reforms is to reduce the incidence of poverty, particularly child poverty, in New Zealand. Perry [2004] estimated the reduction in headcount poverty rates from Working for Families 
with a non-behavioural microsimulation model (TaxMod-A) and assuming Working for Families would be implemented fully and on schedule. Perry's [2004, p. 35] estimates of the impact of Working for Families on headcount rates of poverty are shown in table 10.1. These rates are both for children and the population as a whole and use poverty thresholds of 50 percent and 60 percent of the equivalised median family annual income. These estimates are based on the Revised Jensen Scale, which converts actual family incomes into hypothetical equivalised incomes reflecting family size and the ages and numbers of children [Perry, 2004, p. 25]. These estimates assume full take-up of assistance and no changes in labour market behaviour in response to Working for Families.

Table 10.1: Estimated Impact of Working for Families on Headcount Poverty Rates

\begin{tabular}{|c|c|c|c|c|}
\hline \multirow[b]{2}{*}{ Threshold (1998 Base) } & \multicolumn{2}{|l|}{ Children } & \multicolumn{2}{|c|}{ Whole Population } \\
\hline & $\begin{array}{l}50 \% \text { Family } \\
\text { Median }\end{array}$ & $\begin{array}{l}60 \% \text { Family } \\
\text { Median }\end{array}$ & $\begin{array}{l}50 \% \text { Family } \\
\text { Median }\end{array}$ & $\begin{array}{l}60 \% \text { Family } \\
\text { Median }\end{array}$ \\
\hline $\begin{array}{l}\text { Threshold in Equivalised } \\
\text { Dollars Per-Annum (June } \\
2005 \text { dollars) }\end{array}$ & $\$ 10,750$ & $\$ 12,900$ & $\$ 10,750$ & $\$ 12,900$ \\
\hline $\begin{array}{l}\text { Estimated Pre-Reform } \\
\text { Rate for } 31 \text { March } 2005\end{array}$ & $14.7 \%$ & $29.0 \%$ & $9.3 \%$ & $17.8 \%$ \\
\hline After Phase 1 & $9.3 \%$ & $24.2 \%$ & $7.3 \%$ & $15.8 \%$ \\
\hline After Full Implementation & $4.3 \%$ & $20.5 \%$ & $5.5 \%$ & $13.9 \%$ \\
\hline $\begin{array}{l}\text { Reduction in Measured } \\
\text { Poverty after Full } \\
\text { Implementation } \\
\text { (Proportional Decrease) }\end{array}$ & $71.0 \%$ & $29.0 \%$ & $41.0 \%$ & $22.0 \%$ \\
\hline
\end{tabular}

Source: Perry, 2004, p. 35

The fully implemented Working for Families reforms were estimated to lower the child headcount poverty rate by around 70 percent using the 50 percent poverty threshold and by around 30 percent using the 60 percent poverty threshold. The reduction in total family headcount poverty was estimated as less than the reduction in child headcount poverty. Working for Families was estimated to lower the total family headcount poverty rate by around 40 percent using the 50 percent poverty threshold and by around 20 percent using the 60 percent poverty threshold [Perry, 2004, p. 35]. Perry [2004] argues that the greater reduction in the child headcount poverty rate reflects the child-focus of Working for Families, as families without children (a large proportion of all families in poverty) do not receive increased assistance 
from the modelled changes. However, given limitations of TaxMod-A and HES data, Perry [2004] does not model changes to the Accommodation Supplement and childcare assistance." It is unclear whether excluding this assistance would change the balance between the reduction in child and family headcount poverty, as while some of the increases in the Accommodation Supplement would go to families without children the reduction in child headcount poverty may also increase due to the increase in childcare assistance.

Although these estimates do not account for poverty depth (which would require attributing greater weight to reductions in poverty facing families further below the poverty threshold) the increased poverty reduction at the 50 percent threshold in comparison to the 60 percent threshold indicates that this reform package is targeted towards people further below the poverty threshold [Perry, 2004, p. 36]. This result also partly reflects the equivalence scale used to model these changes. The Revised Jensen Scale increases the cost functions of families with multiple children, shifting them to lower levels in the hypothetical equivalised income distribution. As the levels of assistance provided by Working for Families increase as the numbers of children in the family increase, this targeting of assistance towards families further below the equivalised poverty threshold partly reflects this downwards re-ranking of families with multiple children.

\section{Distribution of Gains from Working for Families}

Often in the design of tax-benefit reforms there is a trade-off between reducing the headcount poverty rate and the efficiency with which income transfers are targeted to low-income families (reflecting spill-over to the pretransfer poor and non-poor). The degree of spill-over to the non-poor from Working for Families has been one criticism of these reforms [Dwyer, 2005, pp. 43-44]. Based on information contained in reports to Cabinet, Dwyer [2005, p. 43] argued that around half of the expenditure on Working for

\footnotetext{
See Nolan [2003, pp. 35-37] for a discussion of difficulties associated with modelling these forms of assistance.
} 
Families would go to those families with net unequivalised incomes in the top six income deciles.

Table 10.2 shows more detailed Treasury non-behavioural estimates of the distribution of the gains from Working for Families by income decile for market and disposable income (both equivalised and unequivalised). Incomes have been equivalised using the Whiteford geometric scale. On the basis of equivalised market income, a little over 55 percent of expenditure goes to family in the bottom five deciles and almost 80 percent of expenditure goes to families in the bottom six deciles. Deciles one to seven have similar numbers of families who gain, with average gains ranging from around $\$ 1,800$ for decile three to around $\$ 4,600$ for decile six. Further, on the basis of equivalised disposable income, a little over 60 percent of expenditure goes to families in the bottom five deciles. Almost 85 percent of expenditure goes to the bottom six deciles on the basis of equivalised disposable income. The decile with the largest number of gainers is decile four, with 106,000 families gaining on average around $\$ 3,000$ per-annum.

Table 10.2: Distribution of Static Financial Gains from WFF

\begin{tabular}{|c|c|c|c|c|c|c|c|c|}
\hline \multirow[b]{2}{*}{$\begin{array}{l}\text { Income } \\
\text { Decile }\end{array}$} & \multicolumn{4}{|c|}{ Market Income } & \multicolumn{4}{|c|}{ Disposable Income } \\
\hline & $\begin{array}{l}\text { Gaining } \\
\text { House- } \\
\text { holds - } \\
\text { Uneqvl }\end{array}$ & $\begin{array}{l}\text { Total } \\
\text { Uneqvl } \\
\text { Gain (\$M) }\end{array}$ & $\begin{array}{l}\text { Gaining } \\
\text { House- } \\
\text { holds - } \\
\text { Equvl }\end{array}$ & $\begin{array}{l}\text { Total } \\
\text { Equvl } \\
\text { Gain (\$M) }\end{array}$ & $\begin{array}{l}\text { Gaining } \\
\text { House- } \\
\text { holds - } \\
\text { Uneqvi }\end{array}$ & $\begin{array}{l}\text { Total } \\
\text { Uneqvl } \\
\text { Gain (\$M) }\end{array}$ & $\begin{array}{l}\text { Gaining } \\
\text { House- } \\
\text { holds - } \\
\text { Equvl }\end{array}$ & $\begin{array}{l}\text { Total } \\
\text { Equvl } \\
\text { Gain (\$M) }\end{array}$ \\
\hline One & 10,000 & 17 & 48,000 & 114 & 8,000 & 20 & 8,000 & 20 \\
\hline Two & 82,000 & 198 & 50,000 & 110 & 16,000 & 11 & 24,000 & 46 \\
\hline Three & 52,000 & 90 & 48,000 & 86 & 24,000 & 10 & 62,000 & 167 \\
\hline Four & 46,000 & 115 & 46,000 & 133 & 92,000 & 171 & 106,000 & 316 \\
\hline Five & 48,000 & 149 & 56,000 & 200 & 72,000 & 208 & 54,000 & 171 \\
\hline Six & 46,000 & 181 & 60,000 & 279 & 64,000 & 260 & 66,000 & 271 \\
\hline Seven & 48,000 & 215 & 58,000 & 203 & 54,000 & 257 & 56,000 & 155 \\
\hline Eight & 58,000 & 175 & 34,000 & 34 & 58,000 & 184 & 20,000 & 13 \\
\hline Nine & 16,000 & 20 & 10,000 & 4 & 18,000 & 38 & 10,000 & 4 \\
\hline Ten & 4,000 & 8 & 4,000 & 5 & 4,000 & 8 & * & * \\
\hline Total & 410,000 & 1,167 & 410,000 & 1,167 & 410,000 & 1,167 & 410,000 & 1,167 \\
\hline
\end{tabular}

* Too few observations to disclose

Source: TaxMod-A based on 2000-01 HES weighted up to 2004-05 income distribution

Spill-over to the non-poor is a feature of social assistance provided through the tax system. However, the targeting efficiency of tax-assistance that directly increases families' net incomes (e.g., refundable or non- 
refundable tax rebates) tends to have higher targeting efficiency than assistance that reduces gross taxable incomes (e.g., allowing partnered families to split gross taxable income between two spouses). For example, with income splitting any return a low-wage worker receives from a policy that reduces gross taxable income would be less than the return for a high-wage worker, as high wage workers would receive a larger reduction in marginal tax rates. Nolan and Fairbrother [2005, p. 21] illustrated that assistance provided in the form of family and employment tax credits (the Working for Families reforms) would be more effectively targeted to lower income families than assistance provided through the personal income tax scale (in the form of income splitting).

\subsection{EMTR Profiles}

Headcount poverty rates and spill-over to the pre-transfer poor and non-poor may be simultaneously reduced if income transfers are set at a level sufficient to raise all family incomes above the poverty line but with a hundred percent effective marginal tax rate on earnings above this threshold until assistance is fully abated. Poverty reduction and targeting efficiency outcomes thus interact with financial incentives to supply labour. Further, the estimates contained in the discussions above all assumed no labour supply behavioural responses from the Working for Families reforms. The distribution of financial incentives to supply labour and the likely behavioural responses from these reforms are considered below.

The Working for Families reforms have been criticised for their aggregate impact on financial incentives to work. Dwyer [2005, p. vii] cites Treasury estimates that the mean EMTR in 2007-08 will be 29.7 percent with the fully implemented Working for Families compared to 28.6 without Working for Families. Yet the distribution of EMTRs among the population is likely to provide a more accurate evaluation of the efficiency effects of taxbenefit reforms than the mean EMTR, due to variations in responsiveness to financial incentives for labour supply among the population (e.g., caregivers' decisions on participation are relatively responsive to financial incentives to supply labour). The following sections illustrate the distribution of financial 
incentives for labour supply facing representative families for up to 50 hours of work with EMTR profiles and budget constraints.

\section{A Sole-Parent with Two Children and Earning $\$ 10.00$ Gross Per-Hour}

The effects of Working for Families on financial incentives to supply labour facing a sole-parent earning $\$ 10$ per-hour are illustrated in figures 10.1 and 10.2. In these figures the sole-parent is assumed to have two children under 13. Figure 10.1 shows a budget constraint and EMTR profile of this soleparent after the Working for Families reforms. Figure 10.2 compares the EMTR profiles for this person before and after Working for Families. These profiles assume Working for Families is implemented fully and on schedule. They contain personal income taxes, main welfare benefits, the Family Assistance programmes, and the ACC earner levy, but not accommodation assistance, childcare subsidies, and indirect taxes.

Figure 10.1: Post-Working for Families Budget Constraint and EMTR Profile of a Sole-

Parent with Two Children (Aged 3 and 5) and Earning \$10.00 Per-Hour

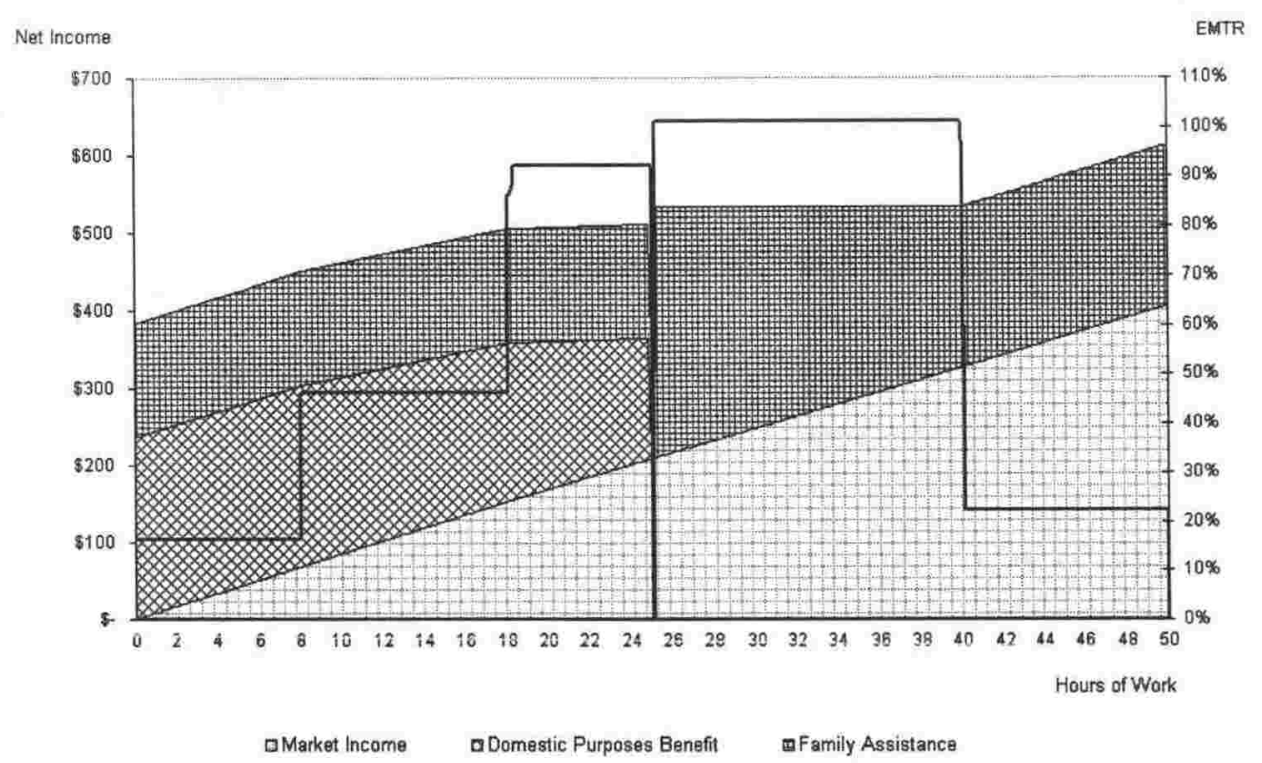


Figure 10.2: Impact of Working for Families on the EMTR Profile of a Sole-Parent with Two Children (Aged 3 and 5) and Earning \$10.00 Per-Hour

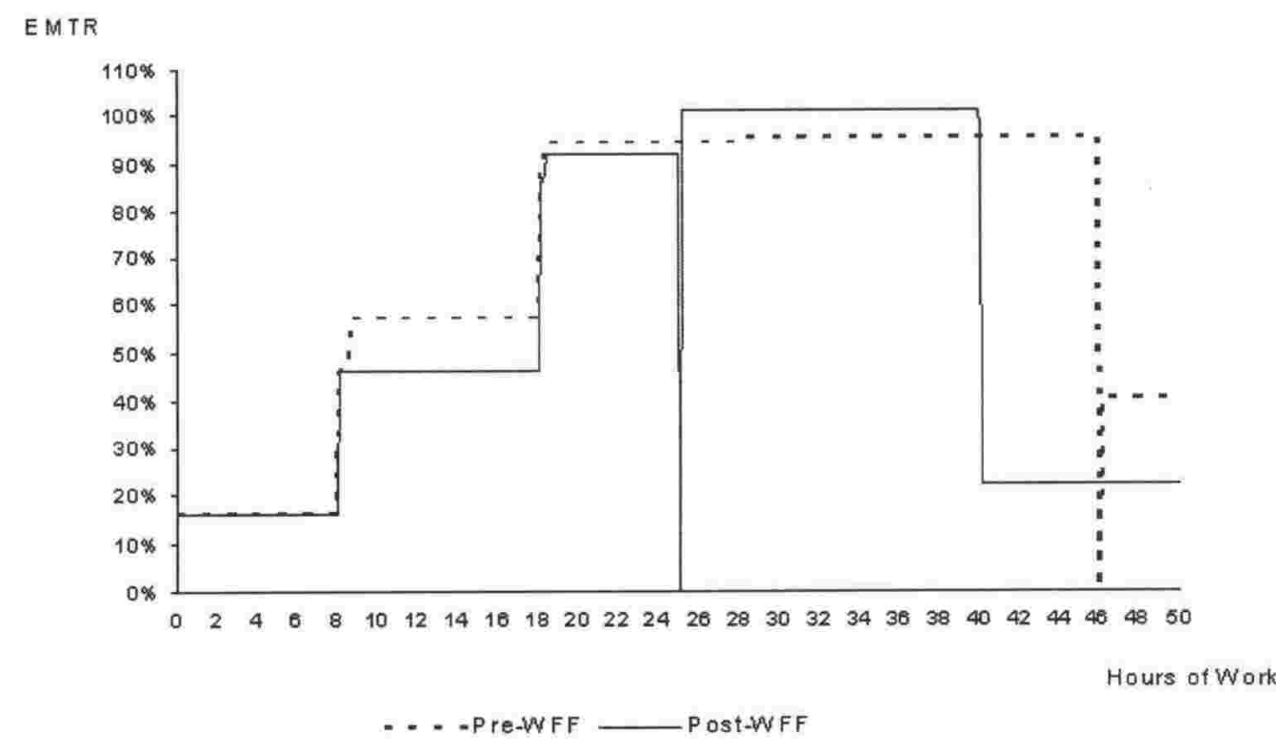

The increase in the Family Tax Credit and the replacement of the Child Tax Credit with the In-Work Payment encourage this sole-parent to exit the Domestic Purposes Benefit at an earlier number of hours than prior to the Working for Families reforms. However, the labour supply outcomes of taxbenefit reforms should not be evaluated solely in relation to incentives to exit a main welfare benefit (the transition between employment and unemployment) but should be evaluated in relation to the income and substitution effects that they create. These income and substitution effects influence financial incentives for both participating in the labour market and changing hours of work.

The removal of Family Assistance abatement against gross joint incomes below $\$ 27,500$ and increases in assistance provided by the Family Support programme create an income effect discouraging labour supply and a substitution effect encouraging labour supply. Beneficiaries would be unlikely to face abatement of Family Support until after they have exited the main welfare benefit. The work-based In-Work Payment and Family Tax Credit may encourage sole-parents who work less than 24 hours per-week (the point at which exiting the Domestic Purposes Benefit becomes financially worthwhile) to increase their hours of work to qualify for these programmes. Sole-parents with hours of work above this point may, however, 
reduce their hours of work to around this point as they would face income and substitution effects discouraging labour supply.

This sole-parent would still face significant poverty traps discouraging labour supply due to the dollar-for-dollar abatement of the Family Tax Credit against increases in net income, which, along with the ACC earner levy, leads to EMTRs in excess of 100 percent. While this person would have faced a poverty trap from 18 to 46 hours of work prior to reform, following reform a poverty trap would apply from around 18 to 40 hours of work. At 18 hours of work this person would receive a net income of around $\$ 503$ perweek and at 40 hours of work this person would receive a net income of around $\$ 529$. With a gross wage of $\$ 10$ this person would receive an average effective net wage of around $\$ 1.20$ over these 22 hours of work. However, financial incentives to work for more than 40 hours per-week have improved for this person.

\section{A Partnered Person with a Non-Working Spouse and Two Children and Earning $\$ 15.00$ Gross Per-Hour}

The effects of Working for Families on financial incentives to supply labour facing a partnered person earning $\$ 15$ per-hour and with a non-working spouse are illustrated in figures 10.3 and 10.4. In these figures the person is assumed to have two children under 13. Figure 10.3 shows a budget constraint and EMTR profile of this partnered parent after the Working for Families reforms. Figure 10.4 compares the EMTR profiles of this person before and after Working for Families. These profiles assume Working for Families is implemented fully and on schedule. They contain personal income taxes, main welfare benefits, the Family Assistance programmes, and the ACC earner levy, but not accommodation assistance, childcare subsidies, and indirect taxes.

The removal of Family Assistance abatement on gross joint incomes below $\$ 27,500$ creates a substitution effect improving financial incentives to work facing this partnered parent. This would be reflected in a slight reduction in the poverty traps facing this parent due to the reduction in EMTRs facing Unemployment Benefit recipients with non-benefit earnings above $\$ 80$ per-week of around two percent. Countering this is an income 
effect from the increased levels of Family Assistance that would discourage these people from supplying labour.

Figure 10.3: Post-Working for Families Budget Constraint and EMTR Profile of a Primary Earner with Two Children (Aged 3 and 5) and Earning \$15.00 Per-Hour

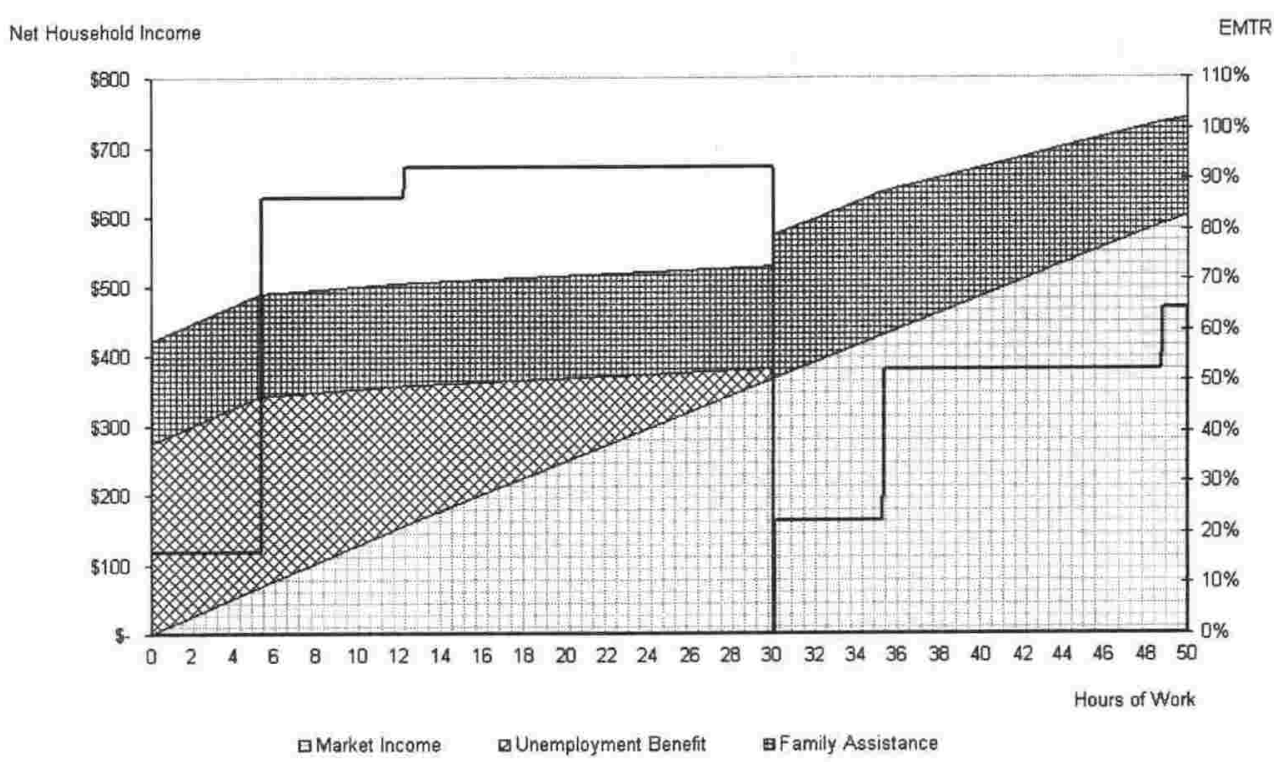

Figure 10.4: Impact of Working for Families on the EMTR Profile of a Primary Earner with Two Children (Aged 3 and 5) and Earning $\$ 15.00$ Per-Hour

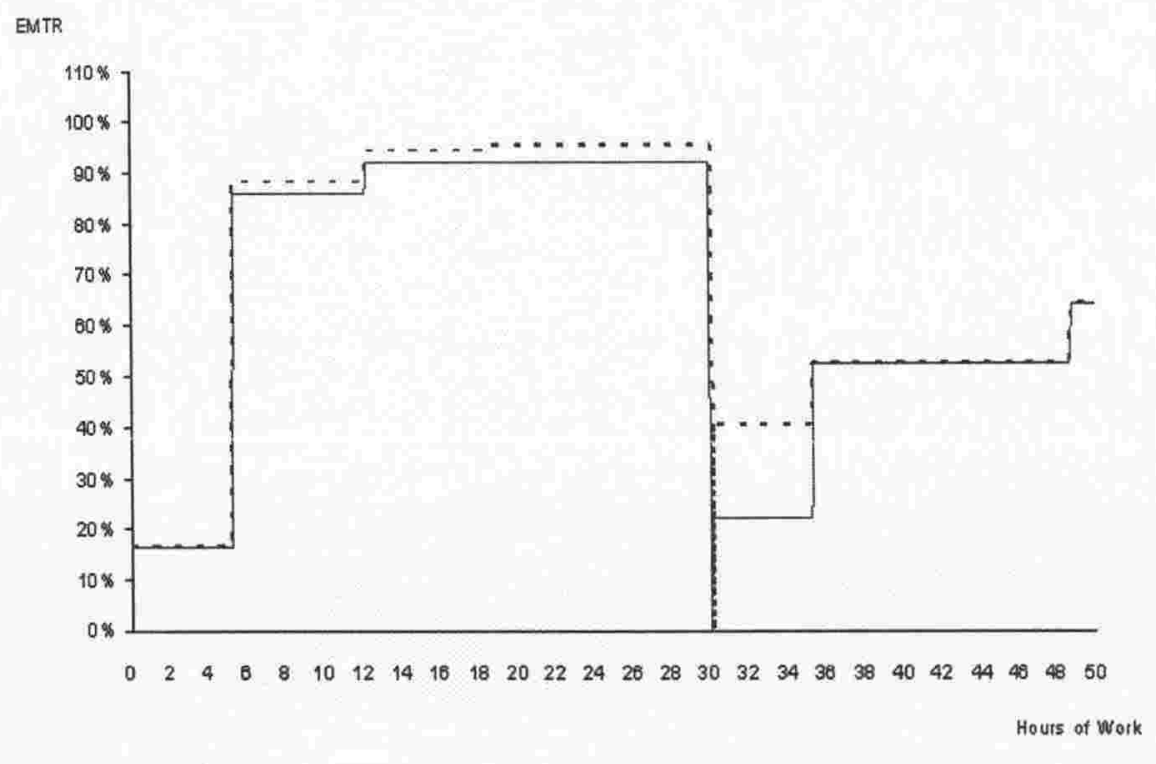

- - Pre-WFF Post-WFF

The point at which the person would exit the benefit has not changed, although the levels of in-work assistance have increased, due to the introduction of an hours-based threshold for the eligibility for the In-Work 
Payment. The additional assistance at 30 hours of work may encourage some families to increase their hours of work in order to become eligible for this assistance. However, for families above this threshold the increased levels of assistance would create an income effect discouraging labour supply. The abatement of this assistance at higher income levels would also create a substitution effect discouraging labour supply.

\section{A Partnered Person with a Working Spouse and Two Children and}

\section{Earning $\$ 15.00$ Gross Per-Hour}

The effects of Working for Families on financial incentives to supply labour facing a partnered person earning $\$ 15$ per-hour and with a working spouse are illustrated in figures 10.5 and 10.6. In these figures the person is assumed to have two children under 13. The person's spouse is assumed to earn a fixed income of $\$ 600$ per-week ( $\$ 31,200$ per-annum). Figure 10.5 shows a budget constraint and EMTR profile of this partnered parent after the Working for Families reforms. Figure 10.6 compares the EMTR profiles for this person before and after Working for Families. These profiles assume Working for Families is implemented fully and on schedule. They contain personal income taxes, main welfare benefits, the Family Assistance programmes, and the ACC earner levy, but not accommodation assistance, childcare subsidies, and indirect taxes.

The removal of Family Assistance abatement at gross joint incomes below $\$ 27,500$ and the increase in the levels of assistance provided by the Family Assistance programmes mean that the abatement of this assistance has increased higher into the income distribution. This is shown in the case of the secondary earner earning $\$ 15$ gross per-hour with two children. Following the Working for Families reforms the family continues to receive the Family Assistance programmes until the secondary earner increases their hours of work to above 42 hours per-week. Prior to reform the family's assistance was fully abated by 15 hours of work. As the secondary earner faces abatement of assistance over a longer range of hours of work the financial incentives to work facing this person have worsened, with increased levels of assistance providing an income effect and increased abatement creating a substitution effect discouraging labour supply. 
Figure 10.5: Impact of Working for Families on the EMTR Profile of a Secondary Earner with Two Children (Aged 3 and 5) and Earning \$15.00 Per-Hour

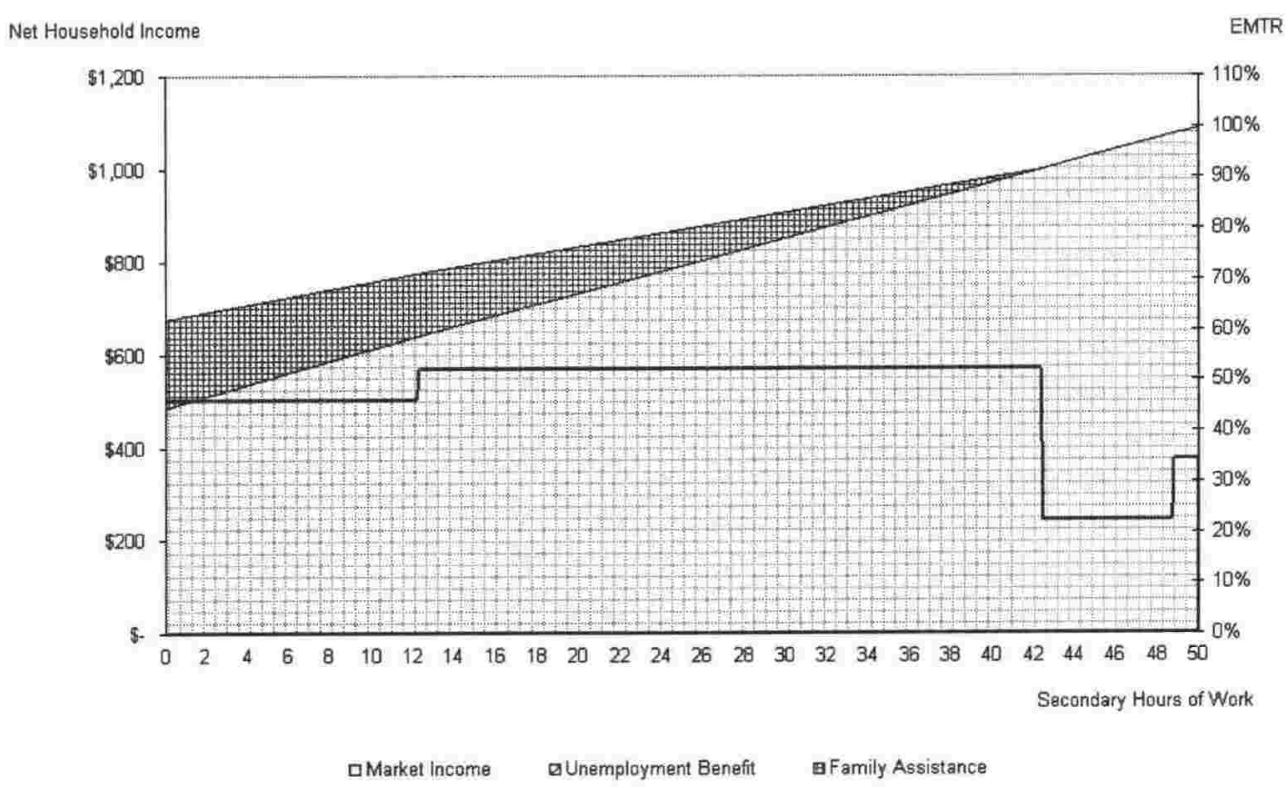

Figure 10.6: Impact of Working for Families on the EMTR Profile of a Secondary Earner with Two Children (Aged 3 and 5) and Earning \$15.00 Per-Hour

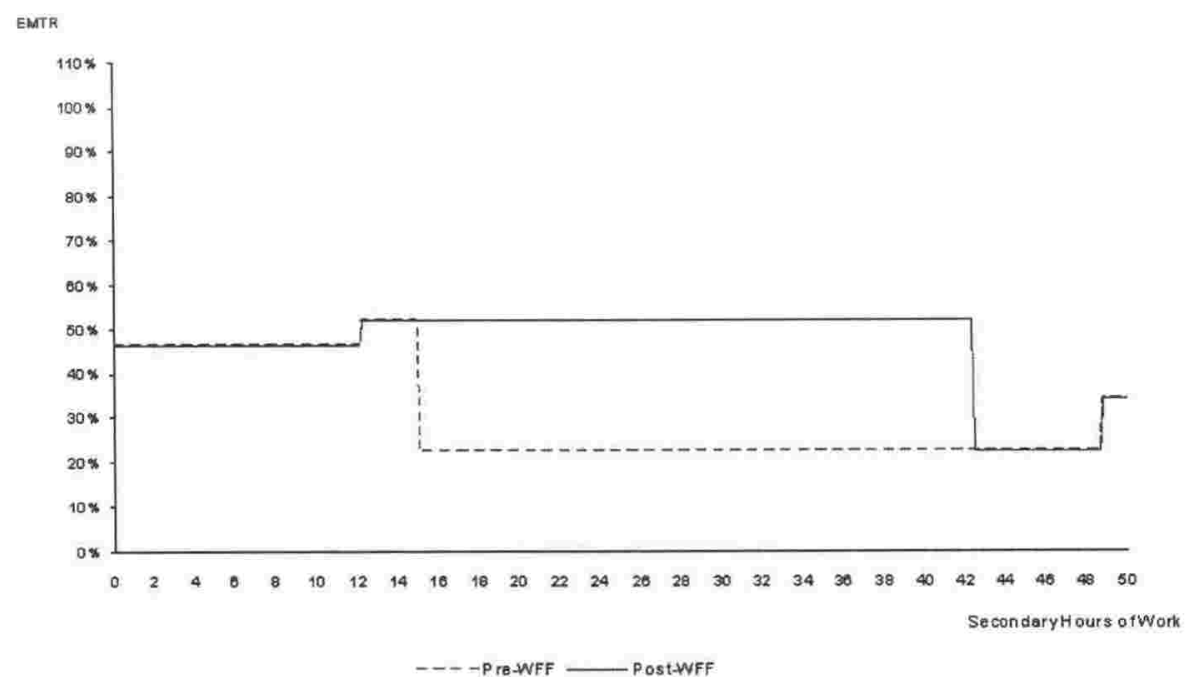

Given the assumptions regarding the primary earner's income, Working for Families does not improve incentives for secondary income earners to enter the labour market and increases the disincentives they face when they increase their hours of work up to around 40 hours per-week. (Reducing the primary earner's fixed income or the secondary earner's wage rate would extend this increase in disincentives.) The impact of the reforms on secondary earners was a particular concern of the Department of Labour 
[Cullen and Maharey, 2004, p. 24]. Based on experiences with work-based income tax assistance in overseas jurisdictions, such as the Earned Income Tax Credit in the United States, this increase in EMTRs will be likely to encourage secondary earners to drop out the labour market, rather than working or registering for unemployment assistance, and lead to some families in this income range choosing to reduce their market incomes [Eissa and Hoynes, 2004]. Working for Families effectively subsidises some secondary earners to stay at home.

\section{Microsimulation Estimates of Secondary Earners' Incentives to Work}

The discussion above illustrated that the impact of Working for Families on secondary earners in partnered families is an issue of particular interest. Johnson [2005, p. 78] contained data on the impact of Working for Families on average EMTRs facing different family types that illustrated that for partnered families with children the average EMTRs rose by five percent, with the largest increase being for single-income families (of seven percent) and followed by dual-income partnered families (of four percent). For soleparent families with children he reported that Working for Families led to no change in the average EMTR. This average was composed of an increase in the average EMTR facing sole-parents in full-time work (of four percent) and decreases in the average EMTRs of sole-parents in part-time work (of five percent) and out of work (of one percent).

To illustrate the changing distribution of EMTRs facing partnered families due to Working for Families in greater detail, table 10.3 contains Treasury's TaxMod-A estimates of primary and secondary earners' average marginal tax rates (MTRs) and effective marginal tax rates (EMTRs) following these reforms [Nolan and Fairbrother, 2005]. These estimates do not include changes to accommodation or childcare assistance. Following Working for Families there is no change in the average MTRs and EMTRs facing families without children due to the targeting of the package towards families with children and the exclusion of the Accommodation Supplement changes (some of which would be received by families without children) from the modelling due to difficulties in modelling this form of assistance [Nolan, 2003, p. 35]. 
Table 10.3: Working for Families and Couples' Financial Incentives to Work

\begin{tabular}{llllllllll}
\hline & \multicolumn{3}{l}{ OChildren } & \multicolumn{3}{l}{ 1 Child } & \multicolumn{3}{l}{ Multiple Children } \\
& \multicolumn{3}{l}{ Workers in Family } & \multicolumn{2}{l}{ Workers in Family } & \multicolumn{2}{l}{ Workers in Family } \\
Average & 0 & 1 & 2 & 0 & 1 & 2 & 0 & 1 & 2 \\
\hline $\begin{array}{l}\text { Primary } \\
\text { MTR }\end{array}$ & 20 & 29 & 30 & 16 & 33 & 29 & 16 & 31 & 31 \\
$\begin{array}{l}\text { Secondary } \\
\text { MTR }\end{array}$ & 20 & 13 & 25 & 17 & 12 & 23 & 17 & 12 & 24 \\
$\begin{array}{l}\text { Primary } \\
\text { EMTR }\end{array}$ & 26 & 34 & 33 & 18 & 45 & 37 & 23 & 49 & 45 \\
$\begin{array}{l}\text { Secondary } \\
\text { EMTR }\end{array}$ & 26 & 22 & 29 & 19 & 29 & 31 & 25 & 35 & 38 \\
\hline
\end{tabular}

Source: TaxMod-A based on 200-01 HES weighted up to 2004-05 income distribution

Table 10.4: Financial Incentives to Work for Low-Wage and High-Wage Couples (Fully Implemented Working for Families)

\begin{tabular}{llllllll}
\hline & & Primary & & \multicolumn{3}{c}{ Spouse } \\
& Average & $\begin{array}{l}\text { 1 Child } \\
\text { Children }\end{array}$ & & $\begin{array}{l}\text { Multiple } \\
\text { Children }\end{array}$ & $\begin{array}{l}0 \\
\text { Children }\end{array}$ & 1 Child & $\begin{array}{l}\text { Multiple } \\
\text { Children }\end{array}$ \\
\hline $\begin{array}{l}\text { Below } \\
\begin{array}{l}\text { Median } \\
\text { Wage }\end{array}\end{array}$ & MTR & 22 & 24 & 25 & 20 & 20 & 19 \\
$\begin{array}{l}\text { Above } \\
\text { Median }\end{array}$ & MTR & 27 & 49 & 52 & 25 & 30 & 39 \\
Wage & 32 & 35 & 35 & 28 & 26 & 24 \\
\hline
\end{tabular}

Source: TaxMod-A based on 200-01 HES weighted up to 2004-05 income distribution

People in partnered families with children and without workers face a fall in their average EMTRs. This fall reflects the reduction in the level of the main benefit (with the removal of the child component of the benefit) and the increase in the abatement threshold for Family Assistance. The reduction in the abatement of the Accommodation Supplement facing beneficiaries would reduce these EMTRs further. The EMTRs facing partnered families with children with workers increase following the reforms. Increasing levels of assistance and reducing abatement of assistance at lower income levels means assistance abates higher into the income distribution. In table 10.4 the MTRs and EMTRs are broken down into below and above median wage groups. Average EMTRs for partnered families with children in both the below median wage and above median wage groups increase following Working for Families. This increase reflects the increase in EMTRs facing partnered families with workers following the reforms. The largest increases 
in EMTRs are for the below median wage group (particularly below median wage secondary earners).

This discussion of financial incentives to supply labour can also be seen in the light of behavioural estimates of labour supply responses to the Working for Families reforms prepared using TaxMod-B (based on the Melbourne Institute Tax and Transfer Simulator (see Creedy, Duncan, et al [2002] for a description of this model)) [Kalb, Cai, and Tuckwell, 2005]. The estimated behavioural responses from Working for Families for sole-parents were 1.94 percent of the total sole-parent population moving into the labour market, 0.03 percent exiting the labour market, and an increase in the average number of hours of work per-week increasing by 0.71 percent as a result of the reforms. Sole-parents' labour market participation and hours of work were thus estimated to increase following these reforms. For single childless women, 0.12 percent of the total single childless women population were estimated to enter the labour market, 0.06 were estimated to exit the labour market, and average hours of weekly work were estimated to fall by 0.02 percent. Single childless women's labour market participation, but not hours of work, was thus estimated to increase following these reforms.

All other population groups had negative estimated labour supply responses. The behavioural responses of married women with and without children were estimated to include 0.20 percent moving into the labour market, 0.63 percent exiting the labour market, and average weekly hours of work falling 0.18 percent. The behavioural responses of married men with and without children were estimated to include 0.29 percent moving into the labour market, 0.38 percent exiting the labour market, and average weekly hours of work falling 0.09 percent. The behavioural responses of singie childless men were estimated to include 0.06 percent moving into the labour market, 0.23 percent exiting the labour market, and average weekly hours of work falling 0.09 percent. Married women with and without children were thus identified as the population group who would be likely to have the strongest reduction in labour market participation and hours of work as a result of the Working for Families reforms.

Johnson [2005] argued that this pattern of EMTRs could encourage some two-income families to become one-income families and create partner 
penalties (where there are differences between the levels of assistance received by a partnered and sole family in otherwise similar circumstances). Although, as Johnson argues, few families will be likely to dissolve or not form in order to receive increased levels of assistance, this issue is likely to increase in prominence given the increasing proportion of Family Assistance expenditure going to partnered families (increasing from approximately one third to one half of Family Assistance recipients) following Working for Families [Johnson, 2005, p. vii].

\subsection{Generosity of Family and Employment Tax}

\section{Credits}

In New Zealand in 2004-05 the assistance provided by family and employment tax credits was the least generous of five Anglo-American countries. The following section discusses how the structure and relative generosity of New Zealand's family and employment tax credits will change after Working for Families. The figures in this section are for the 2007-08 income tax year and assume that the Working for Families package is implemented fully and according to schedule. However, in these figures main welfare benefits, wage rates, and family and employment tax credits have not been indexed for inflation. Further, programmes in jurisdictions other than New Zealand have been assumed to remain unchanged from their 2004-05 parameters.

\section{Assistance to a Sole-Parent with Two Children and Earning $\$ 10.00$ Gross Per-Hour}

The effect of the Working for Families package on the family and employment tax credits provided to a sole-parent with two young children and earning a wage rate of $\$ 10.00$ is shown in figure 10.7. In 2007-08 at zero hours of work this person would receive an unabated Family Support payment of $\$ 7,644$ per-annum for their two children. Further, due to the removal of the child component of the main benefit, the increase in the Family Tax Credit, and the replacement of the Child Tax Credit with an InWork Payment, the Working for Families package has also influenced the 
number of hours of work at which the person would be likely to exit the benefit. The combined effect of these the reforms is that the person would be likely to exit the Domestic Purposes Benefit at 25 hours of work (as opposed to 46 hours of work prior to reform).

Figure 10.7: Family and Employment Tax Credits for a Sole-Parent with Two Children (Aged 3 and 5) and Earning \$10.00 Per-Hour

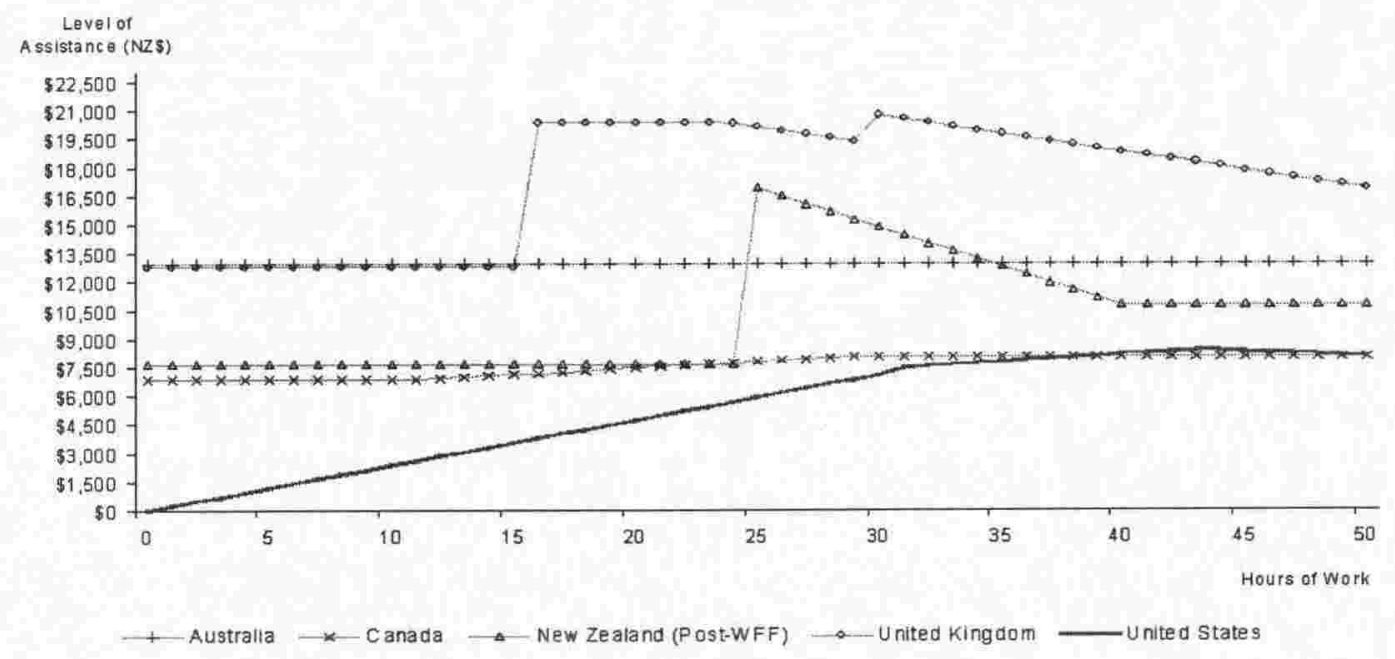

When the person exits the benefit they would be eligible for a Family Tax Credit payment of $\$ 118$ per-week and an In-Work Payment of $\$ 60$ perweek. Although this person would be eligible for in-work assistance if they were to exit the benefit at 20 hours per-week of work, they would be unlikely to do so before 25 hours of work as before this point the value of the remaining abated Domestic Purposes Benefit would exceed the value of the in-work assistance. The Family Tax Credit abates dollar for dollar against increases in net income and would be fully exhausted at around 40 hours of work (this is reflected in the poverty trap illustrated in figure 10.1). For abatement purposes the payments of the In-Work Payment will be added to Family Support payments and the total level of assistance will abate under the Family Support abatement regime. At a wage rate of $\$ 10$ gross per-hour the person will be required to work around 53 hours before facing the 30 percent abatement of Family Support and the In-Work Payment.

At low hours of work the generosity of assistance in New Zealand to this sole-parent would increase to about the levels of Canada following Working for Families. At above 40 hours of work per-week the level of assistance to 
this person would increase to about the levels of the United States. The levels of family and employment tax credits provided to this low-wage soleparent in New Zealand would still be generally less generous than the levels of assistance provided in Australia and the United Kingdom, although the differences would have narrowed.

\section{Assistance to a Partnered Person with a Non-Working Spouse and Two Children and Earning $\$ 15.00$ Gross Per-Hour}

The effect of the Working for Families package on the family and employment tax credits provided to a partnered person with two young children and a non-working spouse and earning a wage rate of $\$ 15.00$ is shown in figure 10.8. In 2007-08 at zero hours of work this person would receive an unabated Family Support payment of $\$ 7,644$ for their two children.

Figure 10.8: Family and Employment Tax Credits for a Primary Earner with Two Children (Aged 3 and 5) and Earning NZ\$15.00 Per-Hour

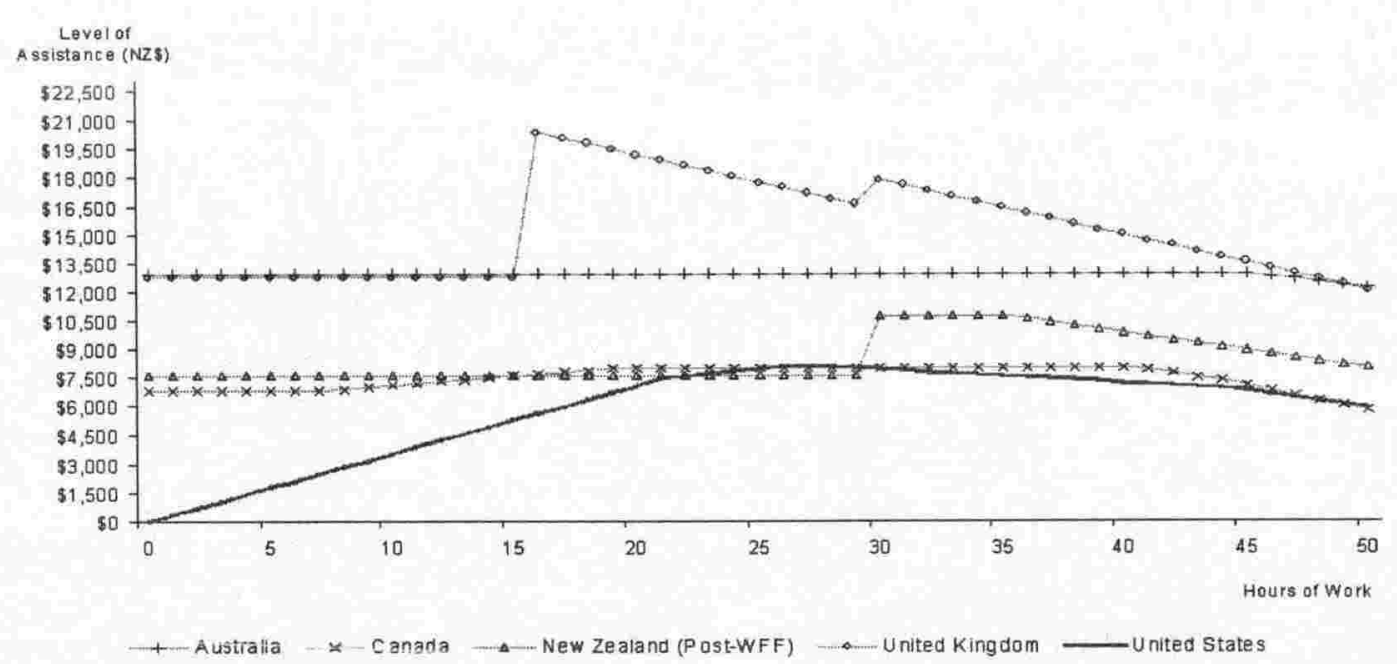

Further, due to the removal of the child component of the main benefit and the replacement of the Child Tax Credit with an In-Work Payment, the Working for Families package has also influenced the number of hours of work at which the person would be likely to exit the benefit. The combined effect of these reforms is that the person would be likely to exit the Unemployment Benefit at 30 hours of work. At 30 hours of work the person would be eligible for an In-Work Payment of $\$ 3,120$ per-annum. At this wage rate and with these hours of work this person would not be eligible for the 
Family Tax Credit. For abatement purposes payments of the In-Work Payment would be added to Family Support payments and the total level of assistance would abate under the Family Support abatement regime. When the person increases their hours of work to around 36 hours their family gross income would increase to above $\$ 27,500$ and the Family Assistance programmes begin to abate at 30 percent.

At low hours of work the generosity of assistance in New Zealand to this primary earner would increase to about the levels of Canada following Working for Families. Both of these countries would be more generous than the United States. The generosity of assistance in the United States increases as the Earned Income Tax Credit phases in and by 20 hours of work per-week New Zealand, Canada, and the United States would provide similar levels of assistance to this primary earner. The levels of family and employment tax credits provided to this primary earner in New Zealand would still be generally less generous than the levels of assistance provided in Australia and the United Kingdom, although the differences would have narrowed.

\section{Assistance to a Partnered Person with a Working Spouse and Two Children and Earning $\$ 15.00$ Gross Per-Hour}

The effect of the Working for Families package on the family and employment tax credits provided to a partnered person with two young children and a working spouse and earning a wage rate of $\$ 15.00$ is shown in figure 10.9. It is assumed that the primary earner earns a fixed income of $\$ 600$ per-week ( $\$ 31,200$ per-annum). With this assumed income of the primary earner the family is already no longer receiving a main welfare benefit (and is thus eligible for the work-based Family Assistance programmes) and faces abatement of their Family Assistance entitlement.

Following Working for Families the higher levels of assistance provided by the Family Assistance programmes and the lower levels of abatement at lower income levels mean that the range of income over which the Family Assistance programmes abate increases. The family thus continues to receive Family Assistance (and face abatement of these programmes) until relatively high hours of work (this is reflected in increased disincentives to 
work illustrated in figure 10.6). However, in comparison to the other four Anglo-American countries, assistance in New Zealand is exhausted at relatively low levels of earned income. With the exception of families at relatively high income levels, following the Working for Families reforms the generosity of assistance increases to the levels of Canada and the United States. Again the levels of assistance provided in New Zealand would still be less generous than the levels of assistance provided in Australia and the United Kingdom, although the differences would have narrowed.

Figure 10.9: Family and Employment Tax Credits for a Secondary Earner with Two Children (Aged 3 and 5) and Earning NZ\$15.00 Per-Hour

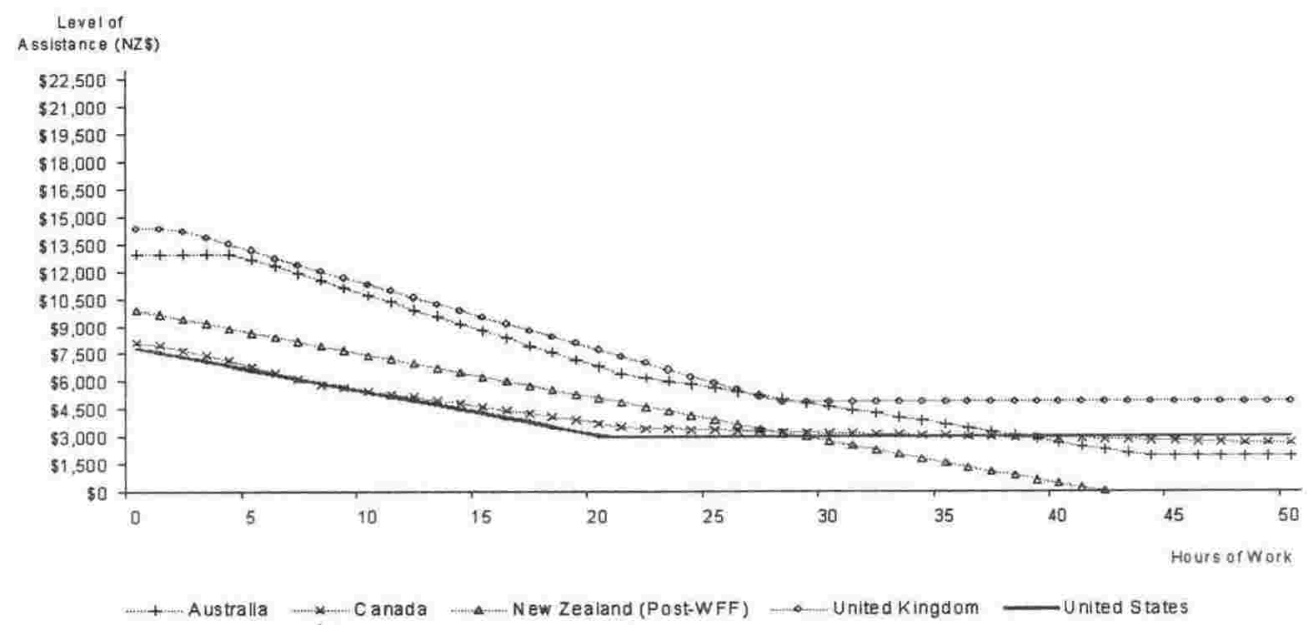

\subsection{Administration and Compliance}

The Working for Families reforms will change the balance in the tax-benefit system, with expenditure moving from main welfare benefits and towards supplementary assistance such as the Family Assistance programmes and Accommodation Supplement. An advantage of this shift in this balance in the system is that when a family moves off a main benefit they could potentially continue to receive assistance. However, this would also mean that the takeup and administration of supplementary assistance would play a larger role in determining outcomes of these programmes. The assistance that families receive would depend to a greater degree on programmes' administration and their knowledge of their entitlements. This shift would also make it easier for governments to increase or reduce tax-benefit expenditure, with cuts in 
expenditure, for example, being possible through administrative measures to tighten eligibility and not requiring legislative change. The greater receipt of supplementary assistance by families in work could also have implications for the current allocation of responsibility between administrative agencies, with the Ministry of Social Development administering assistance like the Accommodation Supplement and the Inland Revenue Department assistance like Family Assistance. There could be increased demand for efforts to combine the administration of assistance, as has been done in both Australia and the United Kingdom in recent years.

An important feature of the Working for Families reforms is the extension of hours-based work tests to the In-Work Payment (formerly the Child Tax Credit) as well as the Family Tax Credit. An hours-based work test creates notches in budget constraints, which could lead to changes in the distribution of hours of work. Basing assistance on a prescribed numbers of hours of work would be inconsistent with the market-based setting of employment conditions, as the flexibility in setting hours of work in employment contracts would be reduced. In the context of deregulated labour markets a feature of many employment contracts is that an employee's hours of work may vary with seasonal or economic conditions. The use of an hoursbased threshold requires determining how these fluctuations in hours of work should be treated in the assessment of entitlement. Having thresholds based on work hours (in association with abatement based on income) is likely to increase the complexity of a programme's administration and may lead to greater uncertainty regarding the level of assistance available when making the transition from benefit to work and when hours of work and earned incomes fluctuate.

A key constraint upon the use of thresholds for paying and abating assistance is the ability to monitor and enforce these thresholds. An hoursbased threshold would also be vulnerable to fraud as the income tax system is not able to easily monitor recipients' hours of work and compliance would not be audited independently of the general taxpayer audit process. Currently the administration of the Family Assistance programmes heavily relies on voluntary compliance. Information on incomes is more readily available than information on hours. Collecting information on hours would be likely to 
increase the costs facing recipients and their employers of complying with the tax-benefit system, which could discourage some employers from hiring lowwage workers. Information on hours is also more difficult to audit than information on incomes. Either a large reliance upon voluntary compliance is required (potentially exposing the programme to fraud (adverse selection)) or the intensity of the administration of the programmes would be required to increase (which would be contrary with current efforts for simplifying the administration of the tax system and lowering business compliance costs). Monitoring compliance with this test would not be likely to be an efficient use of Inland Revenue Department resources.

\subsection{Possible Further Reforms}

While Working for Families represents significant income redistribution towards families with children, little change will be made to the overall design of the Family Assistance programmes, some of which have remained largely unchanged since 1986. Working for Families does not address the need to reform the Family Assistance programmes in the light of important social and economic changes that have taken place over the last two decades, such as the breakdown of the breadwinner model of social arrangements and the liberalisation of the labour market. The remainder of this chapter thus considers a number of improvements to Working for Families.

A number of alternative reforms have been recommended by various commentators. The New Zealand Child Poverty Action Group has, for example, argued that Family Assistance programmes should not be targeted on the basis of work effort and that the child component of main welfare benefits should be restored [St John and Craig, 2004]. These recommendations reflect a concern with immediately reducing child poverty. However, the relatively low degree of targeting of the Family Support programme would mean that increasing the generosity of this programme to offset any losses to low-wage families from the removal of the Family Tax Credit and Child Tax Credit would lead to a significant increase in fiscal costs of the Family Assistance programmes. This approach would also fail to reduce the poverty traps facing low-wage families created by the abatement 
of main welfare benefits. In a context of largely market based setting of wage rates and where the breadwinner model of social arrangements is decreasing in importance, wage subsidies such as employment tax credits play an important social policy role. Assistance to low-wage working families compensates these families for the additional costs they face when in work.

The New Zealand National Party has, in contrast, recommended providing financial relief through reductions in personal income taxes. In order to reduce the disincentives for labour supply facing secondary earners the National Party has also recommended not implementing the final increase in the Family Support Tax Credit in 2007-08, which would free fiscal resources for income tax reductions. However, while tax reductions may improve financial incentives to supply labour (depending on the precise income and substitution effects of the tax reductions, as tax reductions may worsen financial incentives for some groups when reductions in average tax rates dominate reductions in marginal tax rates) such reductions would lack the targeting efficiency of family and employment tax credits, which can be closely targeted to need on the basis of family structure, and would thus either compromise income adequacy objectives or would incur a larger fiscal cost. Such recommendations also do not address the appropriate structure of the Family Assistance programmes.

The remainder of this chapter thus discusses a number of alternative options for reform to Family Assistance. This study has identified a number of reforms aiming to incrementally improve the structure of the Family Assistance programmes (through removing the hours-based work test from the In-Work Payment and removing the Family Tax Credit). These reforms are discussed in greater detail below. As well as these incremental reforms this study has identified a number of structural reforms. These possible structural reforms include:

- Raising the thresholds for abatement to compensate for credit corrosion up to 1 April 2007.

- Lowering the rate at which Family Assistance abates.

- Increasing the rates of Family Support for younger children relative to the rates for older children.

- Extending in-work assistance to families without children. 
- Extending the Parental Tax Credit to all low-income families with a newborn child.

The first two structural reforms are discussed in the following sections of this chapter. The three later structural reforms are not discussed in this chapter but are instead discussed in the context of the overall conclusions of the study in the following chapter.

\section{Simplifying the Structure of the Family Assistance Programmes}

Two largely incremental changes to the Working for Families reforms are considered below. As with the Working for Families reforms, the levels of assistance provided by the Family Assistance programmes and the programmes' abatement thresholds would be increased and indexed for inflation, abatement of the Family Assistance programmes below $\$ 27,500$ would be removed, and the In-Work Payment would be increased as proposed. However, unlike Working for Families eligibility for the In-Work Payment would not require satisfying an hours-based work test and the Family Tax Credit would be removed. The use of an hours-based threshold is inconsistent with the market-based setting of employment conditions and would create significant administration and compliance costs. The Family Tax Credit, with its tight targeting by income and family status, tends to be unresponsive to fluctuations in recipients' circumstances, such as wage rates, hours of work, number of children, and civil status. Given the tight targeting of the Family Tax Credit this programme is likely to be mostly received by low-wage sole-parent families. The hours-based eligibility threshold for the In-Work Payment is most likely to affect primary earners in partnered families. The impacts of these reforms on the EMTR profiles for two family types are thus discussed below. The first familv tvpe is_a sole- 
Families reforms the sole-parent would be encouraged to exit the Domestic Purposes Benefit at around 24 hours of work due to the increase in the workbased Family Assistance programmes. However, due to the dollar-for-dollar abatement of the Family Tax Credit there would be little relief from the poverty traps facing this person. If the Family Tax Credit was removed then the person would exit the benefit at a higher number of hours of work perweek. However, the poverty traps facing this person would have reduced as they would only face abatement of the Domestic Purposes Benefit. The Family Tax Credit makes a larger contribution to poverty traps than abatement of the Domestic Purposes Benefit.

Figure 10.10: EMTR Profiles of a Sole-Parent ( $\$ 10$ Gross Per-Hour) Prior to Working for Families, Post Working for Families, and Post Alternative Reform

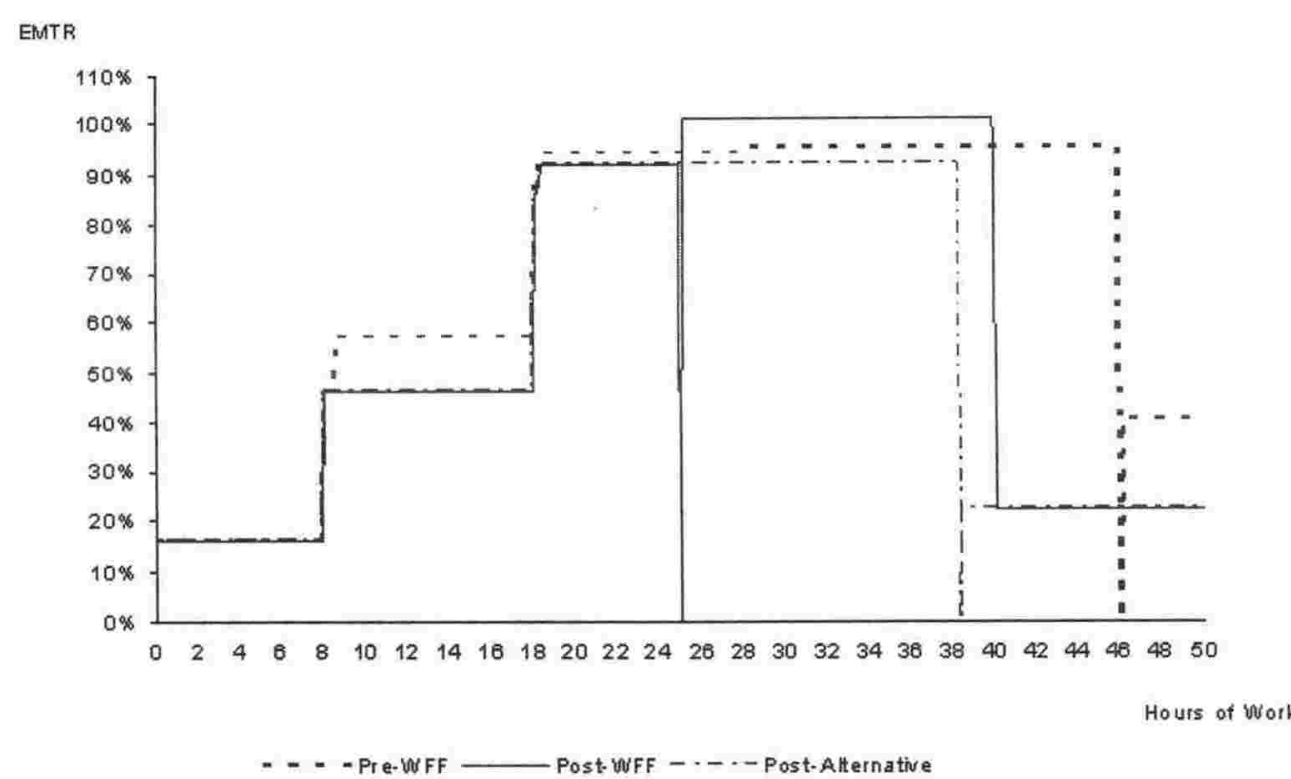

The removal of the Family Tax Credit would mean that some soleparents at low wages would have smaller net incomes at certain hours of work relative to the post-Working for Families static income distribution. At around 25 hours of work the sole-parent's net income would increase to around $\$ 530$ following Working for Families (in comparison to around $\$ 450$ prior to Working for Families). Following the alternative reform their net weekly income would be around $\$ 514$ at these hours of work. However, this difference would narrow so that at around 38 hours of work the family net income would be around $\$ 520$ following the alternative reform (following Working for Families the net income would around $\$ 530$ at these hours of 
work) and from just over 40 hours of work the family would have a net income following the alternative reform at least equal to their net income following Working for Families. Only a small number of families would be likely to experience any reduction in net income relative to the Working for Families reforms and any behavioural responses from the improvement in financial incentives to supply labour may offset these static losses.

Figure 10.11: EMTR Profiles of a Primary Earner (\$15 Gross Per-Hour) Prior to Working for Families, Post Working for Families, and Post Alternative Reform

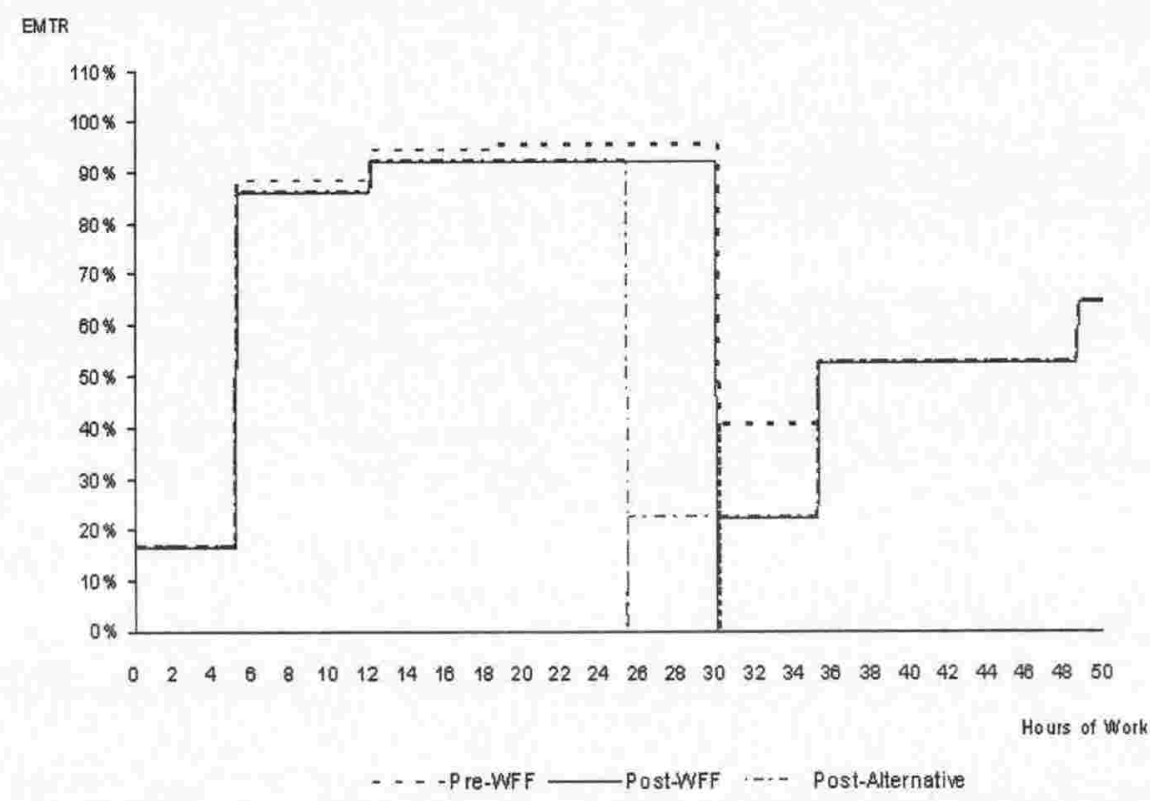

The EMTR profile of a primary earner with two children and earning a wage rate of $\$ 15$ per-hour is shown in figure 10.11. The removal of the hours-based work test improves the EMTR profile of this family. This improvement in the financial incentives to supply labour would not require any reduction in the family's income. At 26 hours of work the family's net income would be $\$ 521$ following the alternative reforms and $\$ 518$ following Working for Families. At 29 hours the family's net income would be $\$ 556$ following the alternative reforms and $\$ 521$ following Working for Families. The rationale for introducing an hours-based threshold was to exclude highwage but low-income workers from assistance. The Government has provided no explanation for the selection of this hours-based threshold at 30 hours per-week for partnered and 20 hours per-week for sole-parent families. As Nolan [2004c] demonstrated setting the hours-based threshold at 30 
hours may exclude recipients at moderate wages from assistance, although there may be few high-wage and low-hour individuals excluded from assistance by this threshold as these programmes are already heavily targeted on the basis of income.

\section{Increasing Abatement Threshold and Lowering Abatement Rate}

In real terms the $\$ 27,000$ threshold for 30 percent abatement in 1988-89 was equivalent to approximately $\$ 40,000$ in 2004-05. This effective shift in the threshold increased the numbers of people facing higher abatement of their Family Assistance entitlement. Further, since 1 April 1989 the highest abatement rate has remained at 30 percent, which contrasts with jurisdictions such as Australia where the rate has been lowered over several years to 20 percent.

During the 2005 general election campaign the New Zealand Labour Party proposed increasing the Family Assistance abatement threshold to $\$ 35,000$ and lowering the rate of abatement of Family Assistance to 20 percent. The effect of these proposals on the secondary earner in a partnered family with two children under 13 is modelled below. Emphasis is given to secondary earners in partnered families as these are the people most likely to be affected by the change in financial incentives to supply labour from these proposals. In contrast there would be little change in the EMTRs facing recipients of main welfare benefits as they will be unlikely to have gross incomes in excess of $\$ 27,500$ and any change in EMTRs facing beneficiaries with total (benefit plus earned) gross income above this threshold would be small as Family Assistance abatement is levied on changes in gross incomes after benefit abatement. In the modelling below it is assumed that the primary earner has a fixed income of $\$ 600$ per-week and that the secondary earner receives a wage rate of $\$ 15$ per-hour. The figure illustrates the fully enacted Working for Families package and the Working for Families package with the two additional Labour proposals in 2007.

Increasing the abatement threshold and lowering the abatement rate would both increase the income range over which Family Assistance would be received and abated. This policy would affect those families receiving Family Assistance and with joint incomes above $\$ 27,500$. For families with 
joint incomes between $\$ 27,500$ and $\$ 35,000$ there would be substitution effects (from the rate of abatement falling from 30 to 0 percent) encouraging work and income effects (from the higher abated value of assistance) discouraging labour supply. The overall effect on these families' labour supply would thus depend on which effect dominates. For families with joint incomes above $\$ 35,000$ but below the previous (before the Labour policy change) point at which Family Assistance would be fully abated there would be substitution effects (from the rate of abatement falling from 30 to 20 percent) encouraging labour supply and income effects (from the higher abated value of assistance) discouraging labour supply. Again the overall effect on these families' labour supply would thus depend on which effect dominates. For families with joint incomes above the previous point at which Family Assistance would be fully abated and below the new point of full abatement there would be substitution and income effects discouraging labour supply. The Labour proposals would thus reduce the financial disincentives to work facing low-wage secondary earners but this would come at a cost of discouraging some higher-wage secondary earners' labour supply.

Figure 10.12: EMTR Profiles of a Secondary Earner (\$15 Gross Per-Hour) Post Working for Families and Post Alternative Reform

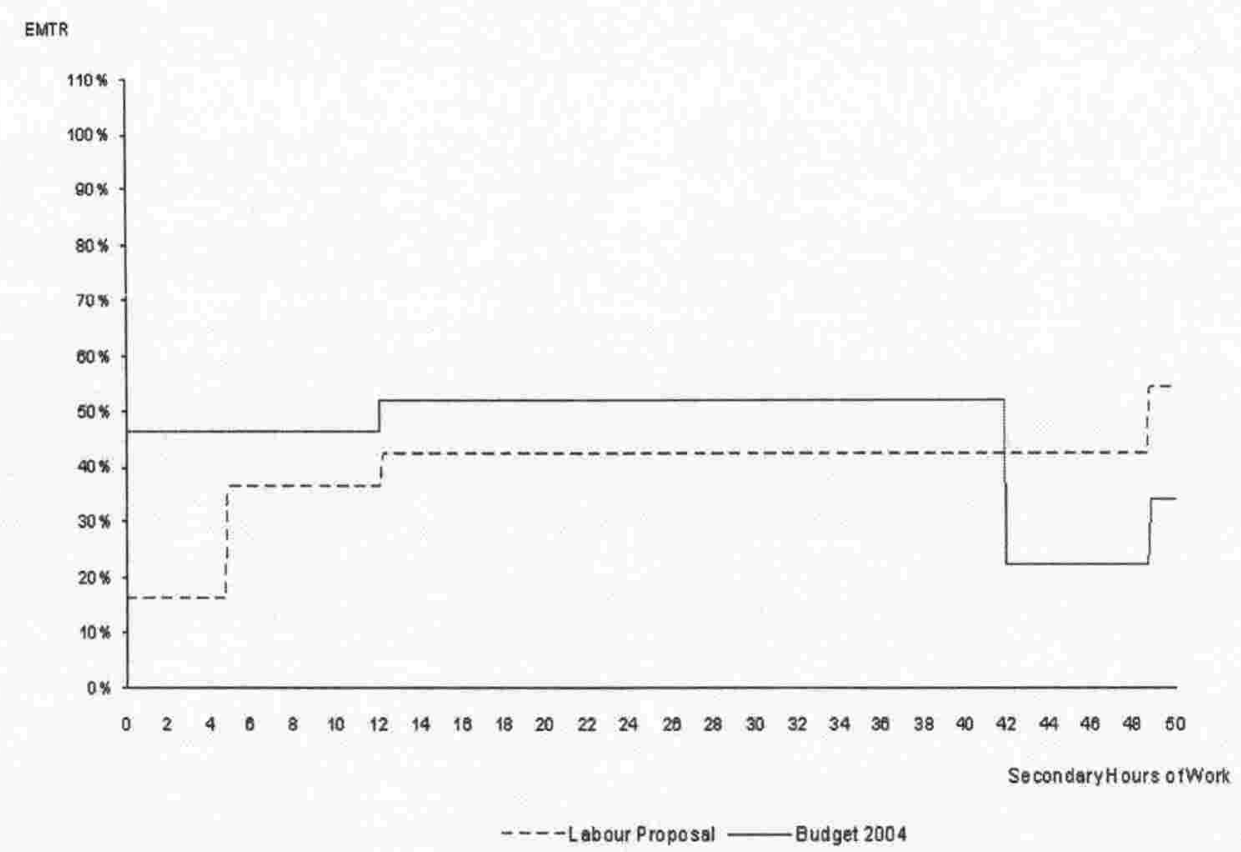




\subsection{Conclusion}

This chapter evaluated the Working for Families reforms. A key feature of these reforms is the shifting of the child component of main benefits into the Family Support Tax Credit. This policy change, along with the Single Benefit reforms, which are proposed for implementation in 2007, represents a significant shift in the balance of the tax-benefit system towards supplementary assistance. The eventual indexation of the Family Assistance Tax Credits will mean that, unlike after the benefit cuts of 1991, the annual increase in main benefits for inflation will not alter this balance in the taxbenefit system.

The design of tax-benefit programmes targeted by income generally requires trade-offs to be made between objectives for poverty reduction, targeting efficiency, and financial incentives to supply labour. The Working for Families reforms will make a significant reduction in the rate of child poverty in New Zealand. In comparison to other Anglo-American countries, the Working for Families reforms represent a significant increase in the generosity of family and employment tax credits in New Zealand. This increase in generosity is, however, reflected in increased disincentives for individuals to work at higher joint hours of work or wage rates. The greater the generosity of assistance then the longer the range of incomes over which abatement takes place. As shown by the impact of Working for Families on EMTR profiles and couples' financial incentives to supply labour, following Working for Families the incentives for sole-parents to supply labour are likely to be improved but some secondary earners will be likely to face larger disincentives for labour supply.

Following Working for Families there is likely to be an increase in the compliance and administration costs of the tax-benefit system due to the use of an hours-based eligibility criterion. Further, the greater receipt of supplementary assistance by families in work may lead to greater demand for increased efforts to combine the administration of assistance of tax-based and welfare-based supplementary assistance programmes.

Overall the Working for Families reforms represent a significant investment in families with children but little change will be made to the 
overall design of the Family Assistance programmes, some of which have remained largely unchanged since 1986. The remainder of this chapter thus discussed a number of alternative options for reform to Family Assistance. Removing the Family Tax Credit would provide sole-parents who take-up this programme with relief from the poverty traps that it creates, although this could lead to some sole-parents delaying their exit from the Domestic Purposes Benefit and could lower the level of assistance they receive from Working for Families. Removing the hours-based eligibility threshold for the In-Work Payment would improve financial incentives for some primary earners to supply labour and would not lead to any fall in recipients' assistance from Working for Families. Increasing the threshold at which the Family Assistance programmes abate and lowering the rate of abatement would improve financial incentives for low-wage secondary earners to supply labour, but would come at an economic cost of shifting disincentives for labour supply onto secondary earners at higher points in the income distribution. A number of other possible changes to Working for Families are discussed in the context of the overall conclusions of the study in the following chapter. 


\section{Conclusion}

\subsection{Introduction}

This study reviewed methods for measuring the effectiveness of family and employment tax credits, evaluated the Working for Families reforms, and considered possible improvements to Working for Families. Questions that this study considered were:

- What roles should family and employment tax credits play in tax-benefit systems?

- How should family and employment tax credits be designed? Should eligibility for assistance reflect work effort as opposed to family structure?

- What lessons do historical and comparative perspectives on Working for Families provide?

- Will New Zealand's Working for Families reforms achieve the optimal design and role of family and employment tax credits?

- What improvements, if any, could be made to the Working for Families reforms?

These questions are each discussed in the following sections of this chapter and are central to understanding what works to improve social policy outcomes in New Zealand.

The origins of New Zealand's tax-benefit system were in an economic and social environment of low and generally short-term unemployment and where couples with children and a single male breadwinner were the most common family type. Over the past two decades work patterns and family structures have changed significantly. New Zealand has had one of the highest rates of increase in income inequality in the world and concern has 
increasingly been expressed regarding the need to alleviate child poverty. New Zealand, like many other OECD countries, has experienced significant changes in family structures, including the breakdown of the breadwinner model of social arrangements, increasing numbers of sole-parent families, and increasing numbers of dual-income families. This increasing population heterogeneity and the growth in part-time and part-year work has increased the complexity of designing tax-benefit programmes to ensure families with children have adequate incomes while improving financial incentives to work (resolving Beveridge's dilemma).

Although the social assistance and income tax systems were largely devised as separate systems large proportions of the population are now affected by both systems simultaneously. There has been a shift towards targeted expenditure on the working-aged. The greater targeting of social assistance expenditure has resulted in increasing poverty traps facing lowwage families with children. Although income tax policies have emphasised a broad based and low rate approach to income taxation, relatively little emphasis has been given to systematically lowering effective marginal tax rates at low income levels. These policy shifts have occurred in tandem with increasing market-based setting of wage rates and the decline of full employment (largely of male primary caregivers).

The five Anglo-American countries have responded to issues such as these through establishing or redesigning family and employment tax credits. Of these five countries New Zealand has been the laggard in this policy domain, although such reforms are now underway with the Working for Families package. Expanding the social policy role of the income tax system in this way will further increase the degree to which the social assistance and income tax systems simultaneously affect the same people. A greater understanding of the relative effectiveness of family and employment tax credits, as opposed to traditional welfare programmes or personal income taxes, at achieving policy outcomes will thus be necessary for effectively understanding what works to change social policy outcomes. 


\subsection{The Role of Family and Employment Tax Credits}

Income taxes, family and employment tax credits, and main welfare benefits should be seen as different components of a unified tax-benefit system. However, any approach taken to evaluating actual or possible tax-benefit reforms must also recognise the relative advantages of tax-based and welfare-based assistance and the role that individual programmes should play in the broader tax-benefit system. Tax-based and welfare-based social assistance programmes differ in the extent to which they can accurately assess entitlement, respond to recipients' changing circumstances, and ensure compliance and participation in programmes. Growing international support for tax-based social assistance programmes reflects the belief that assistance provided through the tax system avoids some of the limitations of traditional social welfare programmes.

Evidence on the Earned Income Tax Credit in the United States, for example, indicates that take-up rates of this assistance are relatively high due to the relatively low stigma associated with receiving assistance through the tax system and the high proportion of recipients taking up assistance at the end of the income tax year. What evidence there is on the take-up of the Family Assistance programmes in New Zealand indicates that take-up of these programmes is likely to be relatively high also. Reflecting the increasing emphasis on the regular and ongoing information transfer between government agencies in New Zealand, this country is unusual among Anglo-American countries in having a relatively high take-up of assistance during the income tax year. These high rates of take-up in the Untied States and New Zealand contrast with countries like the United Kingdom, where take-up of assistance is relatively low.

Nevertheless there are, however, a number of limitations to the use of tax-based social assistance, such as the relatively low flexibility in responding to recipients' changing circumstances, the requirement for relatively narrow definitions of income and the income sharing unit, and the requirement for relatively clear-cut and non-discretionary eligibility criteria. As further 
evidence on the Earned Income Tax Credit indicates, this programme has also been vulnerable to taxpayer fraud with 27.0 to 31.7 percent of the claims made in 1999 being either overpayments to eligible recipients or payments to ineligible recipients [Inland Revenue Service, 2002, p. 3]. Little information is available on taxpayer fraud in relation to New Zealand's Family Assistance programme. Issues such as take-up and taxpayer fraud are likely to increase in importance in the New Zealand tax-benefit system following the expansion of the Family Assistance programmes as part of the Working for Families reforms.

Four key policy objectives have motivated the use of family and employment tax credits in the Anglo-American countries. These programmes have been used to improve financial incentives to work ('make work pay'), reduce poverty (particularly child poverty), compensate families for the costs of children, and support single-income partnered families. These four objectives are each discussed below.

The shift towards market-based setting of wage rates in New Zealand has meant that employment and family tax credits now play an important role in ensuring that low-wage families have adequate incomes. A major rationale for the use of employment and family tax credits has been to provide assistance to families with children without the negative financial incentives for labour supply associated with traditional welfare-based programmes. Yet this simple view of the financial incentives associated with tax-based assistance needs to be tempered in the light of the empirical evidence on the financial incentives that arise from these programmes. Evidence on the labour supply effects of employment tax credits indicates that these programmes involve a trade-off beiween increasing the labour supply of soleparents and decreasing the labour supply of secondary earners. This decrease of labour supply of caregivers in couples reflects the use of joint income as the basis for assessing entitlement. Assessing entitlement on joint income encourages some secondary earners to drop out of the labour market, rather than working or registering for unemployment assistance, and leads to some families choosing to reduce their earned incomes. Basing entitlement on joint income means secondary earners generally face higher effective marginal tax rates from their first dollar of income than primary 
earners and when secondary earners reduce their earned incomes there is little reduction (or an increase) in joint income. Some secondary earners are effectively subsidised to stay at home [Eissa and Hoynes, 2004].

Further, there are important differences in the designs of employment tax credits among the five Anglo-American countries. This study has illustrated two broad approaches to the designs of these tax credits. The United States seeks to improve financial incentives to work through providing an earning subsidy up to a threshold. In contrast both New Zealand and the United Kingdom assess work effort on the basis of hours of work and, in New Zealand, exclude recipients of main welfare benefits from receipt of employment tax credits. A subsidy that increases with earnings up to a threshold improves incentives to increase hours of work but may be criticised on vertical equity grounds. However, hours-based thresholds create discontinuities in budget constraints that can distort distributions of hours of work, could be inflexible in the light of market-based employment contracts that require hours of work to vary, and could create significant administrative and compliance burdens. The increased emphasis on hours-based eligibility thresholds in New Zealand thus appears inconsistent with the liberalisation of the labour market, which has been associated with increasing part-time and casual work, variations in weekly hours of work, variations in wage rates, and participation rates of women.

New Zealand is also unusual among Anglo-American countries in providing employment tax credits to only families with children. Employment tax credits in both the United Kingdom and the United States are available to low-wage working families without children. This narrow role of employment tax credits in New Zealand reflects the weight given to fiscal objectives in the design of the Family Assistance programmes. This dominance of fiscal objectives is also reflected in the relatively low rates of generosity of programmes in New Zealand. As this study demonstrated, of five AngloAmerican countries in 2004-05 New Zealand provided the least generous family and employment tax credits to low-wage families with children.

In New Zealand poverty among families with children and working families has increased. One factor in the increasing poverty among families with children has been the fall in the poverty reduction effectiveness of the 
tax-benefit system, which has partly reflected the decline in value of Family Assistance programmes due to their lack of indexation for inflation. This study has illustrated, however, that as well as reducing the generosity of assistance the failure to index the levels of assistance and thresholds for abatement has been likely to lead to the incidence of poverty traps among families with children increasing. Income adequacy outcomes should thus be seen in conjunction with financial incentives for labour supply. It is in this context that reform to family and employment tax credits is being used in New Zealand to directly alleviate poverty and improve caregivers' (particularly sole-parents') financial incentives to supply labour (as part of a broader poverty reduction strategy). However, the current work focus of the Family Assistance programmes should not be overstated. Expenditure on the work-based Family Assistance programmes is marginal in comparison to expenditure on the Family Support Tax Credit, which is available to families in and not in work.

New Zealand is unusual among Anglo-American countries in not providing base levels of assistance that go high into the income distribution in order to compensate families with children for the additional costs they face relative to families without children. This absence of base levels of assistance illustrates the shift in New Zealand away from a policy objective of ensuring horizontal equity between families with and without children. For much of the second half of the twentieth century the universal Family Benefit was provided to account for additional costs facing families without children and to provide caregivers with an independent source of income. However, the universal Family Benefit was not indexed for inflation so that by its removal in 1991 its role in the tax-benefit system had become a largely token one. As well as the Family Benefit a number of small tax rebates that aimed to assist low-income families were established during the 1970s and early-1980s. These rebates were limited to working families and were largely paid to principal income earners and did not vary according to the number of children in the family. These rebates were replaced by the Family Assistance Tax Credits in 1986.

In the late 1990s there was an attempt to extend the objectives of the Family Assistance programmes to include the provision of support to working 
families with newborn children through introducing the Parental Tax Credit. Influencing the establishment of this programme were efforts to reduce political demand for paid parental leave policies. However, with the subsequent establishment of paid parental leave policies the rationale for and role of this programme, and the exclusion of beneficiary families from this assistance, could be questioned. Policymakers have given little consideration to whether this programme requires restructuring or removal or the particular role that this programme should play in New Zealand's tax-benefit system.

In New Zealand there is increasing voice being given to redesigning family and employment tax credits as a vehicle for partially introducing family based taxation to help arrest the decline in single-income partnered families with children. Programmes with similar objectives are present in other AngloAmerican tax-benefit systems, such as the Family Tax Benefit Part B in Australia and features of the income tax system (tax exemptions) in Canada and the United States. (In the United States it is also possible for some families to opt for joint taxation.) However, these policies conflict with policy objectives for increasing caregivers' labour supply and tend to have low targeting efficiency. If these policies were adopted in New Zealand they would thus be likely to require trade-offs to be made with other important policy objectives. Further, the trend among OECD countries has been to redesign or remove such programmes to improve caregivers' financial incentives for labour supply. There is thus little rationale for extending the Family Assistance programmes in this direction in New Zealand.

\subsection{Designing Family and Employment Tax Credits}

The section above identified a range of possible roles for family and employment tax credits. The effectiveness of family and employment tax credits in filling these roles will, however, largely reflect their designs. Designs of family and employment tax credits in five Anglo-American countries indicate a range of different approaches taken to reconciling policy objectives. Among the Anglo-American countries the designs of family tax 
credits differ in the degree to which they are based on family structure. In Canada, for example, family tax credits are heavily targeted on the basis of family structure. Australia and Canada place little emphasis on employment tax credits, although provincial-level employment tax credits and federal-level unemployment insurance programmes are also provided in Canada. The emphasis given to providing assistance on the basis of family structure in Australia is reflected in the relatively low labour participation of caregivers in this country.

In New Zealand the structure of the Family Assistance Tax Credits prior to the Working for Families reforms largely reflected the structure of assistance introduced in 1986. Since their 1986 establishment the roles of the Family Assistance programmes have been to provide supplementary assistance targeted on the basis of family structure and income (the Family Support Tax Credit) and targeted on the basis of family structure, income, and work effort (the Family Tax Credit and then the Child Tax Credit and Parental Tax Credit). There have, however, have been long periods of little change in the design of the Family Assistance programmes. Apart from increases in levels of assistance and abatement thresholds, the Family Tax Credit is largely identical to the programme established in 1986. The rationale for the Family Tax Credit was to provide a negative income tax type programme (with an income guarantee that abates at 100 percent against changes in annual joint taxable income) for working families with children. Take-up of this programme during the income tax year is based on annual joint taxable income, work status, hours of work, and family status projected forward.

The tight targeting of the Family Tax Credit means that under-payments or over-payments are relatively likely for this programme. Since this programme's establishment in 1986, liberalisation of the labour market has been reflected in greater part-time and part-year work and family structures have become less stable and more heterogeneous. Recipients of the Family Tax Credit are therefore increasingly likely to change circumstances during the income tax year and although the Inland Revenue Department can automatically adjust entitlements during the year for many taxpayers, the tight targeting of the Family Tax Credit reduces the effectiveness with which 
this assistance may respond to these fluctuations. Any responsiveness that may occur will incur relatively high administrative and compliance costs, as information on hours of work is relatively difficult to collect and audit. Overpayments and under-payments during the income tax year are thus relatively likely to arise for recipients who take-up this programme during the income tax year. Prior to Working for Families the erosion of the value of the threshold at which abatement began for this programme meant that relatively few families qualified for this programme and issues of over-payments and under-payments impacted on only a concentrated group of recipients. With the extension of this programme following Working for Families these difficulties will, however, become more common.

In the design of the Family Support Tax Credit since 1986 greater emphasis has been placed on targeting assistance by the numbers and ages of children in families. Since 1986 assistance has increased with the ages of children. However, the failure to index these programmes has led to credit corrosion that reduces both the value of the unabated assistance and the real income levels at which abatement applies. The failure to increase the levels of entitlement of the Family Assistance programmes in line with inflation has been documented by a number of commentators. There has been less recognition of the long periods of little change in abatement thresholds and abatement rates for the Family Assistance programmes. The top income threshold for Family Support abatement, for example, remained unchanged for the twelve years prior to 1 April 2000 and the two abatement rates of 18 and 30 percent have been in place since 1 April 1989. Failure to increase abatement thresholds has meant that in real terms families have faced additional abatement of their Family Assistance entitlement.

The levels of assistance provided by the Family Support Tax Credit currently increase with the ages of children in the family. These age-related scales are based on assumptions that children become more expensive as they age. However the strength of this assumption has been questioned, particularly by research in the United Kingdom that found that age-related scales in tax-benefit programmes in this country overestimated the extra costs of older children. There is a paucity of research on families' spending on children by age of child in New Zealand against which to judge the age- 
related scales in the Family Assistance programmes. Yet spending on younger children is often less discretionary than spending on older children and families with younger children often face particular costs that do not have as great an impact on families with older children (such funding the withdrawal of a caregiver from the labour market (in New Zealand caregivers tend to re-enter the labour market when children are older)). Providing greater assistance to families with younger children would recognise the greater difficulties that these families face in allowing both caregivers to work in the labour market. Subsidising the withdrawal from the labour market of a caregiver with young children would also accord with child development objectives.

Application for the Family Assistance programmes is relatively straightforward. However, application for assistance requires the family to file a tax return and Family Assistance application form with the Inland Revenue Department. Assessment of entitlement is largely based on voluntary compliance and is only audited as part of the general process of auditing income tax returns. Increasing the role that the Family Assistance programmes play in the tax-benefit system is likely to place increasing pressure on these application, assessment, and auditing processes. Increasing the role of the Family Assistance programmes in the tax-benefit system will also place increasing pressure on the joint administration of these programmes by the Inland Revenue Department and the Ministry of Social Development.

\subsection{Evaluating the Working for Families Reforms}

The Working for Families package represents a significant increase in the generosity of family and employment tax credits in New Zealand. The Working for Families reforms will make a significant reduction in the headcount rate of child poverty in New Zealand. The financial incentives for sole-parents to work will be improved. Secondary earners will face increased financial disincentives for labour supply, which is significant given the increasing proportion of Family Assistance expenditure going to partnered families (increasing from approximately one third to one half of Family 
Assistance recipients) following Working for Families [Johnson, 2005, p. vii]. There will be an increase in the compliance and administration costs of the tax-benefit system, particularly due to the use of an hours-based eligibility criterion. Further, the likely greater receipt of supplementary assistance by families in work may lead to greater demand for increased efforts to combine the administration of assistance of tax-based and welfare-based social assistance programmes. Issues of take-up and fraud will become more prominent. Working for Families will also increase the proportions of social assistance expenditure for which the Family Assistance programmes account, which in 2004-05 had a combined total greater than expenditure on the Unemployment Benefit.

An important feature of the Working for Families reforms is the extension of the hours-based work test for the Family Tax Credit to the InWork Payment (formerly the Child Tax Credit). An hours-based work test creates notches in budget constraints, which could be likely to lead to changes in the distribution of hours of work. Basing assistance on a prescribed numbers of hours of work would be inconsistent with the marketbased setting of employment conditions, as the flexibility in setting hours of work in employment contracts would be reduced. A feature of many employment contracts is that an employee's hours of work may vary with seasonal or economic conditions. The use of an hours-based threshold requires determining how these fluctuations in hours of work should be treated in the assessment of entitlement. Having thresholds based on work hours (in addition to abatement based on income) would also increase the complexity of a programme's administration and may lead to greater uncertainty regarding the level of assistance available when making the transition from benefit to work and when people's hours of work and earned incomes fluctuate. Such a test would also be vulnerable to fraud as the income tax system is not able to easily monitor recipients' hours of work and compliance would not be audited independently of the general taxpayer audit process. Monitoring compliance with this test would not be a high priority under the Inland Revenue Department's strategy for auditing taxpayers (which would be likely to emphasise more high-value tax avoidance schemes) or an efficient use of their resources. 
Overall the Working for Families reforms represent significant income redistribution towards families with children but, aside from the extension of hours-based work tests, little change will be made to the overall design of the Family Assistance programmes, some of which have remained largely unchanged since 1986. Chapter 10 illustrated a number of possible changes to the Working for Families reforms. This chapter illustrated that removing the Family Tax Credit and the hours-based eligibility threshold would improve financial incentives to supply labour facing low income families. The dollarfor-dollar abatement of the Family Tax Credit creates significant poverty traps for those recipients who take up this assistance. The majority of recipients of the Family Tax Credit are likely to be sole-parent families and a small number of these families would experience a small static reduction in the level of assistance they would get from the Working for Families reforms following the removal of this programme. These losses could be, however, offset by changes in sole-parents' labour supply in response to this initiative. Removing the hours-based work test would improve the financial incentives to supply labour for a number of primary earners in partnered families. No families would lose assistance from Working for Families as a result of this change. Increasing the threshold at which the Family Assistance programmes abate and lowering the rate of abatement would improve financial incentives for low-wage secondary earners to supply labour, but would come at an economic cost of shifting disincentives for labour supply onto secondary earners at higher points in the income distribution.

As well as changes to the Family Assistance programmes, a key feature of the Working for Families reforms is the shifting of the child component of main benefits into the Family Support Tax Credit. This policy change, along with the Single Benefit reforms, which are proposed for implementation in 2007, represents a significant shift in the balance of the tax-benefit system towards supplementary assistance. The balance of the tax-benefit system has not been shifted to this degree since the 1991 benefit cuts. The indexation of the Family Assistance Tax Credits will mean that, however, unlike after the 1991 reforms the annual increase in main benefits for inflation will not erode the relativities between main and supplementary assistance. Given this shift in the structure of the tax-benefit system issues 
relating to integrating the administration of supplementary assistance (currently spread between the Inland Revenue Department and the Ministry of Social Development) and take-up and fraud will become increasing central to assessing the effectiveness with which the tax-benefit system achieves desired policy outcomes.

\subsection{Conclusion}

Part one of this study developed the criteria and methodology for evaluating tax-benefit programmes. Part two of this study discussed the changing policy settings in New Zealand's tax-benefit system. Key changes in these policy settings have been the shift from a universal Family Benefit, towards targeted expenditure on assistance for families with dependent children, the reduction in the progressivity of the personal income tax scale, and the tax system taking a larger role in providing social assistance. In comparison to four other Anglo-American countries, the levels of assistance provided to families with children in New Zealand were both less generous and more heavily targeted by income. The criteria and methodology developed in part one and the policy context identified in part two were used to evaluate the tax-benefit system in part three of this study.

In part three of the study it was identified that families with children have relatively high rates of poverty and relatively low living standards. The poverty traps in the tax-benefit system were also seen to most heavily impact on families with children. In chapter 10 the Labour-led government's response to these issues, the Working for Families reforms, was evaluated. Overail the Working for Families reforms represent significant income redistribution towards families with children but little change will be made to the overall design of the Family Assistance programmes, some of which have remained largely unchanged since 1986. Working for Families does not fully address the need to reform the Family Assistance programmes in the light of important social and economic changes that have taken place over the last two decades, such as the breakdown of the breadwinner model of social arrangements and the liberalisation of the labour market. 
Reform to the tax-benefit system needs to strike a balance between policy objectives such as reducing child poverty, improving financial incentives for caregivers to work, compensating families with children for the additional costs that they face, and supporting single-income partnered families. Striking this balance requires trade-offs between policy objectives to be made. For instance, a major outcome of the Working for Families reforms will be the likely improvement in financial incentives for sole-parents' labour supply but worsening of incentives for partnered caregivers' labour supply. There was little apparent recognition of this trade-off between caregivers' labour supply incentives in the development of these reforms, although such a trade-off had been associated with the use of family and employment tax credits in several other countries and the targeting of these programmes by income and numbers and ages of children [Nolan, 2004b, p. 7; OECD, $2005 a$, p. 4]. In making tax-benefit reforms policy priorities reflecting tradeoffs between different economic and social objectives need to be clearly established and policy instruments' roles in the tax-benefit system need to reflect their effectiveness at achieving these policy priorities. More clearly established policy priorities and a greater understanding of the relative effectiveness of different policy instruments are required if New Zealand is to develop a tax-benefit system that achieves a desired level of redistribution to families with children at least economic cost. 
Appendix And References 


\section{Appendix Anglo-American Family and Employment Tax Credits}

Table A.1: New Zealand Family and Employment Tax Credits (1 April 2004)

\begin{tabular}{|c|c|c|}
\hline Programme & Features & Design \\
\hline \multirow[t]{8}{*}{$\begin{array}{l}\text { Family Support Tax } \\
\text { Credit }\end{array}$} & $\begin{array}{l}\text { Assistance to families with dependent } \\
\text { children }\end{array}$ & $\begin{array}{l}\text { Unabated payment per-child: } \\
\text { - } \quad \text { eldest child under } 13: \$ 2,444\end{array}$ \\
\hline & $\begin{array}{l}\text { Payments vary between eldest and } \\
\text { additional children }\end{array}$ & - $\quad$ eldest child 13 to $18: \$ 3,380$ \\
\hline & No work test & - additional child under 13: $\$ 2,080$ \\
\hline & Abates against joint income & - additional child 13 to $18: \$ 2,340$ \\
\hline & Refundable tax rebate & $\begin{array}{l}\text { Gross abatement threshold one } \\
\$ 20,356\end{array}$ \\
\hline & Paid to primary caregiver & $\begin{array}{l}\text { Gross abatement threshold two } \\
\$ 27,481\end{array}$ \\
\hline & & $\begin{array}{l}\text { Abatement between thresholds one } \\
\text { and two } 18 \text { percent }\end{array}$ \\
\hline & & $\begin{array}{l}\text { Abatement above threshold two } 30 \\
\text { percent }\end{array}$ \\
\hline \multirow[t]{5}{*}{ Child Tax Credit } & Assistance to working families with & Unabated payment per-child $\$ 780$ \\
\hline & dependent children & For abatement added to Family \\
\hline & Abates against joint income & Support (total amount abates as one) \\
\hline & Refundable tax rebate & Work test excludes recipients of \\
\hline & Paid to primary caregiver & welfare benefits \\
\hline \multirow[t]{5}{*}{ Family Tax Credit } & $\begin{array}{l}\text { Ensures a minimum net income for } \\
\text { working families with dependent }\end{array}$ & $\begin{array}{l}\text { Guaranteed minimum net family } \\
\text { income } \$ 15,080 \text { ( } \$ 18,367 \text { gross) }\end{array}$ \\
\hline & & Work test of 30 hours of work per- \\
\hline & Abates against joint income & week for a couple and 20 hours for a \\
\hline & Refundable tax rebate & $\begin{array}{l}\text { sole-parent. Recipients of weltare } \\
\text { benefits excluded }\end{array}$ \\
\hline & Paid to primary caregiver & $\begin{array}{l}\text { Abates dollar-for-dollar against } \\
\text { increases in net family income above } \\
\$ 15,080\end{array}$ \\
\hline \multirow[t]{4}{*}{ Parental Tax Credit } & $\begin{array}{l}\text { Assistance to working families with a } \\
\text { newly born dependent child }\end{array}$ & $\begin{array}{l}\text { Unabated payment per-child } \$ 150 \\
\text { per-week }\end{array}$ \\
\hline & Abates against joint income & Paid for up to eight weeks \\
\hline & Refundable tax rebate & \multirow{2}{*}{$\begin{array}{l}\text { Work test excludes recipients of } \\
\text { welfare benefits }\end{array}$} \\
\hline & Paid to primary caregiver & \\
\hline
\end{tabular}

Note: Unless stated otherwise annual figures in NZ\$ 
Table A.2: Australian Family Tax Credits (1 July 2004 (NZ\$))

\begin{tabular}{|c|c|c|}
\hline Programme & Features & Design \\
\hline \multirow[t]{11}{*}{$\begin{array}{l}\text { Family Tax Benefit } \\
\text { Part A }\end{array}$} & $\begin{array}{l}\text { Assistance to families with dependent } \\
\text { children }\end{array}$ & $\begin{array}{l}\text { Unabated payment per-child: } \\
\text { - } \quad \text { under 13: } \$ 3,787 \text { (AU\$3,482) }\end{array}$ \\
\hline & $\begin{array}{l}\text { Base level of assistance abates only } \\
\text { at high incomes }\end{array}$ & - $\quad 13$ to $15: \$ 4,803$ (AU $\$ 4,417)$ \\
\hline & $\begin{array}{l}\text { Abatement threshold for base rate } \\
\text { increases with number of children }\end{array}$ & $\begin{array}{l}\text { - } 16 \text { to } 17: \$ 1,218 \text { (AU } \$ 1,121) \\
\text { - } 18 \text { to } 24: \$ 1,639 \text { (AU } \$ 1,507)\end{array}$ \\
\hline & $\begin{array}{l}\text { Additional annual supplement paid at } \\
\text { year-end }\end{array}$ & $\begin{array}{l}\text { Unabated annual year-end } \\
\text { supplement } \$ 667 \text { (AU\$613) per-child }\end{array}$ \\
\hline & $\begin{array}{l}\text { No work test } \\
\text { Abates against joint income }\end{array}$ & $\begin{array}{l}\text { Base rate child under } 18 \$ 1,886 \\
(A \cup \$ 1,734)\end{array}$ \\
\hline & $\begin{array}{l}\text { Abates against joint income } \\
\text { Refundable tax rebate }\end{array}$ & $\begin{array}{l}\text { Base rate child } 18 \text { to } 24 \$ 2,306 \\
\text { (AU\$2,121) }\end{array}$ \\
\hline & \multirow[t]{5}{*}{ Paid to nominated caregiver } & $\begin{array}{l}\text { Gross abatement threshold one (of } \\
\text { assistance excluding base rate) } \\
\$ 35,330 \text { (AU } \$ 32,485)\end{array}$ \\
\hline & & $\begin{array}{l}\text { Gross abatement threshold two (of } \\
\text { assistance including base rate) } \\
\$ 91,383 \text { (AU } \$ 84,023 \text { ) }\end{array}$ \\
\hline & & $\begin{array}{l}\text { Add-on to threshold two } \$ 3,652 \\
(A \cup \$ 3,358) \text { per additional child }\end{array}$ \\
\hline & & $\begin{array}{l}\text { Abatement rate between thresholds } \\
\text { one and two } 20 \text { percent }\end{array}$ \\
\hline & & $\begin{array}{l}\text { Abatement rate above threshold two } \\
30 \text { percent }\end{array}$ \\
\hline \multirow[t]{6}{*}{$\begin{array}{l}\text { Family Tax Benefit } \\
\text { Part B }\end{array}$} & $\begin{array}{l}\text { Assistance to families largely } \\
\text { dependent on a single income }\end{array}$ & \multirow{2}{*}{$\begin{array}{l}\text { Unabated payment per-family: } \\
\text { - youngest child under five: } \$ 3,251 \\
\text { (AU } \$ 2,989)\end{array}$} \\
\hline & $\begin{array}{l}\text { Sole-parents are not subject to } \\
\text { income test }\end{array}$ & \\
\hline & \multirow{2}{*}{$\begin{array}{l}\text { In couples abates against lowest } \\
\text { income earner's income only }\end{array}$} & $(A \cup \$ 2,084)$ \\
\hline & & \multirow{2}{*}{$\begin{array}{l}\text { Gross abatement threshold } \$ 4,350 \\
\text { (AU } \$ 4,000)\end{array}$} \\
\hline & Refundable tax rebate & \\
\hline & Paid to nominated caregiver & Abatement rate 20 percent \\
\hline
\end{tabular}

Note: Unless stated otherwise annual figures in NZ\$ (based on OECD 2004 purchasing power parity rates (OECD, 2005b)) and rounded to nearest dollar 
Table A.3: Canadian Family and Employment Tax Credits (1 July 2004 (NZ\$))

\begin{tabular}{|c|c|c|}
\hline Programme & Features & Design \\
\hline \multirow{7}{*}{$\begin{array}{l}\text { Canada Child Tax } \\
\text { Benefit: Basic } \\
\text { Benefit }\end{array}$} & $\begin{array}{l}\text { Assistance to families with dependent } \\
\text { children }\end{array}$ & $\begin{array}{l}\text { Unabated payment per-child } \$ 1,417 \\
(C \$ 1,208)\end{array}$ \\
\hline & No work test & \multirow{2}{*}{$\begin{array}{l}\text { Add-on for third and additional child } \\
\$ 98.55 \text { (C } \$ 84)\end{array}$} \\
\hline & Abates against joint income (previous & \\
\hline & $\begin{array}{l}\text { year) } \\
\text { Refundable tax rebate }\end{array}$ & $\begin{array}{l}\text { Add-on for child under } 7 \$ 280 \\
(C \$ 239)\end{array}$ \\
\hline & Paid to nominated caregiver & $\begin{array}{l}\text { Net abatement threshold } \$ 41,063 \\
(\mathrm{C} \$ 35,000)\end{array}$ \\
\hline & & $\begin{array}{l}\text { Abatement rate one child family } 2 \\
\text { percent }\end{array}$ \\
\hline & & $\begin{array}{l}\text { Abatement rate } 2+\text { child family } 4 \\
\text { percent }\end{array}$ \\
\hline \multirow{9}{*}{$\begin{array}{l}\text { Canada Child Tax } \\
\text { Benefit: National } \\
\text { Child Benefit } \\
\text { Supplement }\end{array}$} & $\begin{array}{l}\text { Assistance to families with dependent } \\
\text { children }\end{array}$ & $\begin{array}{l}\text { Unabated payment first child } \$ 1,773 \\
(C \$ 1,511)\end{array}$ \\
\hline & No work test & \multirow{2}{*}{$\begin{array}{l}\text { Unabated payment second child } \\
\$ 1,519(\mathrm{C} \$ 1,295)\end{array}$} \\
\hline & Abates against joint income (previous & \\
\hline & year) & \multirow{2}{*}{$\begin{array}{l}\text { Unabated payment additional children } \\
\$ 1,425(C \$ 1,215)\end{array}$} \\
\hline & Refundable tax rebate & \\
\hline & Paid to nominated caregiver & $\begin{array}{l}\text { Net abatement threshold } \$ 26,533 \\
(\mathrm{C} \$ 22,615)\end{array}$ \\
\hline & & $\begin{array}{l}\text { Abatement rate one child family } 12.2 \\
\text { percent }\end{array}$ \\
\hline & & $\begin{array}{l}\text { Abatement rate two child family } 22.7 \\
\text { percent }\end{array}$ \\
\hline & & $\begin{array}{l}\text { Abatement rate } 3+\text { child family } 32.5 \\
\text { percent }\end{array}$ \\
\hline \multirow[t]{7}{*}{ BC Family Bonus } & $\begin{array}{l}\text { Assistance to families with dependent } \\
\text { children }\end{array}$ & $\begin{array}{l}\text { Unabated payment second child } \$ 168 \\
\text { (C\$143) }\end{array}$ \\
\hline & No work test & \multirow{2}{*}{$\begin{array}{l}\text { Unabated payment third child } \$ 290 \\
\text { (C\$247) }\end{array}$} \\
\hline & Abates against joint income (previous & \\
\hline & year) & \multirow{2}{*}{$\begin{array}{l}\text { Net abatement threshold } \$ 24,051 \\
(C \$ 20,500)\end{array}$} \\
\hline & Refundable tax rebate & \\
\hline & Paid to nominated caregiver & $\begin{array}{l}\text { Abatement rate one child family } 9 \\
\text { percent }\end{array}$ \\
\hline & & $\begin{array}{l}\text { Abatement rate } 2+\text { child family } 18 \\
\text { percent }\end{array}$ \\
\hline \multirow{7}{*}{$\begin{array}{l}\text { BC Earned Income } \\
\text { Benefit }\end{array}$} & Assistance to families with dependent & Eligibility threshold $\mathrm{C} \$ 3,750$ \\
\hline & & \multirow{2}{*}{$\begin{array}{l}\text { Abatement threshold } \mathrm{C} \$ 20,921 \\
\text { Maximum monthly assistance: }\end{array}$} \\
\hline & Work tested & \\
\hline & Abates against joint income (previous & 1 Child C $\$ 50.41$ \\
\hline & year) & 2 Children $\$ 84.16$ \\
\hline & Refundable tax rebate & 3 Children $\mathrm{C} \$ 111.66$ \\
\hline & Paid to nominated caregiver & Additional children $\mathrm{C} \$ 27.50$ \\
\hline
\end{tabular}

Note: Unless stated otherwise annual figures in NZ\$ (based on OECD 2004 purchasing power parity rates (OECD, 2005b)) and rounded to nearest dollar 
Table A.4: United Kingdom Family and Employment Tax Credits (1 July 2004 (NZ\$))

\begin{tabular}{|c|c|c|}
\hline Programme & Features & Design \\
\hline \multirow[t]{3}{*}{ Working Tax Credit } & $\begin{array}{l}\text { Eligibility threshold } 16 \text { hours of work } \\
\text { by one worker }\end{array}$ & $\begin{array}{l}\text { Unabated Basic Element } \$ 3,832 \\
(£ 1,569)\end{array}$ \\
\hline & $\begin{array}{l}\text { Full-time premium paid for } 30+\text { joint } \\
\text { hours of work }\end{array}$ & $\begin{array}{l}\text { Unabated Couple and Sole-Parent } \\
\text { Element } \$ 3,770(£ 1,543)\end{array}$ \\
\hline & $\begin{array}{l}\text { Paid to person working } 16 \text { hours } \\
\text { or more per week (couples with } \\
\text { two eligible workers may elect } \\
\text { who receives the payment) }\end{array}$ & $\begin{array}{l}\text { Unabated Full-Time Premium } \$ 1,565 \\
\text { (£641) }\end{array}$ \\
\hline \multirow[t]{10}{*}{ Child Tax Credit } & $\begin{array}{l}\text { Assistance to families with dependent } \\
\text { children }\end{array}$ & $\begin{array}{l}\text { Unabated Family Element (first child) } \\
\$ 1,334 \text { (£546) per-annum }\end{array}$ \\
\hline & No work test & Unabated Family Element (baby) \\
\hline & Abates against joint income & $\$ 1,334$ (£546) per-annum \\
\hline & Refundable tax rebate & $\begin{array}{l}\text { Unabated Child Tax Credit (children } \\
\text { below 16) } \$ 3,965(£ 1,623) \text { per-annum }\end{array}$ \\
\hline & Paid to primary caregiver & $\begin{array}{l}\text { Unabated Child Tax Credit (children } \\
16+) \$ 3,965(£ 1,623) \text { per-annum }\end{array}$ \\
\hline & & $\begin{array}{l}\text { Gross Abatement Threshold (Incl. } \\
\text { WTC) } \$ 12,384(£ 5,070) \text { per-annum }\end{array}$ \\
\hline & & $\begin{array}{l}\text { Gross Abatement Threshold (CTC } \\
\text { only) } \$ 32,815(£ 13,434) \text { per-annum }\end{array}$ \\
\hline & & Abatement rate 37 percent \\
\hline & & $\begin{array}{l}\text { Gross Abatement Threshold (Family } \\
\text { Element) } \$ 121,797 \text { ( } ₫ 49,863) \text { per- } \\
\text { annum }\end{array}$ \\
\hline & & Abatement rate 0.067 percent \\
\hline \multirow[t]{2}{*}{ Child Benefit } & $\begin{array}{l}\text { Universal transfer to all families with } \\
\text { dependent children }\end{array}$ & \multirow{2}{*}{$\begin{array}{l}\text { Eldest qualifying child } \$ 2,096 \\
\text { (£858.00) per-annum } \\
\text { Additional children } \$ 1,404(£ 574.60) \\
\text { per-annum }\end{array}$} \\
\hline & Paid to primary caregiver & \\
\hline
\end{tabular}

Note: Unless stated otherwise annual figures in NZ\$ (based on OECD 2004 purchasing power parity rates (OECD, 2005b)) and rounded to nearest dollar 
Table A.5: United States Family and Employment Tax Credits (1 July 2004 (NZ\$))

\begin{tabular}{|c|c|c|}
\hline Programme & Features & Design \\
\hline \multirow{20}{*}{$\begin{array}{l}\text { Earned Income Tax } \\
\text { Credit }\end{array}$} & \multirow{2}{*}{$\begin{array}{l}\text { Assistance to low-income working } \\
\text { families }\end{array}$} & Subsidy Rate: \\
\hline & & 0 Children 8 percent \\
\hline & Abates against joint income & 1 Child 34 percent \\
\hline & Refundable tax rebate & $2+$ Children 40 percent \\
\hline & Paid to primary caregiver (if & Earnings Phase Threshold: \\
\hline & approprlate) & 0 Children $\$ 7,599$ (US $\$ 5,100$ ) \\
\hline & \multirow{14}{*}{$\begin{array}{l}\text { Where caregiving responsibilities } \\
\text { shared equally in separated } \\
\text { families paid to taxpayer with } \\
\text { highest adjusted gross income } \\
\text { (tie-breaker rule) }\end{array}$} & 1 Child $\$ 11,413$ (US\$7,660) \\
\hline & & $\begin{array}{ll} & 2+\text { Children } \$ 16,018 \\
& (\text { US } \$ 10,750)\end{array}$ \\
\hline & & Married Cap Phase Threshold: \\
\hline & & 0 Children $\$ 9,521$ (US\$6,390) \\
\hline & & 1 Child $\$ 20,920$ (US\$14,040) \\
\hline & & $\begin{array}{l}2+\text { Children } \$ 20,920 \\
\text { (US } \$ 14,040)\end{array}$ \\
\hline & & Other Cap Phase Threshold: \\
\hline & & $\begin{array}{l}\text { - } \quad \text { Children } \$ 11,011 \\
\text { (US } \$ 7,390)\end{array}$ \\
\hline & & 1 Child $\$ 22,410$ (US\$15,040) \\
\hline & & $\begin{array}{l}\text { 2+ Children } \$ 22,410 \\
\text { (US\$15,040) }\end{array}$ \\
\hline & & Abatement Rate: \\
\hline & & 0 Children 8 percent \\
\hline & & 1 Child 16 percent \\
\hline & & " $\quad 2+$ Children 21 percent \\
\hline \multirow[t]{6}{*}{ Child Tax Credit } & $\begin{array}{l}\text { Assistance to families with dependent } \\
\text { children and income over a threshold }\end{array}$ & $\begin{array}{l}\text { Entitlement Threshold } \$ 16,018 \\
\text { (US } \$ 10,750)\end{array}$ \\
\hline & Partly refundable & Credit above threshold 15 percent \\
\hline & $\begin{array}{l}\text { Paid to primary caregiver (if } \\
\text { appropriate) }\end{array}$ & $\begin{array}{l}\text { Credit per-child (under 17) } \$ 1,490 \\
\text { (US\$1,000) }\end{array}$ \\
\hline & $\begin{array}{l}\text { Where caregiving responsibilities } \\
\text { shared equally in separated }\end{array}$ & $\begin{array}{l}\text { Abatement Threshold (single) } \\
\$ 81,950 \text { (US } \$ 55,000 \text { ) }\end{array}$ \\
\hline & $\begin{array}{l}\text { families paid to taxpayer with } \\
\text { highest adjusted gross income }\end{array}$ & \multirow{2}{*}{$\begin{array}{l}\text { Abatement Threshold (married } \\
\text { file) } \$ 111,750 \text { (US } \$ 75,000 \text { ) } \\
\text { Abatement Rate } 5 \text { percent }\end{array}$} \\
\hline & (tie-breaker rule) & \\
\hline \multirow{6}{*}{$\begin{array}{l}\text { Wisconsin Earned } \\
\text { Income Credit }\end{array}$} & Assistance to low-income working & Subsidy rate: \\
\hline & & 0 Children 0 percent \\
\hline & Abates against joint income & 1 Child 4 percent \\
\hline & Refundable tax rebate & 2 Children 14 percent \\
\hline & $\begin{array}{l}\text { Paid to primary caregiver (if } \\
\text { appropriate) }\end{array}$ & $3+$ Children 43 percent \\
\hline & $\begin{array}{l}\text { Where caregiving responsibilities } \\
\text { shared equally in separated } \\
\text { families paid to taxpayer with } \\
\text { highest adjusted gross income } \\
\text { (tie-breaker rule) }\end{array}$ & \\
\hline
\end{tabular}

Note: Unless stated otherwise annual figures in NZ\$ (based on OECD 2004 purchasing power parity rates (OECD, 2005b)) and rounded to nearest dollar 


\section{References}

Adema, W. (2001). 'Net Social Expenditure (Second Edition)', Labour Market and Social Policy - Occasional Papers No. 52, Directorate for Education, Employment, Labour and Social Affairs, OECD, Paris

Adler, M. (2004). 'Combining Welfare-To-Work Measures with Tax Credits: A New Hybrid Approach to Social Security in the United Kingdom', International Social Security Review, Vol. 57, 2/2004, pp. 87-106

Akerloff, G. (1978). 'The Economics of "Tagging" as Applied to the Optimal Income Tax, Welfare Programmes, and Manpower Planning', American Economic Review, Vol. 68, Issue 1, pp. 8-19

Alexander, W., J. Bell, and S. Knowles (2004). 'Quantifying Compliance Costs of Small Businesses in New Zealand', paper presented to the $45^{\text {th }}$ Annual Meeting of the New Zealand Association of Economists, Wellington

Alstott, A. (1994). 'The Earned Income Tax Credit and Some Fundamental Dilemmas of Tax-Transfer Integration', National Tax Journal, Vol. XLVII, No. 3, pp. 609-619

(1995). 'The Earned Income Tax Credit and the Limitations of TaxBased Welfare Reform', Harvard Law Review, 108, pp. 533-592

Apps, P. and R. Rees (1999). 'Individual Versus Joint Taxation in Models with Household Production', Journal of Political Economy, Vol. 107, No. 2, pp. 393-403

Atkinson, A. (1989a). Poverty and Social Security, Harvester Wheatsheaf, New York

(1989b). 'Public Economics and the Economic Public', Discussion Paper No. TIDI/135, Suntory-Toyota International Centre for Economics and Related Disciplines, London School of Economics, London

(1995). 'On Targeting Social Security: Theory and Western Experience with Family Benefits', in van de Walle, D. and K. Nead, Public Spending and the Poor: Theory and Evidence, Johns Hopkins University Press, Baltimore

Atkinson, A. and J. Micklewright (1991). 'Unemployment Compensation and Labour Market Transitions: A Critical Review', Journal of Economic Literature, Vol. XXIX, pp. 1679-1727

Auerbach, A. and M. Feldstein (eds.) (1985). Handbook of Public Economics: Volume One, Elsevier Science Publishers, North-Holland 
Auerbach, A. and K. Hassett (1999). 'A New Measure of Horizontal Equity', Working Paper No. 7035, National Bureau of Economic Research, Massachusetts

Baehler, K. (2002). 'Ethnicity-Based Research and Politics: Snapshots from the United States and New Zealand', Social Policy Journal of New Zealand, Issue 18, pp. 18-30

Barr, N. (1999). 'Fundamentals of Social Security Analysis', Australian Social Policy, Issue 1, pp. 7-29

Battle, K. and M. Mendelson (2001). 'Benefits for Children: Canada', in Battle, K., M. Mendelson, D. Meyer, J. Millar, and P. Whiteford (2001). Benefits for Children: A Four Country Study, Caledon Institute of Social Policy, Ontario

Battle. K., M. Mendelson, D. Meyer, J. Millar, and P. Whiteford (2001). Benefits for Children: A Four Country Study, Caledon Institute of Social Policy, Ontario

Beaglehole, A. (1993). 'Benefiting Women: Income Support for Women, 1893 - 1993', Social Policy Agency, Wellington

Beer, G. (1995). 'Impact of Changes in the Personal Income Tax and Family Payment Systems on Australian Families: 1964 to 1994', Discussion Paper, No. 8, National Centre for Social and Economic Modelling, University of Canberra

Bennett, C. (1991). 'How States Utilize Foreign Evidence', Journal of Public Policy, Vol. 11, pp. $31-54$

Bertram, G. (1988). 'Middle Class Capture: A Brief Survey', Future Directions, Vol. III, Part II, Report of the Royal Commission on Social Policy, Government Printer, Wellington

Binder, A. and H. Rosen (1985). 'Notches', American Economic Review, Vol. 75 , No. 4 , pp. $736-747$

Blank, R. (2002). 'Can Equity and Efficiency Complement Each Other?', Working Paper No. w8820, National Bureau of Economic Research, Massachusetts

Blank, R. and D. Ellwood (2001). 'The Clinton Legacy for America's Poor', NBER Working Paper, w8437, National Bureau of Economic Research, Massachusetts

Blundell, R. (1992). 'Labour Supply and Taxation: A Survey', Fiscal Studies, Vol. 13 , No. 3, pp 15-40

Blundell, R., A. Duncan, J. McCrae, and C. Meghir (2000). 'The Labour Market Impact of the Working Families Tax Credit', Fiscal Studies, 21, pp. $75-104$

Blundell, R., M. Brewer, and A. Shephard (2004). The Impact of the New Tax Credits on Parents' Labour Supply, Briefing Note No. 52, Institute for Fiscal Studies

Buchholz, T. (1990). New Ideas from Dead Economists: An Introduction to Modern Economic Thought, Plume, New York

Bojer, H. and J. Nelson (1999). 'Equivalence Scales and the Welfare of Children: A Comment on "Is There Bias in the Economic Literature on 
Equivalence Scales?"', Review of Income and Wealth, Series 45, No. 4, pp. $531-534$

Boskin, M. (2000). 'The Vickery Lecture: From Edgeworth to Vickery to Mirrlees', Atlantic Economic Journal, Vol. 28, No. 1, pp. 14-20

Boston, J. (1999a). 'New Zealand's Welfare State in Transition', in Boston, Dalziel, and St John (eds.) (1999). Redesigning the Welfare State in New Zealand: Problems, Policies, Prospects, Oxford University Press, Auckland

(1999b). 'Social Justice and the Welfare State', in Boston, Dalziel, and St John (eds.) (1999). Redesigning the Welfare State in New Zealand: Problems, Policies, Prospects, Oxford University Press, Auckland

Boston, J. and S. Church (2002). 'The Budget Process in New Zealand: Has Proportional Representation Made a Difference?', Political Science, Vol. 54 , No. 2, pp. 21-44

Boston, J., J. Martin, J. Pallot, and P. Walsh (1996). Public Management: The New Zealand Model, Oxford University Press, Auckland

Boston, J., P. Dalziel, and S. St John (eds.) (1999). Redesigning the Welfare State in New Zealand: Problems, Policies, Prospects, Oxford University Press, Auckland

Boston, J., P. Dalziel, and S. St John (1999). 'Rebuilding An Effective Welfare State', in Boston, Dalziel, and St John (eds.) (1999). Redesigning the Welfare State in New Zealand: Problems, Policies, Prospects, Oxford University Press, Auckland

Boston, J., S. Levine, E. McLeay, and N. Roberts (1996). New Zealand Under MMP: A New Politics?, Auckland University Press, Auckland

Boston, J. and S. St John (1999). 'Targeting Versus Universality: Social Assistance for All or Just for the Poor?', in Boston, Dalziel, and St John (eds.) (1999). Redesigning the Welfare State in New Zealand: Problems, Policies, Prospects, Oxford University Press, Auckland

Boston, J., R. Stephens, and S. St John (1996). 'The Quest for Social Responsibility', Social Policy Journal of New Zealand, Issue 7, pp. 2-16

Bradbury, B. (1999a). 'Optimal Tax Theory and the Targeting of Social Assistance', European Society for Population Economics Conference, Torino, Italy

(1999b). 'Tax Theory and Targeting: A Survey', SPRC Discussion Paper, No. 100, Social Policy Research Centre, University of New South Wales

(2003a). 'Child Poverty: A Review', Report 3/03, Social Policy Research Centre, University of New South Wales

(2003b). 'The Welfare Interpretation of Consumer Equivalence Scales', International Journal of Social Economics, Vol. 30, No. 7, pp. 770-787

(2004). 'Targeting Social Assistance', Fiscal Studies, Vol. 25, No. 3, pp. 305-324

Bradbury, B. and M. Jantti (1999). 'Child Poverty Across Industrialized Nations', Innocenti Occasional Papers Economic and Social Policy Series No. 71, UNICEF, Florence 
Bradshaw, J., J. Ditch, H. Holmes, and P. Whiteford (1993). Support for Children: A Comparison of Arrangements in Fifteen Countries, Department of Social Security Research Report No. 21, HMSO, London

Bradshaw, J. and N. Finch (2003). A Comparison of Child Benefit Packages in 22 Countries, Department for Work and Pensions Research Report No. 174, HMSO, London

Brown, C. and P. Jackson (1982). Public Sector Economics, Second Edition, Martin Robertson \& Company, Oxford

Brown, L. and A. Harding (2002). 'Social Modelling and Public Policy: What is Microsimulation Modelling and How is it Being Used?', paper presented at 'It's Not Just About the Dollars: Measuring and Reporting the Economic and Social Benefits of Standards Under the Disability Discrimination Act", University of Technology Sydney, 19 July

Brosnan, P., M. Wilson, and D. Wong (1989). 'Welfare Benefits and Labour Supply: A Review of the Empirical Evidence', New Zealand Journal of Industrial Relations, 14, pp. 17-35

Brosnan, P., D. Rea, and M. Wilson (1995). 'Labour Market Segmentation and the State: The New Zealand Experience', Cambridge Journal of Economics, Vol. 19, No. 5, pp. 667

Bryant, J., V. Jacobsen, M. Bell, and D. Garrett (2004). 'Labour Force Participation and GDP in New Zealand', New Zealand Treasury Working Paper, No. 04/07, New Zealand Treasury, Wellington

Burchardt, T. and J. Le Grand (2002). 'Constraint and Opportunity: Identifying Voluntary Non-Employment', CASEpaper 55, Centre for Analysis of Social Exclusion, London School of Economics

Callister, P. (2000). Living and Working in New Zealand: Links Between Labour Market Change and Household Structure, Institute of Policy Studies, Wellington

(2001). 'A Polarisation into Work-Rich and Work-Poor Households in New Zealand? Trends from 1986 to 2000', Occasional Paper 2001/3, Labour Market Policy Group, Department of Labour, Wellington (2004). 'The Future of Work Within Households: Understanding Household-Level Changes in the Distribution of Hours of Paid Work', Department of Labour, Wellington

Campbell, R. (1927). 'Family Allowances in New Zealand', The Economic Journal, Vol. 37, No. 147, pp. 369-383

Castles, F. (1985). The Working Class and Welfare: Reflections on the Political Development of the Welfare State in Australia and New Zealand 1890 - 1980, Allen \& Unwin, Wellington

Chan, W. (1993). 'Taxing the Female - As Woman or Wife', in Scott, C. (ed.) (1993). Women and Taxation, Institute of Policy Studies, Victoria University, Wellington

Chapple, S. (2000). 'Maori Socio-Economic Disparity', Political Science, Vol. 52, No. 2, pp. 101-15

Chiao, Y. and I. Walker (1992). 'Labour Market Behaviour of Prime Age Individuals', in Prebble, M. and P. Rebstock (eds.) (1992). Incentives 
and Labour Supply: Modelling Taxes and Benefits, Institute of Policy Studies, Wellington

Clark, T. and J. McCrae (2001). 'Issues Arising in Tax and Benefit Modelling:

The Case of the Family Credit', Institute for Fiscal Studies Working

Paper WP01/17, Institute for Fiscal Studies, London

Clark, H. and S. Maharey (2001). Pathways to Opportunity: From Social Welfare to Social Development, Ministry of Social Policy, Wellington

Claus, I. and G. Scobie (2002). 'Saving in New Zealand: Measurement and Trends', New Zealand Treasury Working Paper, No. 02/02, New Zealand Treasury, Wellington

Clayton, R. and F. Castles (2000). The Welfare State: A Reader, Polity Press, Cambridge

Clayton, R. and J. Pontusson (1998). 'Welfare State Retrenchment Revisited: Entitlement Cuts, Public Sector Restructuring, and Inegalitarian Trends in Advanced Capitalist Societies', World Politics, 51, pp. 67-98

Condliffe, J. (1959). The Welfare State in New Zealand, George Allen \& Unwin, London

Creedy, J. (1996). Fiscal Policy and Social Welfare: An Analysis of Alternative Tax and Transfer Systems, Edward Elgar, Cheltenham, United Kingdom

(1999). 'Taxation, Redistribution and Progressivity: An Introduction', The Australian Economic Review, Vol. 32, No. 4, pp. 410-422

(2001). 'Tax Modelling', The Economic Record, Vol. 77, No. 237, pp. 189-202

(2002). 'Take-Up of Means-Tested Benefits and Labour Supply', Scottish Journal of Political Economy, Vol. 49, No. 1, pp. 150-161 (2003). 'The Excess Burden of Taxation and Why it (Approximately) Quadruples When the Tax Rate Doubles', New Zealand Treasury Working Paper, No. 03/29, New Zealand Treasury, Wellington

Creedy, J., A. Duncan, M. Harris, and R. Scutella (2002). Microsimulation Modelling of Taxation and the Labour Market: The Melbourne Institute Tax and Transfer Simulator, Edward Elgar, Cheltenham

Creedy, J. and G. Scobie. (2002). 'Population Aging and Social Expenditure in New Zealand: Stochastic Projections', New Zealand Treasury Working Paper, No. 02/28, New Zealand Treasury, Wellington

Creedy J. and R. Scuttella (2003). 'The Role of the Unit of Analysis in Tax Policy Reform Evaluations', Melbourne Institute Working Paper, No. $28 / 03$

Creedy, J. and I. Tuckwell (2003). 'Reweighting the New Zealand Household Economic Survey for Tax Microsimulation Modelling', New Zealand Treasury Working Paper, No. 03/33, New Zealand Treasury, Wellington

Creedy, J. and G. Kalb (2005). 'Behavioural Microsimulation Modelling for Tax Policy Analysis in Australia: Experience and Prospects', Melbourne Institute Working Paper Series, Working Paper No. 2/05, University of Melbourne

Cullen, M. (2004). The Estimates of Appropriations 2004/05, Treasury, Wellington 
Cullen, M. and S. Maharey (2004). 'Reform of Social Assistance: Working for Families Package', Cabinet Policy Committee, Wellington

Cullis, J. and P. Jones (1992). Public Finance and Public Choice: Analytical Perspectives, McGraw-Hill Book Company, London

Diewert, W. and A. Lawrence (1994). 'The Marginal Costs of Taxation in New Zealand', report prepared for the New Zealand Business Roundtable, Swan Consultants Ltd, Canberra

Dixon, S. (2002). 'Using Administrative Data Sources in Labour Market Research: An Introduction', Labour Market Bulletin, Department of Labour, pp. 26-30

Duclos, J., V. Jalbert, and A. Araar (2000). 'Classical Horizontal Inequity and Reranking: An Integrated Approach', Université Laval, Cahiers de Recherche, No. 002, Quebec

Duncan, A. (2002). 'Promoting Employment Through Welfare Reform: Lessons from the Past, Prospects for the Future', R I Downing Lecture, University of Melbourne

Dwyer, G. (2005). 'Dissecting the Working for Families Package', New Zealand Business Roundtable, Wellington

Easton, B. (1996). 'The Post-War Welfare State', Social Policy Journal of New Zealand, Issue, 7, pp. 17-28

Eissa, N. and H. Hoynes (1999). 'The Earned Income Tax Credit and the Labour Supply of Married Couples', NBER Working Paper, w6856, National Bureau of Economic Research, Massachusetts (2004). 'Taxes and the Labor Market Participation of Married Couples: The Earned Income Tax Credit', Journal of Public Economics, 88, pp. 1931-1958

Ellwood D. (2000). 'The Impact of the Earned Income Tax Credit and Social Policy Reforms on Work, Marriage, and Living Arrangements', National Tax Journal, 53, 4 (2), pp. 1063-1106

Esping-Andersen, G. (1990). The Three Worlds of Welfare Capitalism, Princeton University Press, Princeton

Evans, L., A. Grimes, B. Wilkinson, and D. Teece (1996). 'Economic Reform in New Zealand 1984-95: The Pursuit of Efficiency', Journal of Economic Literature, Vol. 34, No. 4, pp. 1856-1902

Fritzell, J. and V-M. Ritakallio (2004). 'Societal Shifts and Changed Patterns of Poverty', Luxembourg Income Study Working Paper 393

Gobbi, M. and D. Rea (2002). 'The Unemployment Spells of Registered Jobseekers', Labour Market Bulletin, pp. 31-56

Goodger, K. (1998). 'Maintaining Sole Parent Families in New Zealand: An Historical Review', Social Policy Journal of New Zealand, Issue 10, pp. 122-153

Gordon, R. (1997). 'Background to the Household Economic Survey', Consumers Price Index Revision Advisory Committee, Statistics New Zealand, Wellington

Gornick, J. and Meyers, M. (2003). Families that Work: Policies for Reconciling Parenthood and Employment, Russell Sage, New York 
Gottfried, P. and W. and Richter (1999). 'The Tax Unit and Household Production: Comment', Journal of Political Economy, Vol. 107, No. 2, pp. 404-409, University of Chicago

Gentry, W. (1999). 'Optimal Taxation', in Cordes, J., R. Ebel, and J. Gravelle (eds.), The Encyclopaedia of Taxation and Tax Policy, Urban Institute Press, Washington

Gerritsen, S. (2004). "Just Not Worth It": The Disincentive of Effective Marginal Tax Rates (EMTRs) for Sole Parents Entering the Workforce', Research Report, Barnardos, Wellington

Green, D. (2001). Poverty and Benefit Dependency, New Zealand Business Roundtable, Wellington

Gregg, P., Scutella, R., and Wadsworth. J. (2004). 'Reconciling Workless Measures at the Individual and Household Level: Theory and Evidence from the United States, Britain, Germany, Spain and Australia, CEP Discussion Paper, No 635

Grosh, M. (1995). 'Towards Quantifying the Trade-off: Administrative Costs and Incidence in Targeted Programmes in Latin America', in van de Walle, D. and K. Nead eds. (1995). Public Spending and the Poor: Theory and Evidence, Johns Hopkins University Press, Baltimore

Hawke, G. (1985). The Making of New Zealand: An Economic History, Cambridge University Press, Cambridge

Heady, C. (1993). 'Optimal Taxation as a Guide to Tax Policy', Fiscal Studies, Vol. 14, No. 1, pp. 15-41

Heckman, J. (1993). 'What Has Been Learned About Labour Supply in the Past Twenty Years?', The American Economic Review, Vol. 83, No. 2, pp. $116-121$

Hines, J. (1999). 'Three Sides of Harberger Triangles', Journal of Economic Perspectives, Vol. 13, No. 2, pp. 167-188 (2000). 'What is Benefit Taxation?', Journal of Public Economics, 75, pp. 483-492

Holcombe, R. and J. Mills (1994). 'Is Revenue-Neutral Tax Reform Revenue Neutral?', Public Finance Quarterly, Vol. 22, No. 1, pp. 65-85

Hollis, M. (1995). The Philosophy of Social Science: An Introduction, Cambridge University Press, Cambridge

Hong, B. (2001). 'Improving the Knowledge Base for Social Policy: Strategic Knowledge Needs', Knowledge Management Group, Ministry of Social Development, Wellington

Howlett, M. and M. Ramesh (1995). Studying Public Policy: Policy Cycles and Policy Systems, Oxford University Press, Toronto

Hyslop, D. and D. Mare (2001). 'Understanding Changes in the Distribution of Household Incomes in New Zealand Between 1983-86 and 1995-98', New Zealand Treasury Working Paper, No. 01/21, New Zealand Treasury, Wellington

Ingles, D. (2001). 'Earned Income Tax Credits: Do They Have Any Role to Play in Australia?', The Australian Economic Review, Vol. 34, no 1., pp 14-32 
Inland Revenue Department (2001). 'Estimates of Tax Expenditures 1980-81 to 1999-2000', Internal Modelling, Sandra Watson, Wellington

(2002). 'Family Assistance Adjustments - Effect on Joint Family Income', internal document, Tax and Social Policy Unit, Policy Advice Division, Wellington

(2003). 'Future Directions: Family Income Delivery Enhancements', joint report with the Ministry of Social Development to the Minister of Revenue and the Minister of Social Development, Inland Revenue Department, Wellington

(2004). Delivering on Our Outcomes: Part One of the Inland Revenue Annual Report 2004, Inland Revenue Department, Wellington

Inland Revenue Service (2002). 'Compliance Estimates for Earned Income Tax Credit Claimed on 1999 Returns', Department of the Treasury, Inland Revenue Service, Washington

Jacobs, J. and J. Gornick (2002). 'Hours of Work in Dual-Earner Couples: The U.S. in Cross-National Perspective', Sociological Focus, 35, pp. 169-87

Jacobsen, V., N., Mays, R., Crawford, B., Annesley, P., Christoffel, G., Johnston, and S., Durbin (2002). 'Investing in Well-being: An Analytical Framework', New Zealand Treasury Working Paper, No. 02/23, New Zealand Treasury, Wellington

Jensen, J. and V., Krishnan (2001). 'Tracking Living Standards: Is It Done Better by EDY or HEDY?' Social Policy Journal of New Zealand, Issue 16 , pp. 127-154

Jensen, J., V. Krishnan, M. Spittal, and S. Sathiyandra (2003). 'New Zealand Living Standards: Their Measurement and Variation, With An Application To Policy, Social Policy Journal of New Zealand, Issue 20, pp. $72-97$

Johnson, N. (2005). "Working for Families" in New Zealand: Some Early Lessons', Report of the Ian Axford (New Zealand) Fellowship in Public Policy, Fulbright Foundation, Wellington

Johnston, G. (2005). 'Women's Participation in the Labour Force', New Zealand Treasury Working Paper, No. 05/06, New Zealand Treasury, Wellington

Kalb, G., L. Cai, and I. Tuckwell (2005). 'The Effect of Changes in Family Assistance: Allowing for Labour Supply Responses', preliminary draft of report prepared for New Zealand Treasury, New Zealand Treasury, Wellington

Kaplow, L. (1985). 'Horizontal Equity: Measures in Search of a Principle', NBER Working Paper, No. 1679, National Bureau of Economic Research, Massachusetts

Koopman-Boyden, P. and C. Scott, 1984, The Family and Government Policy in New Zealand, George Allen and Unwin, Sydney

Le Grand, J. (1997). 'Knights, Knaves or Pawns? Human Behaviour and Social Policy', Journal of Social Policy, Vol. 26, Issue 2, pp. 149-169

Liebschutz, D. (1999). 'Taxes and Poverty in New Zealand: The Impact of the Tax and Benefit Systems on Low-Income New Zealanders', Report of 
the lan Axford (New Zealand) Fellowship in Public Policy, Fulbright Foundation, Wellington

Lunt, N. (2001). 'The Road to Somewhere" Evidence, Public Policy and the Public', Social Policy Journal of New Zealand, Issue 16, pp. 199-202

Lunt, N. and C. Davidson (2002). 'Increasing Social Science Research Capacity: Some Supply-Side Considerations', Social Policy Journal of New Zealand, Issue 18, pp. 1-17

Maani, S. (1989). 'The Unemployment Benefit, Unemployment Duration and Wage Requirements of Job Seekers in New Zealand', New Zealand Economic Papers, 21, pp. 41-55

Mackay, R. (1998). 'Targeting in Social Security: The New Zealand Experience', paper presented to the $2^{\text {nd }}$ International Research Conference on Social Security

Maloney, T. (1997). Benefit Reform and Labour Market Behaviour in New Zealand, Institute of Policy Studies, Wellington

(2000). 'The Impact of Welfare Reform on Labour Supply Behaviour in New Zealand', Labour Economics, 7, pp. 427-448

Marshall, A., (1920 [1949]). Principles of Economics, Eighth Edition, Macmillan and Co., London

Mascarenhas, R. (1996). Government and the Economy in Australia and New Zealand: The Politics of Economic Policy Making, Austin \& Winfield, San Francisco

McClure, M. (1998). A Civilised Community: A History of Social Security in New Zealand 1898 - 1998, Auckland University Press, Auckland

McClure, P., W. Jackson, P. Dawkins, M. Lyons, J. Schwager, J. Longley, and E. Morgan (2000). Participation Support for a More Equitable Society: Final Report of the Reference Group on Welfare Reform, Department of Family and Community Services, Canberra

McKeown, P. and A. Woodfield (1995). 'The Welfare Cost of Taxation in New Zealand Following Major Tax Reforms', New Zealand Economic Papers, Vol. 29, No. 1, pp. 41-62

McKinnon, M (2003). Treasury: The New Zealand Treasury 1840-2000, Auckland University Press, Auckland

McLeod, R, S. Chatterjee, S. Jones, D. Patterson, and T. Sieper (2001a). Issues Paper, 2001 Ministerial Inquiry into the New Zealand Tax System, Treasury, Wellington

McLeod, R, S. Chatterjee, S. Jones, D. Patterson, and T. Sieper (2001b). Final Report, 2001 Ministerial Inquiry into the New Zealand Tax System, Treasury, Wellington

Mendelson, M. (2001). 'Cash-Benefits for Children in Four Anglo-American Countries', Eight International Research Seminar on "Issues in Social Security", Sigtuna, Sweden

(2005). 'Tax Credits in Anglo-American Countries: Convergent in Design, Divergent in Details', paper presented at the Institute of Fiscal Studies Biennial Residential Conference, Cambridge, United Kingdom

Messenger, J. C. (2004.) 'Finding the Balance: Working time and Workers' Needs and Preferences in Industrialized Countries - A summary of the 
Report and its Implications for Working Time Policies', Paper presented at the 9th International Symposium on Working Time, Paris

Meyer, D. (2001). 'Benefits for Children: The United States', in Battle. K., M. Mendelson, D. Meyer, J. Millar, and P. Whiteford (2001). Benefits for Children: A Four Country Study, Caledon Institute of Social Policy, Ontario

Middleton, S., K. Ashworth, and I. Braithwaite (1997). Small Fortunes: Spending on Children, Childhood Poverty and Parental Sacrifice, Joseph Rowntree Foundation, York

Millar, J. (2001). 'Benefits for Children: The United Kingdom', in Battle. K., M. Mendelson, D. Meyer, J. Millar, and P. Whiteford (2001). Benefits for Children: A Four Country Study, Caledon Institute of Social Policy, Ontario

Ministry of Social Development (2001). Social Services Statistical Report for the Year Ending 2000, Ministry of Social Development, Wellington

(2002a) Briefing to the Incoming Minister - Building Leadership for Social Development, Part Two: Strengthening Capacity, Chapter 2: Priorities for Policy and Knowledge Management, Ministry of Social Development, Wellington

(2002b) 'Estimates of Net Social Assistance Expenditure 1997-98 to 2005-06', Internal Modelling, Knowledge Management Group

(2002c) Improving Well-being for all New Zealanders, Ministry of Social Development, Wellington

(2002d) New Zealand Living Standards 2000, Ministry of Social Development, Wellington

(2003). 'Future Directions - Family Assistance Sub-Project: Project WP1 - Context Setting', internal paper, 21 February

Mirrlees, J. (1971). 'An Exploration in the Theory of Optimal Income Taxation', Review of Economic Studies, Vol. 38, pp. 175-208

Morrison, P. and C. Waldegrave (2002). 'Welfare Reform and the IntraRegional Migration of Beneficiaries in New Zealand', Geoforum, 32, pp. 85-103

Mowbray, M (2001). 'Distributions and Disparity: New Zealand Household Incomes', Knowledge Management Group, Ministry of Social Policy, Wellington

Mulgan, R. (1997). 'State and Democracy in New Zealand', in Rudd C. and B. Roper, eds., The Political Economy of New Zealand, Oxford University Press, Auckland

Musgrave, R. (1959). The Theory of Public Finance, McGraw Hill, New York (1976). 'ET, OT and SBT', Journal of Public Economics, 6, pp. 3-16 (1985). 'A Brief History of Fiscal Doctrine', in Auerbach, A. and M. Feldstein eds. (1985). Handbook of Public Economics: Volume 1, Elsevier Science Publishers, North-Holland

Nolan, P. (2002). 'New Zealand's Family Assistance Tax Credits: Evolution and Operation', New Zealand Treasury Working Paper, No. 02/16, New Zealand Treasury, Wellington 
(2003). 'New Zealand's Social Assistance System: Financial Incentives to Work', New Zealand Treasury Working Paper, No. 03/18, New Zealand Treasury, Wellington

(2004a). 'Making Work Pay? Experiences with Family and Employment Tax Credits in Five Anglo-American Countries', paper presented to the Second Social Policy Research and Evaluation Conference, Wellington (2004b). 'Welfare Reform for Low-Wage Workers: Will Working for Families Work?', paper presented to the Eleventh Conference on Labour, Employment and Work in New Zealand, Wellington

(2004c). 'When Work Does Not Pay: Family Structures and Poverty Traps in New Zealand's Social Security System', paper presented to the Forty Fifth Annual Conference of the New Zealand Association of Economists, Wellington

(2005). 'Redesigning Family Tax Benefits in Australia and New Zealand', paper presented to the $17^{\text {th }}$ Australasian Tax Teachers' Association Conference, Wellington

(forthcoming). 'Tax Relief for Breadwinners or Caregivers? The Designs of Earned and Child Tax Credits in Five Anglo-American Countries' Journal of Comparative Policy Analysis

Nolan, P. and E. Fairbrother (2005). 'Single-Income Partnered Households and the Personal Income Tax System', paper presented to the $17^{\text {th }}$ Australasian Tax Teachers Association Annual Meeting, Wellington

Nolan, P., R. Stephens, and P. Callister (2005). 'Tax Relief for Breadwinners or Caregivers? The Designs of Earned and Child Tax Credits in Five Anglo-American Countries', unpublished paper, Victoria University School of Government

Nutley, S., I. Walter, and H. Davies (2002). 'From Knowing to Doing: A Framework for Understanding the Evidence-Into-Practise Agenda', Discussion Paper One, Research Unit for Research Utilisation, University of Saint Andrews

O'Dea, D. (2000). 'The Changes in New Zealand's Income Distribution', New Zealand Treasury Working Paper, No. 00/13, New Zealand Treasury, Wellington

OECD (2000). Labour Force Statistics, OECD, Paris

(2001a). Employment Outlook, OECD, Paris

(2001b). Growth, Equality and Social Protection, OECD, Paris

(2002). '1980-1998 20 Years of Social Expenditure: The OECD

Database', OECD, Paris

(2004a). Babies and Bosses: Reconciling Work and Family Life. New

Zealand, Portugal and Switzerland, OECD, Paris, Vol. 3.

(2004b). Benefits and Wages: OECD Indicators, OECD, Paris

(2005a). Economic Survey of New Zealand: Raising Female Labour

Force Participation, excerpt from the OECD Economic Survey of New

Zealand 2005, OECD, Paris 
(2005b). Purchasing Power Parities (PPPs) for OECD Countries 1980

-2004, OECD, Paris

Oliver, R. (1999). 'Appropriate Ethical Standards During Consultation', paper prepared for the Streamlining Stakeholder Management, Partnerships and Consultation within the Public Sector Conference

Pallot, J. (1993). 'Tax Relief for Childcare Expenses: Issues and Reform', in Scott, C. (ed.) (1993). Women and Taxation, Institute of Policy Studies, Wellington

Perry, B. (2002). 'The Mismatch between Income Measures and Direct Outcome Measures of Poverty', Social Policy Journal of New Zealand, 19 , pp. 101-127

(2004). 'Working for Families: The Impact on Child Poverty', Social Policy Journal of New Zealand, Issue 22, pp. 19-54

Pierson, P. (1996). 'The New Politics of the Welfare State', World Politics, 48, pp. $143-179$

Pierson, P. and F. Castles (2000). The Welfare State: A Reader, Polity Press, Cambridge

Piggot, J. and J. Whalley (1996). 'The Tax Unit and Household Production.' Journal of Political Economy, 104, pp. 398-418

(1999). 'Reply to Apps/Rees and Gottfried/Richter', Journal of Political Economy, Vol. 107, No. 2, pp. 410-418, University of Chicago

Pigou, A. (1932). The Economics of Welfare, Third Edition, Macmillan and Co., London

Prebble, M. and P. Rebstock (eds.) (1992). Incentives and Labour Supply: Modelling Taxes and Benefits, Institute of Policy Studies, Wellington

Preston, D. (1996). 'Reducing Benefit Dependence', Social Policy Journal of New Zealand, Issue 6, pp. 69-91

Reeves, W. (1923). State Experiments in Australia and New Zealand: Volume II, George Allen \& Unwin, London

Riphahn, R. (2001). Rational Poverty or Poor Rationality: The Take-Up of Social Assistance Benefits, Review of Income and Wealth, Series 47, No. 3, pp. 379-398

Roper T. and H. Greenland (2002). 'Government Role in the Housing Sector: Background Material for the 2002 Post-Election Preparedness', unpublished paper, the Treasury, Wellington

Rose, R. (1991). 'What is Lesson Drawing?', Journal of Public Policy, Vol. 11, pp. $3-30$

Rosen, H. (1988). Public Finance, Irwin, Illinois

Royal Commission on Social Policy (1998). 'Income Maintenance and Taxation: Working Paper No. 4', Working Papers on Income Maintenance and Taxation, Royal Commission on Social Policy, Wellington

Sanford, C. and J. Hasseldine (1992). The Compliance Costs of Business Taxes in New Zealand, Institute of Policy Studies, Victoria University, Wellington 
Saunders, P. (1994). Welfare and Inequality: National and International Perspectives on the Australian Welfare State, Cambridge University Press, Melbourne

(1999). 'Introduction', A Guide to Calculating the Costs of Children, Family Matters, No. 54, Spring/Summer, Australian Institute of Family Studies

Scholz, J. (1994), 'The Earned Income Tax Credit: Participation, Compliance, and Antipoverty Effectiveness', National Tax Journal, Vol. 47, No. 1, pp. 63-87

Seefedlt, K. and P. Smock (2004). 'Marriage on the Public Policy Agenda: What Do Policy Makers need to know from Research', National Poverty Center Working Paper Series, 04-2, Gerald R. Ford School of Public Policy, University of Michigan

Sefton, T. (2000). 'Getting Less for More: Economic Evaluation in the Social Welfare Field', CASE paper 44, Centre for Analysis of Social Exclusion, London School of Economics, London

Sen, A. (1979). 'Personal Utilities and Public Judgements: Or What's Wrong with Welfare Economics', The Economic Journal, Vol. 89, pp. 537-558

(1995). 'The Political Economy of Targeting', in van de Walle, D. and K., Nead, Public Spending and the Poor: Theory and Evidence, Johns Hopkins University Press, Baltimore

Shaw, R. and C. Eichbaum (2005). Public Policy in New Zealand: Institutions, Processes and Outcomes, Pearson Education, Auckland

Shipley, J. (1991). Social Assistance: Welfare That Works, GP Print, Wellington

Singley, S. and P. Callister, (2003). 'Polarisation of Employment, 1986-2002: New Zealand in the International Context', report prepared for the Ministry of Social Development, Wellington

Silverstone, B., A. Bollard, and R. Lattimore (1996). A Study of Economic Reform: The Case of New Zealand, Elsevier Science Publishing, Amsterdam

Slemrod, J. (1990). 'Optimal Taxation and Optimal Tax Systems', Journal of Economic Perspectives, Vol. 4, No. 1, pp. 157-178

(1993). 'Do We Know How Progressive the Income Tax System Should Be?', National Tax Journal, Vol. 36, No. 3, pp. 361-370

Smeeding, T. and D. Weinberg (2001). 'Towards a Uniform Definition of Household Income', Review of Income and Wealth, Series 47, Number 1 , pp. $1-24$

Smith, K. and R. Euller (1992). 'Taxmod', in Prebble, M. and P. Rebstock (eds.) (1992). Incentives and Labour Supply: Modelling Taxes and Benefits, Institute of Policy Studies, Wellington

Smith, P. (1991). 'Lessons from the British Poll Tax Disaster', National Tax Journal, Vol. XLIV, No. 4, pp. 421-36

Smith, S. (1999). 'Families Eligible for Parental Tax Credit: Revised Estimates', memorandum to the Office of the Minister of Revenue, Forecasting Unit, Policy Advice Division, Inland Revenue, 25 August, Wellington 
Spittal, M. (2002). 'The New Zealand Conference on Database Integration and Linked Employer-Employee Data', Social Policy Journal of New Zealand, Issue 18, pp. 198-201

St John, S. (1996). 'The Welfare Mess Revisited', Policy Discussion Paper No. 21, Economics Department, University of Auckland

(1999). 'Accident Compensation in New Zealand: A Fairer Scheme?', in Boston, Dalziel, and St John (eds.) (1999). Redesigning the Welfare State in New Zealand: Problems, Policies, Prospects, Oxford University Press, Auckland

St John, S. and D. Craig (2004). 'Cut Price Kids: Does the 2004 'Working for Families' Budget Work for Children?', Child Poverty Action Group, Auckland

St John, S. and K. Rankin (2002). 'Entrenching The Welfare Mess', Policy Discussion Paper No. 24, Economics Department, University of Auckland

Statistics New Zealand (1999). New Zealand Now - Incomes (Census 1996), Statistics New Zealand, Wellington

(2001). 'Information Paper: The Introduction of Integrated Weighting to the 2000/01 Household Economic Survey', Statistics New Zealand, Wellington

(2002a). A Changing New Zealand, Statistics New Zealand, Wellington (2002b). 2001 Census: Snapshot 17 Families and Households, Statistics New Zealand, Wellington

Stephens, R. (1988). 'Issues in the Measurement of Poverty and Standards of Living', Department of Economics Discussion Paper, No. 48, Victoria University of Wellington

(1993). 'Radical Tax Reform in New Zealand', Fiscal Studies, 14 (3), pp. $45-63$

(1997). 'The Interaction and Coordination of Taxation and Expenditure Programmes', in Krever, R. (ed.), Tax Conversations, Kluwer Law International, Great Britain

(1999). 'Poverty, Family Finances and Social Security', in Boston, J., P. Dalziel, and S. St John (eds.), Redesigning the Welfare State in New Zealand: Problems, Policies, Prospects, Oxford University Press, Auckland

(2000) 'Poverty and Employment: A Comparison of Policy and Outcomes between the United States and New Zealand', Research paper prepared at the Institute for Policy Studies, Johns Hopkins University

(2003). 'The Level of Financial Assistance to Families with Dependent Children: A Comparative Analysis', Social Policy Journal of New Zealand, Issue 20, pp. 173-196

Stephens, R. and J. Bradshaw (1995). 'The Generosity of New Zealand's Assistance to Families with Dependent Children', Social Policy Journal of New Zealand, Issue 4, pp. 53-75

Stephens, R., P. Frater, and C. Waldegrave (2000). 'Below the line: an analysis of income inadequacy in New Zealand, 1984-1998', The 
GSBGM Working Paper Series, Working Paper 2/00, Victoria University of Wellington.

Stephens, R. and C. Waldegrave (2001). 'The Effectiveness of the Transfer and Tax System in Reducing Poverty in 1998', Social Policy Journal of New Zealand, Issue 16, pp. 77-107

Stephens, R. C. Waldegrave, and P. Frater (1995). 'Measuring Poverty in New Zealand', Social Policy Journal of New Zealand, Issue 5, pp. 88112

Stroombergen, A. and T. O'Brien (2003). 'Labour Supply in New Zealand: A Preliminary Analysis Using Unit Record Data from the Household Labour Force Survey', Labour Market Policy Group, Department of Labour, Wellington

Talbut, K. (2004). 'The Household Economic Survey', edited and updated background paper, prepared for the $2004 \mathrm{CPI}$ Revision Advisory Committee, Statistics New Zealand, Wellington

Tan, L. (1995). 'Coping with Tax Obligations - An In-Dept Study of Some Small Businesses in New Zealand', report prepared for the Compliance Cost Reduction Unit, Inland Revenue Department, Wellington

Treasury (1996). Putting it Together: An Explanatory Guide to the New Zealand Public Sector Financial Management System, Treasury, Wellington

(1999). 'Effective Marginal Tax Rate Profiles', unpublished internal paper, Treasury, Wellington

(2001). 'Towards an Inclusive Economy', New Zealand Treasury Working Paper, No. 01/15, New Zealand Treasury, Wellington

UNICEF (2005). 'Child Poverty in Rich Countries 2005', Innocenti Report Card, No. 6, UNICEF Innocenti Research Centre, Florence

United States Treasury, (2005). Budget of the United States Government: Supplementary Materials Table 26-1, United States Department of the Treasury, Washington

van de Ven, J. and J. Creedy (2003). 'Taxation, Reranking and Equivalence Scales', New Zealand Treasury Working Paper, No. 03/11, New Zealand Treasury, Wellington

van de Walle, D. and K. Nead eds. (1995). Public Spending and the Poor:

Theory and Evidence, Johns Hopkins University Press, Baltimore

Varuhas, J., L. Fursman, and V. Jacobsen (2003). 'Work and Family Balance: An Economic View', New Zealand Treasury Working Paper, No. 03/26, New Zealand Treasury, Wellington

Waldegrave, C., R. Stephens, and P. King (2003). 'Assessing the Progress on Poverty Reduction', Social Policy Journal of New Zealand, 20, pp. 197-222

Walsh P. and P. Brosnan (1999). 'Redesigning Industrial Relations: The Employment Contracts Act and its Consequences', in Boston, Dalziel, and St John (eds.) (1999). Redesigning the Welfare State in New Zealand: Problems, Policies, Prospects, Oxford University Press, Auckland 
Whiteford, P. (1985). 'A Family's Needs: Equivalence Scales, Poverty and Social Security', Department of Social Security Research Paper, No. 27, Canberra

(2001). 'Benefits for Children: Australia', in Battle. K., M. Mendelson, D. Meyer, J. Millar, and P. Whiteford (2001). Benefits for Children: A Four Country Study, Caledon Institute of Social Policy, Ontario

Whiteford, P., M. Mendelson, and J. Millar (2003). 'Timing it Right?: Tax Credits and How to Respond to Income Changes', Joseph Rowntree Foundation, York

Whitehouse, E. (1996). 'Designing and Implementing In-Work Benefits', The Economic Journal, Vol. 106, No. 434, pp. 130-141

Wilson, M. (1996). 'Institutional Labour Economics, Benefit Levels and Unemployment', Social Policy Journal of New Zealand, Issue 6, pp. 222

(1999). 'The Duration of Benefit Receipt: New Findings from the Benefit Dynamics Data Set', Social Policy Journal of New Zealand, 13, pp. 59-82

(2002). 'Children on Benefit: Who Says Longest?', Social Policy Journal of New Zealand, 19, pp. 48-75 